PAULO ROGÉRIO CELLINE

\title{
ESTUDO EXPERIMENTAL DA INFLUÊNCIA DE SISTEMA DE VENTILAÇÃO PERSONALIZADA INSTALADO NA POLTRONA NA DISPERSÃO DE PARTICULAS EXPIRATÓRIAS EM CABINE DE AERONAVE
}

São Paulo

2017 
PAULO ROGÉRIO CELLINE

\section{ESTUDO EXPERIMENTAL DA INFLUÊNCIA DE SISTEMA DE VENTILAÇÃO PERSONALIZADA INSTALADO NA POLTRONA NA DISPERSÃO DE PARTICULAS EXPIRATÓRIAS EM CABINE DE AERONAVE}

Dissertação de Mestrado apresentada à Escola Politécnica da Universidade de São Paulo para obtenção do título de Mestre em Ciências

Área de concentração:

Engenharia Mecânica

Orientador:

Prof. Dr. Arlindo Tribess

São Paulo 
Este exemplar foi revisado e alterado em relação à versão original, sob responsabilidade única do autor e com a anuência de seu orientador.

São Paulo, 27 de junho de 2017

Assinatura do Autor

Assinatura do Orientador

\section{FICHA CATALOGRÁFICA}

Celline, Paulo Rogério

Estudo experimental da influência de sistema de ventilação personalizada instalado na poltrona na dispersão de partículas expiratórias em cabine de aeronave. Paulo Rogério Celline, ed. rev. - São Paulo, 2017. 121p.

Dissertação (Mestrado) - Escola Politécnica da Universidade de São Paulo. Departamento de Engenharia Mecânica.

1. Ventilação personalizada 2. Qualidade do ar 3. Dispersão de partículas 4. Cabines 5. Aeronaves I. Universidade de São Paulo. Escola Politécnica. Departamento de Engenharia Mecânica II. t 
À minha amada esposa Érika, minha Companheira, minha Amiga, minha Mulher e pessoa de quem eu muito me orgulho, por estar ao meu lado em todos os momentos, fáceis ou difíceis, pelos quais passei nos últimos anos. Aos meus amados pais, Antônio e Neide, por me ensinarem desde cedo os princípios da educação e do caráter. Igualmente, dedico este trabalho a todos da minha família que compreenderam minhas ausências e que torceram pelo meu sucesso.

"Considerar o que você faz de relevante e acreditar que seu trabalho tem valor é uma das formas mais eficientes de permanecer motivado, apesar dos obstáculos"

Heidi Grant Halvorson 


\section{AGRADECIMENTOS}

Ao meu orientador, Prof. Dr. Arlindo Tribess, por toda ajuda, paciência e dedicação que teve ao longo de todo o curso e que foi fundamental para o desenvolvimento deste trabalho. Mais do que meu orientador, o senhor foi um grande amigo.

Ao Prof. Dr. Cyro Albuquerque Neto e ao Prof. Dr. Maurício Silva Ferreira pelas relevantes contribuições no Exame de Qualificação.

À Profá. Dra. Brenda Chaves Coelho Leite, do Departamento de Engenharia de Construção Civil da Escola Politécnica da USP, pelo empréstimo de medidor de vazão, de fundamental importância para a leitura correta da vazão de ar do sistema de ventilação personalizada.

Aos meus estimados amigos doutorandos Douglas Fabichak Jr. e Victor Felix por toda a ajuda que me ofereceram no procedimento experimental e pela companhia ao longo das inúmeras horas de atividades experimentais que realizamos. Meus sinceros agradecimentos e desejos de boa sorte em vossas respectivas Teses.

À minha família, em especial minha esposa Érika que esteve ao meu lado em todas as etapas do Mestrado e sempre me apoiou. Em igual agradecimento, aos meus pais, meus sogros, à minha irmã Simone e ao meu irmão Marcos por compreenderem o quão importante este trabalho representa em minha vida.

Aos meus colegas, que felizmente são muitos! Agradeço a todos pelos incentivos e pelas boas energias que me deram. Um grande abraço para todos vocês, que direta ou indiretamente me ajudaram na realização deste trabalho. 


\section{SUMÁRIO}

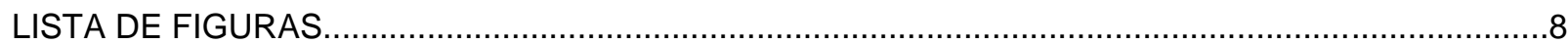

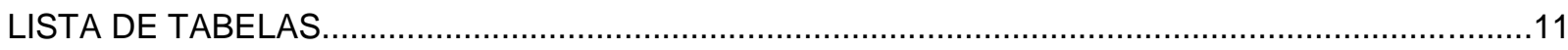

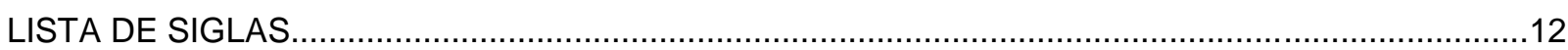

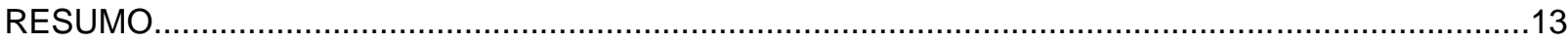

ABSTRACT

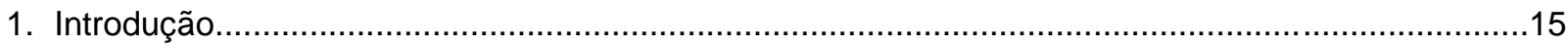

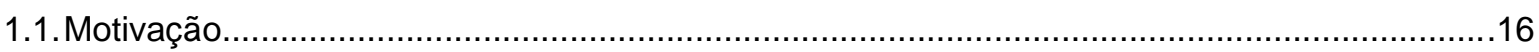

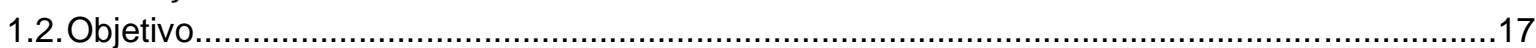

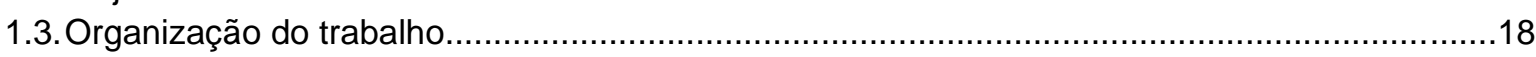

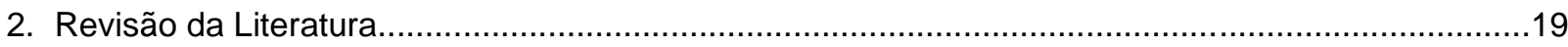

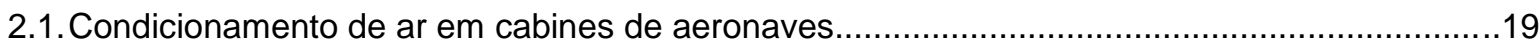

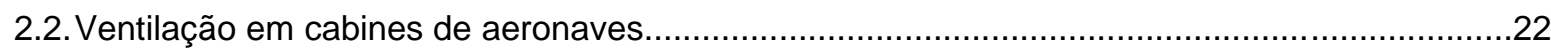

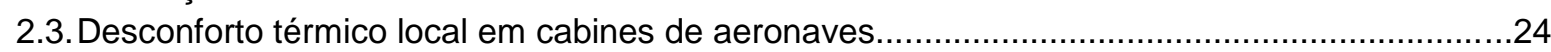

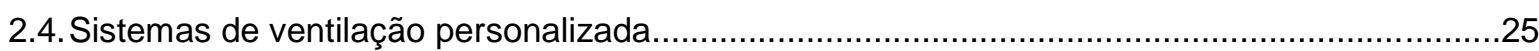

2.5. Estudos sobre a dispersão de partículas em aeronaves..........................................................30

2.6. Estudos desenvolvidos no Departamento de Engenharia Mecânica da Escola Politécnica da

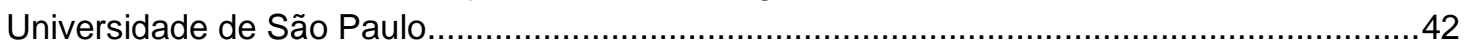

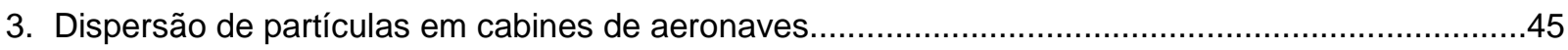

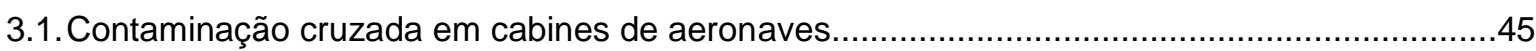

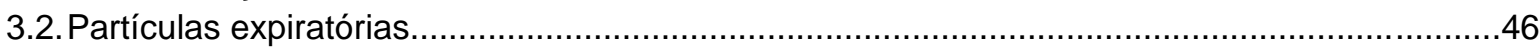

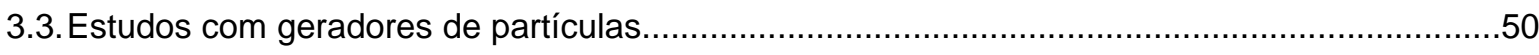

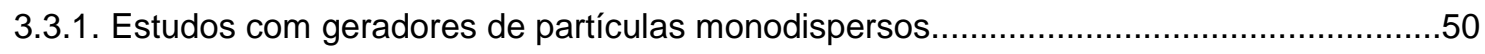

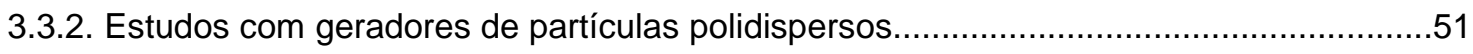

3.4. Efeitos dos filtros de ar na retenção de partículas em cabines de aeronaves............................53

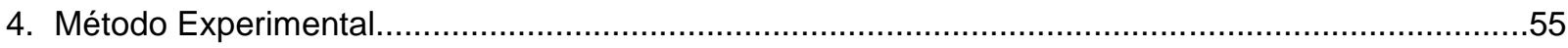

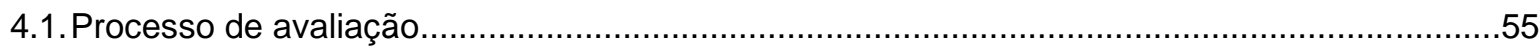

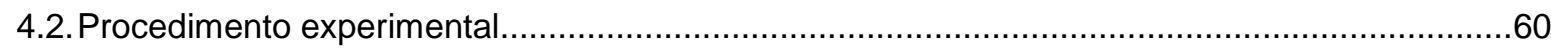

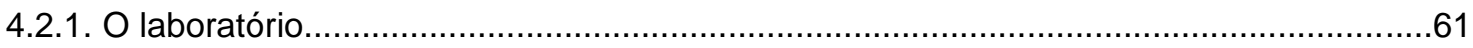

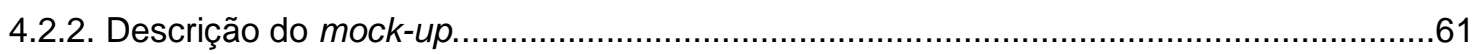

4.2.3. Sistema de ventilação personalizada instalado na poltrona...........................................63

4.2.4. Monitoramento e controle da temperatura do mock-up...............................................66

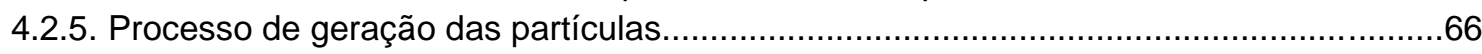

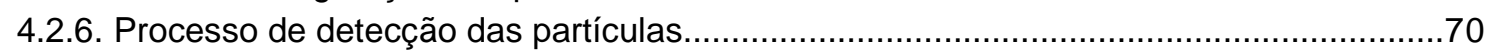

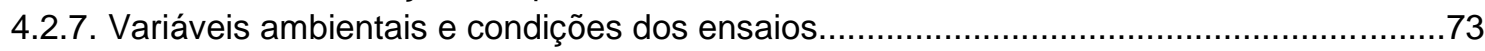

4.2.7.1. Temperatura do ar de insuflamento e das paredes do mock-up......................73

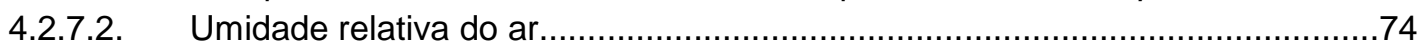

4.2.7.3. Vazão do ar de insuflamento e de renovação..................................................74

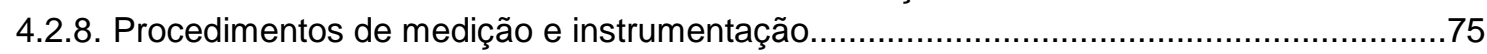

4.2.8.1. Medição da velocidade e da temperatura do ar no mock-up.............................75

4.2.8.2. Medição da temperatura das paredes do mock-up.........................................77

4.2.8.3. Medição da vazão de ar no mock-up.............................................................78

4.2.8.4. Medição da vazão de ar no sistema personalizado...........................................8

4.2.9. Processo de geração e de medição da concentração de partículas.................................81

4.2.9.1. Intervalo entre as medições e tempo de medição das partículas.......................84

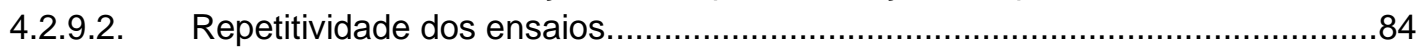

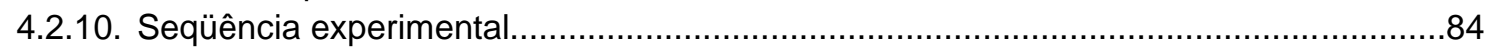




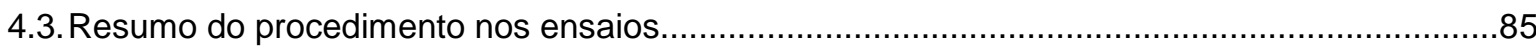

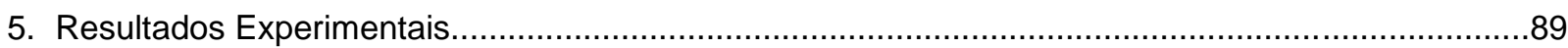

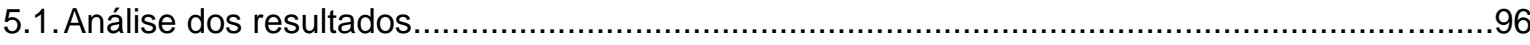

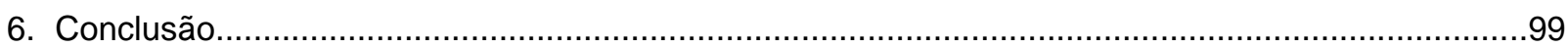

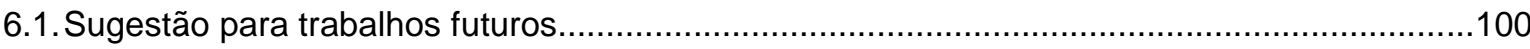

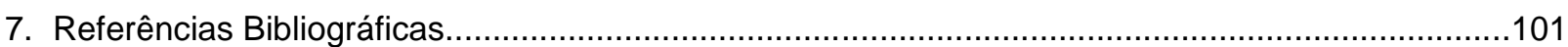

Anexo A

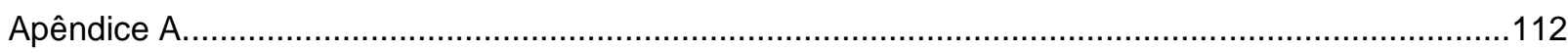

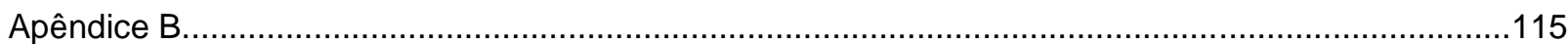




\section{LISTA DE FIGURAS}

Figura 2.1 - Esquema básico do sistema de climatização em cabines de aeronaves (figura adaptada de Walkinshaw, 2008)

Figura 2.2 - Sistema de resfriamento em cabines de aeronaves (Boeing, 2015)

Figura 2.3 - Sistema de distribuição com mistura de ar na cabine (figura adaptada de Gao e Niu, 2007a; Zhang et al., 2007)

Figura 2.4 - Sistema de distribuição por deslocamento de ar na cabine (figura adaptada de Gao e Niu, 2007a; Zhang et al., 2007)

Figura 2.5 - Sistema de distribuição por insuflamento de ar pelo piso (figura adaptada de Gao e Niu, 2007a; Zhang et al., 2007)

Figura 2.6 (a) Saídas de ar personalizadas do tipo válvula gasper (Conceição, 2012); (b) aplicação - em destaque - em cabine de aeronave (Walkinshaw, 2011)

Figura 2.7 - Sistema personalizado com insuflamento de ar por bocal instalado na poltrona (figura adaptada de Gao e Niu, 2007a)

Figura 2.8 - (a) Sistema personalizado com insuflamento frontal de ar por meio de painel ajustável (Kaczmarczyk; Melikov; Fanger, 2004); (b) estudo de aplicação em ambiente de escritório (Kaczmarczyk et al., 2006; Melikov, 2010)

Figura 2.9 - Vetores velocidade em sistema personalizado com insuflamento de ar pela poltrona à frente (figura adaptada de Zhang e Chen, 2007)

Figura 2.10 - Sistema personalizado com insuflamento de ar tipo travesseiro de pescoço (Nielsen et al., 2008)

Figura 2.11 - Sistema personalizado com insuflamento de ar pela lateral da poltrona (figura adaptada de Zhang, Li e Wang, 2012)

Figura 2.12 - Pontos de injeção e de medição de partículas para diferentes vazões de ar em mock-up de cabine (Wan et al., 2005)

Figura 2.13 - Mock-up de cabine de aeronave e planos de medição (Zhang et al., 2007)

Figura 2.14 - Linhas de corrente resultantes: (a) sistema MV, (b) sistema UFAD e (c) sistema UFAD com ventilação personalizada (Zhang e Chen, 2007)

Figura 2.15 - (a) Mock-up de cabine de aeronave; (b) Planos de medição das partículas contaminantes (Padilla, 2008)

Figura 2.16 - Estudo da dispersão de contaminantes em mock-up de Boeing 767-300 (Yan et al., 2009)

Figura 2.17 - Ocupação de mock-up de cabine de aeronave e pontos de injeção e de medição de partículas (Sze To et al., 2009)

Figura 2.18 - Partículas exaladas: (a) Durante uma tosse; (b) na respiração. (Chen et al., 2012)

Figura 2.19 - Simulação de partículas expiratórias: (a) exaladas por passageiro infectado e (b) caminho percorrido pelas partículas (Li et al., 2014)

Figura 2.20 - Representação de cabine com dois corredores (figura adaptada de Mazumdar et al., 2014)

Figura 2.21 - Concentração de partículas ao longo da seção transversal da cabine (Mazumdar et al., 2014)

Figura 2.22 - Interior da cabine da aeronave MD-82 (adaptado de Li et al., 2016) 
Figura 2.23 - Medições da concentração de $\mathrm{SF}_{6}$ no interior da cabine (adaptado de Li et al., 2016)

Figura 2.24 - Mock-up de 20 lugares utilizado na avaliação da dispersão de partículas (Conceição, 2012)

Figura 2.25 - Mock-up de 12 lugares: (a) Esquema interno e (b) Acesso e vista externa (Fabichak Jr., 2013)

Figura 3.1 - Gotículas expiratórias, baseado nas medições de Duguid (1946)

a) quantidade absoluta de partículas. b) distribuição do tamanho de partículas normalizada pelo intervalo de medição. c) distribuição acumulada (adaptado por Conceição, 2012)

Figura 3.2 - Distribuição do tamanho de gotículas produzidas por um gerador polidisperso próprio (adaptado de Wan et al., 2005)

Figura 4.1 - Fluxograma I: Processo de avaliação da dispersão de partículas em cabines climatizadas (Conceição, 2012)

Figura 4.2 - Fluxograma II: Processo para definição do gerador de partículas (Conceição, 2012)

Figura 4.3 - Representação esquemática do sistema da cabine (em azul claro) e personalizado (em amarelo) do mock-up (Fabichak Jr., 2013)

Figura 4.4 - Configuração do mock-up: (a) Representação isométrica do exterior; (b) Vista do interior

Figura 4.5 - Sistema de ventilação personalizada de poltrona: (a) Configuração dos dutos dos sistema PV; (b) Vista do assento equipado com sistema PV

Figura 4.6 - Difusor de ar do sistema de ventilação personalizada de poltrona:

(a) Geometria e dimensional; (b) Mecanismo para inclinação do difusor

Figura 4.7 - Difusor de ar do sistema de ventilação personalizada de poltrona:

(a) Configuração sem inclinação; (b) Configuração com inclinação

Figura 4.8 - Localização Vista interna do mock-up com os manequins aquecidos

Figura 4.9 - Manequins aquecidos e suas respectivas dimensões (Moura, 2009)

Figura 4.10 - Localização dos termopares no mock-up

Figura 4.11 - Gerador de aerossol TSI modelo 3475 (TSI, 2010) - imagem de catálogo

Figura 4.12 - Concentração de partículas em função do tamanho da gotícula produzida pelo gerador TSI modelo 3475 (TSI, 2010) - imagem de catálogo

Figura 4.13 - Gerador de aerossol TSI modelo 3475 associado ao indicador de monitoramento de partículas PAM 3375 (TSI, 2010) - imagem de catálogo

Figura 4.14 - Esquema interno do gerador de aerossol TSI modelo 3475 (TSI, 2010)

Figura 4.15 - Contadores de partículas da Met-One, modelo HHPC6 (Met-One HHPC6, 2010)

Figura 4.16 - Sensor de anemômetro omnidirecional (elemento sensor livre)

Figura 4.17 - Distribuição dos pontos de temperatura e de velocidade do ar

Figura 4.18 - Pedestal para posicionamento da sondas do Comfort Sense

Figura 4.19 - Posicionamento das sondas para medição de temperatura e velocidade do ar na altura de 0,60 $\mathrm{m}$ e de $1,10 \mathrm{~m}$ a partir do piso (Fabichak Jr., 2013)

Figura 4.20 - Posicionamento das sondas para medição de temperatura e velocidade do ar na altura de $0,10 \mathrm{~m}$ a partir do piso (Fabichak Jr., 2013)

Figura 4.21 - Vista dos tubos de Pitot antes e após a instalação (Fabichak Jr., 2013) 
Figura 4.22 - Manômetro diferencial para a determinação e monitoramento da vazão de ar (Fabichak Jr., 2013)

Figura 4.23 - Configuração para instalação do medidor de vazão - imagem de catalogo

Figura 4.24 - Instalação do medidor de vazão - em detalhe, valor da vazão no sistema personalizado

Figura 4.25 - Gerador de aerossol TSI modelo 3475 e monitor PAM 3375:

(a) Posicionamento externo ao mock-up; (b) Detalhe dos tubos e mangueiras de conexão; (c) Detalhe da medição do tamanho e da concentração das partículas

Figura 4.26 - Pontos de injeção e de medição das partículas no mock-up:

(a) injeção de partículas pela poltrona 3A; (b) injeção de partículas pela poltrona 3B

Figura 4.27 - Posição dos contadores de partículas

Figura 4.28 - Arquitetura I (referência): Sistema de ventilação por mistura (MV)

Figura 4.29 - Arquitetura II: Sistema de ventilação por mistura acrescentado de sistema de ventilação personalizada por bocal instalado na poltrona (MV+PV)

Figura 5.1 - Estabilização da temperatura do mock-up ao longo do tempo

Figura 5.2 - Perfis de temperatura e de velocidade do ar no interior do mock-up, considerando injeção de partículas pelo corredor (posição 3B)

Figura 5.3 - Perfis de temperatura e de velocidade do ar no interior do mock-up, considerando injeção de partículas pela lateral (posição 3A)

Figura 5.4 - Distribuição de partículas pela cabine - injeção de partículas pelo corredor

Figura 5.5 - Distribuição de partículas pela cabine - injeção de partículas pela lateral 


\section{LISTA DE TABELAS}

Tabela 4.1. Matriz dos ensaios experimentais

Tabela 5.1. Potencial de contaminação - sistema MV

Tabela 5.2. Potencial de contaminação - sistema PVesq sem inclinação

Tabela 5.3. Potencial de contaminação - sistema PVesq com inclinação

Tabela 5.4. Potencial de contaminação - sistema PVdir sem inclinação

Tabela 5.5. Potencial de contaminação - sistema PVdir com inclinação

Tabela 5.6. Remoção das partículas expiratórias entre 3 e $5 \mu \mathrm{m}$ insufladas via corredor

Tabela 5.7. Remoção das partículas expiratórias entre 3 e $5 \mu \mathrm{m}$ insufladas via lateral

Tabela B.8. Dados referentes ao insuflamento das partículas pelo corredor

Tabela B.9. Dados referentes ao insuflamento das partículas pela lateral

Tabela B.3. Incertezas na contagem das partículas insufladas pelo corredor - Sistema MV

Tabela B.4. Incertezas na contagem das partículas insufladas pelo corredor - Sistema PVesq (sem inclinação)

Tabela B.5. Incertezas na contagem das partículas insufladas pelo corredor - Sistema PVesq (com inclinação)

Tabela B.6. Incertezas na contagem das partículas insufladas pelo corredor - Sistema PVdir (sem inclinação)

Tabela B.7. Incertezas na contagem das partículas insufladas pelo corredor - Sistema PVdir (sem inclinação)

Tabela B.8. Incertezas na contagem das partículas insufladas pela lateral - Sistema MV

Tabela B.9. Incertezas na contagem das partículas insufladas pela lateral - Sistema PVesq (sem inclinação)

Tabela B.10. Incertezas na contagem das partículas insufladas pela lateral - Sistema PVesq (com inclinação)

Tabela B.11. Incertezas na contagem das partículas insufladas pela lateral - Sistema PVdir (sem inclinação)

Tabela B.12. Incertezas na contagem das partículas insufladas pela lateral - Sistema PVdir (com inclinação) 


\section{LISTA DE SIGLAS}

ACER

ASHRAE

CFD

Cfm

CLP

$\mathrm{CO}_{2}$

DEHS

DV

FAA

$\mathrm{H} 1 \mathrm{~N} 1$

HEACE

HEPA

ICE

ICEE

ISO

MV

$\mathrm{N}_{2}$

NAS

NRC

PIV

Psi

PV

SARS

$\mathrm{SF}_{6}$

UFAD

UR
Airliner Cabin Environment Research

American Society of Heating, Refrigerating and Air-Conditioning Engineers

Computational Fluid Dynamics - Dinâmica dos fluidos computacional

Cubic feet per minute - pés cúbicos por minuto ( $\mathrm{ft}^{3} / \mathrm{min}$.)

Controlador Lógico Programável

Gás carbônico

Di-Etil-Hexil-Sebacato

Displacement Ventilation - Ventilação por deslocamento

Federal Aviation Administration - Administração Federal de Aviação - US

Subtipo do vírus Influenza $A$

Health Effects in Aircraft Cabin Environment

High Efficiency Particulate Air

Ideal Cabin Environment - Ambiente de Cabine Ideal

International Centre for Indoor Environment and Energy

International Organization for Standardization

Mixing Ventilation - Ventilação por mistura

Nitrogênio

National Academy of Science - Academia Nacional de Ciências

National Research Council - Conselho Nacional de Pesquisa - US

Particle Image Velocimetry - Velocidade de partícula por imagem

Pound Square Inch - libra por polegada quadrada (lbf/in $\left.{ }^{2}\right)$

Personalized Ventilation - Ventilação personalizada

Severe Acute Respiratory Syndrome

Gás Hexafluoreto de Enxofre

Under Floor Air Distribution - Insuflamento de ar pelo piso

Umidade relativa do ar 


\section{RESUMO}

Cabines de aeronaves vêm sendo desenvolvidas de modo a tornar o ambiente a bordo mais aceitável e confortável para os seus usuários. No presente trabalho, a influência de sistema de ventilação personalizada instalado na poltrona na dispersão de partículas expiratórias foi estudada em um mock-up de 12 lugares, que reproduz o interior de uma aeronave comercial com quatro poltronas por fileira. Os ensaios foram realizados com temperatura do ar insuflado na cabine a $18^{\circ} \mathrm{C}$, correspondendo a uma leve sensação de frio, e temperatura do ar insuflado pelo sistema personalizado a $24^{\circ} \mathrm{C}$ com vazão de $3,0 \mathrm{l} / \mathrm{s}$. As partículas simulando uma pessoa espirrando foram injetadas em dois pontos no fundo da cabine, respectivamente, na poltrona próxima da fuselagem e naquela perto do corredor, a 1,10m do piso, que corresponde à região de respiração. A contagem de partículas foi realizada nos assentos da fileira imediatamente à frente do ponto de injeção das partículas, ou seja, na fileira do meio do mock-up, onde se encontra instalado o sistema de ventilação personalizada, respectivamente, na poltrona próxima da fuselagem e naquela perto do corredor. Medições para o mapeamento dos perfis de temperaturas e de velocidades do ar também foram realizadas. Os resultados mostraram que a dispersão de partículas sofre forte influência do sistema de ventilação personalizada e do ponto de injeção de partículas. A quantidade de partículas expiratórias na cabine sempre foi maior quando a injeção foi feita pelo assento junto ao corredor. Isto ocorre devido ao sistema de ventilação por mistura da cabine, com exaustão do ar pela parte inferior próximo da fuselagem. O sistema personalizado avaliado no assento próximo da fuselagem e junto do corredor foi capaz de reduzir, respectivamente, em $40 \%$ e $65 \%$ a quantidade de partículas expiratórias na zona de respiração dos ocupantes destas poltronas. Adicionalmente, quando o sistema personalizado está funcionando junto ao corredor, a redução das partículas em toda a fileira é de quase $60 \%$ em comparação ao sistema personalizado desligado.

Palavras-chave: Ar condicionado; Cabines; Aeronaves; Ventilação Personalizada; Partículas expiratórias; Dispersão 


\begin{abstract}
Aircraft cabins have been developed in order to make the onboard environment more acceptable and comfortable for their users. In the present work, the influence of a personalized ventilation system installed on the armchair in the dispersion of expiratory particles was studied in a 12-seat mock-up, which reproduces the interior of a commercial aircraft with four seats per row. The tests were performed with inlet air temperature into the cabin at $18^{\circ} \mathrm{C}$, corresponding to a slight cold sensation, and inlet air temperature of the customized system at $24^{\circ} \mathrm{C}$ with a flow rate of $3.0 \mathrm{l} / \mathrm{s}$. Particles simulating a person sneezing were injected at two points in the bottom of the cabin, respectively, in the seat near the fuselage and in the one near the corridor, $1.10 \mathrm{~m}$ from the floor, which corresponds to the breathing zone. Particle counting was carried out in the row seats immediately in front of the particles' injection point, i.e. in the middle row of the mock-up, where the custom ventilation system is installed, respectively, in the seat near the fuselage and in that one near the aisle. Measurements for the mapping of temperature and air velocities profiles were also performed. The results showed that the particle dispersion is strongly influenced by the custom ventilation system and the particle injection point. The amount of expiratory particles in the cabin was always greater when the injection was done by the seat near the aisle. This occurs due to the mixing ventilation system of cabin, with air exhaust located nearby the fuselage low part. The personalized ventilation evaluated on the fuselage seat and the aisle seat was able to reduce by $40 \%$ and $65 \%$, respectively, the amount of expiratory particles in the breathing zone in these seats. Moreover, when the custom system is working along the corridor, the particle reduction across the row is nearly $60 \%$ less compared to the custom system, when it is off.
\end{abstract}

Keywords: Air conditioning; Cabins; Aircrafts; Personalized Ventilation; Expiratory particles; Dispersion 


\section{Introdução}

O desenvolvimento das aeronaves vem ocorrendo, não somente visando a segurança nos voos, mas também com o propósito de prover bem-estar e conforto a bordo. Devido ao crescente número de voos, de passageiros e de rotas aéreas cada vez mais longas, a preocupação em tornar o ambiente interno em cabines de aeronaves mais saudável e agradável tem motivado diversos estudos. No entanto, devido às inúmeras variáveis inerentes a esse tipo de ambiente, são encontradas grandes dificuldades quando se trata do conforto térmico e da qualidade do ar interno. Consequentemente, são necessários grandes esforços para ofertar aos usuários um ambiente confortável e saudável que, adicionalmente, também seja uma alternativa economicamente viável para os fabricantes de aviões, permitindo oferecer produtos tecnologicamente modernos aliados a um baixo custo por passageiro.

Em geral, em ambientes climatizados de edificações onde a condição de conforto térmico é atingida, verifica-se que a umidade relativa do ar fica em torno dos 50\%. Em aeronaves, contudo, em função da baixa umidade do ar exterior em condições de voo, são verificadas umidades relativas bastante mais baixas por períodos longos de exposição, podendo chegar a $5 \%$, amplificando 0 desconforto térmico e comprometendo a salubridade a bordo (Strom-Tejsen et al., 2005; Grun et al., 2008; Stancato, 2009).

Por outro lado, a proximidade entre os passageiros, as baixas taxas de renovação do ar e a reduzida umidade relativa do ar interno são fatores que tendem a aumentar os efeitos da contaminação do ar em cabines de aeronaves, seja por agentes transmissores de doenças, ou por partículas expiratórias que se deslocam pelo ambiente fechado (ASHRAE, 2008; Wan et al., 2009; Fiser; Miroslav, 2013; Volavý; Fiser; Nöske, 2013). Para diminuir os riscos de contaminação faz-se necessário que ocorra funcionamento adequado do sistema de climatização, do sistema de distribuição do ar e de sistemas de ventilação personalizada, descritos no Capítulo 2. 


\subsection{Motivação}

O tema conforto e qualidade do ar em cabines de aeronaves vêm recebendo grande enfoque nos últimos anos:

- Por parte dos fabricantes de aeronaves, que tendem a desenvolver sistemas que ofereçam a seus usuários maior comodidade e salubridade durante o voo. Agregar conforto e qualidade do ar como um parâmetro no desenvolvimento de aeronaves, não apenas potencializa a chance de satisfação dos usuários, como também se mostra critico para manter a competitividade tecnológica entre as diversas aeronaves disponíveis no mercado (Yanagihara; Gasparotti, 2006);

- Por parte das companhias aéreas, que passaram a oferecer maiores benefícios aos passageiros. Um número maior de pessoas tende a utilizar a aviação como uma opção prática, rápida e segura para ir de um lugar para outro. Conseqüentemente, um número maior de passageiros é transportado;

- Por parte dos passageiros, onde surge a expectativa de usufruir de uma opção que até pouco tempo atrás era bem mais cara em relação a outros meios de transporte.

Por outro lado, o significativo aumento da demanda de passageiros também preocupa tanto fabricantes quanto companhias aéreas. Estudos mostram que os sistemas de ventilação empregados nos aviões ainda não são totalmente eficientes ao ponto de propiciar conforto térmico e qualidade do ar aos ocupantes sem gerar correntes de ar, principal causa de desconforto térmico em ambientes climatizados, embora a velocidade do ar seja baixa em aeronaves (Zhang; Chen, 2007; Gao; Niu, 2007b; Stancato, 2009).

Mangili e Geandreau (2005) citam vários casos em que o ambiente em cabines de aeronaves propiciou a disseminação de doenças provocadas por vírus e microorganismos. Estudos recentes mostram que um ambiente saudável para quem viaja de avião tem relação íntima com a contaminação cruzada entre os passageiros, sobretudo depois dos surtos de agentes virais, dentre os principais, o vírus SARS (Severe Acute Respiratory Syndrome ou Síndrome Respiratória Aguda Severa), a gripe suína (H1N1) e a gripe aviária (Olsen; Chang; Cheung, 2003; Mangili; Geandreau, 2005; Brooker, 2007; Fabian et al., 2008; Wagner; Coburn; Blower, 2009; Walkinshaw, 2010; Fabichak Jr., 2013), motivando os fabricantes e companhias 
aéreas, instituições de pesquisa e, em alguns casos, até órgãos governamentais a atuarem fortemente nas áreas de pesquisa e desenvolvimento (NRC, 1986; NAS, 2002; NRC, 2002; ACER, 2010; HEACE, 2010; ICE, 2010; Poussou et al., 2010; Gupta; Lin; Chen, 2011; FAA, 2012).

Os problemas advindos da disseminação de doenças em aeronaves têm motivado a realização de estudos sobre qualidade do ar interior em cabines de aeronaves (Hunt; Space, 1994; Preston; Ernsting; King, 1995; Ballouet, 1996; Hocking, 1998; Pierce et al., 1999; Uva, 2000; Uva, 2002; Zhang et al., 2007; Wan et al., 2009) e de estudos sobre a contaminação em cabines de aeronaves relacionados com a dispersão de partículas geradas internamente, isto é, pelos próprios usuários, por processos expiratórios (Fairchild; Stampfer, 1987; Yu et al., 2004; Mangili; Geandreau, 2005; Wan; Chao; Fang, 2005; Mazumdar; Chen, 2007; Bhangar; Nazaroff, 2008; Zhang et al., 2007; Wan et al., 2009; Sze To et al., 2009; Gupta; Lin; Chen, 2011; Conceição, 2012; Bosbach et al., 2012; Chen et al., 2012; Fabichak Jr., 2013; Pang et al., 2013).

No entanto, a dinâmica da dispersão de partículas e a influência dos sistemas de ventilação das aeronaves é um tema que, embora bastante estudado, ainda requer maior esforço, pois em muitos casos, ainda são desconhecidos os mecanismos de propagação de partículas expiratórias nesse tipo de ambiente (Morawska, 2005; Li et al., 2007; Yang et al., 2007; Nielsen et al., 2007; Nielsen et al., 2008; Müller; Schmidt; Müller, 2011; Bosbach et al., 2012), também incentivando a um maior aprofundamento sobre este tema.

A proposição e o estudo da influência de sistemas de ventilação personalizada na dispersão de partículas expiratórias, por sua vez, é um tema ainda muito pouco estudado, conforme apresentado no Capítulo 2.

\subsection{Objetivo}

O objetivo deste trabalho consiste na realização de estudo experimental da influência de sistema de ventilação personalizada instalado na poltrona na dispersão de partículas expiratórias em cabine de aeronave equipada com arquitetura de ventilação por mistura, em mock-up de 12 lugares, utilizando gerador e contadores de partículas. 


\subsection{Organização do trabalho}

No Capítulo 1 foi feita uma breve introdução ao tema, enfatizando o ambiente térmico interior e a disseminação de doenças em cabines de aeronaves.

No Capítulo 2 são abordados aspectos relativos aos sistemas de ventilação de cabine, aos sistemas de ventilação personalizada e ao desconforto térmico local, bem como a apresentação de estudos relativos à dispersão de partículas no interior de cabines de aeronaves.

> No Capítulo 3 são apresentados aspectos gerais sobre a dispersão de partículas expiratórias e sobre estudos realizados com geradores de partículas.

No Capítulo 4 é apresentado o método experimental, descrevendo o processo de análise da dispersão de partículas a ser utilizado no presente trabalho, bem como a descrição do laboratório, do mock-up e do sistema de ventilação personalizada estudado, além do procedimento experimental, dos instrumentos utilizados e das condições de ensaio.

No Capítulo 5 são apresentados os resultados dos ensaios e respectiva análise.

No Capítulo 6 são apresentadas as conclusões do trabalho, bem como sugestões de continuidade do trabalho.

No Capítulo 7 são apresentadas as referências bibliográficas.

No Anexo A é apresentado o memorial de cálculo do manômetro diferencial utilizado para o cálculo da vazão de ar fornecida ao mock-up.

No Apêndice A é apresentado o memorial de cálculo da vazão de ar do sistema personalizado, de acordo com o critério de desconforto térmico local devido a correntes de ar.

> No Apêndice B são mostradas as tabelas dos resultados experimentais referentes à dispersão de partículas para os ensaios avaliados e o análise das incertezas de medição. 


\section{Revisão da Literatura}

Neste Capítulo é apresentada revisão bibliográfica de estudos relativos à dispersão de partículas no interior de cabines de aeronaves. Inicialmente, para melhor entendimento da dinâmica da dispersão de partículas, faz-se necessário entender o funcionamento do sistema de condicionamento, de sistemas de distribuição de ar e de ventilação personalizada em cabines de aeronaves, apresentados a seguir.

\subsection{Condicionamento do ar em cabines de aeronaves}

A função do sistema de climatização é prover ventilação, resfriamento ou aquecimento para todo o ambiente interior das cabines de aeronaves, impedindo que as trocas de calor com o ambiente exterior e o calor trocado pelos passageiros contribuam para tornar impróprias as condições ambientais no interior da aeronave. Com isso, o sistema de climatização deve ser ajustado para reduzir ou elevar a temperatura do ambiente por meio da mistura do ar conforme a necessidade.

Segundo a norma ASHRAE 161 (ASHRAE, 2007), a temperatura no interior da cabine de aeronaves comerciais deve ficar na faixa de 18 a $24^{\circ} \mathrm{C}$ - podendo eventualmente atingir $27^{\circ} \mathrm{C}$ durante o voo e $29^{\circ} \mathrm{C}$ com a aeronave em solo.

A ventilação é obtida através de dutos de ar pressurizado, instalados na parte dianteira, inferior, superior ou através de tomadas de ar instaladas na lateral da cabine da aeronave (FAA, 2012). O ar que flui por essas aberturas circula dentro do mesmo duto utilizado pelo subsistema de aquecimento e resfriamento. $O$ ar interior é reciclado por meio do auxílio de ventiladores e sopradores.

A necessidade de um sistema de aquecimento é, muitas vezes, conseguida por meio do processo termodinâmico de compressão do ar e, na maioria das situações, não há a necessidade da utilização de sistemas auxiliares para se obter uma maior temperatura interior na aeronave. Quando necessário, o aquecimento pode ser feito:

- Utilizando um sistema de combustão com um queimador, que utiliza uma mistura de ar com o próprio combustível da aeronave em um sistema paralelo, produzindo ar a uma temperatura mais elevada que é posteriormente filtrado e misturado com o ar da cabine; 
- Utilizando sistema de reaproveitamento dos gases de exaustão. Após ser armazenado em um invólucro, o ar quente é direcionado para um trocador de calor, misturando o ar quente com o ar da cabine. Em seguida, o ar é direcionado para os filtros com o objetivo de remover partículas de monóxido de carbono presentes nos gases de exaustão. Este sistema é relativamente eficiente em aeronaves onde os gases de escape são ejetados por grandes tubos (Boeing, 2015).

Os sistemas de aquecimento acima citados requerem que os motores estejam em funcionamento. No entanto, quando a aeronave encontra-se estacionada e exposta por períodos longos em climas frios, o pré-aquecimento da aeronave faz-se necessário. Nestes casos, os sistemas elétricos auxiliares, isto é, os que requerem uma tomada de energia externa, são comumente utilizados devido a sua alta eficiência e reduzidos tempos para aquecimento da cabine.

No sistema de resfriamento o ar é captado do exterior da aeronave e aspirado para um trocador de calor primário, que irá efetuar a mistura do ar externo capturado com o ar que é exaurido dos motores (FAA, 2012). Esta massa de ar misturada é movimentada por um compressor e, posteriormente, segue para um trocador de calor secundário - normalmente do tipo ar/água - com o objetivo de diminuir ainda mais a sua temperatura. A massa de ar segue então para um aquecedor, onde uma parte é desviada para movimentar a turbina que capta o ar externo e a outra parte segue para o condensador, onde sofre uma queda brusca de temperatura e pressão. Finalmente, o ar que passou pelo condensador é centrifugado e todo o excesso de umidade gerado é captado. Somente após esse ciclo, o ar é distribuído para o interior da cabine da aeronave através dos dutos e tubulações existentes.

Pode ser observada na área em destaque da Figura 2.1, a distribuição dos dutos de um sistema de climatização típico de aeronaves, que contém os equipamentos que realizam o ciclo termodinâmico para o resfriamento do ar, podendo eventualmente também ser utilizado para o aquecimento. Na Figura 2.2, pode ser observado em detalhe um esquema simplificado de um sistema de resfriamento utilizado em aeronaves comerciais de médio e grande porte. 


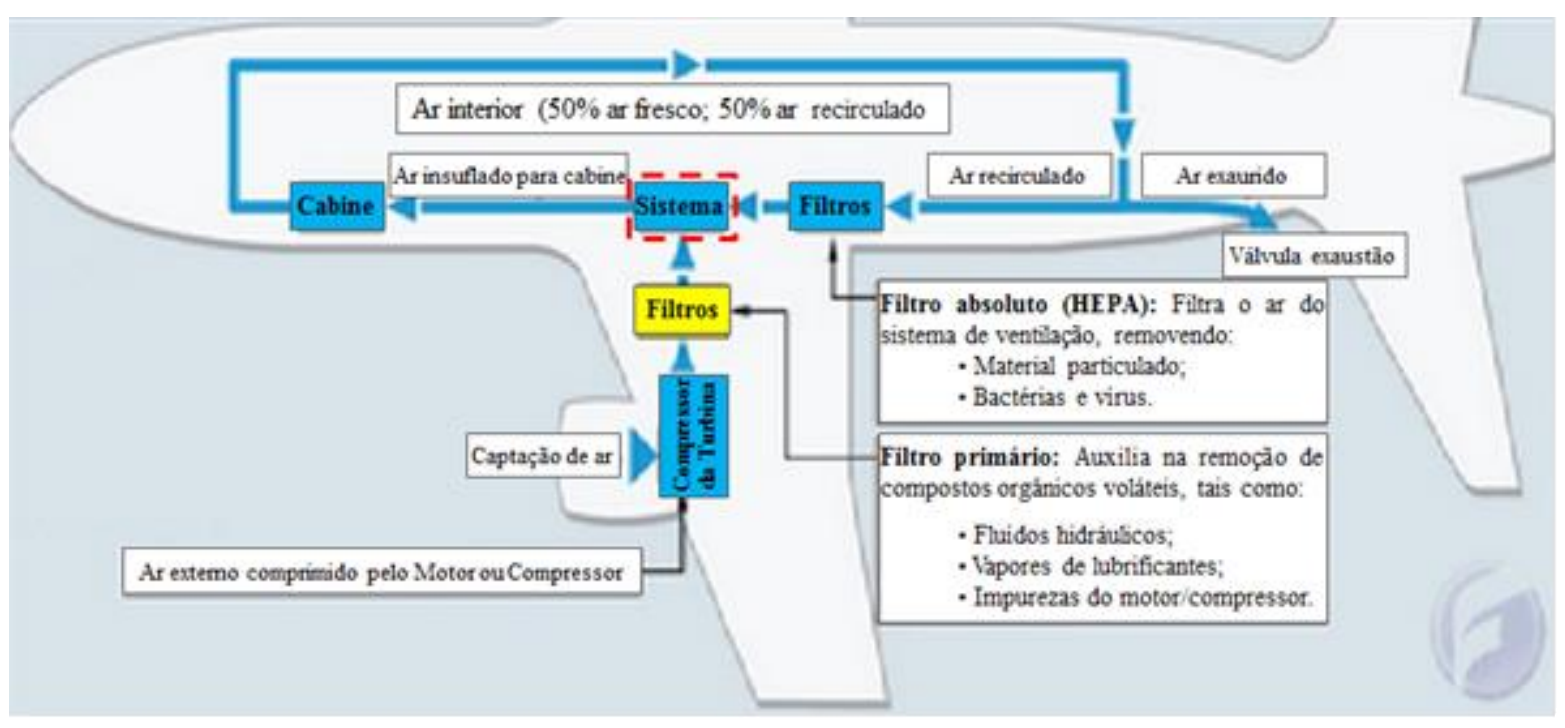

Figura 2.1 - Esquema básico do sistema de climatização em cabines de aeronaves (figura adaptada de Walkinshaw, 2008)

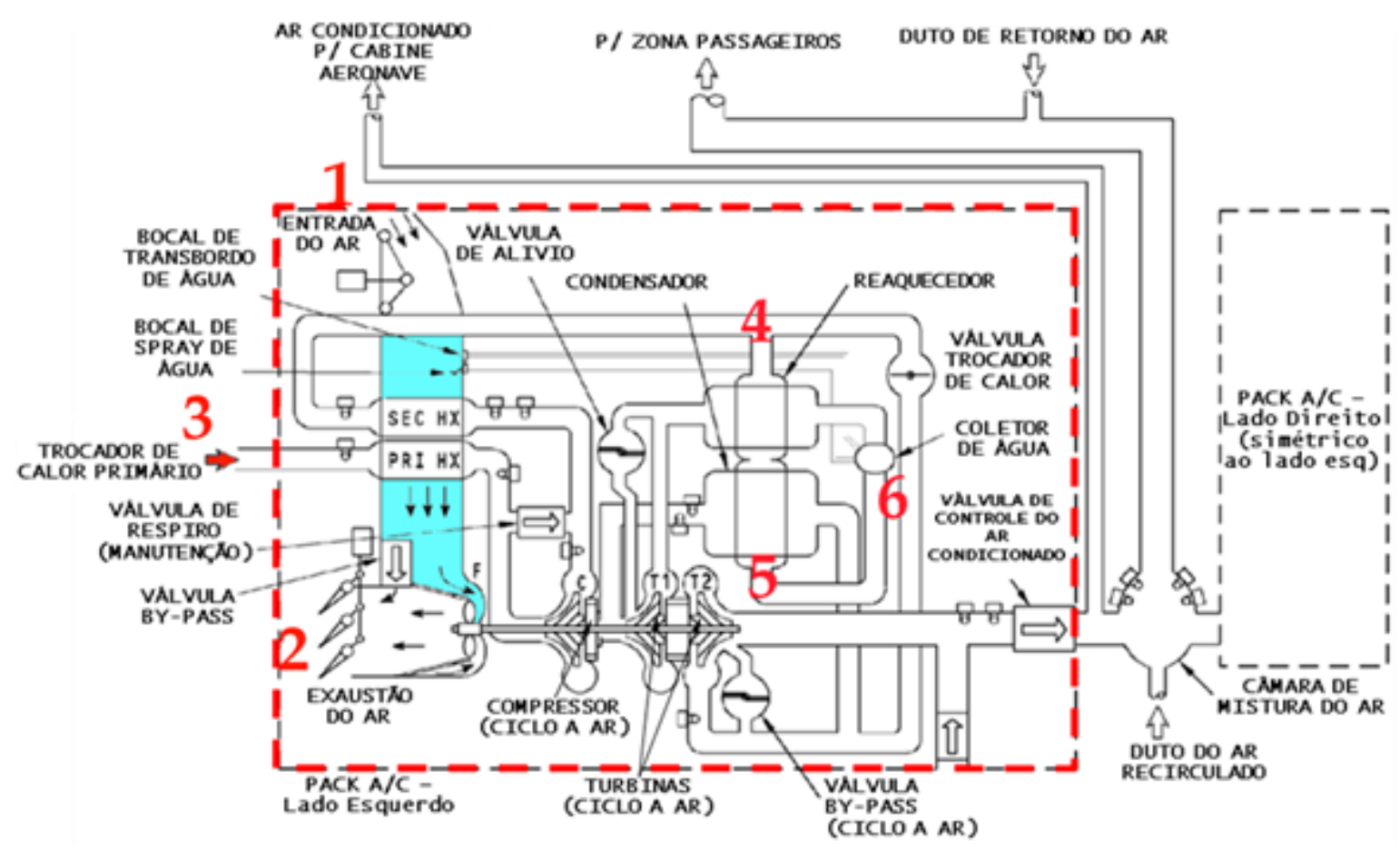

Figura 2.2 - Sistema de resfriamento de cabines de aeronaves (figura adaptada de Boeing, 2015) 


\subsection{Ventilação em cabines de aeronaves}

O sistema de ventilação mais utilizado em cabines de aeronaves consiste em insuflar 0 ar pela parte superior e retornar $o$ ar pela parte inferior, misturando $o$ ar na cabine. Este sistema, mostrado na Figura 2.3, denominado de MV (Mixing Ventilation) permite que a temperatura ao longo das diferentes seções de cabine se mantenha praticamente uniforme, devido à característica de mistura do ar, sendo possível obter variações de temperatura vertical inferiores a $3^{\circ} \mathrm{C}$ (Zhang et al., 2007; Stancato, 2009).

Embora o sistema MV normalmente proporcione um ambiente com baixa estratificação de temperatura, problemas de conforto térmico têm sido verificados (Moura, 2009; Stancato, 2009; Conceição, 2012, Silva, 2013). Além disso, a recirculação do ar na cabine pode dispersar contaminantes com maior facilidade pelo interior da aeronave (Gao; Niu, 2007a; Zhang et al., 2007; Fabichak Jr., 2013).

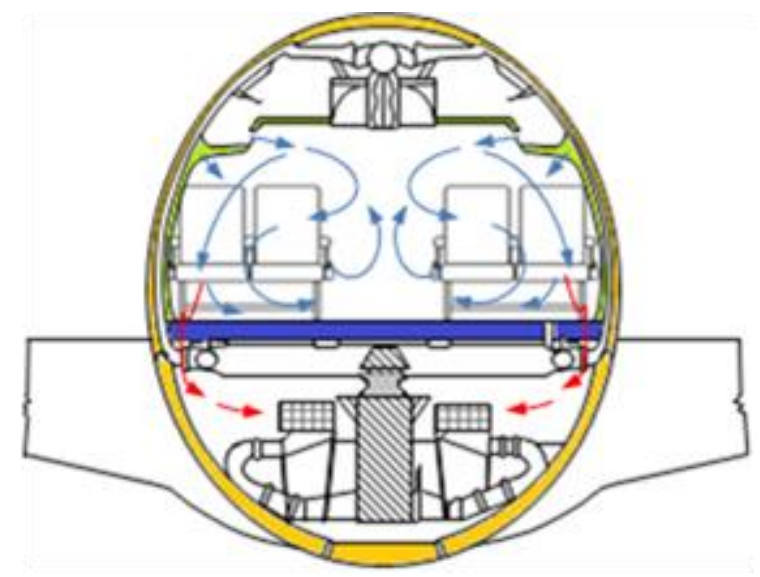

Figura 2.3 - Sistema de distribuição com mistura de ar na cabine (figura adaptada de Gao; Niu, 2007a; Zhang et al., 2007)

Com o propósito de melhorar as condições de conforto térmico e minimizar a dispersão de partículas no interior de aeronaves, algumas propostas de sistemas de distribuição de ar vêm sendo estudadas, tanto numérica quanto experimentalmente. Dentre os modelos propostos, destacam-se o sistema de ventilação por deslocamento de ar (sistema DV - Displacement Ventilation); o sistema de insuflamento de ar pelo piso (sistema UFAD - Under Floor Air Distribution), além dos sistemas de ventilação personalizada (sistemas PV - Personalized Ventilation).

No sistema de ventilação por deslocamento (DV), conforme pode ser visto na Figura 2.4, o ar é introduzido lateralmente no interior da cabine, insuflado pelos 
difusores montados na parte inferior das paredes próximo ao piso. O ar circulado é exaurido pelas grelhas localizadas no teto, fazendo com que o escoamento do ar acompanhe o sentido natural da pluma térmica dos ocupantes (Leite; Tribess, 2006; Pereira et al., 2009) e auxiliando na remoção dos contaminantes por eles gerados. Posteriormente, o ar retorna ao sistema de condicionamento da aeronave.

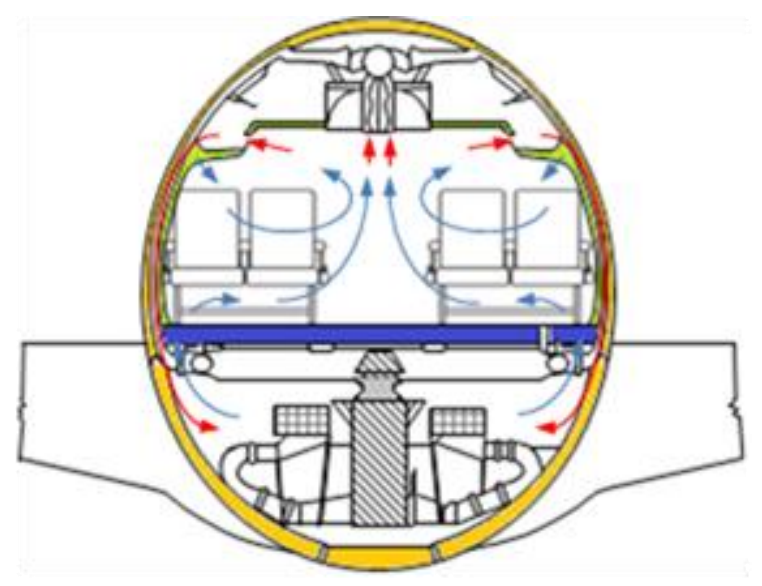

Figura 2.4 - Sistema de distribuição por deslocamento de ar na cabine (figura adaptada de Gao; Niu, 2007a; Zhang et al., 2007)

No sistema de insuflamento de ar pelo piso (UFAD), ilustrado na Figura 2.5, a forma de ventilação é semelhante ao sistema DV; a diferença se dá na saída do ar dos difusores, que é insuflado no ambiente a partir do piso, sendo o seu retorno realizado pelo teto, de maneira que o escoamento do ar também acompanhe o sentido natural da pluma térmica dos ocupantes na remoção dos contaminantes internamente gerados. Analogamente aos demais sistemas, o ar retorna ao sistema de condicionamento da aeronave.

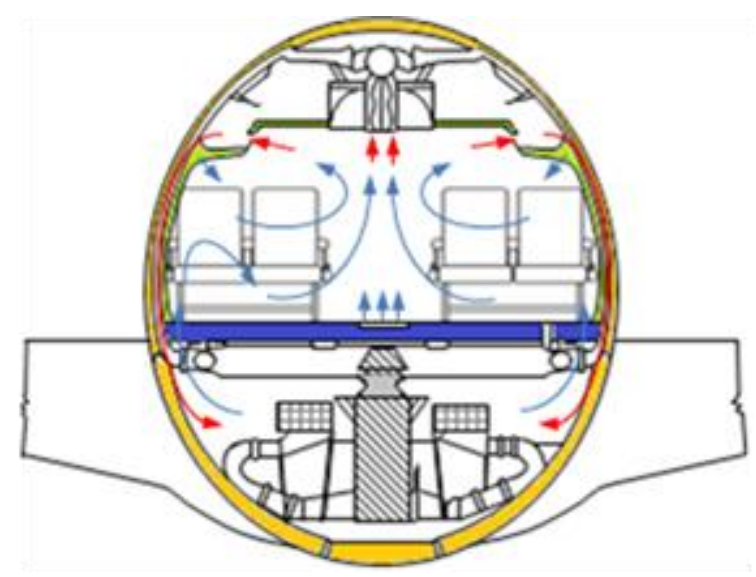

Figura 2.5 - Sistema de distribuição por insuflamento de ar pelo piso (figura adaptada de Gao; Niu, 2007a; Zhang et al., 2007) 
Tanto as propostas do sistema DV quanto do UFAD tendem a melhorar a qualidade do ar na zona de respiração. No entanto, a velocidade de insuflamento do ar pode causar correntes de ar na região inferior do corpo - pés, tornozelos e pernas causando desconforto térmico local aos passageiros (Fanger et al., 1988; Zukowski, 2007).

\subsection{Desconforto térmico local em cabines de aeronaves}

O ambiente no interior de aeronaves é caracterizado pela não homogeneidade nas diferentes seções da cabine. Quando em solo, a temperatura da fuselagem pode atingir, sob certas condições de incidência de radiação térmica, até $80^{\circ} \mathrm{C}$. Durante 0 voo, a temperatura exterior pode atingir até $-40^{\circ} \mathrm{C}$ (Stancato, 2009). Tal amplitude térmica pode gerar assimetrias de temperatura, podendo influenciar seriamente nas condições de conforto térmico dos ocupantes.

Dependendo do tipo de arquitetura de distribuição de ar empregado nas aeronaves, podem ainda existir outras duas causas do desconforto térmico local: a diferença vertical na temperatura do ar entre o piso e o teto (Leite; Tribess, 2006; Zhang et al., 2007); e o surgimento de correntes de ar devido à movimentação irregular proveniente do insuflamento do ar no interior da aeronave (Zukowsky, 2007; Zhang; Li; Wang, 2012). Este último fator é o mais fácil de ser percebido pelos ocupantes, pois a sensibilidade às correntes de ar é maior em partes do corpo descobertas, especialmente na região da cabeça, pescoço e ombros e na região dos pés, tornozelos e pernas (Fanger et al., 1988).

Segundo Fanger et al. (1988), para atividade sedentária ou leve, o percentual de insatisfação (PPD - Predicted Percentage of Dissatisfaction) com correntes de ar é dado pela equação 2.1 (ISO 7730, 2005; ASHRAE 55, 2013):

$$
P D=3,143 \cdot\left(34-T_{A R}\right)\left(\overline{v_{A R}}-0,05\right)^{0,6223}+0,3696 \cdot \bar{v}_{A R}^{--} \cdot T_{U} \cdot\left(34-T_{A R}\right)\left(\overline{v_{A R}}-0,05\right)^{0,6223}
$$

Onde:

$\mathrm{T}_{\mathrm{AR}}$ é a temperatura do ar local, em $\left[{ }^{\circ} \mathrm{C}\right]$;

$\overline{v_{A R}}$ é a velocidade média do ar local, em $[\mathrm{m} / \mathrm{s}]$; 
$T_{\cup}$ é a intensidade de turbulência, em [\%], expressa pela equação 2.2, que se baseia nos valores da velocidade do ar, medidos com intervalos de 0,2 segundos durante, pelo menos, três minutos e o desvio padrão referente à respectiva amostra de dados.

$$
T_{U}=\frac{\sigma_{v_{A R}}}{v_{A R}^{--}} .100
$$

Onde:

$\sigma_{v_{A R}}$ é o desvio padrão da velocidade do ar local, em [m/s];

O memorial de cálculo para adotar o valor da vazão do sistema personalizado utilizada no presente trabalho está descrito no Apêndice $A$.

\subsection{Sistemas de ventilação personalizada}

Uma forma de minimizar o desconforto térmico em aeronaves pode ser conseguida pela utilização de sistemas de ventilação personalizada (PV), fornecendo ao usuário opções para o controle e ajuste de condições térmicas de forma a oferecer conforto térmico individual, além de fornecer ar mais limpo na zona de respiração, diminuindo a possibilidade de contaminação cruzada por meio dos contaminantes dispersos no ambiente (Melikov, 2004; Kaczmarczyk; Melikov; Fanger, 2004; Leite; Tribess, 2006; Kaczmarczyk et al., 2006; Gao; Niu, 2007b; Li; Sekhar; Melikov, 2010; Zhang; Li; Wang, 2012; Conceição, 2012).

Contudo, a utilização de sistemas personalizados pode aumentar a possibilidade de contaminação de outros passageiros em função da dispersão das partículas na cabine, o que é estudado no presente trabalho.

Um sistema PV que é encontrado em cabines de aeronaves, e mostrado na Figura 2.6, consiste na utilização das válvulas gasper. Este difusor, instalado nas saídas de ar localizadas sob o compartimento de bagagem, possibilita aumentar ou diminuir a vazão do ar direcionado para a região da cabeça dos passageiros. Com isto, é possível obter um efeito de resfriamento localizado. 
a)

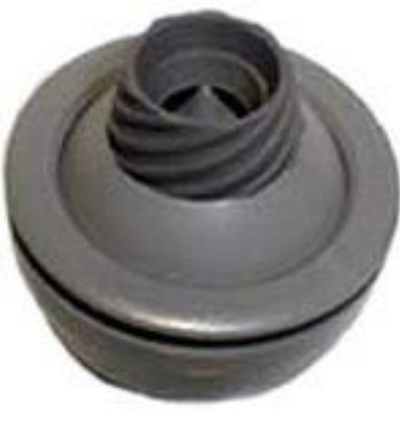

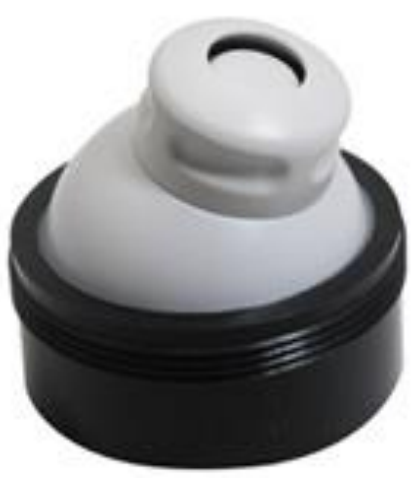

b)

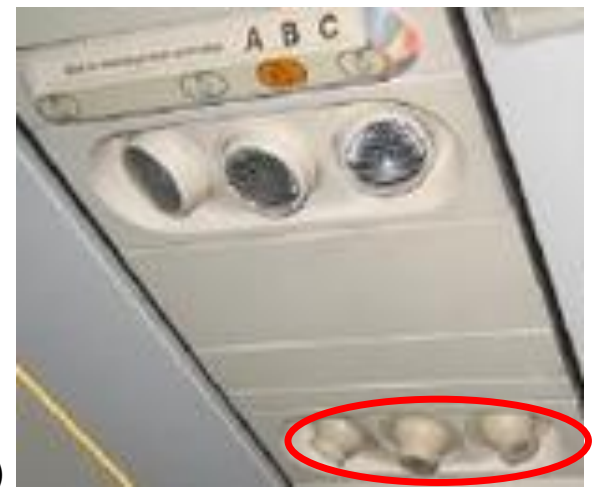

Figura 2.6 - (a) Saídas de ar personalizadas do tipo válvula gasper (Conceição, 2012); (b) aplicação - em destaque - em cabine de aeronave (Walkinshaw, 2011)

Outros sistemas de ventilação personalizada mais complexos estão sendo desenvolvidos, aperfeiçoados e testados (DLR, 2011), razão pela qual ainda não têm sido efetivamente empregados em cabines de aeronaves.

Gao e Niu (2007a) utilizaram um código de dinâmica dos fluidos computacional (CFD - Computational Fluid Dynamics) para simular e avaliar o sistema de distribuição de ar por mistura (MV) e um sistema personalizado (PV) em uma cabine de aeronave. A utilização do sistema personalizado de distribuição de ar proposto, conforme a Figura 2.7, foi capaz de reduzir em $60 \%$ o nível de contaminantes na zona de respiração dos ocupantes. Porém, os autores mostraram que os sistemas MV e $\mathrm{MV}+\mathrm{PV}$ dispersam os contaminantes para outras regiões da cabine.

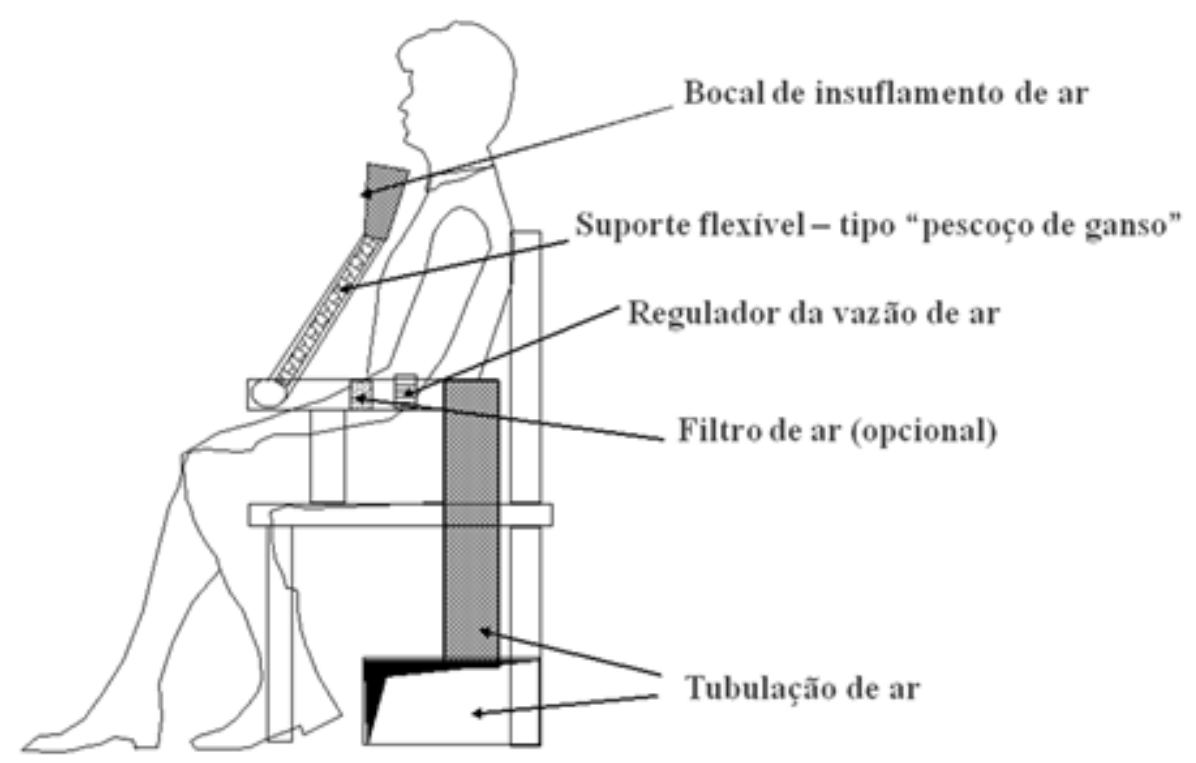

Figura 2.7 - Sistema personalizado com insuflamento de ar por bocal instalado na poltrona (figura adaptada de Gao; Niu, 2007a) 
Zhang e Chen (2007) estudaram tanto experimentalmente quanto por meio de simulação numérica computacional, o desempenho de três formas de distribuição de ar em um mock-up de cabine de aeronave Boeing 767-300. No primeiro teste foi simulado insuflamento de ar utilizando sistema convencional MV. Na segunda análise, foi simulado o insuflamento de ar pelo piso com retorno pelo teto da cabine, ou seja, um sistema UFAD. Finalmente, a terceira análise foi baseada no sistema UFAD e acrescentado de um sistema de ventilação personalizada, conforme mostrado na Figura 2.8, baseado em modelo proposto por Kaczmarczyk et al. (2004) para ambientes de escritórios.

Nesta terceira análise, metade da vazão de ar foi insuflada diretamente por trás da poltrona imediatamente à frente do passageiro e a outra metade foi insuflada pelo piso (UFAD). Conforme mostrado na Figura 2.9, pode ser visto o campo dos vetores de velocidade do ar resultantes do funcionamento do sistema PV.

a)

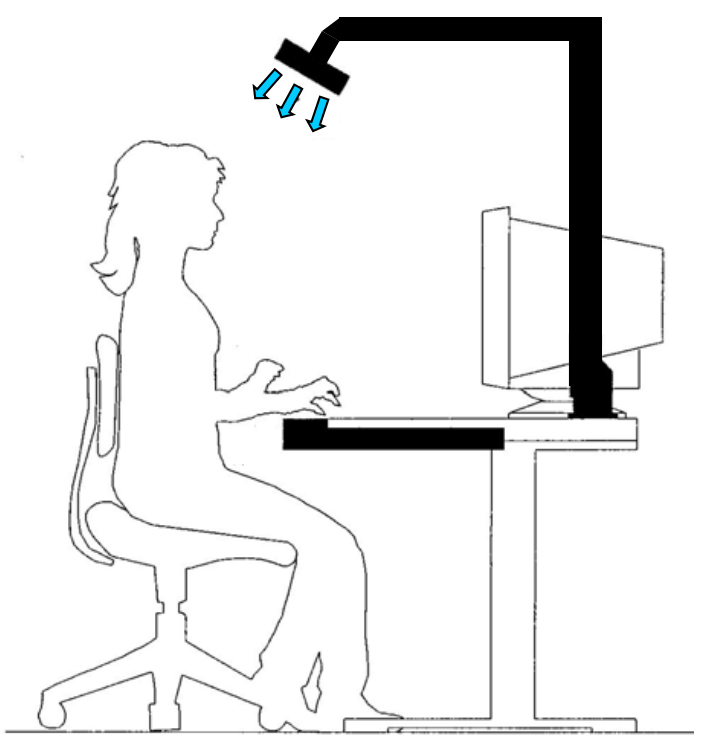

b)
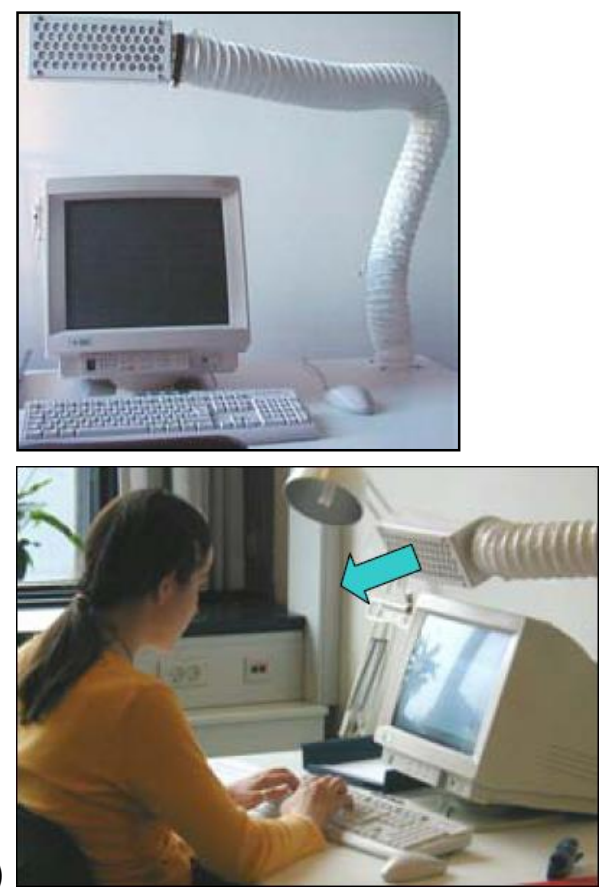

Figura 2.8 - (a) Sistema personalizado com insuflamento frontal de ar por meio de painel ajustável (Kaczmarczyk; Melikov; Fanger, 2004); (b) estudo de aplicação em ambiente de escritório (Kaczmarczyk et al., 2006; Melikov, 2010)

Em todas as avaliações realizadas por Zhang e Chen (2007), a vazão de insuflamento de ar foi de $10 \mathrm{l} / \mathrm{s}$ e a temperatura média de cabine foi ajustada para $24^{\circ} \mathrm{C}$. Os autores concluíram que os níveis de contaminantes presentes na zona de respiração eram menores quando era utilizado o sistema UFAD com sistema de ventilação personalizada, PV. Embora constatada a estratificação da temperatura do 
ar, inerente ao sistema UFAD, a quantidade de partículas dispersas ao longo da cabine foi ligeiramente inferior quando comparada com o sistema MV.

Zhang e Chen (2007) verificaram que a utilização combinada do sistema UFAD junto com o sistema PV estudado resultou em menores índices de concentração de $\mathrm{CO}_{2}$, com eliminação quase total do risco de partículas infecciosas na zona de respiração dos passageiros. Função disso, os pesquisadores concluíram que a proposta apresentada é recomendável para ser utilizada em cabines de aviões comerciais.

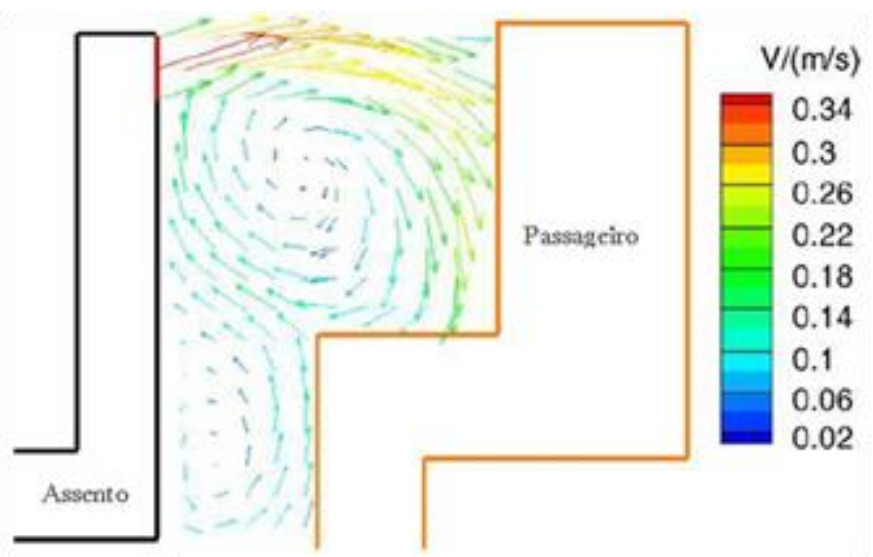

Figura 2.9 - Vetores velocidade em sistema personalizado com insuflamento de ar pela poltrona à frente (figura adaptada de Zhang; Chen, 2007)

Nielsen et al. (2008) desenvolveram um sistema de ventilação personalizado, concebido em formato de travesseiro, no qual se apoiava o pescoço do passageiro ao encosto da poltrona, conforme modelo ilustrado na Figura 2.10. Como resultado da pesquisa, concluiu-se que esse sistema é altamente eficiente na remoção da contaminação cruzada, desde que o sistema PV também seja capaz de controlar os níveis de contaminantes no ambiente por meio das taxas de renovação do ar recomendadas. O sistema de ventilação personalizada proposto fornecia ar fresco para a zona de respiração com uma vazão máxima de até $16 \mathrm{l} / \mathrm{s}$. Os autores concluíram que o sistema é mais eficiente para taxas de insuflamento de ar entre 7 a 8 l/s - em conformidade com o preconizado pela norma ASHRAE 161 (ASHRAE, 2007), que recomenda vazões de ar entre 5,9 e 9,6 l/s/pessoa. Além disso, o risco de correntes de ar pode ser minorado ou até evitado pelo controle da temperatura do ar do sistema PV. 


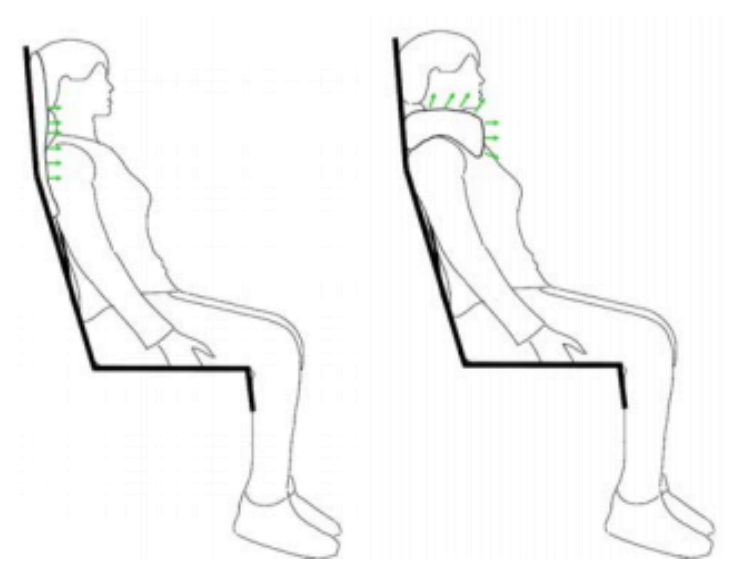

Figura 2.10 - Sistema personalizado com insuflamento de ar tipo travesseiro de pescoço (Nielsen et al., 2008)

Zhang, Li e Wang (2012) também desenvolveram um sistema de ventilação personalizada para cabines de aeronaves. A proposta consistia em insuflar uma parte do ar pelo piso (UFAD) e a outra parte era fornecida diretamente para a zona de respiração do passageiro através de um difusor localizado nos braços do assento, conforme ilustrado na Figura 2.11. O ar era exaurido pelo teto, por meio de exautores, localizados acima da cabeça dos ocupantes. $O$ estudo foi realizado tanto numérica quanto experimentalmente, sendo que o percentual de pessoas insatisfeitas devido a correntes de ar, avaliado quando o sistema PV era utilizado em todos os assentos, foi calculado diretamente pelo algoritmo de simulação CFD. Como conclusão, o trabalho mostra que o percentual de pessoas insatisfeitas era ligeiramente menor quando 0 sistema de ventilação personalizada estava em funcionamento. Porém, não há uma conclusão quanto à eficiência do sistema de ventilação personalizada na remoção de partículas na zona de respiração dos passageiros.

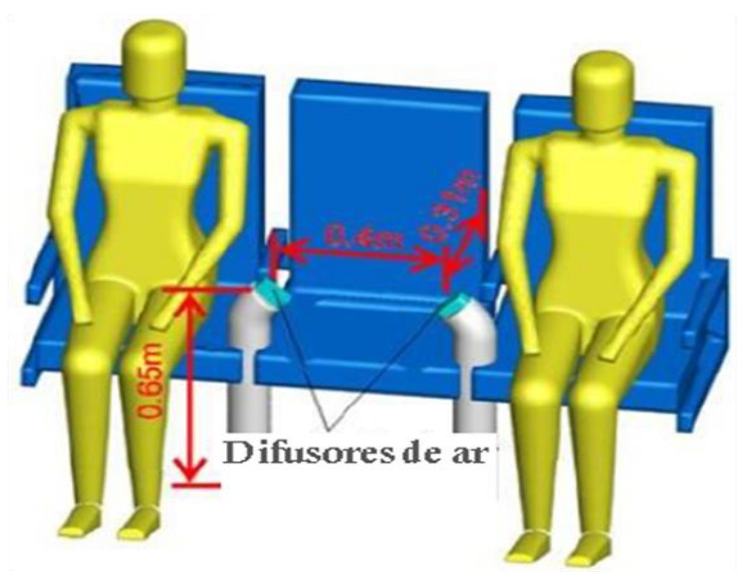

Figura 2.11 - Sistema personalizado com insuflamento de ar pela lateral da poltrona (figura adaptada de Zhang; Li; Wang, 2012) 


\subsection{Estudos sobre a dispersão de partículas em aeronaves}

A crescente preocupação em tornar o interior de cabines de aeronaves um ambiente mais confortável e saudável para seus usuários vem motivando o desenvolvimento de sistemas de climatização, ventilação e filtragem com o objetivo de evitar a disseminação de contaminantes na cabine.

Os primeiros estudos experimentais referentes à dispersão de partículas e a qualidade do ar interior em aeronaves foram conduzidos por meio de monitoramento em situações reais de voos (Nagda et al., 1992; Hocking, 1998; Uva, 2000; Hocking, 2000; Uva, 2002; Osman et al., 2008). Mas devido aos altos custos e dificuldades para a realização de ensaios em voos e, principalmente, do procedimento de certificação, as análises experimentais têm sido realizadas em mock-ups de aeronaves de uma seção da cabine simulando as mesmas condições normais do escoamento em voo (Wan; Chao; Fang, 2005; Zhang et al., 2007; Yan et al., 2009; Sze To et al., 2009; Gupta; Lin; Chen, 2011; Chen et al., 2012; Conceição, 2012; Fabichak Jr., 2013; Li et al., 2014).

Os dados obtidos das análises experimentais muitas vezes têm sido empregados para comparação e validação de modelos de simulação numérica CFD, que vem sendo utilizados para predição e aperfeiçoamento dos sistemas de ventilação e condicionamento de ar para aeronaves.

É importante destacar que muitos desses estudos estão sendo desenvolvidos em centros de pesquisa e desenvolvimento ligados à indústria aeronáutica, a exemplo dos estudos desenvolvidos na University of Illinois at Urbana-Champaign, EUA (Wang et al., 2006; Yan et al., 2009); no German Aerospace Center, Alemanha (Günther et al., 2006; Zeidler et al., 2008); no Air Transportation Center of Excellence for Airliner Cabin Environmental Research - School of Mechanical Engineering of Purdue University, EUA (Zhang et al., 2007; Mazumdar; Chen, 2007; Mazumdar; Chen, 2008; Gupta; Lin; Chen, 2009; Zhang et al., 2009; Chen et al., 2012; Liu; Chen, 2013); no International Center for Indoor Environment and Energy, Dinamarca (Wan; Chao; Fang, 2005; Nielsen et al., 2008; Sze To et al., 2009); no Jet Propulsion Laboratory of California Institute of Technology, EUA (Osman et al., 2008); no Institute for Environmental Research at Kansas State University, EUA (Padilla, 2008; Beneke, 2010; Khosrow, 2012, Anderson, 2012); da School of Hydraulic Engineering of Dalian University of Technology, China (Yin; Zhang, 2009; Zhang; Yin; Wang, 2010; Zhang; 
Li; Wang, 2012) e no Departamento de Engenharia Mecânica da Escola Politécnica da USP (Moura, 2009; Stancato, 2009; Conceição, 2012; Silva, 2013; Fabichak Jr., 2013).

Wan; Chao; Fang (2005) realizaram um estudo experimental sobre a dispersão de partículas expiratórias em um mock-up de três fileiras com sete assentos, totalizando, portanto 21 assentos. O mock-up, instalado no International Center for Indoor Environment and Energy, da Dinamarca, possui sistema de ventilação convencional (MV). Para a ocupação dos assentos, foram utilizados manequins aquecidos. Para simular os contaminantes, os próprios pesquisadores desenvolveram e utilizaram um gerador de partículas com o objetivo de dispersar gotículas no ambiente, em processo análogo ao de uma pessoa tossindo. Os ensaios foram feitos para duas vazões de ar na cabine, com 100 l/s e 200 l/s, com medições efetuadas a $1,10 \mathrm{~m}$ do piso, isto é, na zona de respiração dos passageiros quando sentados. $\mathrm{Na}$ Figura 2.12 mostra-se os pontos de injeção e de medição das partículas para cada uma das situações de vazão de ar.
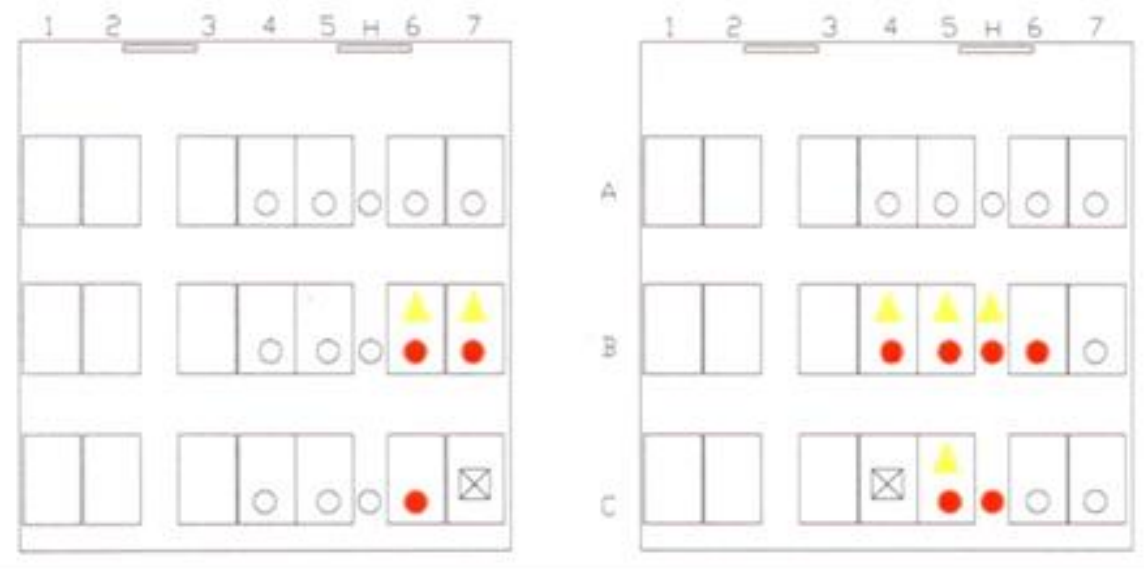

Medição para $200 \mathrm{~L} / \mathrm{s}$

Medição para $100 \mathrm{~L} / \mathrm{s}$

Pontos de Medição

Pontos de Injeção

Figura 2.12 - Pontos de injeção e de medição de partículas para diferentes vazões de ar em mock-up de cabine (Wan; Chao; Fang, 2005)

Os resultados mostraram que a dispersão de partículas foi menor quando a injeção foi feita simulando um passageiro sentado mais próximo da fuselagem em comparação com passageiro sentado em um assento no centro do mock-up. De acordo com os autores, sugere-se que o fluxo de ar descendente junto à fuselagem tenha suprimido a dispersão de partículas, ao passo que o fluxo ascendente no centro do mock-up tenha aumentado à dispersão. Os autores também concluíram que o aumento da vazão de ar de renovação tende a diminuir a concentração de partículas 
próximas ao ponto onde são injetadas devido ao efeito de diluição. No entanto, a maior vazão de ar aumentou a dispersão de partículas pela cabine, o que provocou um aumento na concentração de contaminantes nos assentos mais distantes do ponto de injeção.

Zhang et al. (2007) também estudaram a dispersão de partículas em um mock-up de aeronave Boeing 767-300. Uma ilustração do mock-up é mostrada na Figura 2.13. Para as avaliações, foram utilizados simuladores térmicos em formato de caixa. Foi utilizado o sistema de ventilação MV para estudar a dispersão de partículas no interior da cabine e, com base nas medições da velocidade e temperatura do ar e concentração de contaminantes, foi possível comparar os resultados obtidos experimentalmente com os resultados extraídos do modelo computacional, desenvolvido pelos próprios pesquisadores. Adicionalmente, os pesquisadores realizaram por meio do mesmo código CFD, a estimativa da dispersão de contaminantes utilizando sistema de ventilação com insuflamento de ar pelo piso (UFAD) e sistema de insuflamento de ar pelo piso com ventilação personalizada $(\mathrm{UFAD}+\mathrm{PV})$.

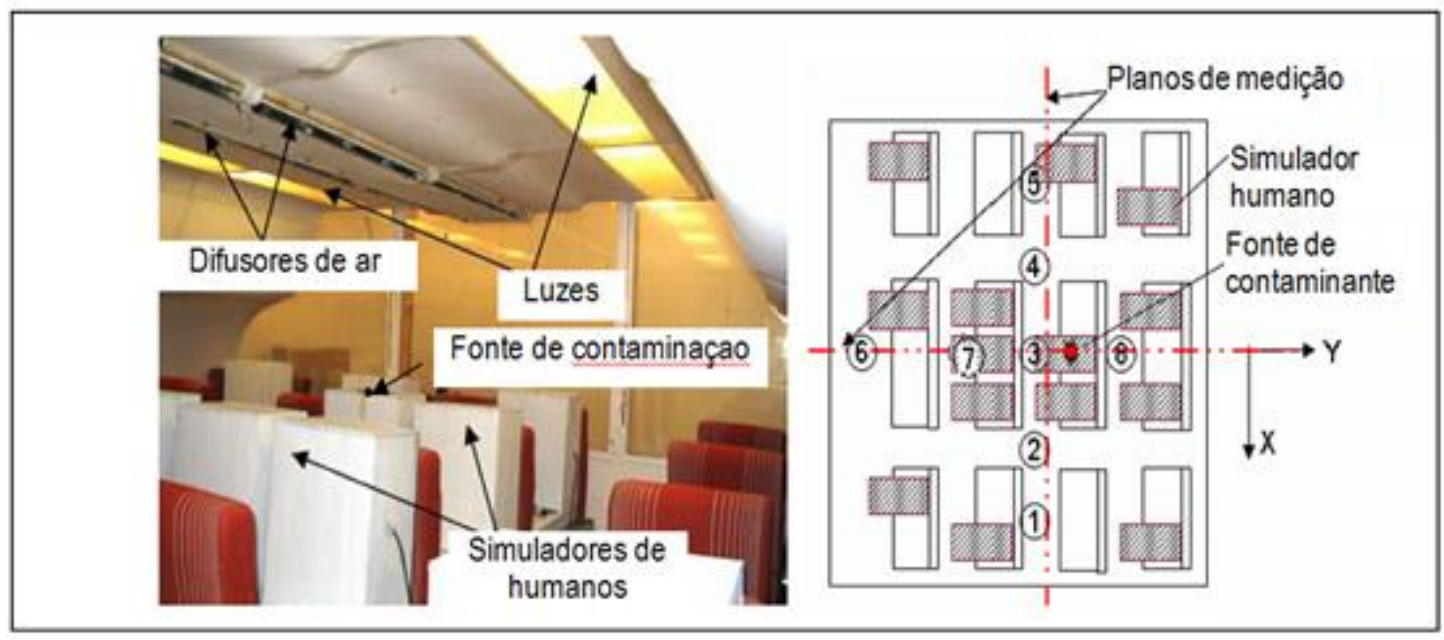

Figura 2.13 - Mock-up de cabine de aeronave e planos de medição (Zhang et al., 2007)

A partir dos resultados obtidos da simulação numérica, mostrados na Figura 2.14, os autores verificaram que o sistema MV proporciona temperatura mais homogênea do ar. Porém, esse sistema oferece um risco maior de dispersar a contaminação gerada de um local para as demais regiões da cabine. No sistema UFAD, o risco de contaminação diminui, pois as velocidades de insuflamento de ar são mais baixas e o ar segue um fluxo ascendente, mais regular. O sistema de insuflamento pelo piso 
aliado ao sistema de ventilação personalizada (UFAD + PV) proporcionou os melhores resultados de qualidade do ar na zona de respiração.

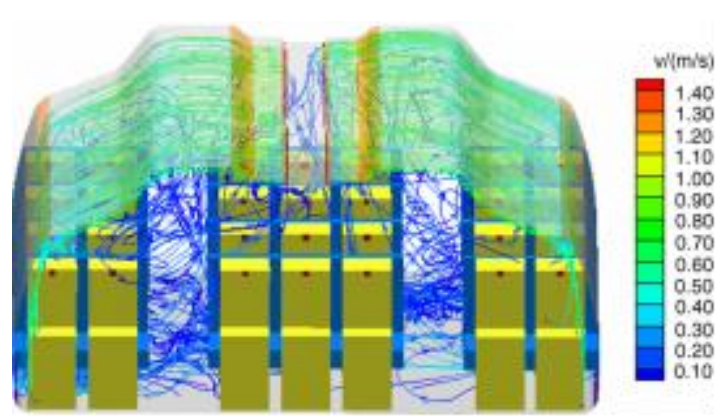

a)

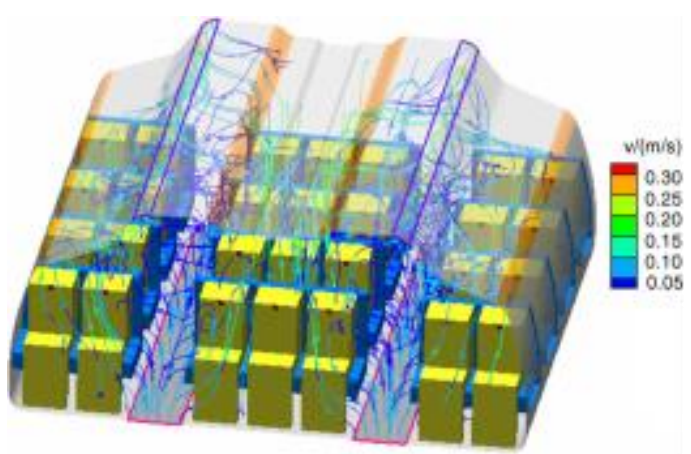

b)

c)

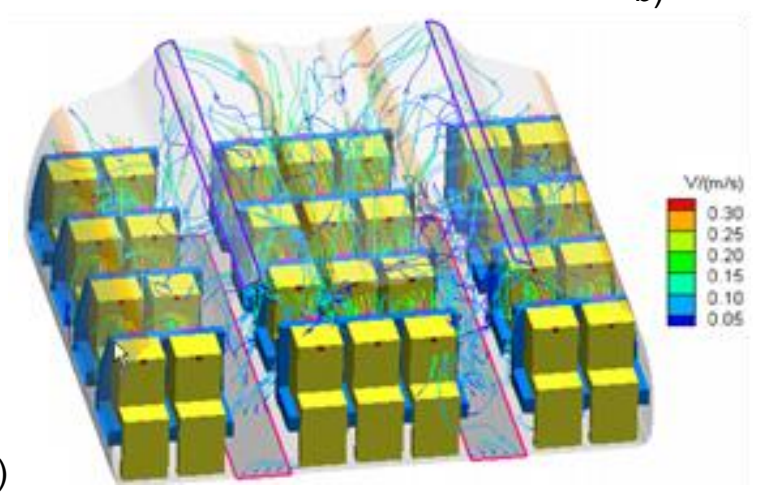

Figura 2.14 - Linhas de corrente resultantes: (a) sistema MV, (b) sistema UFAD e (c) sistema UFAD com ventilação personalizada (Zhang; Chen, 2007)

Padilla (2008) estudou a dispersão de $\mathrm{CO}_{2}$ e a concentração de partículas expiratórias monodispersas em um mock-up de cabine de um Boeing 767-300, dotado de sistema de ventilação MV. Para isso, foram injetadas, de forma uniforme e controlada, partículas monodispersas pontuais na direção do escoamento utilizando um gerador de partículas. As medições, feitas com o auxilio de um contador ótico, foram realizadas em vários locais da cabine, além da entrada dos dutos de ventilação e da saída do ar de exaustão. Os dados coletados serviram, posteriormente, para validar um modelo de simulação CFD da própria fabricante da aeronave com o objetivo de definir os valores de vazão de ar de insuflamento capaz de remover ou dispersar partículas contaminantes no interior da cabine, além de predizer quantos passageiros seriam expostos a uma liberação acidental ou intencional contaminantes em uma aeronave. Na Figura 2.15 mostra-se o mock-up utilizado e os pontos onde foram realizadas as medições de concentração de dióxido de carbono no interior da cabine. 
a)

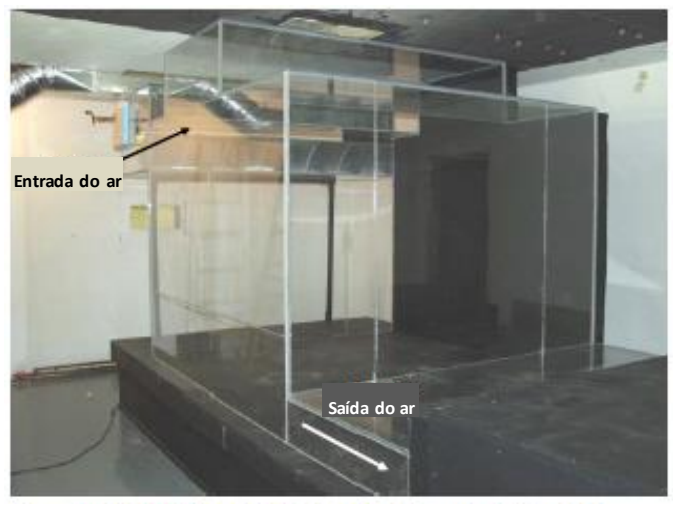

b)

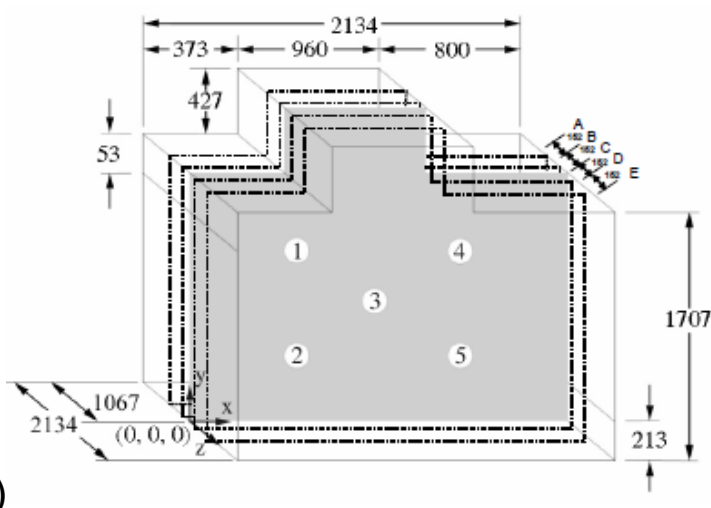

Figura 2.15 - (a) Mock-up de cabine de aeronave; (b) Planos de medição das partículas contaminantes (Padilla, 2008)

Yan et al. (2009) estudaram a dispersão de contaminantes simulando a dispersão de partículas pequenas, equivalentes às produzidas por atividades expiratórias. As avaliações foram feitas em um mock-up de um Boeing 737-300 equipado com sistema de ventilação MV e utilizando manequins aquecidos, conforme visto na Figura 2.16. Os pesquisadores injetaram 4,5 l/min. de gás traçador $\mathrm{CO}_{2}$ durante 5 minutos nas proximidades da zona de respiração e, durante esse período, foi monitorada a concentração de $\mathrm{CO}_{2}$ nas regiões próximas. Essa avaliação experimental também serviu para validar o modelo CFD desenvolvido pelos próprios pesquisadores.

Do mesmo modo que Zhang et al. (2007), Yan et al. (2009) concluíram que o sistema de ventilação influencia significativamente a distribuição de partículas pela cabine, devido aos fluxos de ar na direção longitudinal, que contribuem para transportar partículas por maiores distâncias. Ainda de acordo com os autores, se o local de origem da contaminação estiver em pontos próximos da exaustão do ar, menor será a probabilidade de contaminação no ambiente.

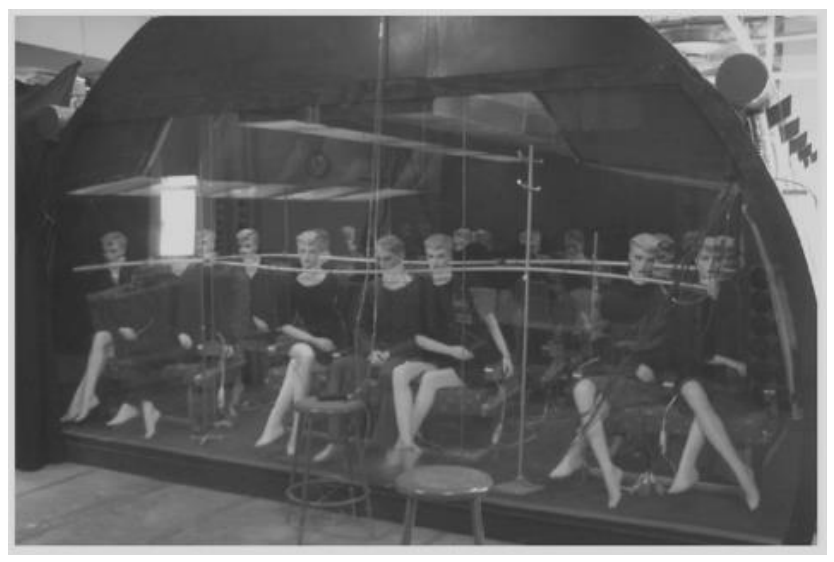

Figura 2.16 - Estudo da dispersão de contaminantes em mock-up de Boeing 767-300 (Yan et al., 2009) 
Em continuidade ao trabalho de Wan, Chao e Fang (2005), Sze To et al. (2009) avaliaram a dispersão e deposição de partículas provenientes de atividades expiratórias em cabines de aeronaves, além de identificar os efeitos do sistema de ventilação na diluição e remoção dessas partículas. Os ensaios foram realizados com o mesmo mock-up utilizado por Wan, Chao e Fang (2005). Os manequins térmicos tipo caixa foram substituídos por cilindros aquecidos que simulavam a carga térmica equivalente a pessoas sentadas em atividade sedentária, típica de passageiros de aeronaves. A contaminação do ambiente foi feita através de um bocal injetor de gotas, utilizando-se uma solução corante de glicerina e sódio em ar comprimido. A disposição dos equipamentos no mock-up pode ser vista na ilustração da Figura 2.17.

Sze To et al. (2009) verificaram que a dispersão de partículas depende de seu tamanho médio, sendo que entre 60 e $70 \%$ do total de partículas foram depositadas em regiões diversas da cabine, como os assentos e o piso. Nesse estudo não foi investigada a influência de diferentes formas de ventilação na dispersão dos contaminantes na cabine.

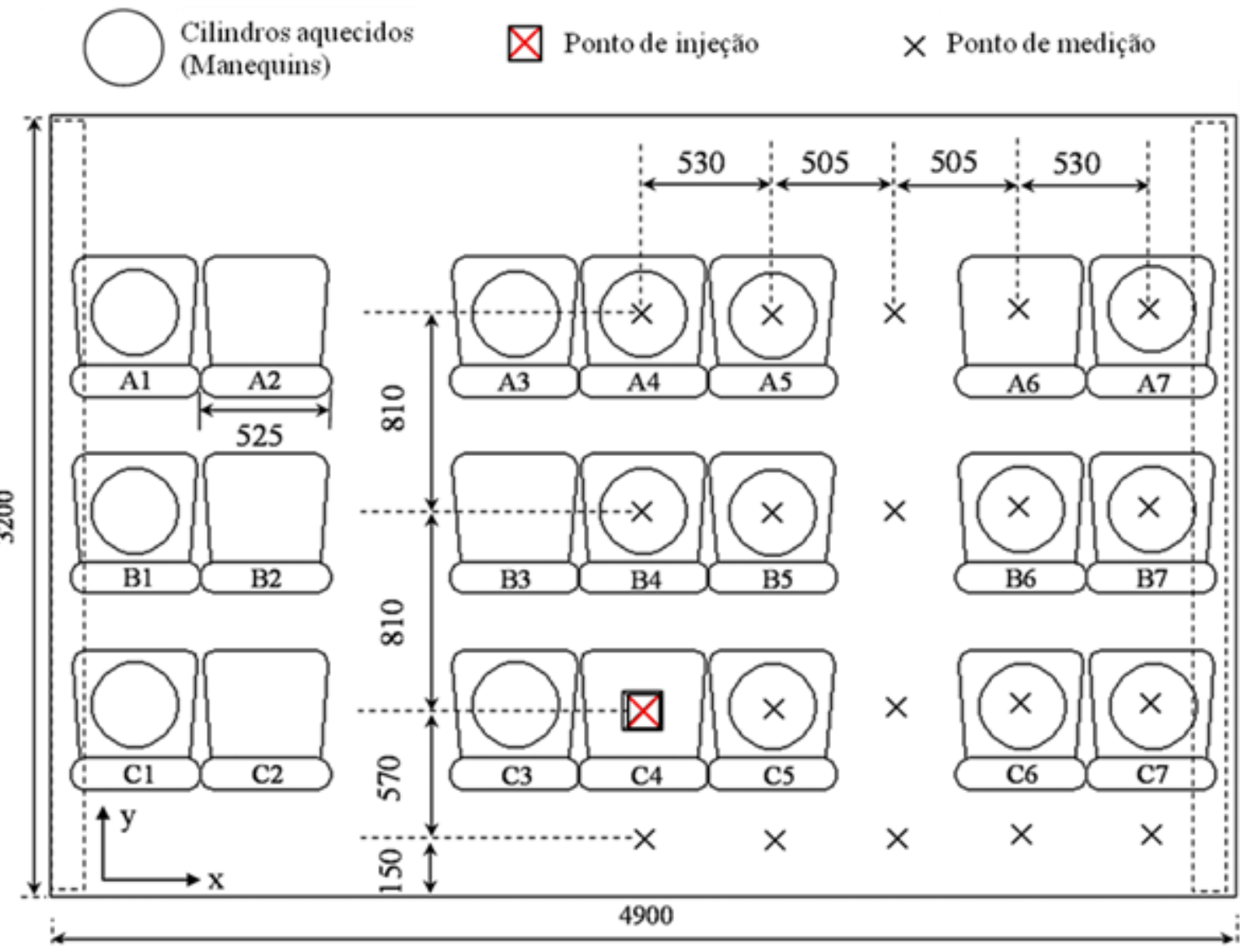

Figura 2.17 - Ocupação de mock-up de cabine de aeronave e pontos de injeção e de medição de partículas (Sze To et al., 2009) 
Chen et al. (2012) realizaram análises experimentais com pessoas saudáveis para quantificar a quantidade média de partículas dispersadas por seres humanos quando estes estão respirando/expirando, conversando e tossindo. Os candidatos utilizaram uma máscara desenvolvida especificamente para esse experimento com o objetivo de capturar as partículas dispersadas em cada uma dessas atividades.

Posteriormente, as partículas coletadas pelo filtro da máscara foram contadas com o auxilio de um microscópio eletrônico de alta resolução. Para avaliar, a sua dispersão no ambiente, os candidatos foram submetidos a dois testes: o primeiro consistia em respiração em condições normais e o segundo teste consistia em simular tosse - primeiramente uma tosse simples e depois uma tosse contínua de dois estágios. Para visualizar o fluxo das partículas ao serem exaladas, foi utilizada uma fumaça semelhante à emitida por cigarro, pois de acordo com os autores, ao incidir a luz sobre a fumaça, é possível identificar diâmetro de partículas de até 0,2 $\mu \mathrm{m}$ (Klepeis; Nazaroff, 2002), tamanho esse muito próximo ao das gotículas de saliva e de agentes virais. Os fluxos da fumaça foram fotografados por câmeras de alta resolução. A partir dessas medições, foi possível estabelecer modelos matemáticos para a quantidade de partículas emitidas pelas pessoas em situações de respiração, conversação e tosse, conforme mostradas na Figura 2.18.

Em seguida, essas informações foram inseridas em um algoritmo CFD com o objetivo de quantificar a dispersão de partículas expiratórias e o risco de contaminação dos passageiros ocupando uma seção de cabine de aeronave - neste caso, foi simulada uma seção com sete fileiras, dois corredores e sete assentos por fileira. O sistema de ventilação empregado foi o convencional MV em condições normais de funcionamento, isto é, com temperatura de insuflamento do ar na cabine próxima de $19^{\circ} \mathrm{C}$ e umidade relativa em $20 \%$ e alta velocidade de insuflamento do ar devido à característica inerente do sistema.

Os pesquisadores concluíram que um passageiro exalando partículas pode dispersar contaminantes para até três fileiras distantes, seja para frente ou para trás da cabine. Além disso, a contaminação em cabines de aeronaves pode ocorrer também por meio da deposição de partículas sobre as superfícies, podendo também vir a ser um fator para a disseminação de agentes virais, já que a baixa umidade relativa nas cabines é um fator que contribui para a sobrevivência de alguns tipos específicos de vírus. 


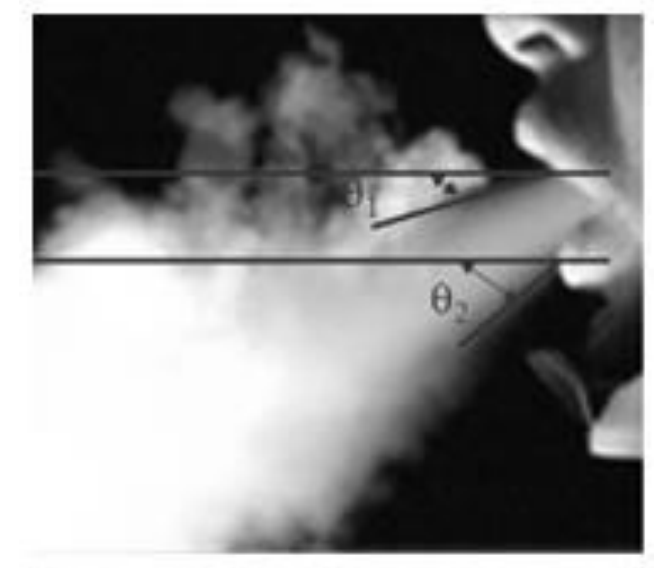

a)

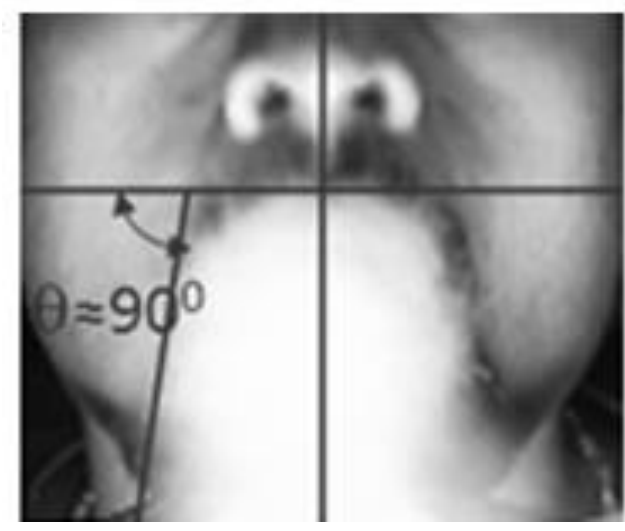

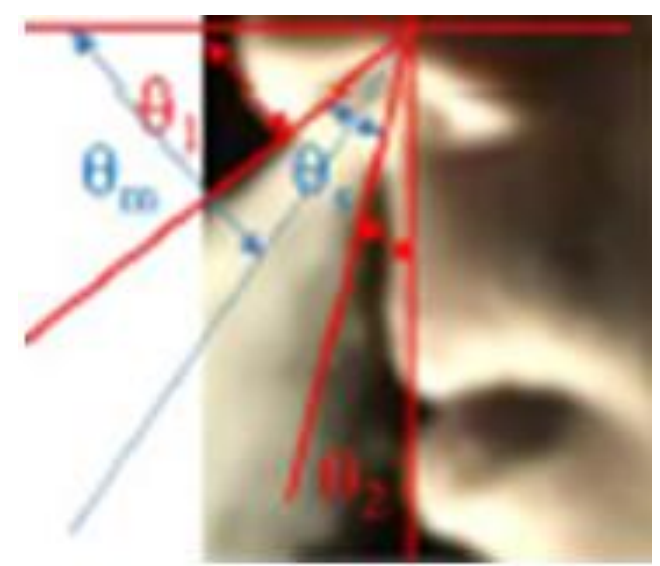

b)

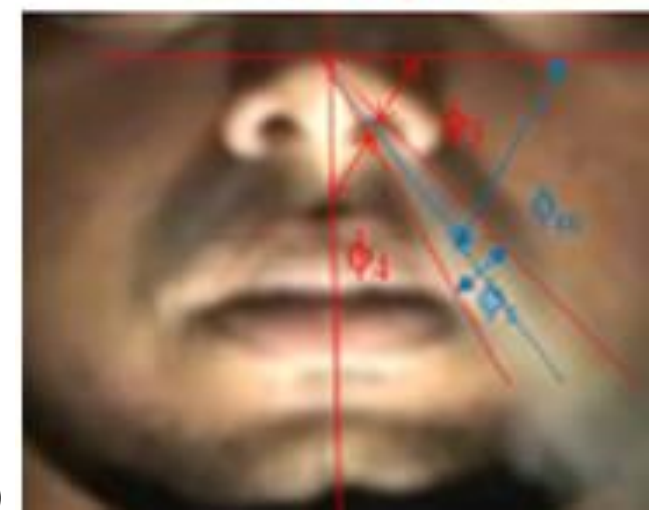

Figura 2.18 - Partículas exaladas: (a) Durante uma tosse; (b) na respiração.

(Chen et al., 2012)

Li et al. (2014) realizaram estudos experimentais, com posterior avaliação computacional, para avaliar os campos de distribuição de contaminantes expiratórios gerados por um passageiro na classe econômica e outro na primeira classe de uma cabine funcional de aeronave MD-82, que utilizava um sistema de ventilação MV capaz de fornecer até 10 l/s/pessoa de ar na cabine. A temperatura do ar insuflado foi mantida em $20 \pm 1^{\circ} \mathrm{C}$. Todos os 12 assentos da primeira classe foram ocupados por manequins térmicos com carga térmica de $75 \mathrm{~W}$ cada. Os contaminantes foram gerados a partir da altura da zona de respiração de um passageiro sentado, conforme mostrado na Figura 2.19, e medidos por meio de um contador de partículas.

As principais conclusões dos autores foram que, devido ao campo de velocidade do ar provocado pelo sistema de ventilação, o local de origem e as plumas térmicas dos passageiros afetam significativamente a dispersão de poluentes, isto é, os contaminantes gerados pelo passageiro na primeira classe foram mais rapidamente inalados pelos passageiros ao redor, ao passo que os contaminantes gerados na classe econômica, que por não estar totalmente ocupada, fez com que as partículas se dispersassem em uma maior área da cabine. Além disso, os resultados da 
simulação CFD mostraram que as partículas com diâmetro menor que $3 \mu \mathrm{m}$ são mais difíceis de se depositarem, facilitando a disseminação de contaminantes na cabine.

(a)

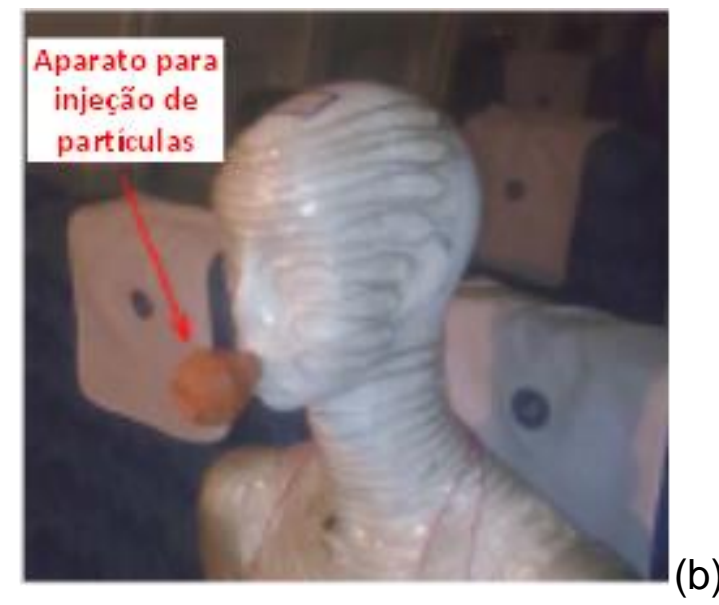

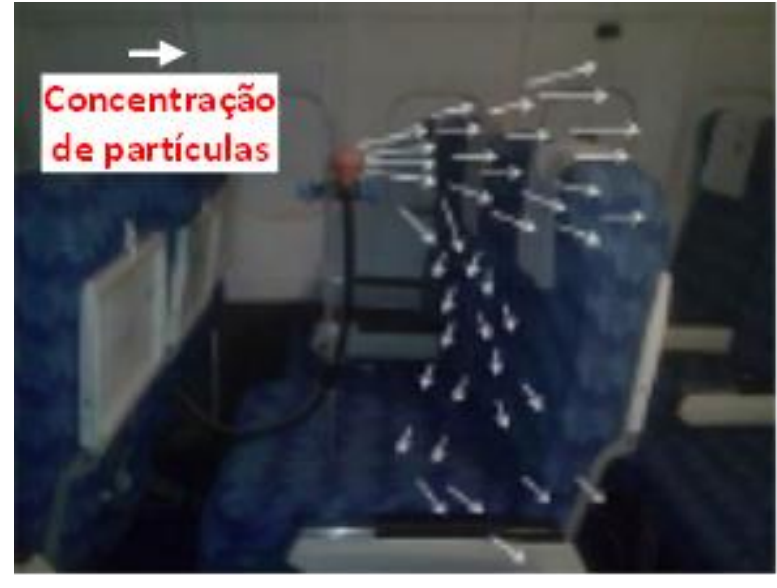

Figura 2.19 - Simulação de partículas expiratórias: (a) exaladas por passageiro infectado e (b) caminho percorrido pelas partículas (Li et al., 2014)

Mazundar, Long e Chen (2014) realizaram estudo CFD para predição de contaminação expiratória em cabine de aeronave. Para esta análise, foi considerada uma cabine de aeronave com três fileiras de assentos e dois corredores, perfazendo um total de sete assentos por fileira. O volume de controle total da malha constituiu-se de 21 assentos. Para cálculo de contaminação foi considerado que todos os assentos estavam ocupados. O sistema de ventilação adotado foi o de ventilação convencional (MV), fornecendo $10 \mathrm{l} / \mathrm{s} /$ ocupante. O ponto de origem da fonte contaminante foi adotado no assento central da segunda fileira e a taxa de partículas expiratórias foi

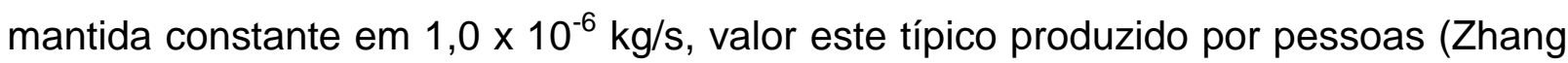
et al., 2009). Para simplificar o cálculo foi considerada somente avaliação ao longo da seção transversal da cabine correspondente à segunda fileira. Portanto, não foi considerada influência da velocidade do ar ao longo da direção longitudinal da cabine. Na Figura 2.20 mostra-se o esquema de cabine adotado para o cálculo CFD. 


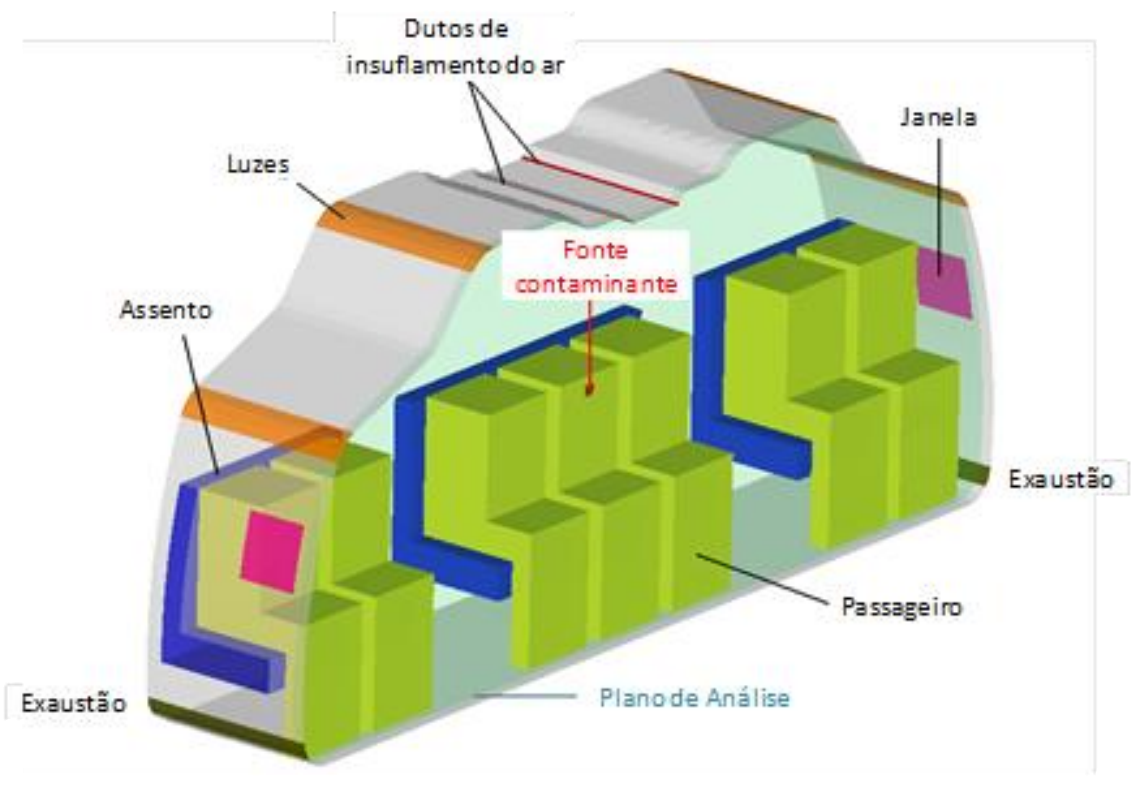

Figura 2.20 - Representação de cabine com dois corredores (figura adaptada de Mazundar; Long; Chen, 2014)

Os pesquisadores observaram que a concentração de contaminantes tende a se misturar muito rapidamente ao longo da seção transversal. No gráfico da Figura 2.21 é possível notar que os contaminantes estão dispersos quase que em sua totalidade nos assentos imediatamente ao lado do ponto de origem da fonte. No entanto, os próprios autores sugerem uma investigação mais profunda para avaliar a dispersão de partículas para outras regiões da cabine.

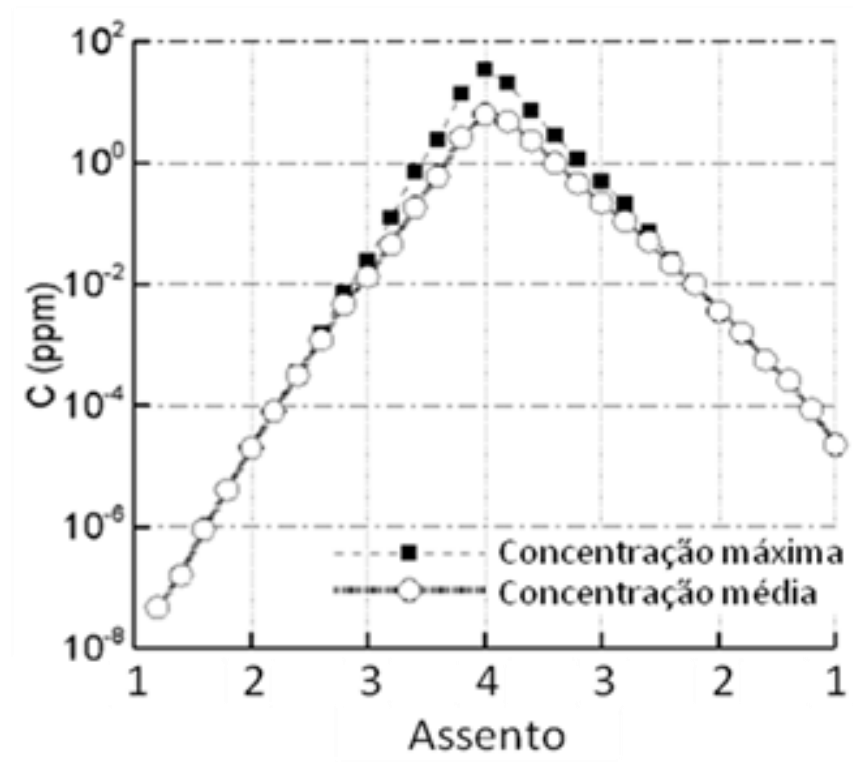

Figura 2.21 - Concentração de partículas ao longo da seção transversal da cabine (figura adaptada de Mazundar; Long; Chen, 2014) 
Li et al. (2016) realizaram estudo numérico e análise experimental para investigar o efeito das válvulas gasper na qualidade do ar interior e na dispersão de partículas contaminantes no interior de uma cabine funcional de aeronave MD-82 com cinco assentos por fileira. O sistema de ventilação empregado foi o de ventilação por mistura (MV), configurado para fornecer $10 \mathrm{l} / \mathrm{s} /$ passageiro. Durante os ensaios, dois gaspers próximos à fonte foram mantidos ligados e cada um fornecia $0,66 \mathrm{l} / \mathrm{s}$ de ar na zona de respiração. Foram avaliadas cinco fileiras de assentos, perfazendo um total de 25 assentos avaliados. Em cada um deles foram posicionados manequins térmicos, cada um dissipando $75 \mathrm{~W}$ de carga térmica. A temperatura de insuflamento do ar foi mantida em $20,1 \pm 0,2^{\circ} \mathrm{C}$. As temperaturas de parede e do piso foram, respectivamente, de $25,1 \pm 1,8^{\circ} \mathrm{C}$ e $23,0 \pm 3,1^{\circ} \mathrm{C}$. A velocidade do ar na saída do gasper foi em média de $1,42 \mathrm{~m} / \mathrm{s}$, valor este situado na faixa de 1 a $3 \mathrm{~m} / \mathrm{s}$ recomendada pela ASHRAE 161 (ASHRAE, 2007). Para simular a fonte contaminante foi utilizada uma mistura de gás traçador contendo $1 \%$ de $\mathrm{SF}_{6}$ e $99 \%$ de $\mathrm{N}_{2}$, gerado a uma taxa de 2,5 × $10^{5} \mathrm{ppm}$. Na Figura 2.22 mostra-se a configuração da cabine de aeronave e a disposição dos manequins e da fonte contaminante.

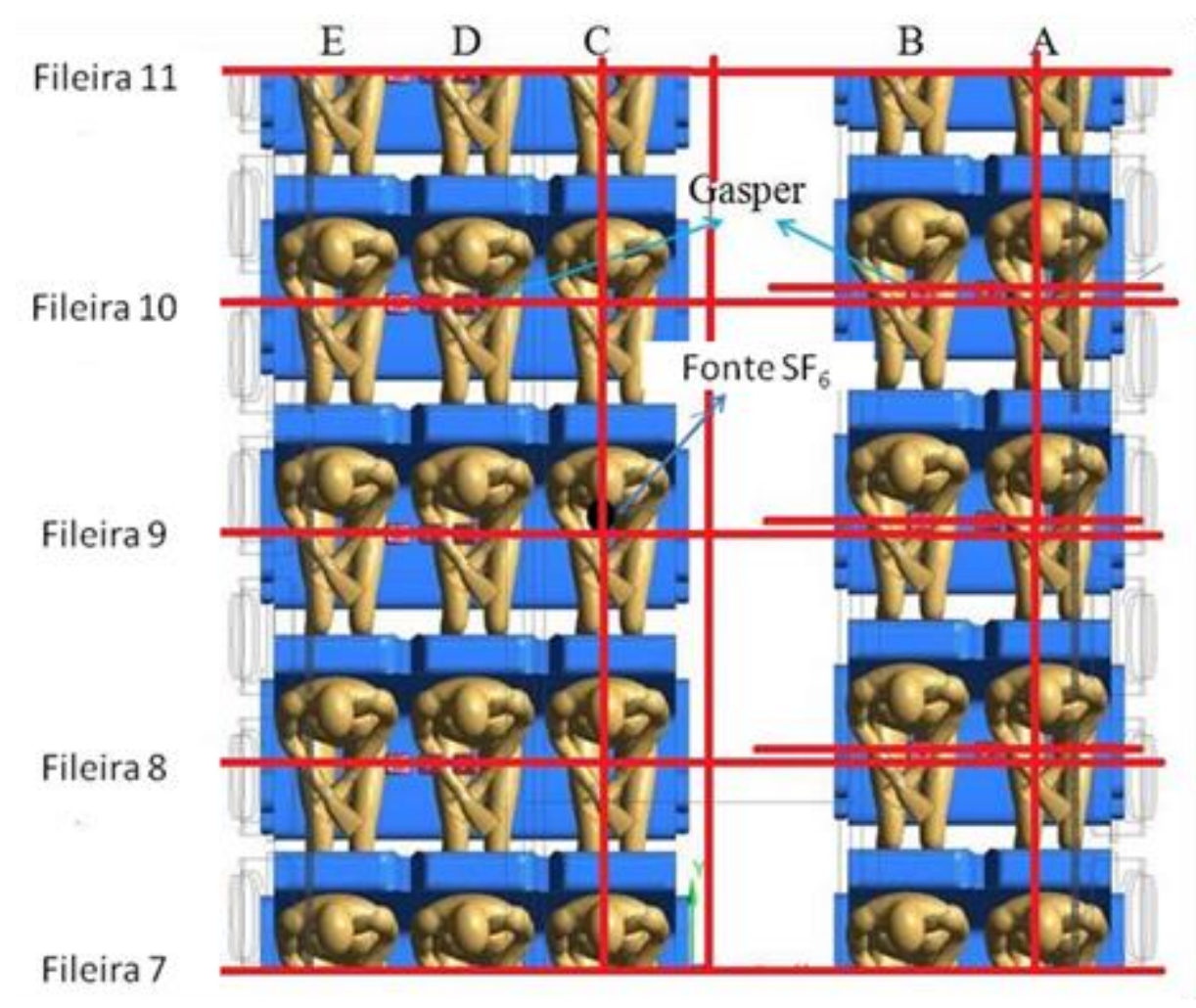

Figura 2.22 - Interior da cabine da aeronave MD-82 (figura adaptada de Li et al., 2016) 
Os pesquisadores concluíram que, nas condições avaliadas, os resultados numéricos e experimentais mostraram que a utilização das válvulas gasper tem forte impacto no perfil de velocidade e na dispersão de partículas, podendo disseminar os contaminantes para outras regiões da cabine. Embora a temperatura do ar fosse mais uniforme quando os gaspers estavam ligados, o jato de ar proveniente dos gaspers era capaz de adentrar as plumas térmicas formadas pelos manequins, empurrando as partículas contaminantes para baixo. Como consequência, não se teve ar mais limpo na zona de respiração, conforme pode ser observado na Figura 2.23.

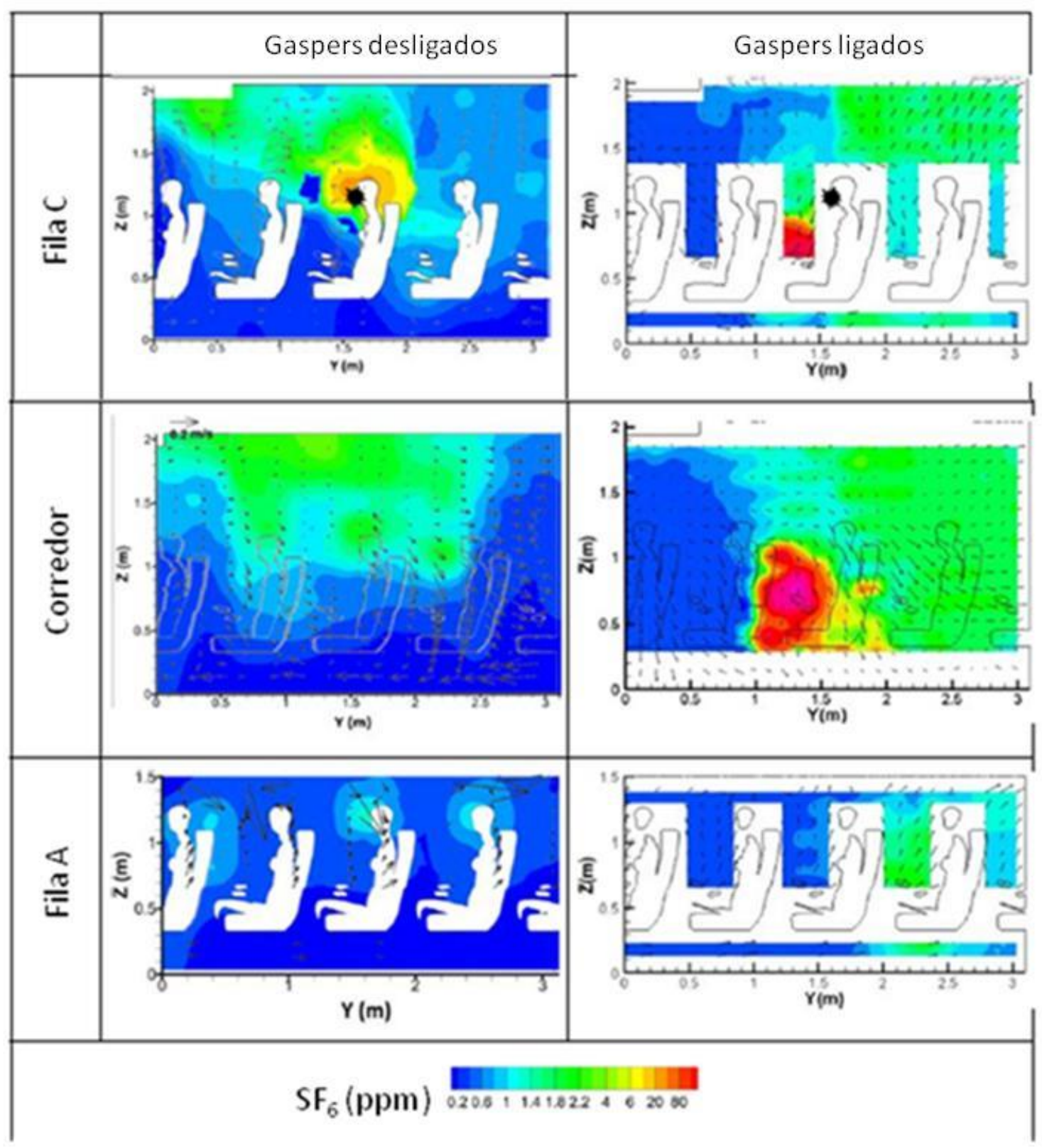

Figura 2.23 - Medições da concentração de $\mathrm{SF}_{6}$ no interior da cabine (figura adaptada de Li et al., 2016) 
Observa-se nos estudos apresentados que a grande maioria das análises experimentais sobre dispersão de partículas foi realizada utilizando o sistema de ventilação por mistura (MV), por ser o sistema atualmente utilizado nas aeronaves comerciais.

\subsection{Estudos desenvolvidos no Departamento de Engenharia Mecânica da Escola Politécnica da Universidade de São Paulo}

Paralelamente aos estudos realizados nas diferentes instituições no exterior, no Laboratório de Conforto Térmico e Qualidade do Ar da Escola Politécnica da Universidade de São Paulo também estão sendo realizados estudos para a análise do escoamento e distribuição do ar, do conforto térmico e da dispersão de partículas expiratórias. Estudos referentes ao ambiente térmico, condições de escoamento e de dispersão de partículas em cabines de aeronave foram realizados em mock-up de 20 lugares (Moura, 2009; Stancato, 2009; Conceição, 2012). Mais recentemente, estudos sobre conforto térmico e dispersão de partículas expiratórias envolvendo diferentes arquiteturas de ventilação foram realizados em mock-up de 12 lugares (Silva, 2013; Fabichak Jr., 2013). Neste mock-up de 12 lugares foi desenvolvido o presente trabalho.

Conceição (2012), em sua tese de doutorado, desenvolveu uma metodologia para avaliar a dispersão de contaminantes em cabines de aeronaves, focando no estudo da contaminação cruzada de poluentes gerados por passageiros através de atividades expiratórias. Para isso, foi utilizado um mock-up de 20 lugares de aeronave, mostrado na Figura 2.24, utilizando sistema de ventilação MV. O objetivo principal foi avaliar a dispersão das partículas expiratórias na cabine e investigar se a válvula gasper pode oferecer proteção para os passageiros contra a contaminação gerada no interior da cabine. Além disso, foi fundamentada a implementação das condições de cabine em um código CFD a fim de realizar comparação com os resultados experimentais. Uma das conclusões do autor é que o sistema de ventilação personalizada estudado, a válvula gasper, pode minimizar a possibilidade de contaminação cruzada entre os assentos, mostrando boa correlação entre os resultados numéricos com os obtidos experimentalmente. 


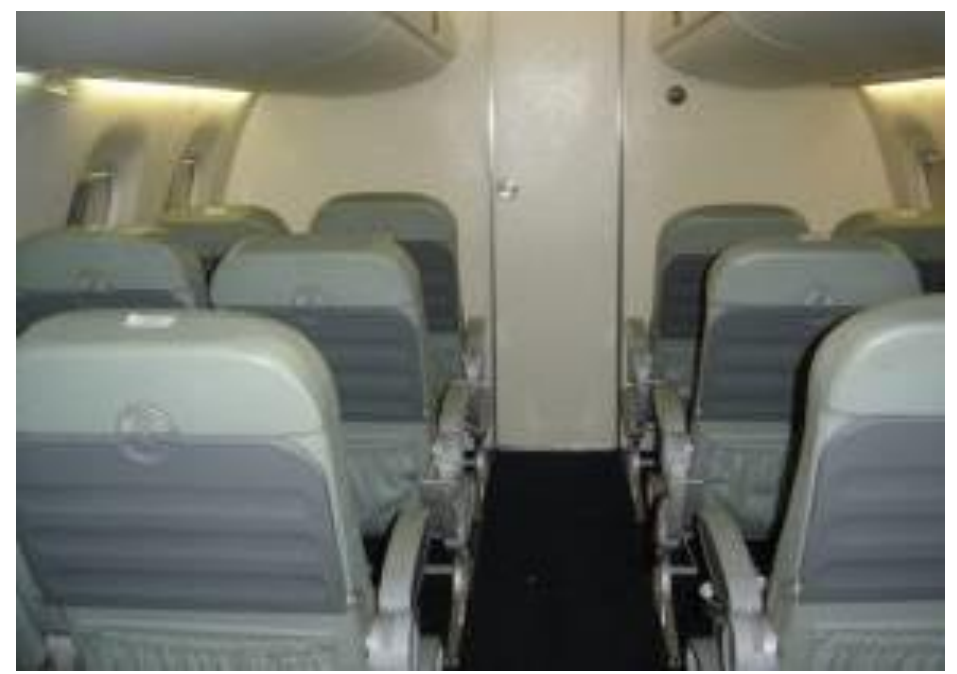

Figura 2.24 - Mock-up de 20 lugares utilizado na avaliação da dispersão de partículas (Conceição, 2012)

Em continuidade ao trabalho de Conceição (2012), Fabichak Jr. (2013) realizou análise experimental de dispersão de partículas expiratórias em cabine de aeronave, considerando arquiteturas de distribuição de ar dos tipos MV, UFAD e UFAD modificado em mock-up de 12 lugares, mostrado na Figura 2.25, Porém, sem a utilização de sistema de ventilação personalizada.

Fabichak Jr. (2013) concluiu, do mesmo modo que Wan, Chao e Fang (2005), que o ponto de geração de partículas (próximo à fuselagem ou do corredor) bem como a temperatura do ar insuflado na cabine têm grande influência na dispersão e na concentração de partículas na cabine nas três arquiteturas de distribuição de ar testadas. A injeção de partículas na zona de respiração do assento simulando passageiro junto à fuselagem, em comparação com passageiro sentado em assento próximo ao corredor do mock-up, resultou em uma menor dispersão de partículas na zona de respiração ao longo da cabine. Ou seja, as partículas expiratórias geradas por um passageiro sentado junto ao corredor têm um potencial maior de serem inaladas por outros passageiros da cabine do que aquelas geradas por um passageiro sentado junto à fuselagem nas arquiteturas de distribuição analisadas. Em relação à temperatura do ar insuflado, quanto mais baixa for a temperatura mais favorável é a formação de plumas térmicas junto aos passageiros, aumentando a eficiência na remoção de partículas da cabine na zona de respiração. $O$ autor enfatiza ainda que 0 sistema UFAD apresentou a maior eficiência na remoção de partículas, removendo partículas expiratórias de 3 a $5 \mu \mathrm{m}$ com eficácia de até $63 \%$ em relação ao sistema convencional MV. 
a)

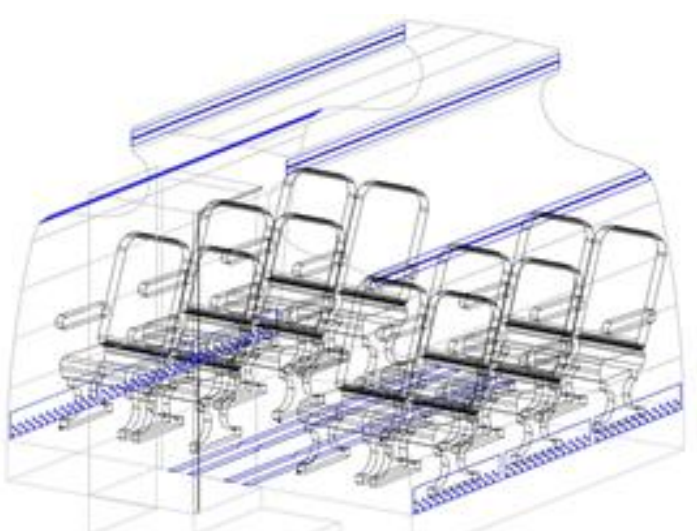

Figura 2.25 - Mock-up de 12 lugares: (a) Esquema interno e (b) Acesso e vista externa (Fabichak Jr., 2013) 


\section{Dispersão de partículas em cabines de}

\section{aeronaves}

Conforme a revisão bibliográfica feita no Capítulo 2, diversos autores vêm estudando o comportamento da dispersão de partículas e contaminantes em diferentes tipos de aeronaves comerciais, seja por meio de análise experimental, seja por meio da implementação de códigos computacionais (Wan; Chao; Fang, 2005; Zhang et al., 2007; Yan et al., 2009; Sze To et al., 2009; Gupta; Lin; Chen, 2011; Chen et al., 2012; Conceição, 2012; Fabichak Jr., 2013; Li et al., 2014). A maioria desses trabalhos visa o estudo da contaminação cruzada em ambientes de cabines de aeronaves a partir da dispersão de partículas expiratórias geradas pelos passageiros.

Neste capítulo são abordadas as características das partículas expiratórias e a sua dispersão em cabines de aeronaves. Agentes virais e infecciosos não são profundamente discutidos neste trabalho, visto que a proposta de estudo não é focada em aspectos biológicos, mas na caracterização do tamanho e da quantidade de partículas dispersas em aeronaves provenientes de atividades expiratórias. $O$ fato das partículas poderem conter microorganismos não interfere na dinâmica do escoamento dessas partículas. Uma boa revisão bibliográfica mais abrangente deste assunto pode ser encontrada nos trabalhos de Mangili e Geandreau (2005), Brooker (2007), Osman et al. (2008) e Walkinshaw (2010).

\subsection{Contaminação cruzada em cabines de aeronaves}

Pessoas são a principal fonte de bactérias no ar e são os mais importantes transmissores de agentes infecciosos a bordo de aeronaves (Masterton; Green, 1991). Estudos que mediram a concentração de microorganismos no ar concluíram que bactérias cultiváveis e fungos em aviões surgem principalmente dos ocupantes da cabine (Mangili; Geandreau, 2005).

Fontes de contaminantes em cabines de aeronaves associadas aos ocupantes têm origem a partir das próprias partículas expiratórias provenientes da respiração e 
das gotículas de saliva, eliminadas via oral ou nasal. Além disso, passageiros com eventuais doenças respiratórias causadas por vírus e bactérias podem disseminar no ambiente estes agentes patogênicos, por exemplo, ao tossir ou espirrar, podendo ser uma potencial fonte para contaminação. Em função das elevadas densidades ocupacionais e do volume interior em aeronaves ser relativamente reduzido, a dispersão dessas partículas pode resultar em potenciais agentes contaminantes para seus ocupantes.

\subsection{Partículas expiratórias}

As gotículas produzidas durante atividades expiratórias, tais como respiração, fala, bocejo, soluço, tosse e espirro, são inerentes ao processo respiratório e se formam ao passarem pelas vias orais e nasais do corpo, em um processo denominado atomização, que consiste em gerar partículas líquidas pela passagem de meios gasosos a uma determinada velocidade, sobre a superfície de uma substância líquida (Morawska, 2005). Esse processo é idêntico ao que ocorre com a brisa sobre o mar, sendo possível observar as gotículas de água carregadas pelo vento ao fluir sobre o oceano.

As gotículas expiratórias podem conter vírus, bactérias ou alérgenos, ou seja, biocontaminantes. Os biocontaminantes dispersos no ar podem ser transmitidos diretamente para outras pessoas via inalação ou indiretamente pelo contato com superfícies da cabine, tais como assentos, apoios de mão, maçanetas, entre outros (Mangili; Geandreau, 2005; Conceição; Pereira; Tribess, 2011).

As gotículas expiratórias, uma vez dispersas no ar, sofrem processos químicos e físicos que modificam a sua composição química, características físicas e a concentração no ar, influenciando na dinâmica desse tipo de partícula. Os processos mais relevantes que ocorrem com partículas suspensas no ar são a coagulação, onde partículas de tamanhos semelhantes colidem umas com as outras formando partículas maiores; a deposição de partículas menores na superfície de partículas maiores; mudanças no tamanho das partículas devido a mudanças no seu conteúdo de umidade (crescimento higroscópico ou redução por evaporação); a sedimentação; e a deposição em superfícies (Morawska, 2005). Ainda segundo Morawska (2005), esses processos modificam o tamanho das gotículas, que em conjunto com a sua velocidade inicial, são as variáveis que mais afetam a sua trajetória. 
Partículas denominadas respiráveis são constituídas por partículas sólidas ou líquidas, com diâmetro inferior a $10 \mu \mathrm{m}$, pois são facilmente suspensas no ar, podendo ser inaladas por pessoas expostas (ASHRAE, 2007). Alguns estudos mostraram que grandes concentrações de partículas estão presentes no interior de cabines de aeronaves durante voos usuais, e grande parte delas sendo geradas internamente pelos ocupantes (Pierce et al., 1999; Dumyahn et al., 2000; Nagda et al., 2000).

Segundo Duguid (1946), as atividades expiratórias podem gerar milhares de partículas polidispersas, sendo que $95 \%$ delas possuem tamanho médio situado entre 2 e $100 \mu \mathrm{m}$, e a maior quantidade está entre 4 e $8 \mu \mathrm{m}$. Por meio de medições experimentais, o autor coletou gotículas geradas durante algumas atividades expiratórias, como espirro, tosse e fala, posicionando um tipo de filme fino aderido em uma placa oleada próximo à boca dos voluntários e, em seguida, contou as gotículas coletadas sobre o filme com o auxilio de um microscópio e mediu a sua dimensão com micrômetro. Os resultados das medições, mostrados na Figura 3.1, revelaram que o espirro é a atividade expiratória que mais gera partículas atomizadas, seguida pela tosse e depois pela atividade da fala.

Contagens mais recentes do tamanho e da quantidade de partículas geradas durante atividades expiratórias foram realizadas, utilizando diferentes técnicas de geração e de medição. Papineni e Rosenthal (1997) aplicaram contadores de partículas óticos, reportando que a maior parte das gotículas geradas em atividades expiratórias seria menor do que $1 \mu \mathrm{m}$. Uma das conclusões dos autores é que a frequência com que cada tipo de atividade expiratória ocorre é fator relevante para a dispersão de partículas. Com isso, segundo esses autores, a atividade expiratória que mais gera partículas é a tosse devido à frequência com que ela ocorre em um indivíduo. Posteriormente, estudos realizados por Xie et al. (2007) mostraram que falar por 5 minutos gera a mesma quantidade de partículas que uma tosse. 


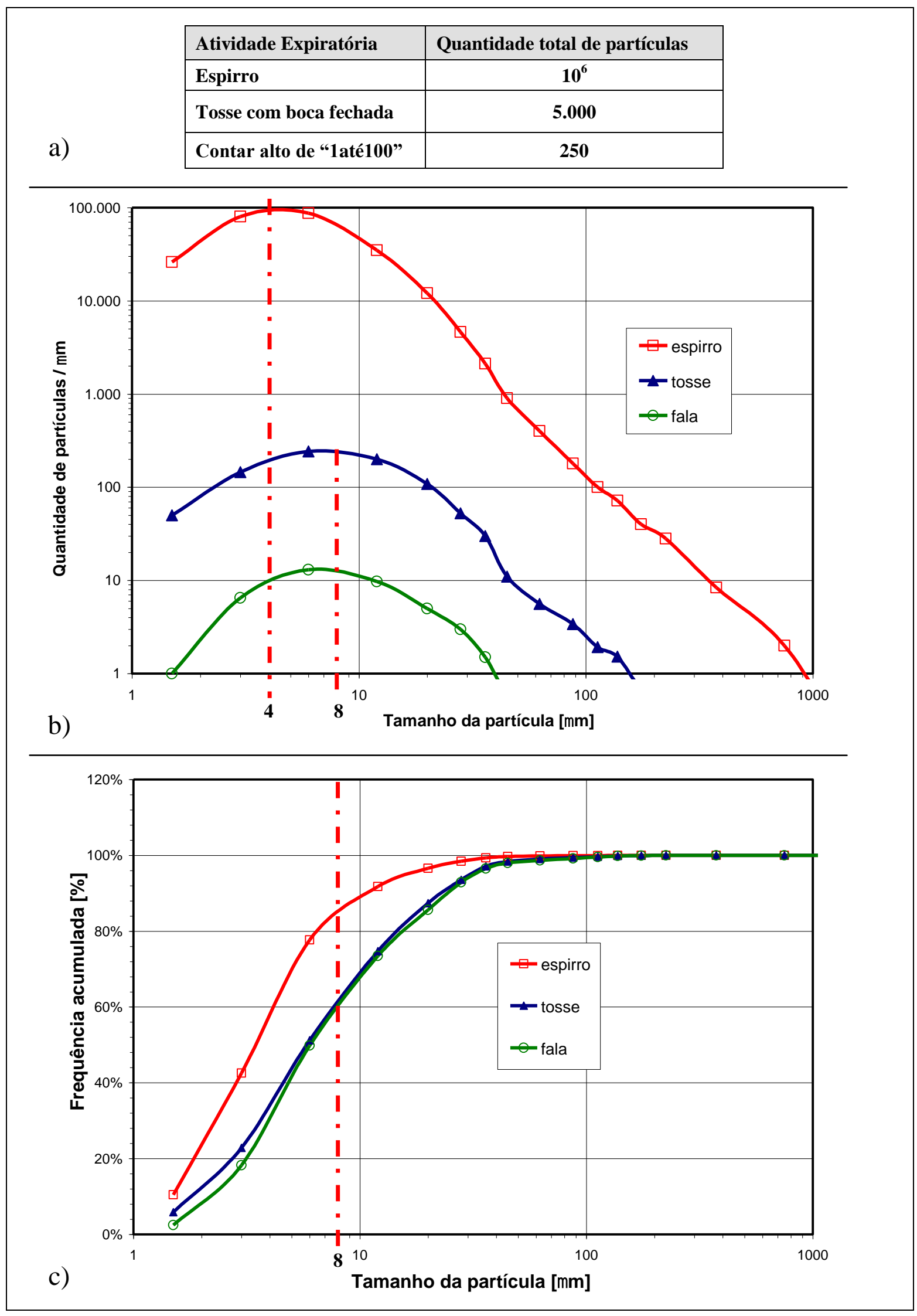

Figura 3.1 - Gotículas expiratórias, baseado nas medições de Duguid (1946)

a) quantidade absoluta de partículas. b) distribuição do tamanho de partículas normalizada pelo intervalo de medição. c) distribuição acumulada (adaptado por Conceição, 2012) 
Por outro lado, Nicas, Nazaroff e Hubbard (2005) revisaram o estudo de dispersão de partículas expiratórias e concluíram que os estudos originais de Duguid (1946) são mais consistentes. Na mesma direção, Chao et al. (2009) utilizaram o método por interferometria ótica de imagem para medir gotículas expiratórias liberadas na tosse e fala, e obtiveram certa concordância com os resultados obtidos por Duguid (1946).

Yang et al. (2007) mediram a concentração de gotículas liberadas na tosse e obtiveram valores da ordem de $10^{3}$ partículas por $\mathrm{cm}^{3}$ de ar por tosse. Pelos estudos de Duguid (1946), observa-se que a quantidade de partículas liberadas no espirro é da ordem de 200 vezes maior do que a quantidade liberada na tosse. Considerando que a concentração aumente na mesma proporção, pode-se dizer que a concentração de um espirro seria da ordem de $10^{5}$ partículas por $\mathrm{cm}^{3}$. Já os estudos de Chao et al. (2009) estimam que a concentração de gotículas liberadas por tosse é da ordem de $10^{1}$ partículas por $\mathrm{cm}^{3}$, valor duas ordens de grandeza menor do que os resultados obtidos por Yang et al. (2007).

Pesquisas realizadas com bioaerossóis mostraram que, de modo geral, o seu nível médio em cabines de aeronaves é baixo. Contudo, elevados picos de concentração de bioaerossóis foram observadas, principalmente em espirros e tosses, sugerindo que essas atividades expiratórias apresentam o maior risco de contaminação em cabines de aeronaves, a partir da dispersão de gotículas expelidas (Dechow; Sohn; Stainhanses, 1997).

As gotículas menores que $5 \mu \mathrm{m}$ possuem coeficiente de transporte por difusão similar ao coeficiente de difusão dos gases (Bémer et al., 2000) e, portanto, são carregadas mais facilmente pelo escoamento. Por este motivo, tais gotículas permanecem em suspensão por tempo suficiente para evaporar formando os resíduos de gotículas (droplet nuclei). Estes resíduos podem permanecer em suspensão por longos períodos de tempo e transportar os biocontaminantes por distâncias maiores (Tang et al., 2006).

Os estudos experimentais de Thatcher et al. (2002) mostraram que a taxa de deposição de partículas líquidas menores do que $1 \mu \mathrm{m}$ cresce significativamente com o aumento da mobília interna dos ambientes, confirmando a teoria de Bémer et al. (2000), de que partículas (líquidas ou sólidas) aderem depois do choque em superfícies. Além disso, Thatcher et al. (2002) observaram que a taxa de deposição 
de partículas maiores do que $10 \mu \mathrm{m}$ praticamente não se altera em decorrência de obstáculos contidos no interior de cabines de aeronaves. De acordo com o estudo posterior de Connor (2009), em geral, as gotículas maiores do que $5 \mu \mathrm{m}$ depositam-se em superfícies mais rapidamente devido à força peso.

Em suma, baseado na literatura consultada, observa-se que os dados de Duguid (1946) possuem ótimas concordâncias e continuam sendo referenciados em estudos recentes da dispersão de biocontaminantes em ambientes interiores (Chao; Wan, 2006; Wan et al., 2007; Sze To et al., 2009; Wan et al., 2009; Conceição, 2012). Assim sendo, tais informações são consideradas como referência também no desenvolvimento do presente estudo.

\subsection{Estudos com geradores de partículas}

Atomizadores são equipamentos capazes de gerar partículas e dispersá-las de maneira controlada em um ambiente. Diversos tipos de atomizadores têm sido utilizados para a geração de aerossóis. O método de geração pode ser basicamente diferenciado por dois modelos principais: os de partículas monodispersas, capazes de gerar particulado de tamanho único; e os de partículas polidispersas, capazes de gerar partículas de tamanho variado. Aerossol monodisperso é definido como os que contêm um desvio padrão do diâmetro das partículas $\sigma_{d}<1,15 \mu \mathrm{m}$. Por outro lado, aerossol polidisperso contém desvio padrão do diâmetro das partículas $\sigma_{d}>1,5 \mu \mathrm{m}$ (VDI, 2005).

\subsubsection{Estudos com geradores de partículas monodispersos}

Zhang et al. (2007), ao estudarem a dispersão de partículas em mock-up de aeronave Boeing 767-300, utilizaram em suas avaliações tanto o gás traçador SF6 quanto as partículas monodispersas de Di-etil-hexil-sebacato (DEHS), com tamanho médio de 0,7 $\mu \mathrm{m}$. As partículas - gasosas e líquidas - foram geradas e injetadas mediante tubos metálicos e a dispersão foi monitorada em 48 pontos distintos, distribuídos em dois planos de medição. Cada medição durava cerca de 30 segundos e era repetida dez vezes, utilizando analisador multi-gás foto-acústico e um contador de partículas ótico. 
Padilla (2008) estudou a dispersão de $\mathrm{CO}_{2}$ e a concentração de partículas expiratórias monodispersas em um mock-up de cabine de um Boeing 767-300, conforme detalhado no item 2.4 da página 33.

Jones e Nicas (2009) também utilizaram gerador de aerossol monodisperso para atomizar partículas sólidas com tamanho médio variando entre 3 e $14 \mu \mathrm{m}$, objetivando a geração de banco de dados experimentais para avaliação da distribuição de contaminantes, bem como validação de modelos de transporte de contaminantes em ambientes com ventilação natural e forçada, porém de baixa complexidade (sem mobília e sem ocupantes). Para a caracterização do campo de velocidades, anemômetros ultrassônicos de três eixos foram empregados. Para não perturbar o escoamento dentro do ambiente de teste, o gerador de aerossol foi posicionado no ambiente externo, e as partículas geradas foram misturadas em um escoamento com vazão de ar de $50 \mathrm{l} / \mathrm{min}$, direcionados mediante tubo de polivinil de $1,8 \mathrm{~m}$ de comprimento e $3,2 \mathrm{~cm}$ de diâmetro. Mediante um teste de deflexão, o experimento era abortado sempre que identificado que as partículas no ambiente não eram de fato monodispersas. Os autores aplicaram metodologia específica para medir a deposição de partículas no piso e nas paredes, bem como o seu tempo de mistura, empregando monóxido de carbono como gás traçador. Devido a estas técnicas experimentais, os autores consideram seus resultados únicos, quando comparados com outros estudos.

\subsubsection{Estudos com geradores de partículas polidispersos}

Wan, Chao e Fang (2005) realizaram estudo experimental de dispersão de gotículas expiratórias em mock-up com 21 assentos (três fileiras de sete assentos), construído no ICIEE (International Centre for Indoor Environment and Energy), localizado na Universidade Técnica da Dinamarca. Os assentos do mock-up foram ocupados com manequins aquecidos, que simularam os passageiros da aeronave. No trabalho de Wan, Chao e Fang (2005) foi utilizado gerador de partículas simulando pessoa tossindo, desenvolvido pelos próprios pesquisadores, que utilizava uma solução a base de água destilada. A distribuição do tamanho das partículas foi caracterizada com um espectômetro posicionado a $10 \mathrm{~cm}$ de distância da saída do bico injetor, obtendo um pico de concentração de $2,5 \times 10^{9}$ partículas $/ \mathrm{dm}^{3}$ no tamanho médio de 6,75 $\mu \mathrm{m}$, como mostrado no gráfico da Figura 3.2. Cada injeção de aerossol durava 1 segundo e continha em média $0,4 \ell$ da solução, cuja velocidade máxima do 
jato de saída era da ordem de $10 \mathrm{~m} / \mathrm{s}$. A injeção de gotículas foi feita em dois locais distintos dentro da cabine e as medições foram feitas $1,10 \mathrm{~m}$ do piso, utilizando três contadores de aerossol simultaneamente: um contador por condensação, que media somente o número total de aerossóis de 0,02 a 1,0 $\mu \mathrm{m}$, com tempo de amostragem de 1 segundo, utilizado para captar o transiente da concentração total de partículas; um contador ótico para contagem na faixa de 0,1 a 2,0 $\mu \mathrm{m}$ e um espectrômetro por espalhamento de luz para contagem de 0,875 a $15 \mu \mathrm{m}$, ambos com tempo de amostragem de 6 segundos, para caracterizar a distribuição do tamanho das partículas.

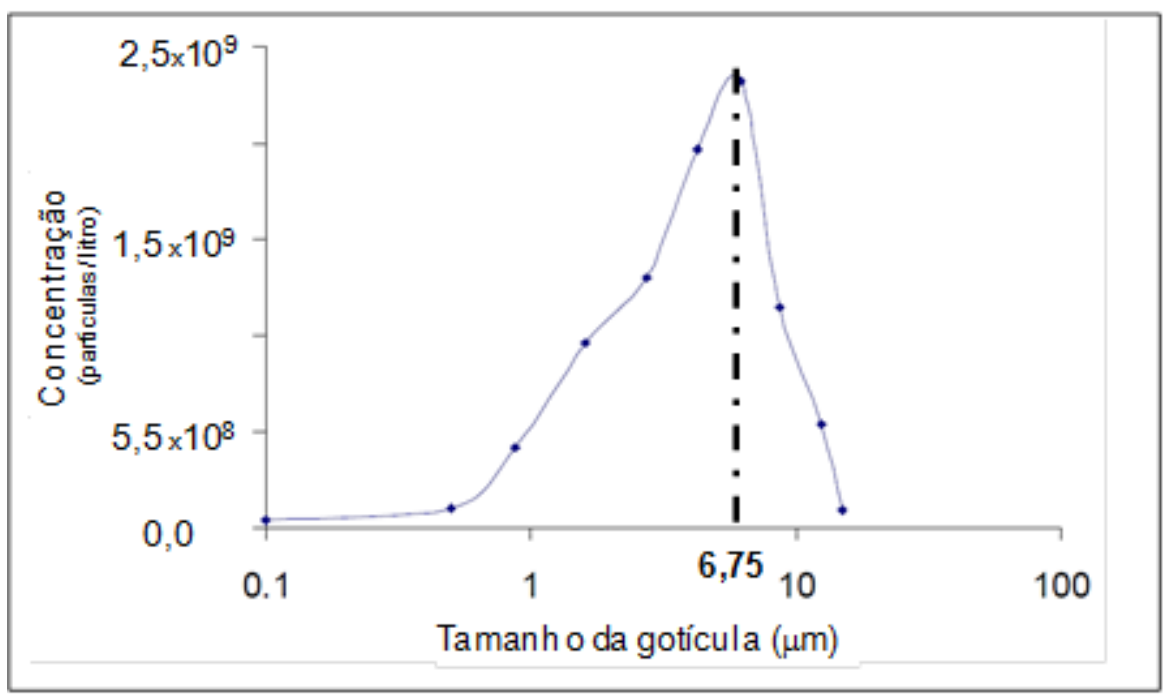

Figura 3.2 - Distribuição do tamanho de gotículas produzidas por um gerador polidisperso próprio (figura adaptada de Wan, Chao e Fang, 2005)

Em continuidade ao trabalho de Wan, Chao e Fang (2005), Sze To et al., (2009) avaliaram a dispersão e deposição de partículas provenientes de atividades expiratórias em cabines de aeronaves, além de identificar os efeitos do sistema de ventilação na diluição e remoção dessas partículas, conforme destacado no item 2.4 da página 35. Com o objetivo de avaliar o desempenho do sistema de ventilação na diluição e remoção de partículas, a cabine foi mantida sem recirculação e pressurizada com $7 \mathrm{~Pa}$ acima do entorno, para evitar qualquer tipo de infiltração de ar externo. Para a medição da velocidade das partículas, foi utilizado o PIV (Particle Image Velocimetry ou medidor de velocidade de partículas por imagem) e um espectômetro de aerossol de 16 canais, capaz de medir partículas no intervalo de 0,3 a $20 \mu \mathrm{m}$, tendo uma vazão de sucção de 1,2l/min, para caracterizar a distribuição do 
tamanho das partículas. Para medir partículas maiores de $20 \mu \mathrm{m}$, foi utilizada a técnica de medição por fluorescência das partículas que se depositavam nas superfícies do mock-up.

Os resultados de Sze To et al. (2009) mostraram que o aumento da vazão de ar de renovação provoca redução na concentração de partículas nas proximidades do ponto de injeção, devido ao efeito de diluição. Porém, a dispersão de partículas aumentou o que provocou uma elevação da concentração de contaminantes nos assentos mais distantes do ponto de injeção. Foi observado também que a dispersão das partículas depende do seu tamanho médio, tendo sido obtidos níveis de deposição de partículas da ordem de 60 a 70\%. Neste estudo foi avaliado somente o sistema de ventilação MV, sem investigar a influência de diferentes formas de ventilação na dispersão dos contaminantes na cabine.

\subsection{Efeitos dos filtros de ar na retenção de partículas em cabines de aeronaves}

Conforme citado no Capítulo 2, o ar que é entregue em cabines de aeronaves é proveniente do compressor da turbina. Esse ar não filtrado contém partículas de sujeira, vapor de óleo e demais impurezas em quantidades suficientes ao ponto de causar sintomas como dor de cabeça e náuseas, além de ter um característico odor desagradável. Por esse motivo, os filtros de ar são instalados junto à tubulação com o objetivo de reter impurezas e purificar o ar. Na maioria das aeronaves comerciais cerca de metade do ar fornecido ao passageiro é recirculado como forma de melhorar o controle da umidade do ar e da eficiência no consumo de combustível (Mangili; Gendreau, 2005).

Praticamente todas as aeronaves fabricadas atualmente utilizam os filtros tipo HEPA (High Efficiency Particulate Air). Esses filtros são altamente eficazes, capazes de essencialmente reter todo material particulado - sejam partículas de impurezas sólidas ou organismos patogênicos - que fluem pela corrente de ar que passa por eles com uma eficácia mínima de 99,97\% para partículas com diâmetro de 0,3 $\mu \mathrm{m}$ (NRC, 2002; Steffens, 2007). Portanto, são recomendados para evitar a propagação de contaminantes pelo interior da cabine (Thibeault, 1997). No entanto, embora os filtros HEPA sejam eficazes na remoção de vírus e bactérias, os contaminantes gerados por 
um passageiro podem ser inalados por outros passageiros antes de serem coletados por estes filtros (Conceição et al., 2011).

Convém ressaltar que embora as aeronaves utilizem o ar de recirculação, é necessário sempre que 0 ar recirculado seja misturado ao ar exterior. A norma ASHRAE 161 (ASHRAE, 2007) recomenda que a vazão total de ar, considerando recirculação mais o ar externo de renovação, deve estar no intervalo entre 5,9 e 9,6

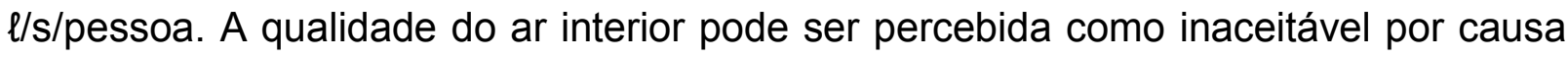
da quantidade de partículas dispersas no ambiente devido à geração no interior da cabine - e não nos sistemas e dutos de ventilação. O funcionamento do sistema de distribuição de ar, em particular o sistema MV devido à sua característica de mistura, pode dispersar mais facilmente os biocontaminantes gerados pelos ocupantes ao longo do interior da aeronave. Adicionalmente, a interação dessas partículas com a temperatura e umidade relativa, normalmente mais baixa que às encontradas em outros ambientes, prejudica sensivelmente a sensação de conforto térmico e a percepção da qualidade do ar interno - facilmente notada ao expirar o ar e sentir um odor levemente desagradável, conhecido como "ar velho".

Uma avaliação experimental foi realizada por Mendell et al. (1999), que utilizou filtros HEPA em um edifício de escritórios. Como conclusões, os autores verificaram que a concentração de partículas foi reduzida significativamente para diâmetros maiores que $2 \mu \mathrm{m}$. Além disso, este estudo também demonstrou que um aumento na temperatura até $1^{\circ} \mathrm{C}$, embora dentro da faixa de conforto, resultou em um significativo aumento das queixas em relação à qualidade do ar, pois os filtros deveriam compensar as melhorias na filtração em um fator de 2 a 5 vezes (NRC, 2002). Por esta razão, o ambiente no interior das cabines de aeronaves é relativamente mais frio - fora da zona de conforto - visando compensar uma deficiência natural dos filtros HEPA em relação à absorção de partículas de menor diâmetro. 


\section{Método experimental}

Neste Capítulo é apresentado o processo de avaliação e o procedimento para análise experimental de dispersão de partículas em cabines de aeronaves que é utilizado no estudo da influência da ventilação personalizada na dispersão de partículas expiratórias em cabine de mock-up de 12 lugares.

\subsection{Processo de avaliação}

No presente trabalho é utilizado o procedimento proposto por Conceição (2012) e utilizado por Fabichak Jr. (2013), apresentado no fluxograma da Figura 4.1.

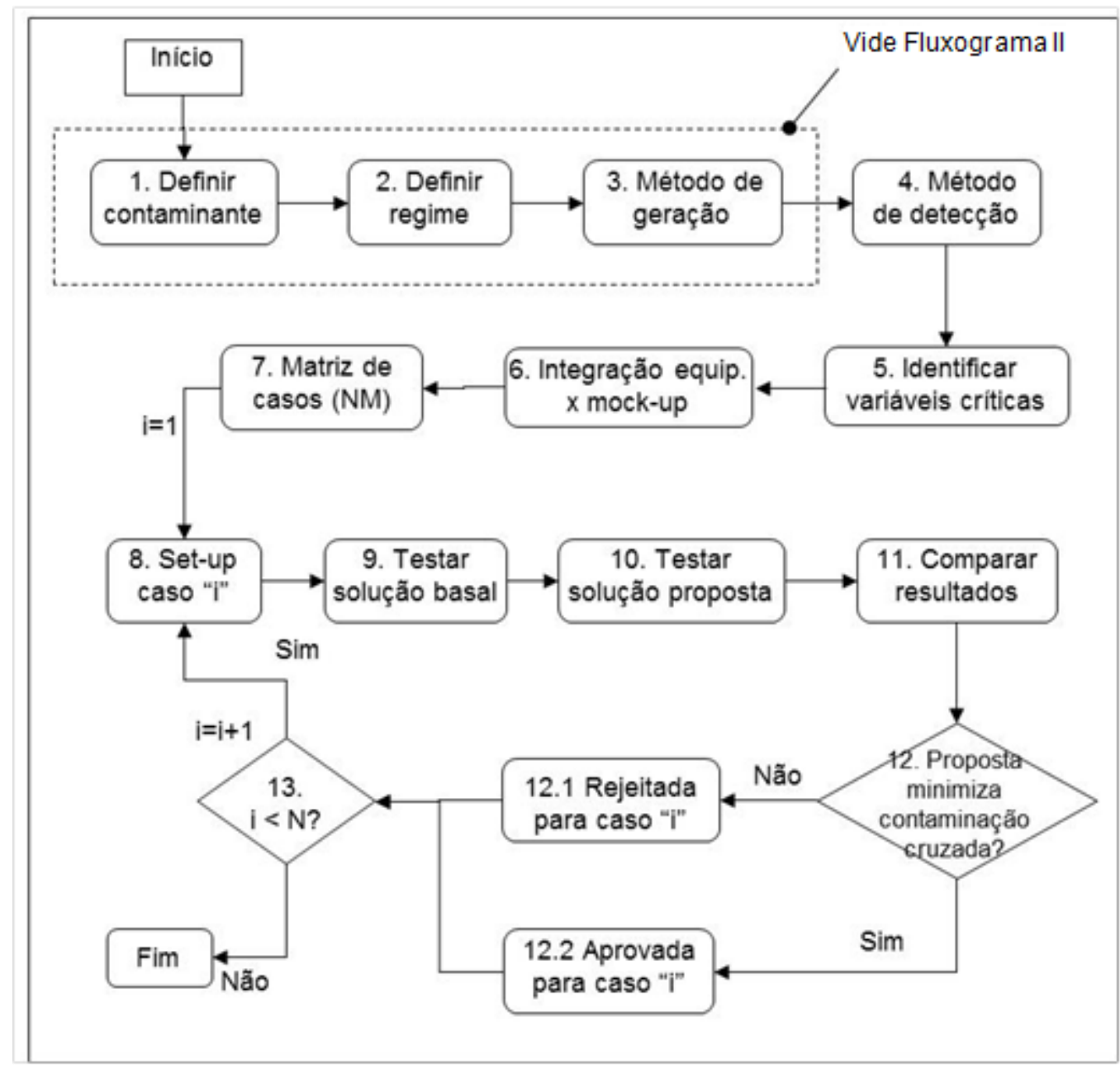

Figura 4.1 - Fluxograma I: Processo de avaliação da dispersão de partículas em cabines climatizadas (Conceição, 2012)

A fim de investigar o comportamento da dispersão de partículas expiratórias geradas por pessoas, os passos de 1 a 3, detalhados no fluxograma da Figura 4.2, 
são importantes para definir o método em que as partículas serão dispersas no interior do mock-up.

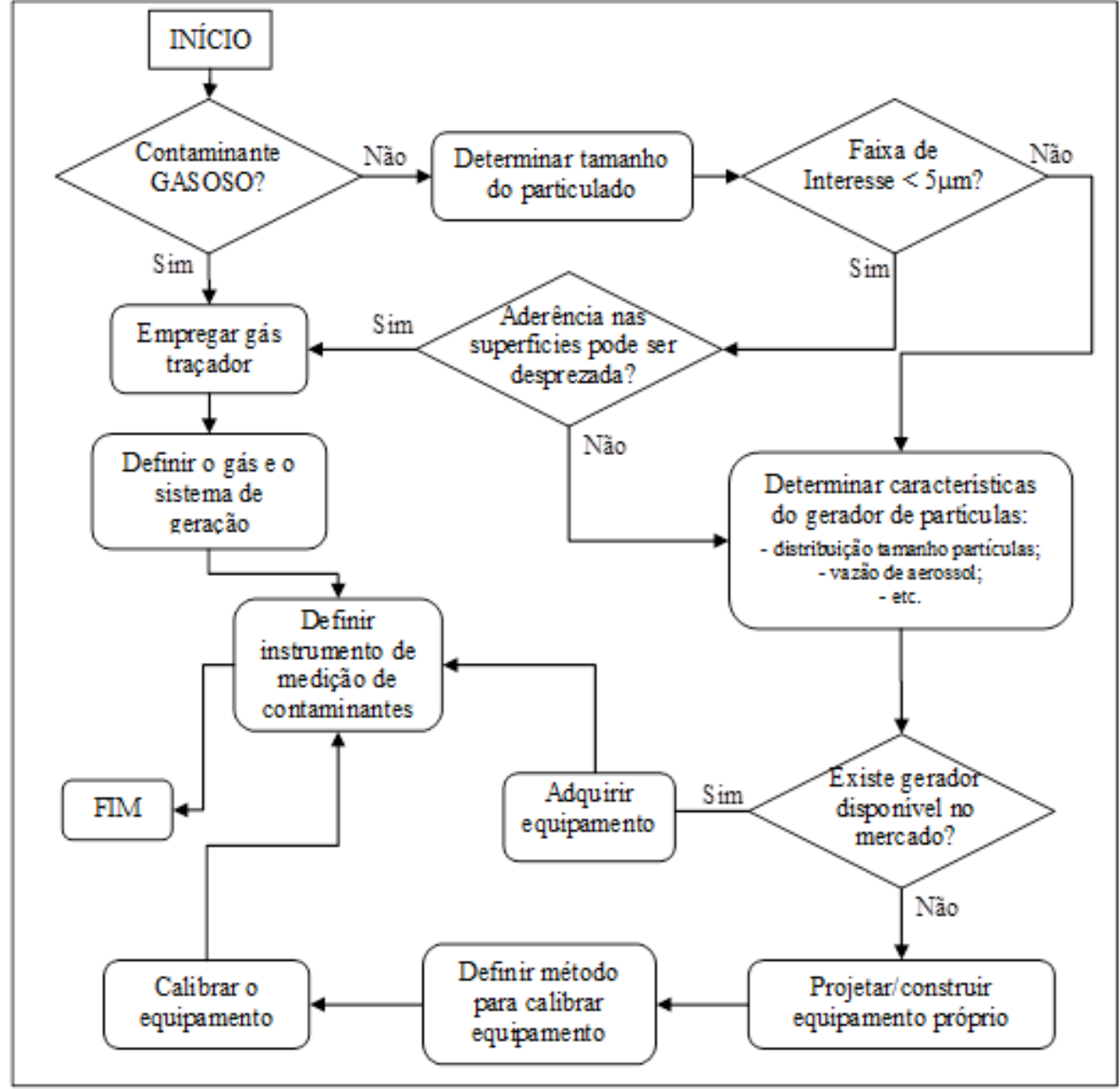

Figura 4.2 - Fluxograma II: Processo para definição do gerador de partículas (Conceição, 2012)

\section{Passo 1: Definir o tipo de partículas}

O primeiro passo é definir o tipo de partícula que se deseja avaliar e o processo físico pelo qual estas são geradas. Com isto é possível especificar o método mais adequado para a geração dessas partículas em laboratório.

Assim como nos trabalhos de Conceição (2012) e Fabichak Jr. (2013), o foco do presente trabalho também está nas partículas provenientes de atividades expiratórias, como espirro, tosse, bocejo, fala ou respiração, muitas das quais são responsáveis pela contaminação cruzada em cabines de aeronaves. 
Pela sua confiabilidade e uso em trabalhos recentes, conforme mencionado no Capítulo 3, é considerada como referência a curva de distribuição de partículas determinada por Duguid (1946). Em função disso, considera-se que a maior quantidade de gotículas expiratórias possui tamanho médio entre 4 e $8 \mu \mathrm{m}$, e concentração da ordem de $10^{5}$ partículas por $\mathrm{cm}^{3}$.

\section{Passo 2: Definir o regime}

O primeiro passo é definir o tipo de partícula que se deseja avaliar e o processo físico pelo qual estas são geradas. Com isto é possível especificar o método mais adequado para a geração dessas partículas em laboratório.

Dependendo do interesse específico de cada estudo, o fenômeno pode ser tratado como regime permanente ou transiente. A definição por regime transiente ou permanente deve ser feita no começo, pois pode influenciar no método de geração/detecção de partículas, definidos na sequência.

Observando o fenômeno físico da tosse ou espirro, logo após a injeção (geração) das partículas no ambiente, estas são liberadas em forma de jato e aos poucos vão se dispersando, com as partículas maiores depositando-se mais rapidamente nas superfícies próximas ao ponto de injeção, e as partículas menores arrastadas pelo escoamento alcançando regiões mais distantes.

É conveniente propor o regime de geração das partículas imaginando o fenômeno físico de como ocorre a liberação de partículas expiratórias no ambiente. Normalmente, as gotículas são liberadas a partir de um jato, que pode ter maior ou menor intensidade a depender do tipo de atividade expiratória. Esse jato, aos poucos, se dispersa no ambiente, onde partículas com maior diâmetro são mais facilmente depositadas, e as partículas menores são carregadas pelo escoamento, alcançando pontos mais afastados ao seu ponto de injeção.

Segundo Conceição (2012), se um dado sistema de distribuição de ar é capaz de barrar os contaminantes dispersos neste cenário real e efetivamente transitório, parece adequado considerar que este seja efetivo para barrar infinitos "disparos" realizados continuamente, ou seja, um jato contínuo de aerossol, desde que a quantidade de movimento do jato de aerossol e a distribuição do tamanho de partículas nas duas situações sejam semelhantes. Além disso, depois da injeção pulsada de partículas expiratórias em um ambiente interior, a sua concentração em 
um dado local do espaço começa a se reduzir continuamente até que a instabilidade e a incerteza na contagem alcançam níveis inadequados, conforme análise experimental de Wan et al. (2009). Por essa razão, não parece ser adequado considerar o regime transiente para essa proposta.

Portanto, no presente trabalho também é efetuada a geração contínua de partículas em uma dada região da cabine, simulando a geração de aerossóis durante atividades expiratórias.

\section{Passo 3: Método de geração}

Uma vez definido o tipo de contaminante, o processo físico de geração que se deseja representar e o regime de operação, parte-se para a definição do método de geração das partículas. Como as etapas de definição do tipo de partículas e do método de geração destas partículas são cruciais, esses passos foram desmembrados em um segundo fluxograma (Conceição, 2012) e apresentado na Figura 4.2.

No processo de escolha do método de geração, Conceição (2012) partiu de dois argumentos que direcionam à utilização de gerador de partículas ao invés de gás traçador: o primeiro é que a maior parte das partículas expiratórias possuem tamanho entre 4 e $8 \mu \mathrm{m}$ (Duguid, 1946) e não podem ser caracterizadas como "aerossóis menores"; o segundo é que as gotículas expiratórias depositam-se nas superfícies dos obstáculos depois do choque, ao passo que as partículas gasosas são refletidas. Além disso, é característica das cabines de aeronave possuir a relação "área superficial x volume" maior do que os ambientes de escritório, o que potencializa as taxas de deposição de partículas nas suas superfícies internas (Wan et al., 2009).

$\mathrm{Na}$ escolha do gerador de partículas os principais requisitos considerados por Conceição (2012) foram:

1. Faixa de tamanho das partículas geradas;

2. Vazão e concentração das partículas;

3. Disponibilidade no mercado;

4. Custo do equipamento.

Os passos de 4 a 6 referem-se a como as partículas geradas nas etapas anteriores são coletadas e medidas para, posteriormente, avaliar a influência dos 
sistemas de ventilação personalizada propostos na dispersão de partículas expiratórias.

\section{Passo 4: Método de detecção}

Tendo definido o método de geração, é preciso definir a metodologia de medição desses contaminantes. Para contaminantes gasosos, basta definir o gás e a faixa de concentrações que se deseja trabalhar, para então definir o medidor de gases mais adequado. Já para a identificação de partículas, têm-se utilizado contadores ópticos portáteis, capazes de fazer a contagem de partículas por unidade de volume de ar em diferentes faixas de tamanho, ou os espectrômetros, que fazem a contagem de partículas e a medição da sua concentração em massa, normalmente até partículas com diâmetro médio de $20 \mu \mathrm{m}$. Maiores detalhes sobre os equipamentos utilizados são apresentados no item 4.2.9.

\section{Passo 5: Identificar variáveis críticas}

Uma vez definido o tipo de partículas, o regime de operação, o processo de geração e a definição do método de geração do contaminante, a próxima etapa é a identificação das variáveis que podem influenciar significativamente nos resultados do experimento, denominadas de variáveis críticas (Conceição, 2012).

Essas variáveis foram monitoradas e/ou controladas, de maneira a garantir a adequada repetibilidade e reprodutibilidade do experimento. Isto é de fundamental importância, tendo em vista a limitação da quantidade de equipamentos usualmente utilizados para medir partículas, decorrente do alto custo envolvido.

Além disso, existem vários parâmetros que influenciam diretamente os resultados deste tipo de experimento. Para que a influência de cada parâmetro seja avaliada individualmente, os outros parâmetros devem ser mantidos constantes. Por conseqüência, o número de experimentos cresce e, com isso, a necessidade de garantir adequada repetibilidade das condições de contorno dos experimentos. As variáveis críticas e os procedimentos adotados para tratar cada uma delas ao longo dos experimentos também são detalhadamente mencionados no item 4.2.7. 


\section{Passo 6: Integração de equipamentos no mock-up}

Nesta etapa é feita a definição do(s) ponto(s) de injeção das partículas, bem como o(s) ponto(s) de medição dessas partículas. Mesmo quando forem requeridos diversos pontos de geração de partículas, esses devem ser avaliados individualmente, possibilitando assim uma melhor interpretação dos resultados. Como os equipamentos de medição de partículas são, em geral, de alto custo, deve-se repetir o experimento diversas vezes, reposicionando o instrumento de medição para cada repetição.

Quando o tamanho dos equipamentos é considerável e pode afetar a dinâmica do escoamento e das partículas contaminantes, o posicionamento dos equipamentos normalmente é feito fora da câmara experimental. No entanto, no presente trabalho, como a ideia é avaliar a dispersão de partículas geradas por ocupantes em cabines de aeronaves, a geração de partículas deve ser feita internamente no mock-up. Maiores detalhes do processo de injeção das partículas são discutidos no Procedimento Experimental, mencionado no item 4.2.

\subsection{Procedimento Experimental}

Conforme ressaltado no Capítulo 2, o sistema de distribuição de ar em cabines de aeronaves tem um papel fundamental para criar um ambiente seguro, saudável e confortável no interior dessas cabines. Normalmente, o sistema de distribuição de ar utilizado é por mistura (MV), ou seja, insuflamento de ar pela parte superior e lateral inferior dos bagageiros (bins) e retorno pela parte inferior lateral da cabine. A distribuição de temperaturas nesse sistema é mais uniforme. Entretanto, ocorre grande circulação de ar com velocidade elevada próxima aos difusores, não provendo boas condições de conforto térmico e possibilitando uma maior dispersão de partículas, aumentando assim o risco de propagação de doenças infecciosas.

No presente trabalho é realizada análise experimental da dispersão de partículas expiratórias considerando arquitetura de distribuição por mistura de ar (MV) no mockup, reproduzindo o interior de cabine de aeronave comercial. Adicionalmente, também é avaliada a influência de sistemas de ventilação personalizada instalados na poltrona (PV), integrados ao sistema de distribuição de ar convencional (MV). A descrição do procedimento experimental, bem como os resultados das avaliações são mostrados no Capitulo 5. 


\subsubsection{O laboratório}

O experimento é desenvolvido no mock-up de cabine de 12 lugares do Laboratório de Conforto Térmico e Qualidade do Ar da Escola Politécnica da Universidade de São Paulo, com a finalidade de realizar estudos para a análise do escoamento e distribuição do ar, do conforto térmico e da dispersão de partículas expiratórias. O laboratório permite a análise de diferentes sistemas de distribuição de ar (sistema da cabine), bem como de diferentes sistemas de ventilação personalizada (sistema personalizado) no mock-up de cabine de aeronave instrumentado, conforme detalhado na Figura 4.3.

O laboratório possui um sistema de climatização do tipo expansão indireta, composto por chiller e fan-coil, e possibilidade de aquecimento e umidificação do ar, com controlador lógico programável (CLP), que fornece ar tratado ao mock-up instrumentado. A captação do ar do fan-coil é efetuada na casa de máquinas através de um duto com damper, ligado ao ambiente externo. Um exaustor, instalado na linha de retorno do ar, permite a exaustão e renovação de até $100 \%$ do ar, importante para a realização do presente trabalho.

O controle e o ajuste da temperatura e da umidade do ar são obtidos por meio de transmissores de temperatura e umidade relativa do ar, cujas faixas de operação estão situadas entre -40 a $80^{\circ} \mathrm{C}\left( \pm 0,2^{\circ} \mathrm{C}\right)$ e 0 a $100 \%$ UR $( \pm 1,0+0,008$ x leitura)\% UR, respectivamente, e instalados nos dutos de insuflamento de ar do mock-up.

\subsubsection{Descrição do mock-up}

O interior do mock-up foi construído de modo a representar adequadamente o interior de uma seção de cabine de aeronave comercial, contendo 12 lugares dispostos em três fileiras de quatro assentos e um corredor central. As curvas internas dos bagageiros (bins) e as paredes foram construídas em tubo estrutural e chapa metálica, com acabamento interno em revestimento melamínico, simulando acabamento superficial de interior de aeronaves. O piso foi confeccionado em madeira e revestido com carpete.

Conforme destacado anteriormente, o sistema de distribuição de ar do mock-up utilizado nesse trabalho empregou arquitetura convencional de ventilação por mistura (MV), onde ar é insuflado com alta velocidade através de dois dutos localizados nos plenum superiores às seis aberturas na região inferior do maleiro (overhead bins) e 0 
retorno sendo realizado através das grelhas laterais inferiores. Na Figura 4.4 mostrase a configuração do mock-up: uma vista isométrica exterior, sendo que os detalhes em vermelho representam o posicionamento das entradas e saídas de ar do mock-up; ao lado desta imagem, é mostrada uma vista do interior do mock-up.

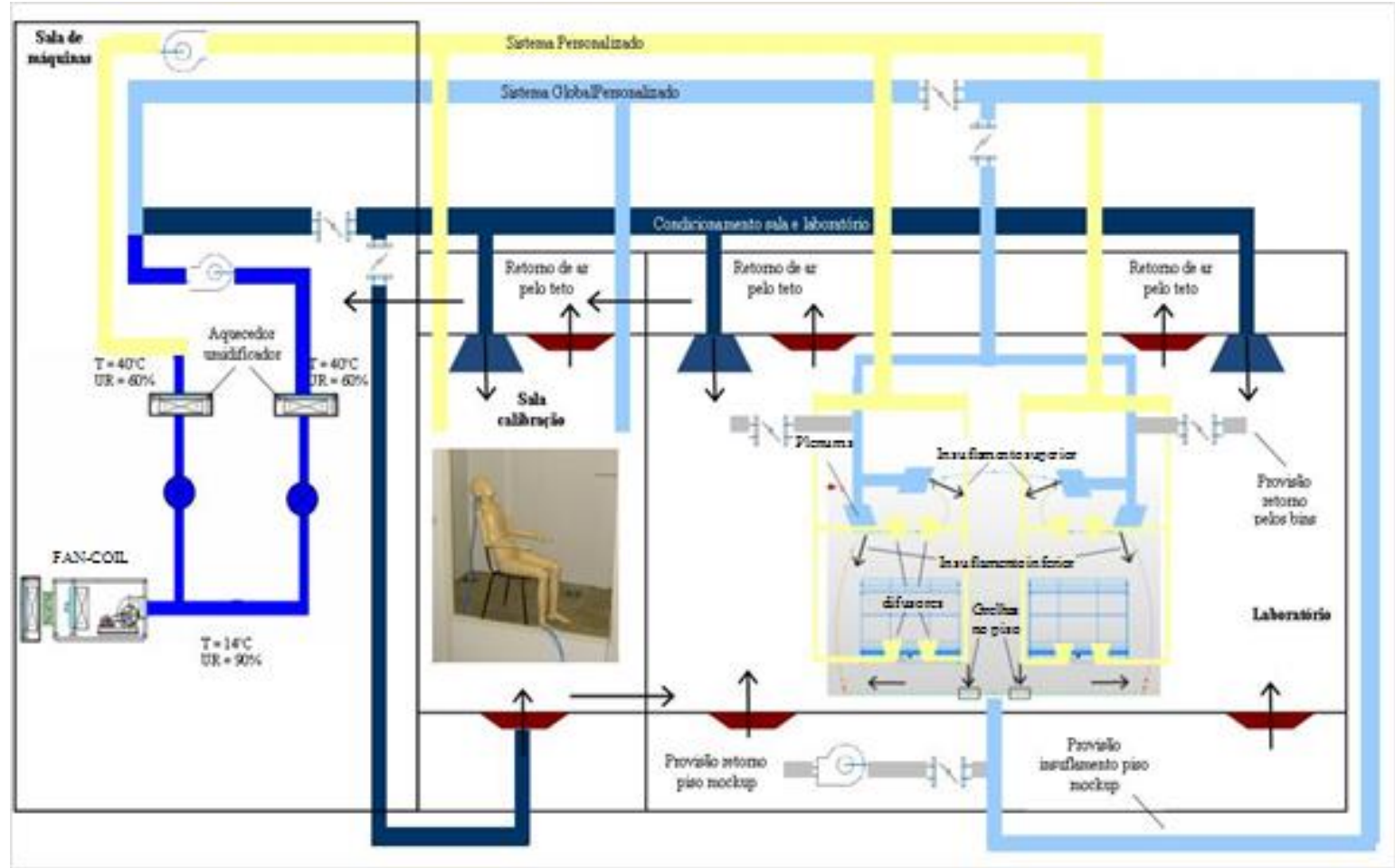

Figura 4.3 - Representação esquemática do sistema da cabine (em azul claro) e personalizado (em amarelo) do mock-up (Fabichak Jr., 2013)

a)

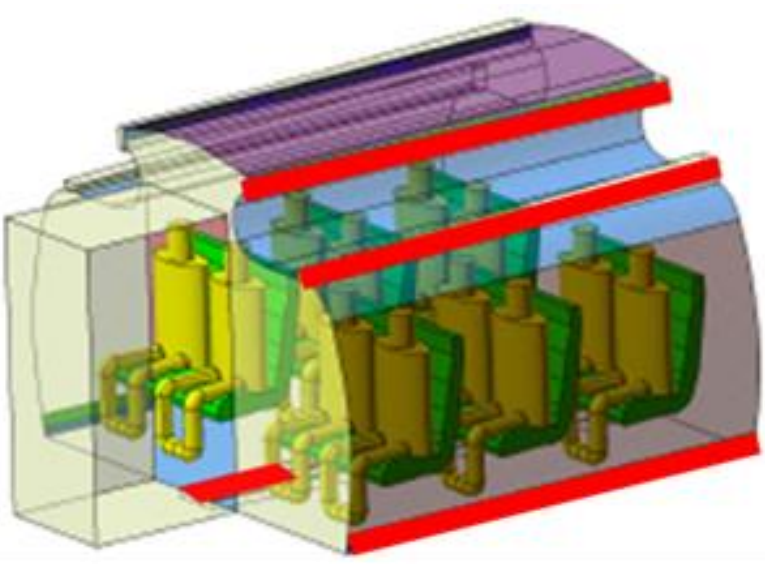

b)

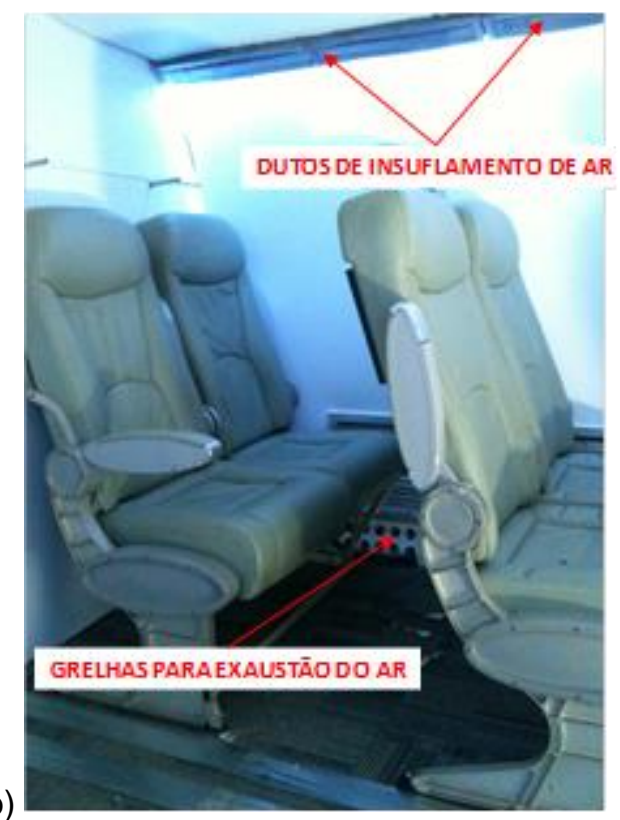

Figura 4.4 - Configuração do mock-up: (a) Representação isométrica do exterior; (b) Vista do interior 


\subsubsection{Sistema de ventilação personalizada instalado na poltrona}

$\mathrm{Na} 2^{\mathrm{a}}$ fileira de assentos estão localizados os sistemas de microclima instalados na poltrona. Os sistemas PV recebem ar do sistema personalizado apresentado na Figura 4.3, que é independente do sistema MV da cabine do mock-up. Isto é, a temperatura de insuflamento do ar dos sistemas PV pode ser diferente da temperatura de insuflamento do ar na cabine. A vazão nos sistemas de ventilação personalizada, por sua vez, pode ser controlada individualmente pelo passageiro por meio de uma válvula manual.

$\mathrm{Na}$ Figura 4.5 apresenta-se a configuração destes sistemas de ventilação personalizada com insuflamento de ar pela poltrona (PV). Ao lado desta figura, é mostrada a disposição dos difusores no encosto da poltrona. Os difusores de ar utilizados possuem formato de "U" invertido, conforme apresentado em detalhe na Figura 4.6. A geometria do difusor foi definida considerando que pode ser adaptado um display multimídia central, já disponível neste tipo de aeronave de passageiros. $\mathrm{O}$ mecanismo de articulação, conforme mostrado na Figura 4.7, possibilita direcionar o jato de ar para a zona de respiração.

a)

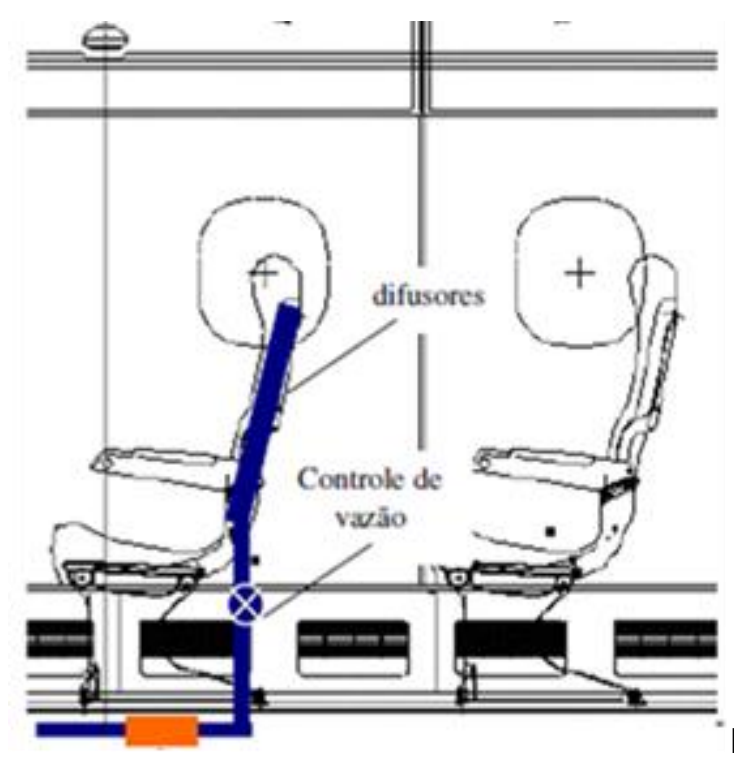

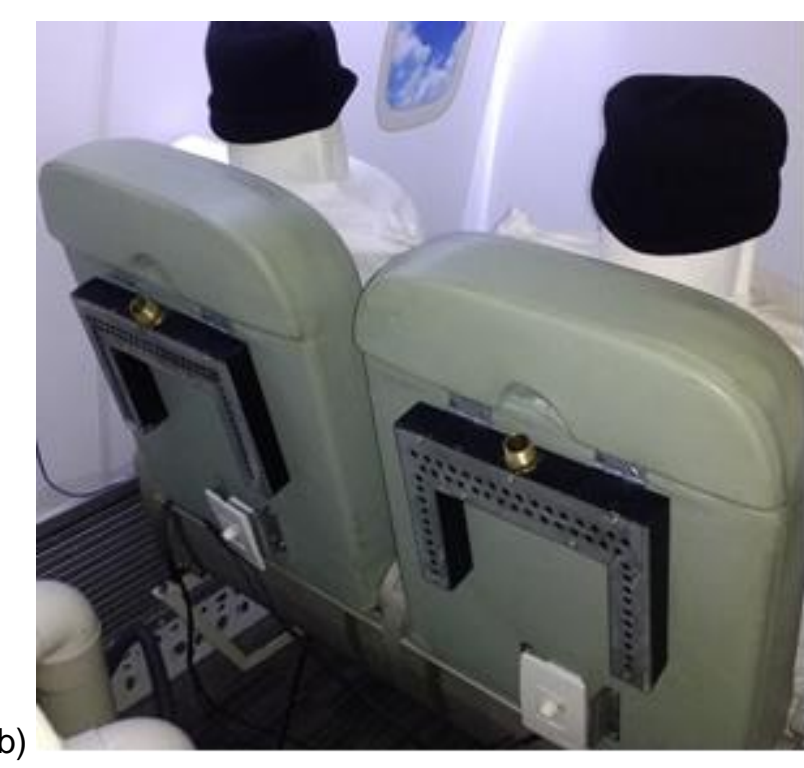

b)
Figura 4.5 - Sistema de ventilação personalizada de poltrona: (a) Configuração dos dutos dos sistema PV; (b) Vista do assento equipado com sistema PV 

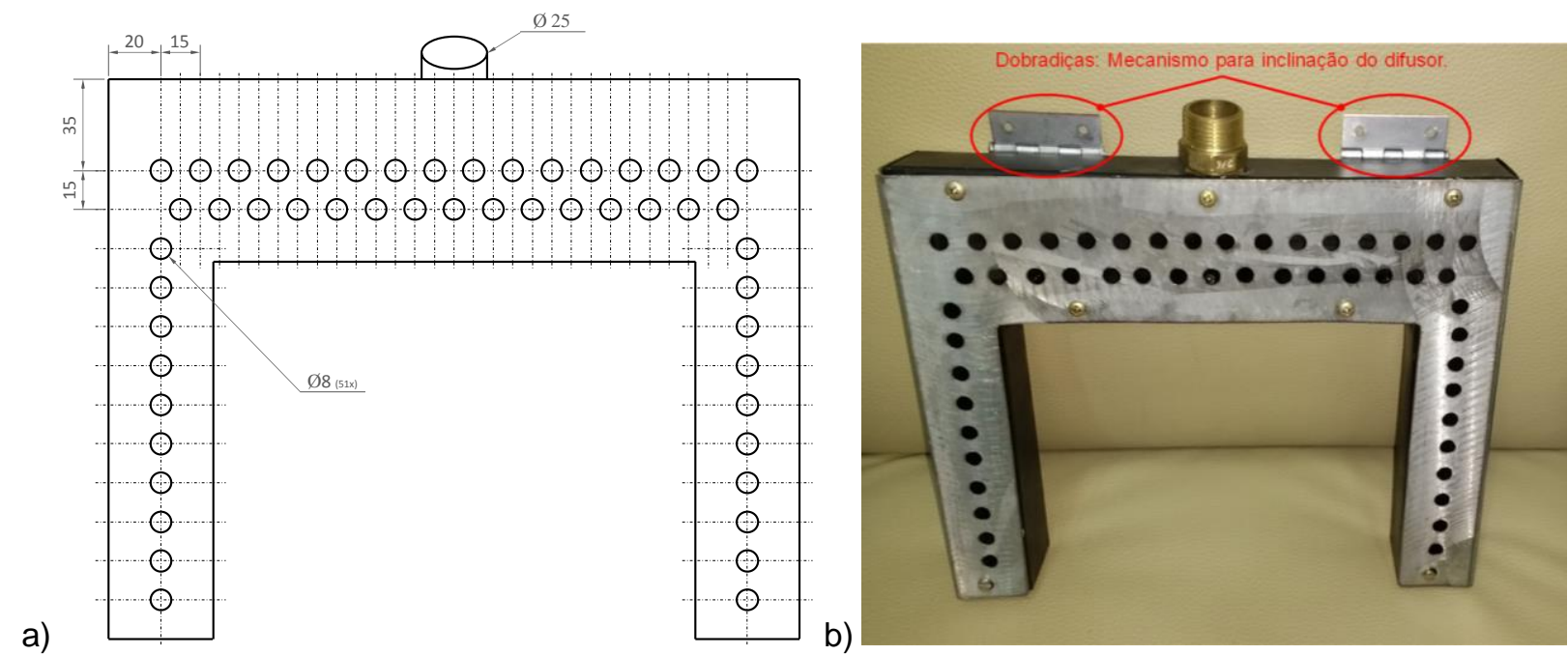

Figura 4.6 - Difusor de ar do sistema de ventilação personalizada de poltrona:

(a) Geometria e dimensional; (b) Mecanismo para inclinação do difusor
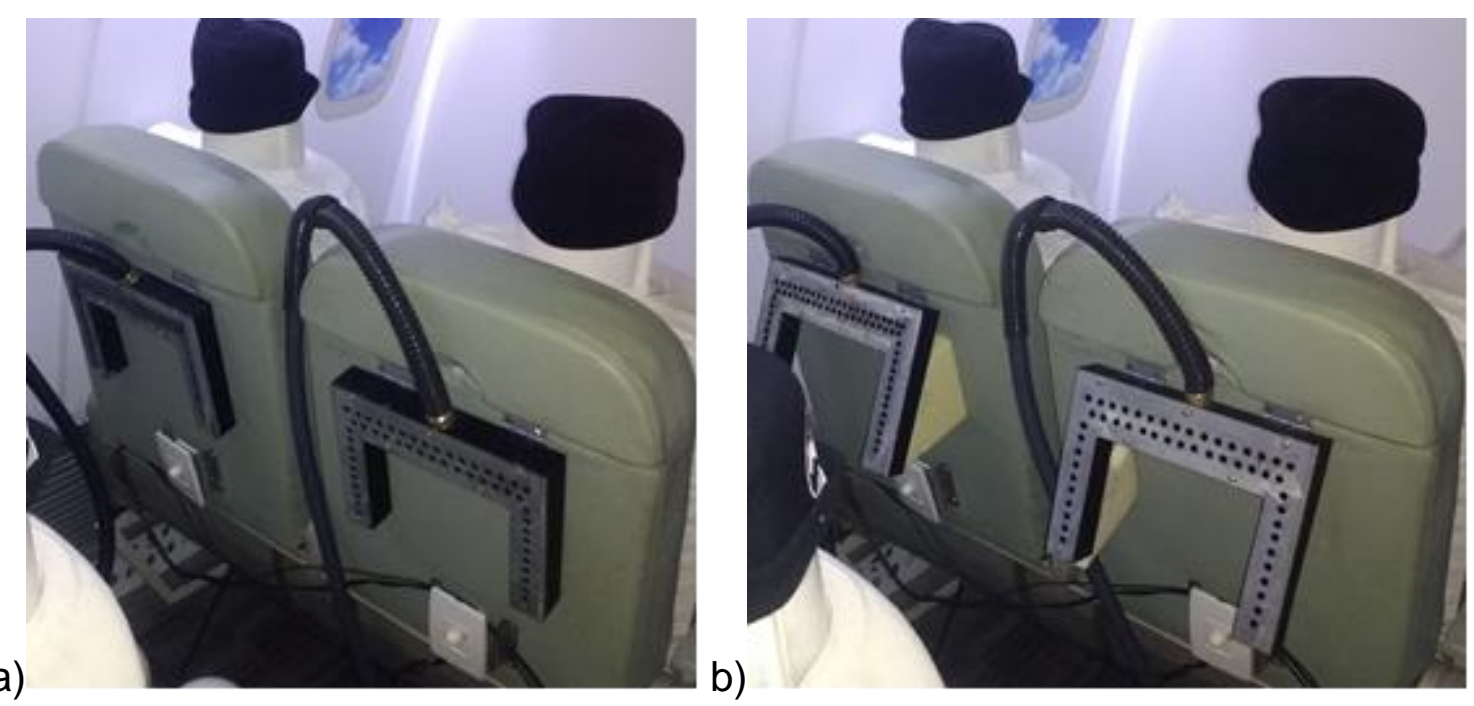

Figura 4.7 - Difusor de ar do sistema de ventilação personalizada de poltrona:

(a) Configuração sem inclinação; (b) Configuração com inclinação

Os assentos utilizados são os mesmos empregados no modelo de aeronave comercial e suas dimensões e espaçamentos entre assentos representam o interior deste tipo de cabine de aeronave. Na Figura 4.8 mostra-se o interior do mock-up, juntamente com os manequins aquecidos, simulando a presença de passageiros. 


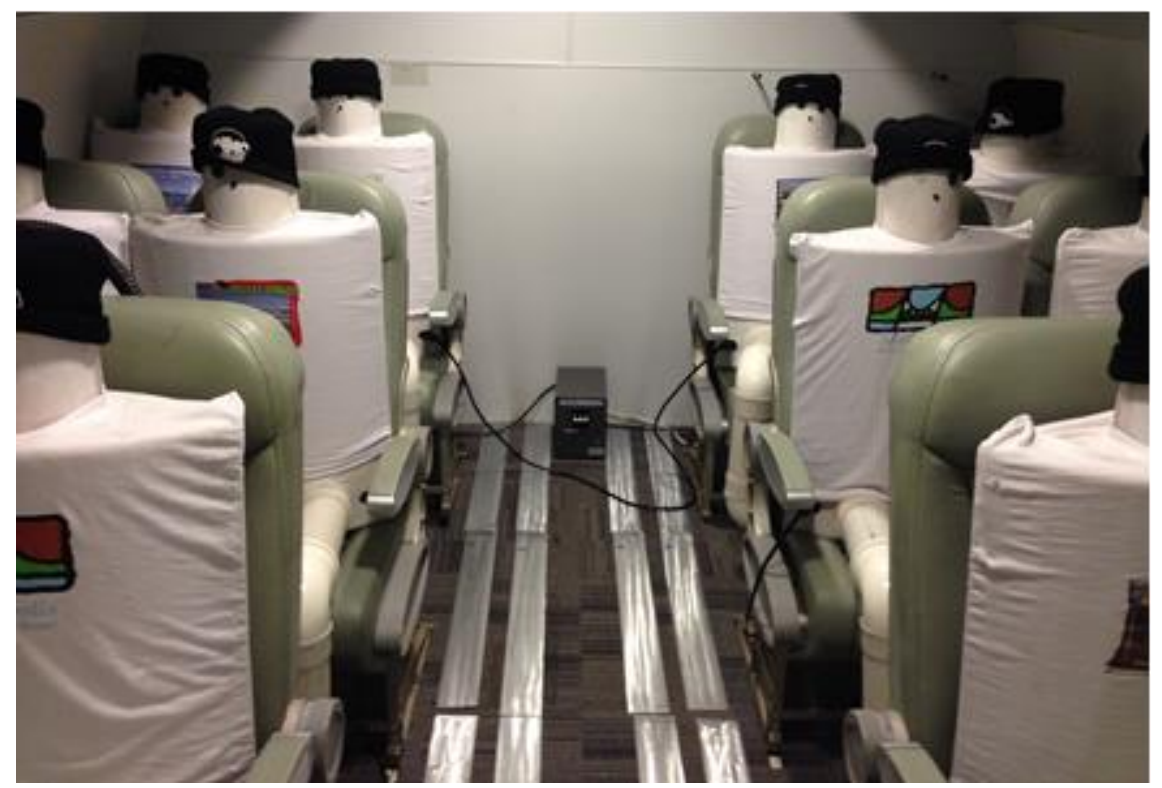

Figura 4.8 - Localização Vista interna do mock-up com os manequins aquecidos

Os manequins aquecidos foram construídos em fibra de vidro e tubos e conexões de PVC com forma semelhante a um corpo humano sentado, conforme mostrado na Figura 4.9. Na parte interna existe uma resistência elétrica, que dissipa calor, e um ventilador que propicia uma distribuição uniforme da temperatura do ar ao longo de toda a superfície do manequim. Os manequins são acoplados a uma unidade de potência por meio de cabos tripolares. A potência de dissipação de calor é ajustável por meio de software. A faixa de operação dos manequins é de 30 a $120 \mathrm{~W} / \mathrm{m}^{2}$.
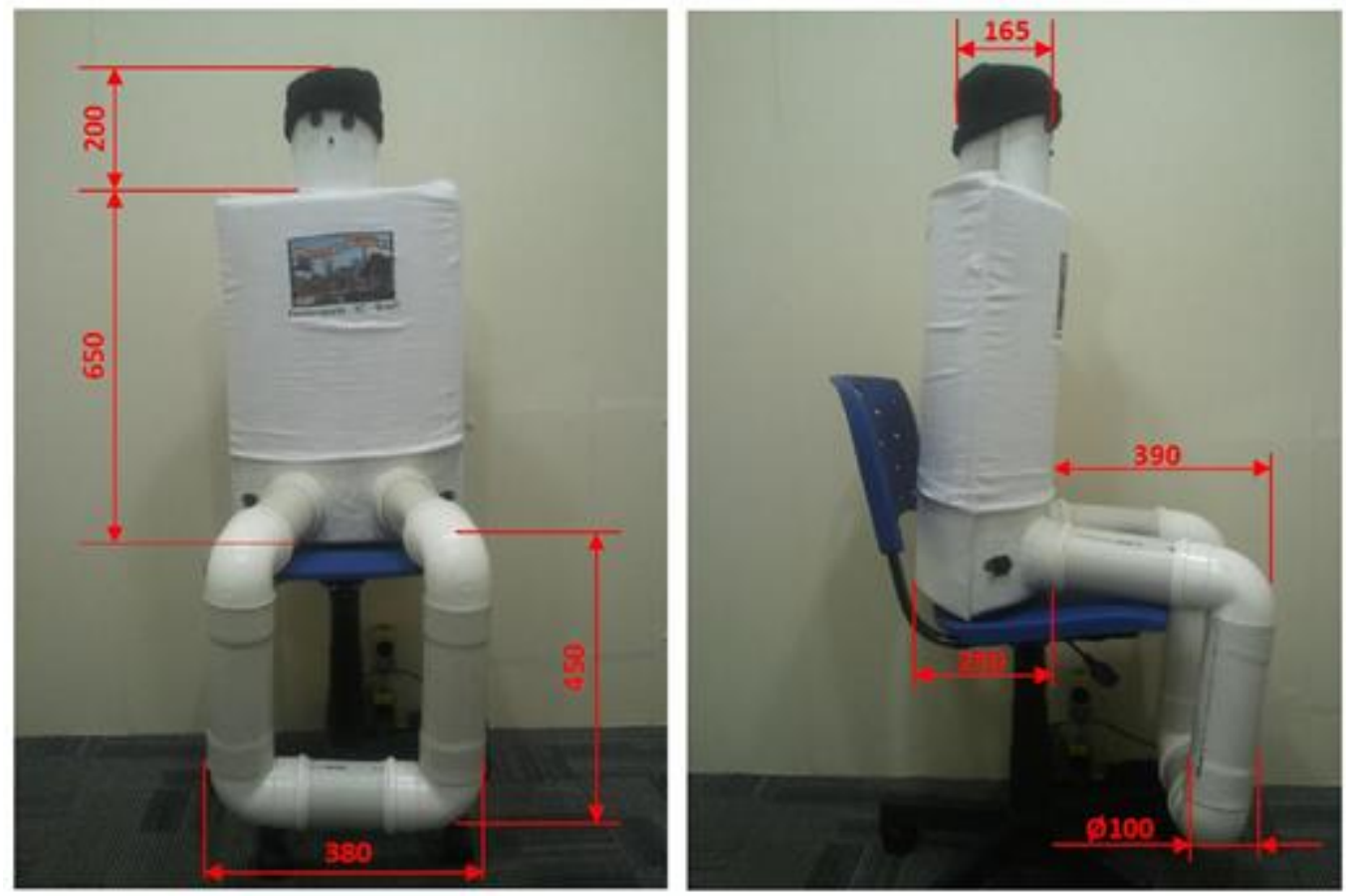

Figura 4.9 - Manequins aquecidos e suas respectivas dimensões (Moura, 2009) 


\subsubsection{Monitoramento e controle da temperatura do mock-up}

Ao longo do interior do mock-up foram alocados termopares tipo T para monitorar a temperatura em diferentes pontos da cabine. Este monitoramento auxiliava a identificar em quanto tempo o sistema de climatização do mock-up atingia as condições de estabilização, antes de se iniciar os ensaios. Os termopares foram conectados a um Data-Logger modelo Agilent 34907-A. Na Figura 4.10 é mostrada a disposição dos termopares ao longo do mock-up.

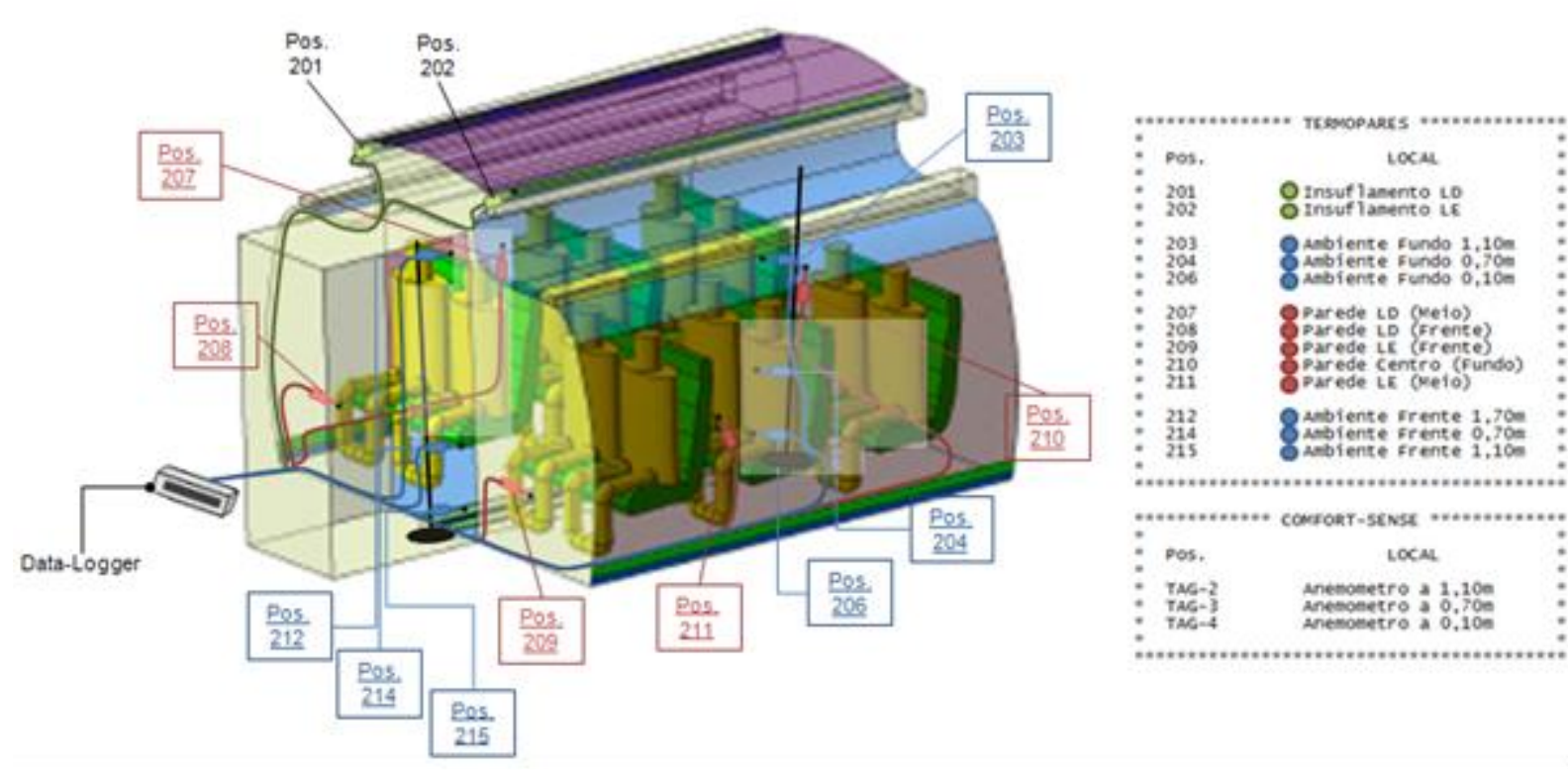

Figura 4.10 - Localização dos termopares no mock-up

\subsubsection{Processo de geração das partículas}

Para o processo de geração de partículas, a escolha do equipamento foi fundamentada na capacidade de produção dos contaminantes nas mesmas condições em que são produzidos pelas pessoas durante atividades expiratórias. Assim sendo, e conforme o fluxograma da Figura 4.2, os passos a seguir descrevem o processo de geração de partículas para avaliação da sua dispersão.

\section{Tipo de Contaminante}

No presente trabalho, o foco está na avaliação da dispersão de partículas geradas a partir de atividades expiratórias. Função disso é razoável a opção por geradores que produzam partículas, ao invés de gás traçador. Além do mais, as superfícies no interior de cabines de aeronaves podem reter as partículas expiratórias dispersas no ambiente, isto é, as partículas geradas pelos ocupantes podem 
depositar-se nas paredes laterais, no piso ou no teto da cabine da aeronave, aumentando o risco de contaminação cruzada das pessoas a bordo (Zhang et al., 2009; Wang; Lin; Chen, 2011). Esse efeito somente é possível de ocorrer se forem utilizadas partículas líquidas em forma de gotículas, ao invés de gás traçador.

Para a avaliação da dispersão das partículas que simulem atividades expiratórias, é conveniente que as partículas a serem geradas tenham a mesma forma e quantidade que as partículas geradas pelas pessoas, em situações normais. Para isso, a curva de distribuição proposta por Duguid (1946) será a referência do presente trabalho. Assim sendo, considera-se que a maior parte das partículas possui tamanho situado na faixa entre 4,0 e 8,0 $\mu \mathrm{m}$, e que a concentração seja da ordem de $10^{5}$ partículas $/ \mathrm{cm}^{3}$.

\section{Escolha do equipamento}

Tendo sido definido o tipo, a forma e a concentração das partículas, além do método de geração e o regime de trabalho, a escolha do equipamento também considerou a necessidade de aquisição de um gerador que esteja disponível no mercado.

Com isso, foi escolhido o gerador de aerossol da TSI, modelo 3475, mostrado na Figura 4.11. Embora este gerador produza, em sua grande maioria, partículas com o tamanho e a concentração desejados, ele também produz partículas, em menor quantidade, nas outras faixas de tamanho de 0,1 até $8,0 \mu \mathrm{m}$. A concentração de partículas geradas depende do tamanho de partícula escolhido, conforme o gráfico da Figura 4.12. Na faixa de tamanho de partícula a ser estudada $(4,0 \pm 1,1 \mu \mathrm{m})$, a quantidade de partículas produzidas é da ordem de $1,2 \times 10^{6} / \mathrm{cm}^{3}$.

Este gerador não possui indicador do tamanho nem da concentração da partícula gerada. Por isso, é instalado em série um monitor de partículas PAM 3375, mostrado na Figura 4.13, capaz de monitorar o diâmetro médio da partícula gerada, bem como a sua concentração (TSI, 2010). 


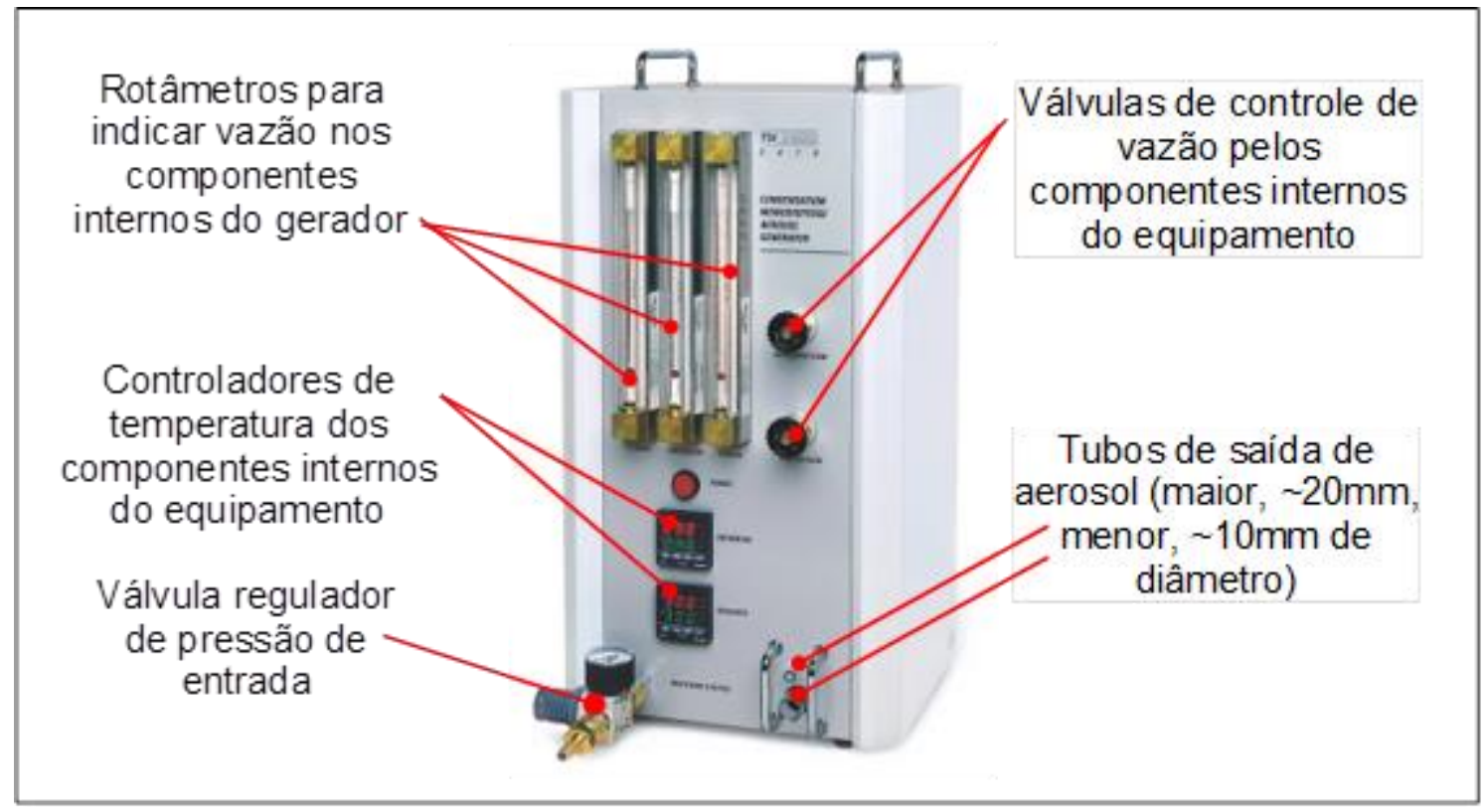

Figura 4.11 - Gerador de aerossol TSI modelo 3475 (TSI, 2010) - imagem de catálogo

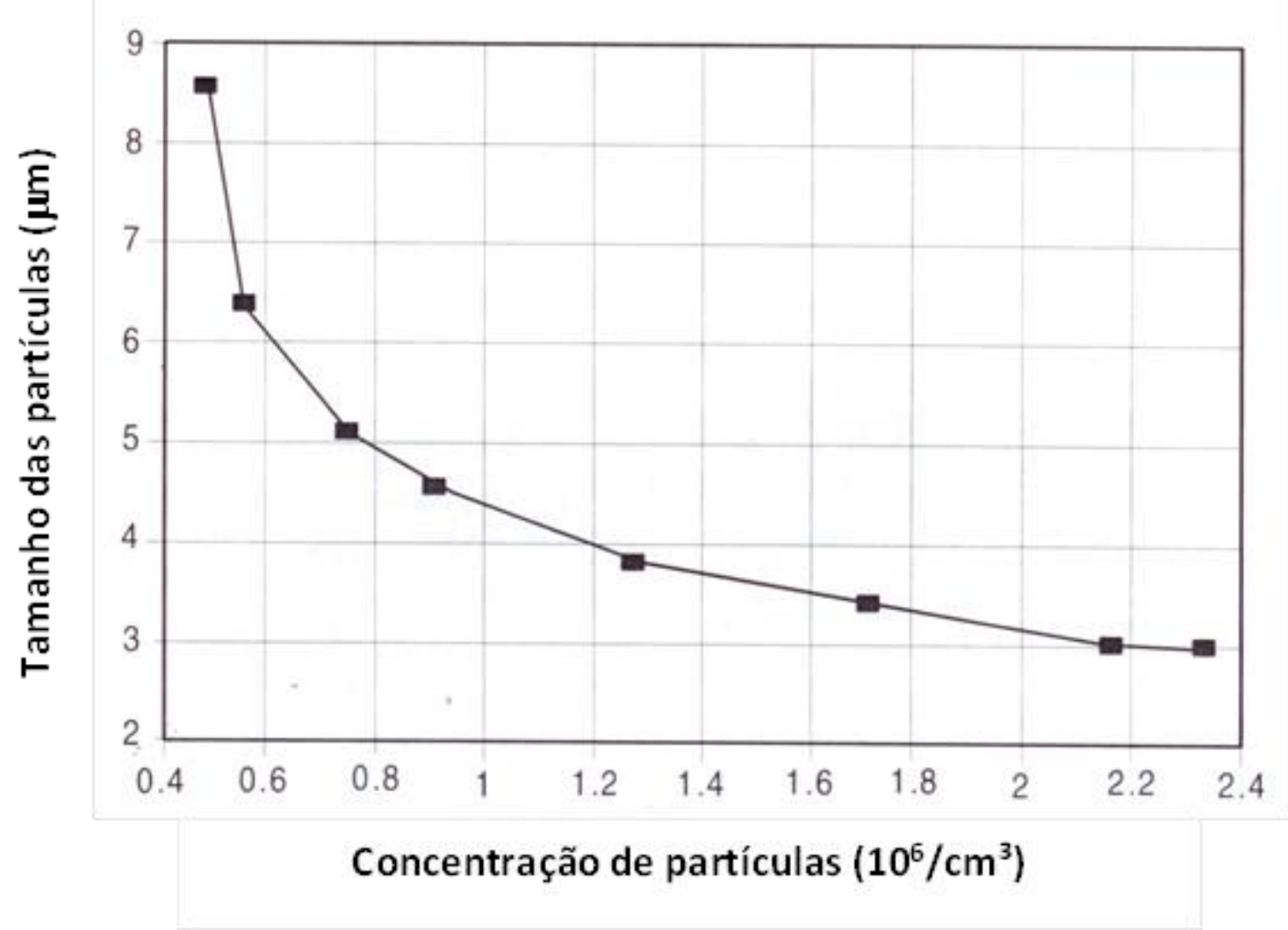

Figura 4.12 - Concentração de partículas em função do tamanho da gotícula produzida pelo gerador TSI modelo 3475 (TSI, 2010) - imagem de catálogo 


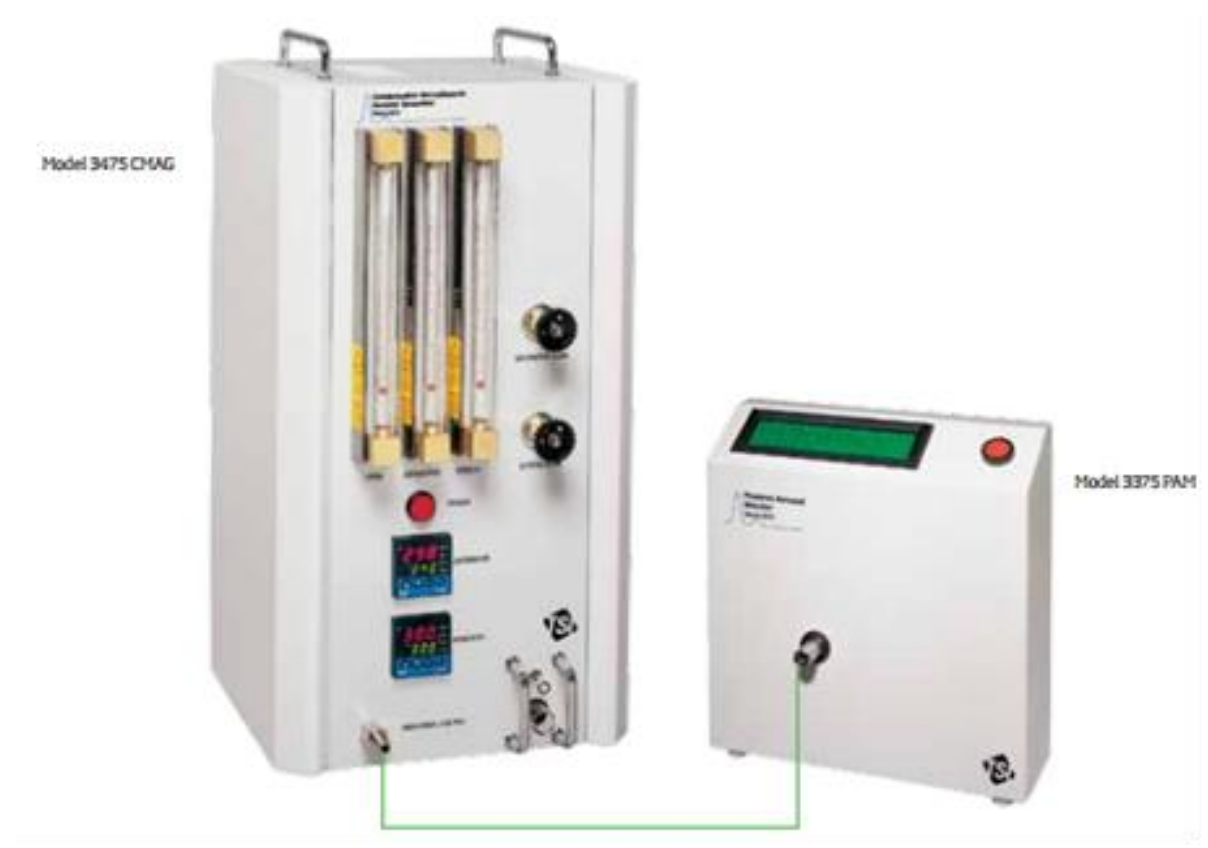

Figura 4.13 - Gerador de aerossol TSI modelo 3475 associado ao indicador de monitoramento de partículas PAM 3375 (TSI, 2010) - imagem de catálogo

O aerossol é gerado com DEHS (Di-etil-hexil-sebacato), que é um líquido com baixa taxa de evaporação e massa específica de $915 \mathrm{~kg} / \mathrm{m}^{3}$ (Hinds, 1999). O fato da geração não ser totalmente monodispersa mostra-se interessante, pois permite a análise da dispersão de partículas também em faixas de tamanhos além das que são propostas no presente trabalho.

$O$ gerador de aerossol necessita de uma fonte de nitrogênio $\left(N_{2}\right)$ para seu funcionamento; um atomizador interno produz um spray a partir de uma solução aquosa de cloreto de sódio. As gotículas geradas passam através de uma coluna de secagem para retirar o excesso de umidade e, posteriormente, para formar um aerossol de alta concentração. Essas partículas seguem para uma unidade de reaquecimento, que serve para assegurar que o excesso de aerossol que não se aglutinou seja completamente vaporizado. Finalmente, as partículas seguem para uma câmara de condensação antes de serem injetadas no ambiente. Todo o processo de geração das partículas, conforme ilustrado na Figura 4.14, requer uma pressão de operação de 6 a 8 bar (equivalente de 87 a 116 psi).

Este equipamento opera com vazão de aerossol entre 3,5 e 4,0 l/min., semelhante à vazão média de ar de inalação e exalação das pessoas (Yan et al., 2009). Considerando que o diâmetro do tubo de saída de aerossol é de aproximadamente $10 \mathrm{~mm}$, a velocidade das partículas na saída do duto é de 
aproximadamente $1 \mathrm{~m} / \mathrm{s}$. Esse mesmo modelo de gerador também foi utilizado por outros pesquisadores em estudos correlatos, dentre eles Zhang et al. (2007); Jones e Nicas (2009); Conceição (2012) e Fabichak Jr. (2013).

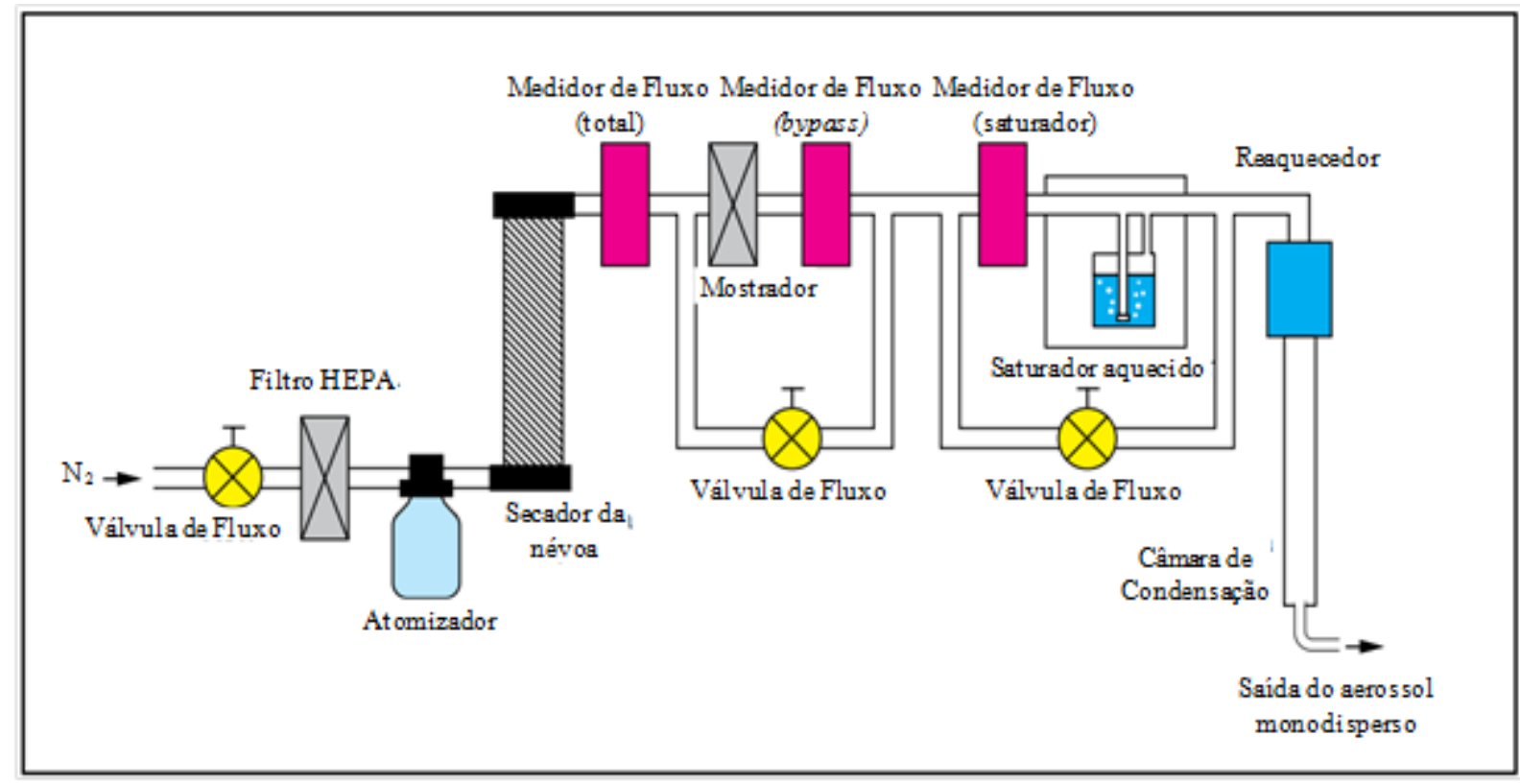

Figura 4.14 - Esquema interno do gerador de aerossol TSI modelo 3475 (TSI, 2010)

\subsubsection{Processo de detecção das partículas}

A medição das partículas será realizada com o auxílio de contadores ópticos da marca Met-One. Os contadores possuem 6 canais para contagem de partículas na faixa de 0,5 a 10,0 $\mu \mathrm{m}(0,5$ a 1,0 $\mu \mathrm{m}$; de 1,0 a $3,0 \mu \mathrm{m}$; de 3,0 a $5,0 \mu \mathrm{m}$; de 5,0 a 7,0 $\mu \mathrm{m}$; de 7,0 a $10,0 \mu \mathrm{m}$ e maior do que $10,0 \mu \mathrm{m}$ ). Portanto, mostram-se adequados, tendo em vista a faixa de partículas geradas pelo gerador TSI modelo 3475 , conforme descrito no item 4.2.5.

O contador opera pelo princípio de dispersão de um feixe luminoso (laser de diodo) ocasionada pela passagem das partículas presentes no ar, aspirado por uma bomba interna do equipamento. Um tubo coletor de partículas com diâmetro interno de $10 \mathrm{~mm}$ acompanha o contador de partículas. Segundo o manual deste equipamento, o erro de coincidência é da ordem $5 \%$ para concentrações de $2,0 \times 10^{6} /$ pés $^{3}\left(7,0 \times 10^{7} / \mathrm{m}^{3}\right)$ e a eficiência de contagem é de $50 \%$ para partículas de $0,3 \mu \mathrm{m}$ e de $100 \%$ para partículas maiores que $0,45 \mu \mathrm{m}$.

Na Figura 4.15 mostra-se os contadores no momento da calibração de contagem zero, com um filtro HEPA conectado ao tubo coletor de partículas por meio de uma 
mangueira flexível de silicone. Esta calibração deve anteceder as medições para avaliar se o contador não possui impurezas aprisionadas nas proximidades do seu sensor ótico que pudessem alterar o resultado das medições. Esta tarefa é executada colocando o contador em operação, forçando o ar amostrado a passar pelo filtro HEPA, retendo considerável parte das impurezas. Assim, espera-se que durante esses testes iniciais, os contadores realizem de fato contagem nula.

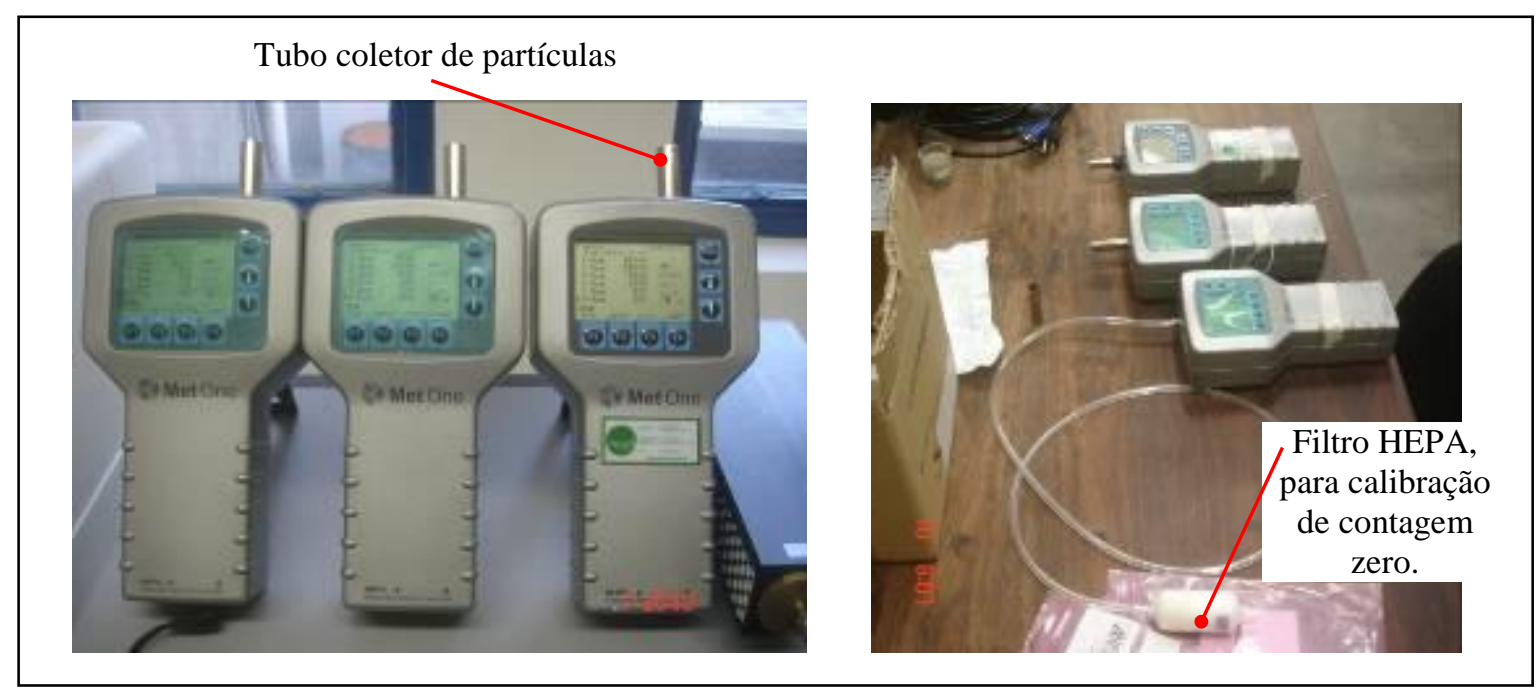

Figura 4.15 - Contadores de partículas da Met-One, modelo HHPC6 (Met-One HHPC6, 2010)

Este equipamento captura $o$ ar do seu entorno por sucção promovida por uma bomba interna com vazão volumétrica de $0,1 \mathrm{cfm}(2,83 \mathrm{\ell} / \mathrm{min}$.). A duração de cada amostragem pode ser definida entre 6 segundos e 10 minutos, o que determina 0 volume total de ar amostrado em cada medição. Já o intervalo entre as amostragens pode ser definido entre 1 segundo e 1 hora. $O$ tempo de duração mais adequado pode variar em função da aplicação específica e deve ser definido empiricamente.

De acordo com informações do catálogo do equipamento, os contadores HHPC-6 possuem um erro de coincidência máximo de $5 \%$ para concentrações até $10^{7} / \mathrm{m}^{3}$, subindo para patamares impraticáveis ao ser operado acima deste limite. Esta informação estabelece, portanto, os limites máximos de operação do equipamento, e são discutidos no capítulo dos resultados da contagem de partículas. Quando o equipamento está exposto a concentrações menores do que este limite, o fabricante informa que as perdas por coincidência são menores do que $5 \%$, porém, não informa o valor exato. 
Conforme artigo técnico publicado pelo fabricante do equipamento (Latimer; Tang, 2012), a incerteza de medição na classificação de tamanhos das partículas coletadas é da ordem 7\%. Porém, como não se sabe o tamanho exato das partículas contadas em cada faixa de medição, esta informação parece não ajudar na definição das incertezas de medição.

Já segundo Hinds (1999), o erro sistemático de um contador de partículas óptico é função, principalmente, do diâmetro da partícula e de seu índice de refração. Como, de fato, os contadores utilizados são calibrados com partículas esféricas de poliestireno látex, que possuem índice de refração de 1,59 (Met-One HHPC6, 2010) ao passo que o aerossol de DEHS contado nos experimentos possui índice de refração de 1,45 (Topas, 2012), este desvio precisaria ser investigado. Porém, com base nos estudos desenvolvidos por Yoo et al. (1996) com contadores ópticos semelhantes ao empregado no presente trabalho, entende-se que uma diferença de aproximadamente 0,15 no índice de refração não deve impactar significativamente nos resultados das medições.

Não obstante, se considerado que a incerteza na contagem de partículas segue a estatística de Poisson (Kulkarniet; Baron; Willeke, 2011), a mesma poderia ser estimada pela raiz quadrada do número de partículas contadas em cada medição.

Cabe ainda ressaltar que foram realizadas algumas avaliações do erro quadrático de Gauss com resultados preliminares da contagem de partículas na cabine, e percebeu-se que este se manteve sempre abaixo de $5 \%$.

Portanto, utiliza-se como valor de incerteza na contagem das partículas ( $\Delta N$ ), o valor numérico combinado ${ }^{1}$ entre os três critérios listados a seguir:

- $\Delta N= \pm \sqrt{N}$ (estatística de Poisson);

- $\Delta N=+5 \% N$ (perdas por coincidência);

- $\Delta N= \pm \sqrt{\frac{\sum\left(N_{i}-\bar{N}\right)^{2}}{n(n-1)}}$ (erro quadrático de Gauss),

em que " $N_{i}$ " é o valor contado em uma dada medição; " $\bar{N}$ " é a média dos valores medidos; e " $n$ " é o número de amostras.

\footnotetext{
${ }^{1} \mathrm{O}$ memorial de cálculo para a incerteza de medição das partículas encontra-se no Apêndice B.
} 


\subsubsection{Variáveis ambientais e condições dos ensaios}

As variáveis críticas referentes ao ensaio são aquelas que estão relacionadas com o ambiente interno do mock-up. A norma ISO 7726 (ISO, 1998) apresenta recomendações de procedimento para realizar a medição das variáveis ambientais (temperatura, umidade, velocidade e vazão de ar). Além disso, para garantir as condições propostas no set-up do sistema, deve-se atentar às recomendações do fabricante do sistema de ar condicionado, que em geral, recomenda o monitoramento das variáveis ambientais até sua estabilização, cujo tempo médio costuma ser em torno de 10 a 15 minutos para que as condições ambientais tornem-se estáveis (Zhang; Chen, 2007; Zhang et al., 2007; Stancato, 2009; Conceição, 2012; Fabichak Jr., 2013). Esse procedimento deve ser adotado também quando o sistema for submetido à mudança de qualquer uma das variáveis acima mencionadas. São apresentados a seguir cada uma das condições utilizadas nos ensaios.

\subsubsection{Temperatura do ar de insuflamento e das paredes do mock-up}

As temperaturas do ar insuflado no mock-up foram estabelecidas em conformidade com a norma ASHRAE 161 (ASHRAE, 2007), que recomenda temperaturas de cabine entre $18^{\circ} \mathrm{C}$ a $24^{\circ} \mathrm{C}$, com tolerância de $\pm 1,1^{\circ} \mathrm{C}$. Para ser possível manter a temperatura de cabine dentro destes limites, em geral a temperatura do ar de insuflamento no interior das aeronaves é mais baixa, denotando a sensação de frio que grande parte dos ocupantes costuma sentir neste tipo de ambiente. Deste modo, o acionamento do sistema personalizado serviria para fornecer ao usuário condições de se sentir termicamente confortável. Com base nisso, as condições de temperaturas definidas para os ensaios foram:

- Temperatura de insuflamento do ar do sistema global de $18,0^{\circ} \mathrm{C} \pm 0,5^{\circ} \mathrm{C}$ : simulação de leve condição de frio;

- Temperatura de insuflamento do ar do sistema personalizado de $24,0^{\circ} \mathrm{C} \pm 0,5^{\circ} \mathrm{C}$ : simulação de condição para atingir conforto térmico na busca de condição de microclima para o passageiro, resultando em temperatura intermediária, mais próxima da neutralidade térmica. 


\subsubsection{Umidade relativa do ar}

Conforme mencionado no Capitulo 2, a umidade relativa do ar em cabines de aeronaves pode atingir valores extremamente baixos, muitas vezes abaixo dos $10 \%$ (Strom-Tejsen et al., 2005; Grun et al., 2008; Zhang et al., 2007; Stancato, 2009).

Por outro lado, nos ensaios realizados a umidade relativa do ar não tem influência significativa na concentração de partículas dispersas no ambiente (Conceição, 2012; Fabichak Jr., 2013), pois o tipo de partícula gerada utiliza um fluido com baixa taxa de evaporação para geração do aerossol (Hinds, 1999). De qualquer forma, a umidade relativa do ar é monitorada ao longo dos ensaios, de modo que o ambiente interno do mock-up esteja o mais fielmente representado possível em todos os ensaios.

\subsubsection{Vazão do ar de insuflamento e de renovação}

Em todas as três arquiteturas de distribuição de ar propostas, a vazão de ar de insuflamento da cabine será a mesma e em conformidade com os valores preconizados na norma ASHRAE 161 (ASHRAE, 2007), que estabelece um limite de 9,6 l/s/ocupante. Considerando que a cabine do mock-up comporta até 12 pessoas, a vazão total de ar é controlada para fornecer aproximadamente $415 \mathrm{~m}^{3} / \mathrm{h}(244 \mathrm{cfm}) \mathrm{de}$ ar para o ambiente, tendo o equivalente a 22 renovações completas de ar por hora.

Conforme ressaltado no Capitulo 2, na maioria das aeronaves comerciais, 50\% do ar fornecido ao passageiro é recirculado como forma de melhorar o controle da circulação do ar na cabine, a umidade e a eficiência da aeronave no consumo de combustível. Para controlar a quantidade de partículas devido à recirculação, filtros HEPA são instalados nos dutos de recirculação para reter os contaminantes gerados na cabine.

No presente trabalho, contudo, conforme descrito no item 4.2.1, o sistema de climatização do mock-up conta com sistema de exaustão, instalado na linha de retorno do ar, que permite a exaustão e renovação de $100 \%$ do ar do mock-up. Assim, não há a necessidade da instalação de filtro HEPA para retenção das partículas geradas na cabine, que são eliminadas na exaustão.

Paralelamente, o sistema de filtragem instalado na linha de insuflamento do ar na cabine impede a passagem de partículas acima de 5,0 $\mu \mathrm{m}$. Medições de partículas no ar insuflado no mock-up mostraram valores bastante baixos para partículas entre 3,0 
e 5,0 $\mu \mathrm{m}$ (Fabichak Jr., 2013). Portanto, também não há a necessidade de instalação de filtro adicional no sistema de climatização.

\subsubsection{Procedimentos de medição e instrumentação}

A seguir é detalhado o processo de medição das variáveis críticas, apresentada a instrumentação utilizada e discutidos os procedimentos de ensaio realizados em conformidade com a norma ISO 7726 (ISO, 1998).

\subsubsection{Medição da velocidade e da temperatura do ar no mock-up}

A velocidade e a temperatura do ar foram obtidas a partir de medições com 0 sistema Comfort Sense da Dantec Dynamics, mostrado na Figura 4.16. Foram utilizados três transdutores, compostos de três sondas omnidirecionais para medição de velocidades do ar com frequência de resposta de $5 \mathrm{~Hz}$ e com sensores de temperatura de resposta rápida integrados, com intervalo de operação de 0,05 até $10 \mathrm{~m} / \mathrm{s}$ e de $-20^{\circ} \mathrm{C}$ até $70^{\circ} \mathrm{C}$, e incertezas de medição de, respectivamente, $\pm(0,02+$ $0,02 \mathrm{~V}) \mathrm{m} / \mathrm{s}$ e $\pm 0,2^{\circ} \mathrm{C}$, que atendem aos requisitos de precisão de equipamentos da norma ISO 7726 (ISO, 1998).

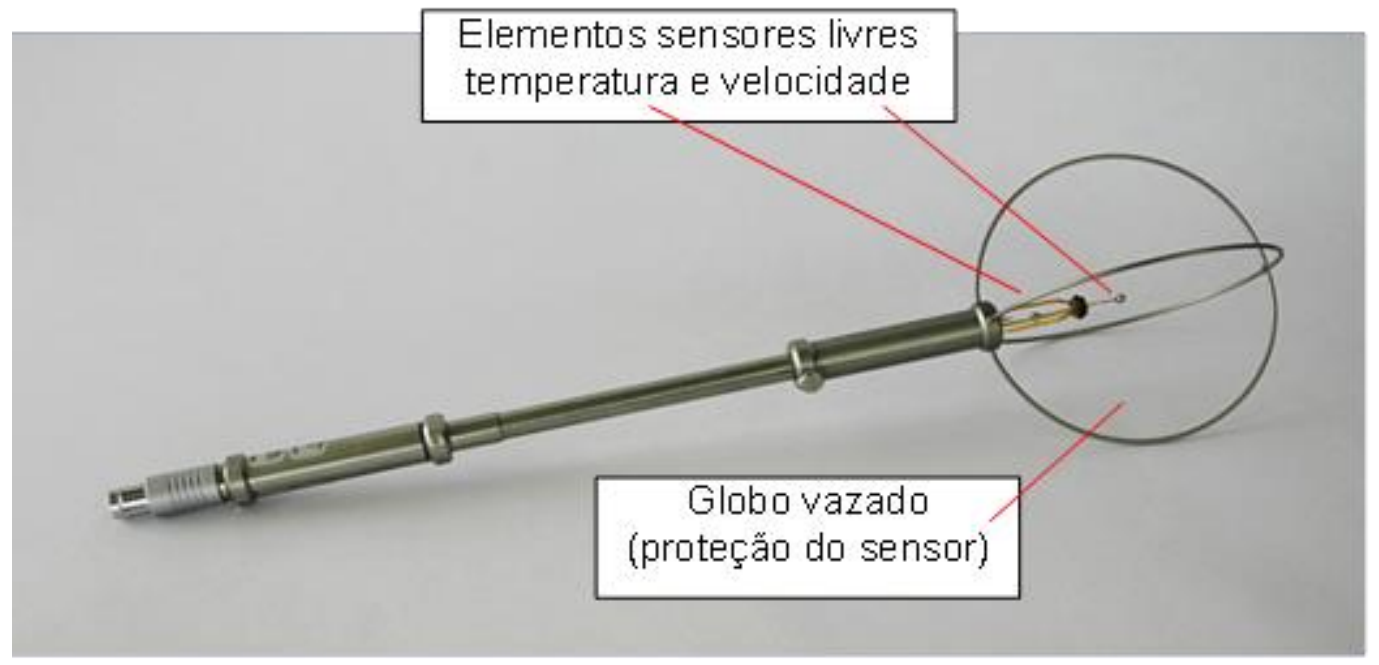

Figura 4.16 - Sensor de anemômetro omnidirecional (elemento sensor livre)

As medidas foram realizadas em três pontos longitudinais, abordando as fileiras 1,2 e 3, contidas nas cinco retas transversais, colunas $A, B, C, D$ e $E$, seguindo a recomendação da ASHRAE 55 (ASHRAE, 2013) com medição nas alturas de $0,10 \mathrm{~m}, 0,60 \mathrm{~m}$ e 1,10 $\mathrm{m}$ a partir do piso, correspondendo à região dos pés e 
tornozelos, das mãos e braços e do pescoço e cabeça, respectivamente, de uma pessoa sentada. Para a situação de pessoas em pé (corredor) é adotada altura de 1,60 m. A disposição dos transdutores de velocidade no mock-up é mostrada na Figura 4.17.

Para exemplificar, na Figura 4.18 mostra-se a disposição das sondas do Comfort Sense. Na Figura 4.19 e na Figura 4.20 mostram-se a instalação das três sondas na cabine.

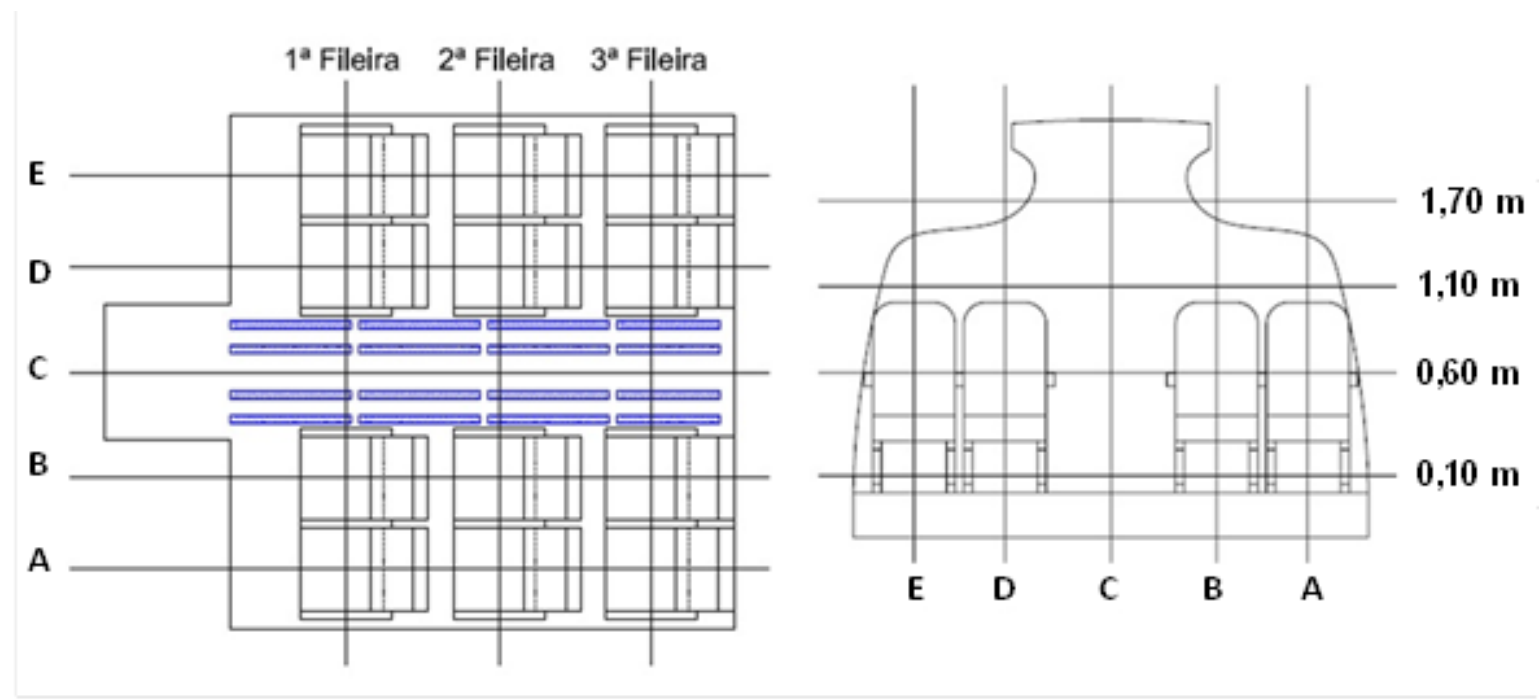

Figura 4.17 - Distribuição dos pontos de temperatura e de velocidade do ar

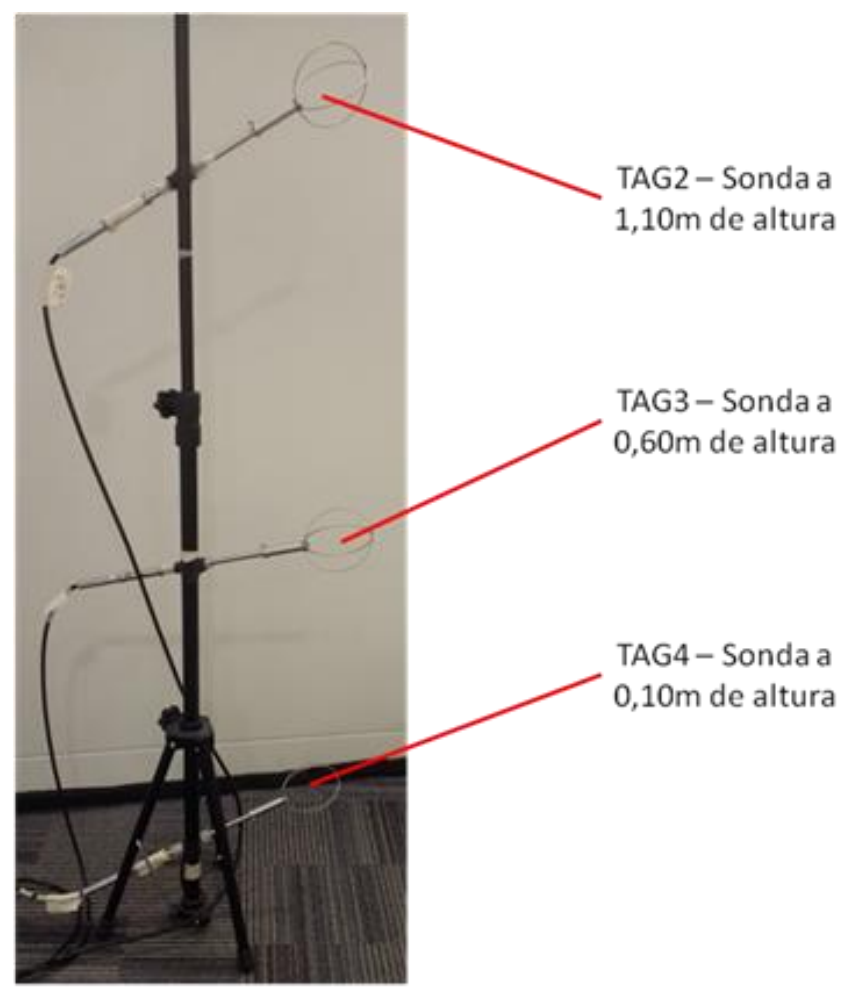

Figura 4.18 - Pedestal para posicionamento da sondas do Comfort Sense 


\subsubsection{Medição da temperatura das paredes do mock-up}

As temperaturas superficiais das paredes do mock-up também foram medidas e monitoradas por meio de termopares tipo $\mathrm{T}$ (cobre/constantan), bitola AWG 8 $(\varnothing=3,26 \mathrm{~mm})$ e haste de $200 \mathrm{~mm}$ de comprimento, com faixa de operação de $-270{ }^{\circ} \mathrm{C}$ a $370{ }^{\circ} \mathrm{C}$ e f.e.m. (força eletromotriz) de $-6,258 \mathrm{mV}$ a 20,872 mV. Os termopares foram conectados a um Data-Logger modelo Agilent 34970A. Um dos termopares foi posicionado no duto de insuflamento para comparar os valores com o transmissor do sistema de automação e controle.

O Data-Logger possui um programa de computador para a aquisição de dados denominado Agilent Bench Link Data Logger 3, que permiti configurar os canais (termopares) que são utilizados para monitorar a temperatura das superfícies. $O$ programa também gera, em tempo real, o gráfico da temperatura da parede e do ar de insuflamento em função do tempo. Essa função é importante para estabelecer se as temperaturas das paredes encontram-se em regime permanente (condição de estabilidade).

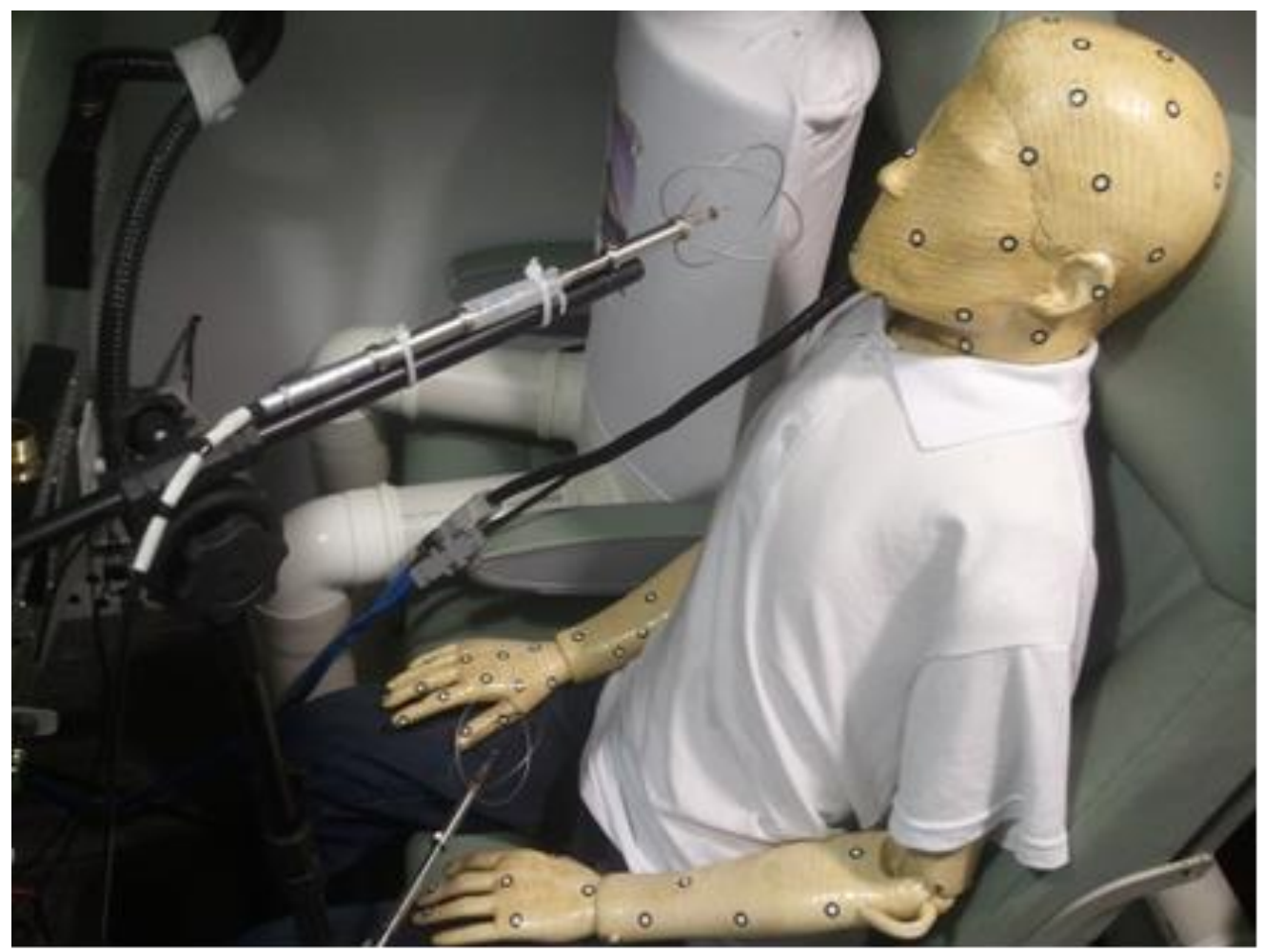

Figura 4.19 - Posicionamento das sondas para medição de temperatura e velocidade do ar na altura de $0,60 \mathrm{~m}$ e de $1,10 \mathrm{~m}$ a partir do piso (Fabichak Jr., 2013) 


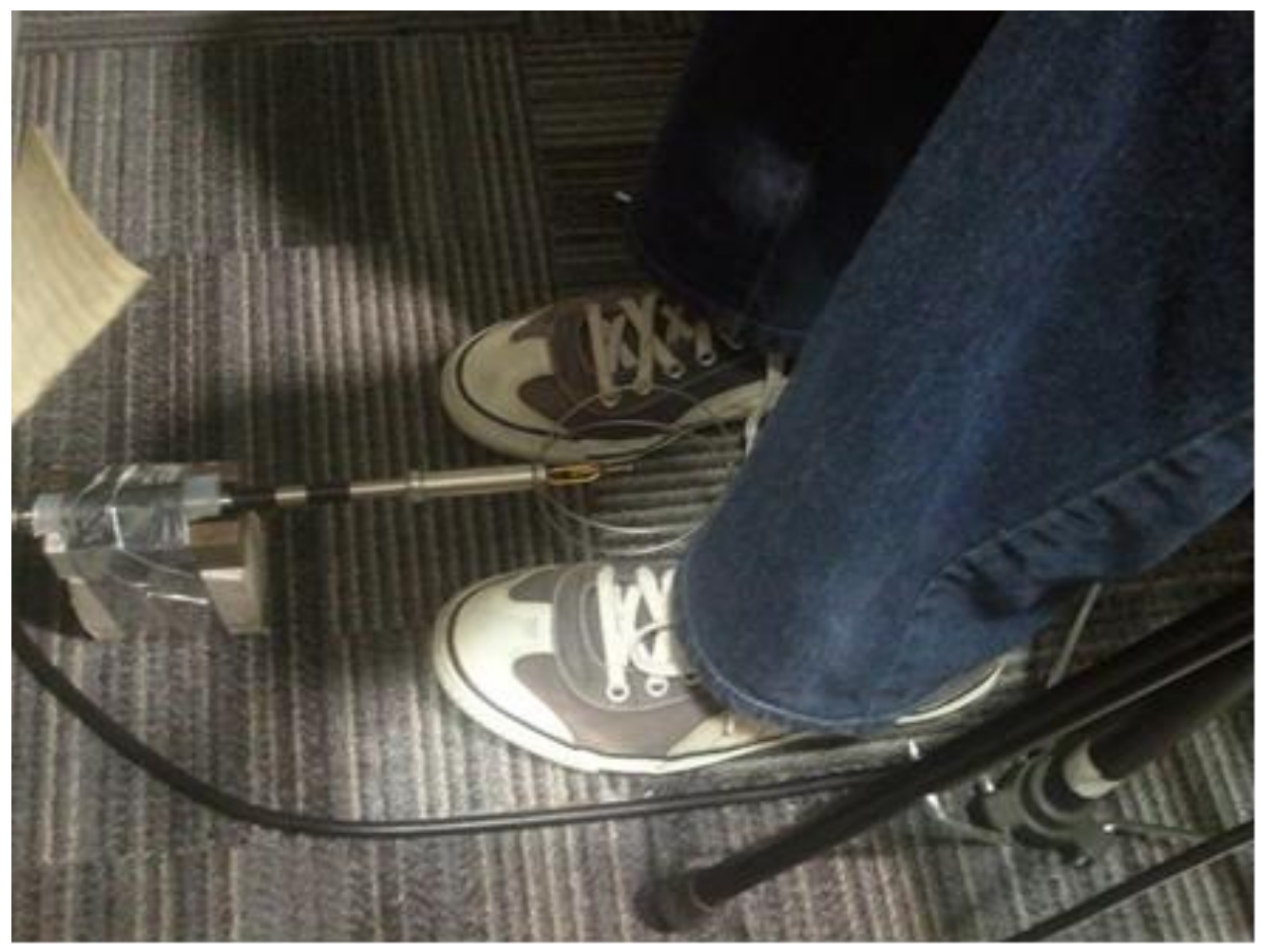

Figura 4.20 - Posicionamento das sondas para medição de temperatura e velocidade do ar na altura de $0,10 \mathrm{~m}$ a partir do piso (Fabichak Jr., 2013)

\subsubsection{Medição da vazão de ar no mock-up}

A vazão de ar da cabine é determinada e monitorada a partir da medição de velocidade do ar nos dutos de exaustão do ar da cabine utilizando tubos de Pitot, mostrados na Figura 4.21. Foi projetado um sistema composto por um conjunto de manômetros diferenciais e tubos de Pitot instalados em tubos de PVC de $100 \mathrm{~mm}$ de diâmetro nas linhas de exaustão.

O tubo de Pitot utilizado é da série 160 de aço inoxidável. Os manômetros diferenciais, mostrados na Figura 4.22, são do fabricante Dwyer. A conexão dos tubos de Pitot com os manômetros foi realizada com mangueiras transparentes de silicone com diâmetro de 5/16". Foi realizado memorial de cálculo ${ }^{2}$ para converter o valor da diferença pressão manométrica em vazão.

\footnotetext{
${ }^{2} \mathrm{O}$ memorial de cálculo encontra-se no Anexo A.
} 


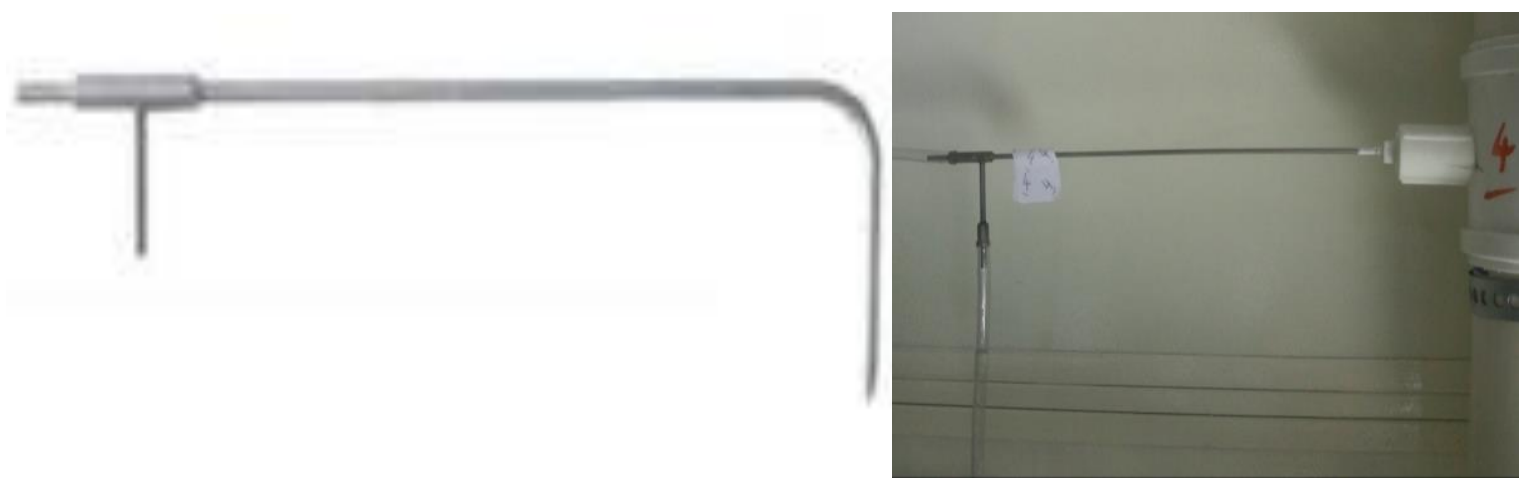

Figura 4.21 - Vista dos tubos de Pitot antes e após a instalação (Fabichak Jr., 2013)

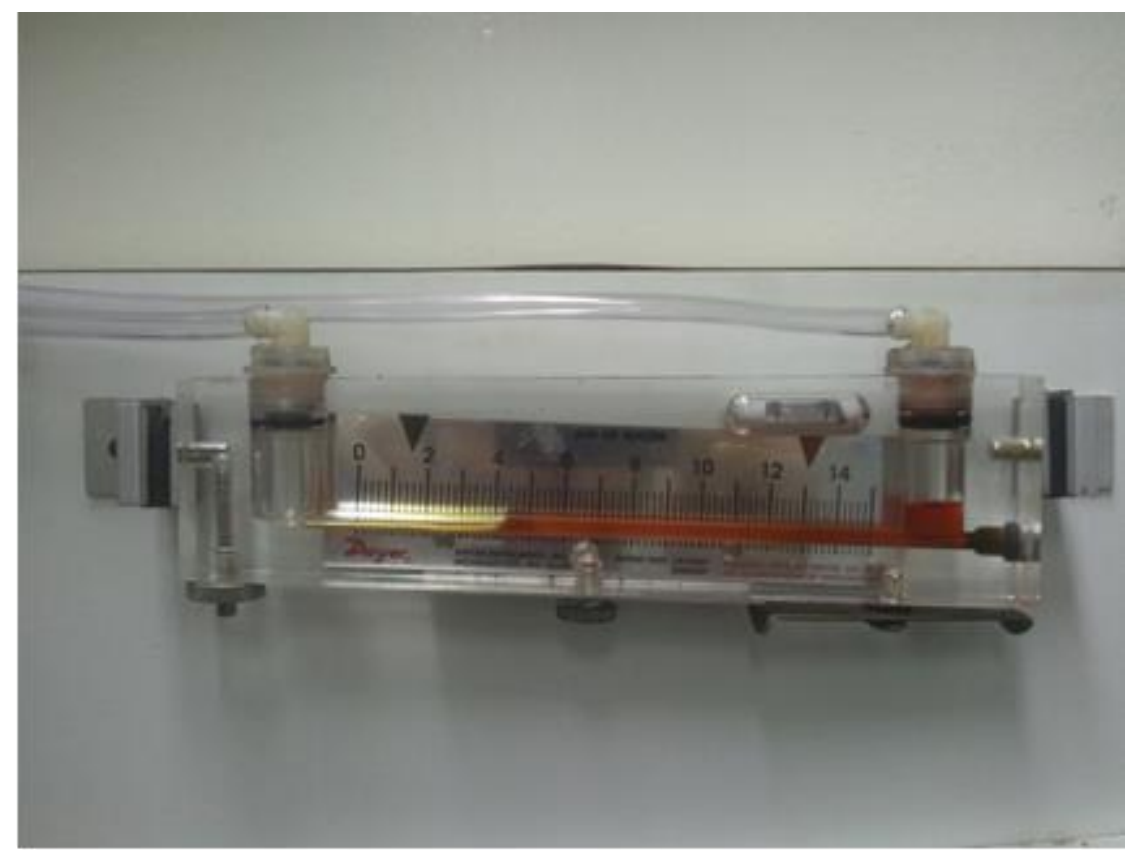

Figura 4.22 - Manômetro diferencial para a determinação e monitoramento da vazão de ar (Fabichak Jr., 2013)

$\mathrm{Na}$ entrada das linhas de exaustão (saídas do mock-up) foram instaladas telas metálicas retificadoras de fluxo e a 1000 mm (correspondente a 10 diâmetros dos dutos de PVC) das telas retificadoras foram instalados os tubos de Pitot, para garantir condições de perfil completamente desenvolvido no local de medição de velocidades máximas do ar no centro dos dutos (Fox; Mc Donald; Pritchard, 2006).

Uma vez que cada linha de exaustão do ar é independente uma da outra, a vazão total foi calculada como a soma das vazões em cada linha. Este fato é importante, pois permite ajustar, de forma independente, a vazão de ar conforme a necessidade de cada ensaio. 


\subsubsection{Medição da vazão de ar no sistema personalizado}

Para a medição da vazão de ar no sistema personalizado, foi utilizado um medidor de fluxo de massa do fabricante Contech, modelo FT2. Este equipamento é um fluxômetro de massa térmica que contem um transdutor de temperatura. $O$ sensor aquecido é colocado junto a uma sonda com comprimento calibrado e introduzido dentro da tubulação do sistema de ventilação personalizada, de modo a permanecer exatamente no centro da tubulação. Um segundo sensor, isolado e calibrado sob uma temperatura de referencia pré-definida, é mantido a uma temperatura constante. A diferença de temperatura entre os dois sensores é monitorada pelo sistema de controle que gera uma diferença de potencial, que é lida pelo circuito interno a uma frequência máxima de $100 \mathrm{~Hz}$. Este circuito faz a respectiva conversão do valor da diferença de potencial para velocidade da massa de fluido que está sendo lida instantaneamente. Como são conhecidos os valores da velocidade do ar, da área do volume de controle onde está localizada a sonda e da temperatura do ar, o sistema de controle faz o cálculo e exibe no display do equipamento o valor instantâneo da vazão mássica de ar, medido em Normal Metro Cúbico por unidade de tempo. A Figura 4.23 mostra a configuração do equipamento e na Figura 4.24, é mostrada a sua instalação nos dutos do sistema personalizado do mock-up.

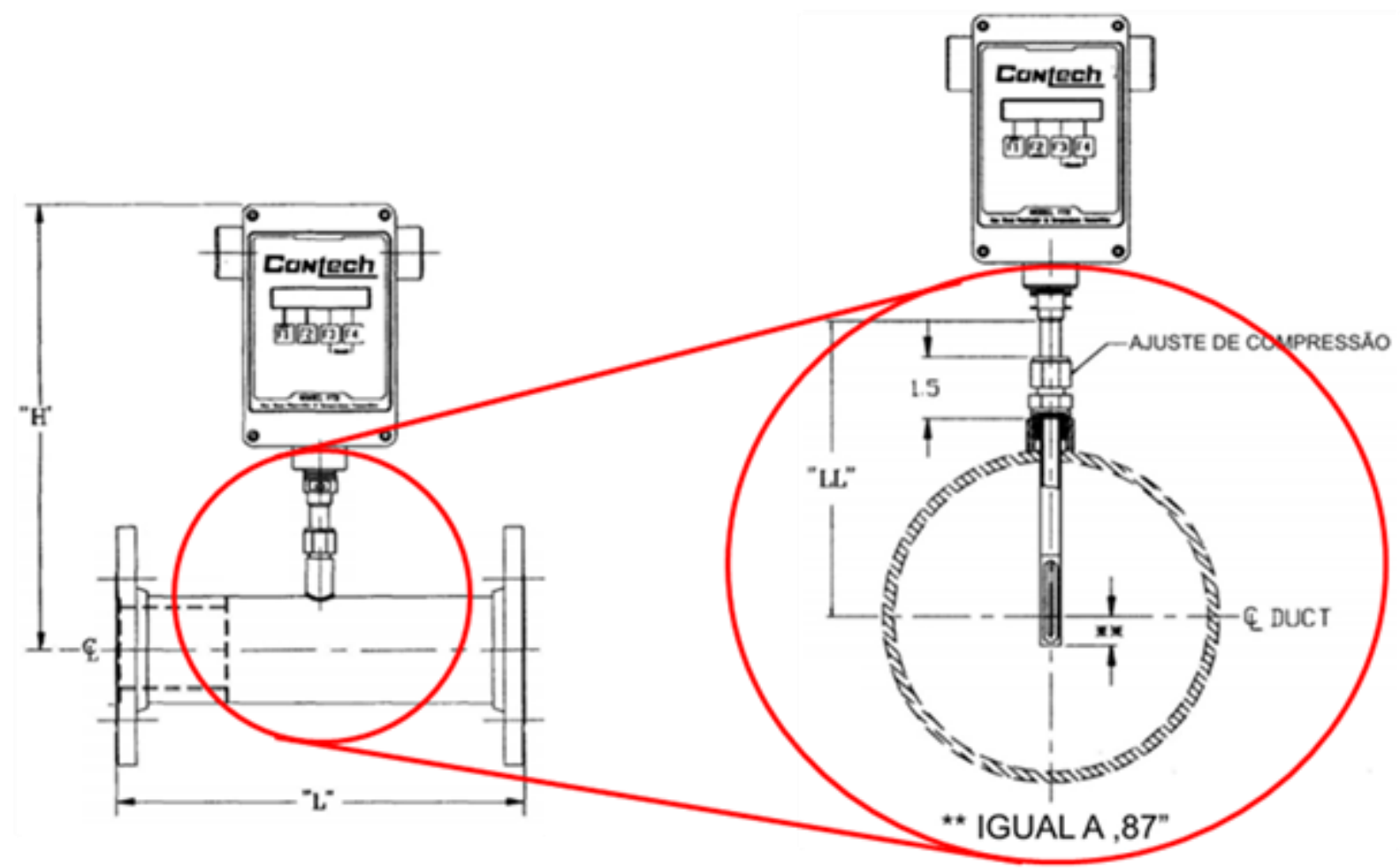

Figura 4.23 - Configuração para instalação do medidor de vazão - imagem de catalogo 


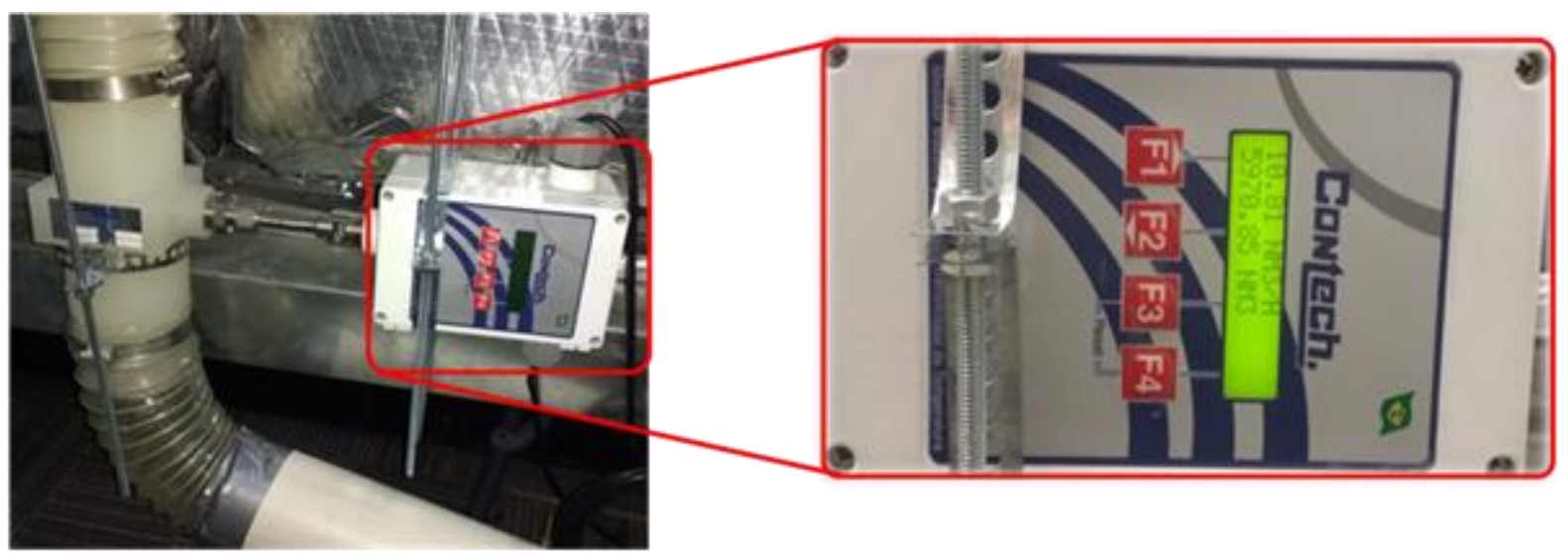

Figura 4.24 - Instalação do medidor de vazão - em detalhe, valor da vazão no sistema personalizado

\subsubsection{Processo de geração e de medição da concentração de partículas}

Para minimizar influências no escoamento do ar no interior da cabine, o gerador de aerossol foi posicionado externamente ao mock-up, e o aerossol gerado injetado no ambiente interno da cabine mediante tubos metálicos e mangueiras de silicone de 10 mm de diâmetro interno, como ilustrado no detalhe na Figura 4.25.

O tamanho e a concentração das partículas geradas foram constantemente monitorados com o uso do monitor PAM 3475. Este procedimento é de importância fundamental, porque assim pode-se garantir que em todos os testes sejam realizados com a mesma quantidade e concentração de partículas geradas e injetadas no ambiente.

Adotando procedimento similar ao realizado por Wan, Chao e Fang (2005) e Fabichak Jr. (2013), a injeção das partículas, simulando pessoa liberando partículas expiratórias ao tossir, foi feita, inicialmente, na poltrona junto à fuselagem e, posteriormente, na poltrona do passageiro sentado junto ao corredor. As partículas foram injetadas a $1,10 \mathrm{~m}$ a partir do piso, que corresponde à zona de respiração das pessoas, nas posições 3A e 3B, respectivamente, como ilustrado na Figura 4.26.

$\mathrm{Na}$ medição da concentração de partículas em cada poltrona do mock-up, os contadores de partículas também foram posicionados na zona de respiração dos manequins a $1,10 \mathrm{~m}$ do piso, como mostra a Figura 4.27. 
a)

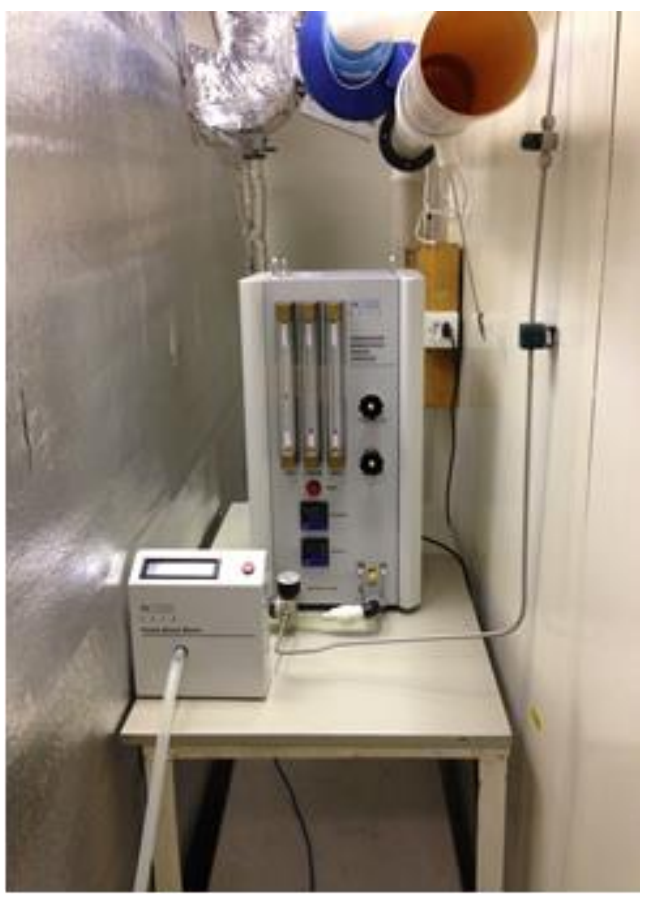

b)

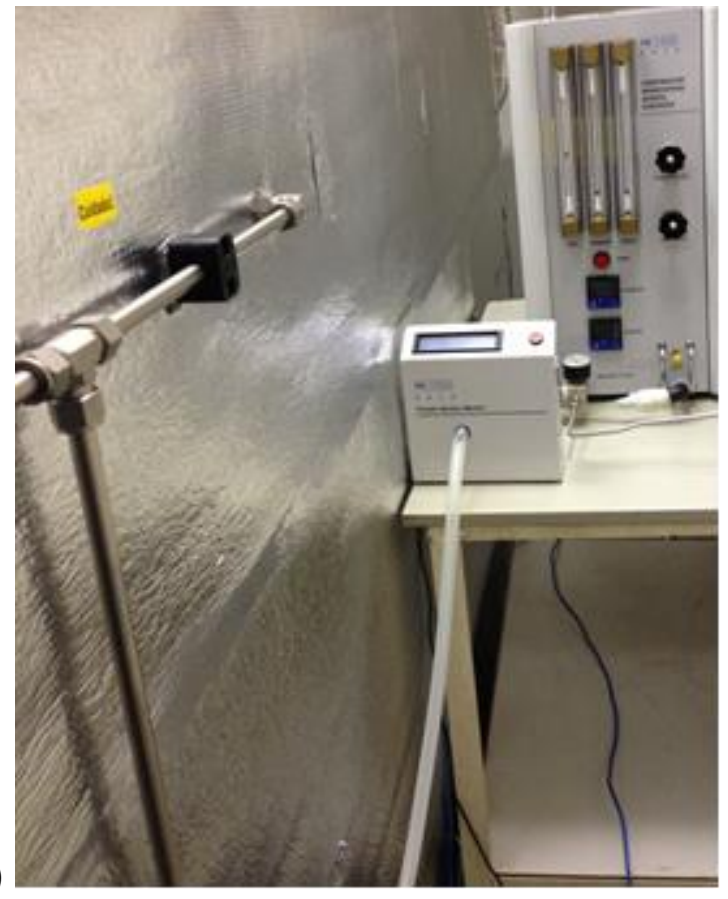

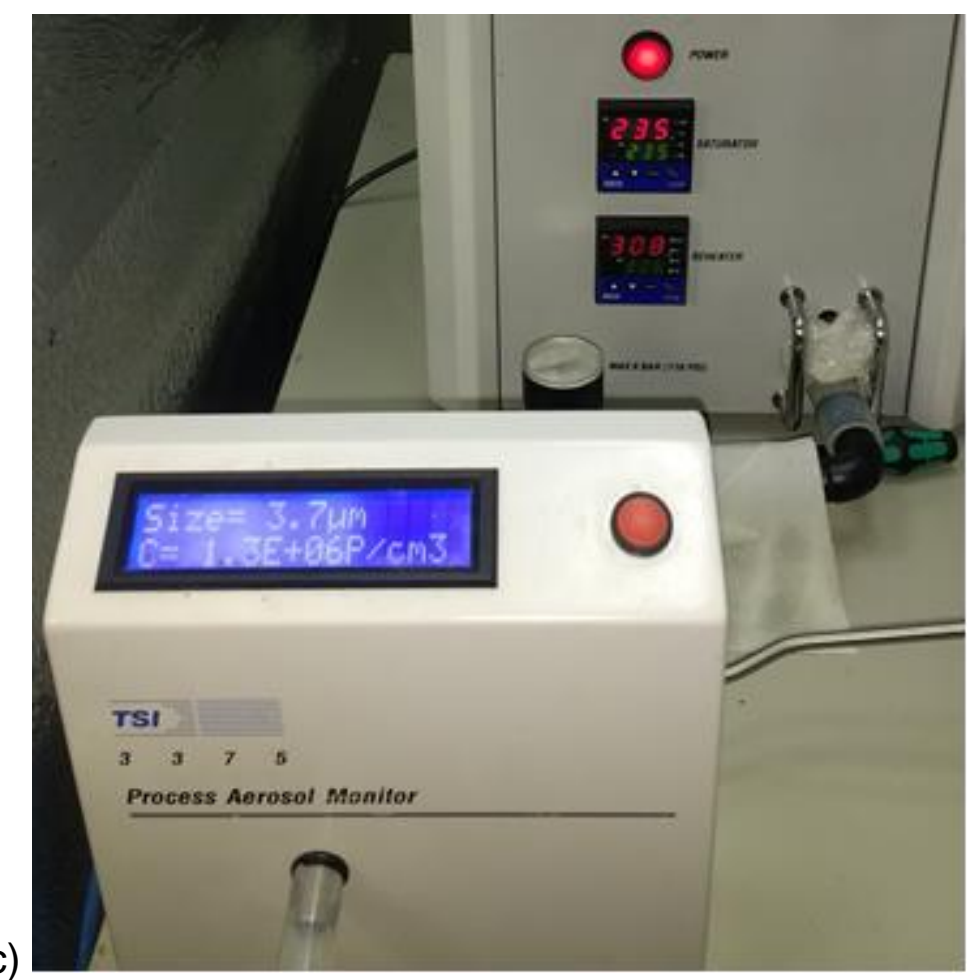

Figura 4.25 - Gerador de aerossol TSI modelo 3475 e monitor PAM 3375:

(a) Posicionamento externo ao mock-up; (b) Detalhe dos tubos e mangueiras de conexão;

(c) Detalhe da medição do tamanho e da concentração das partículas 


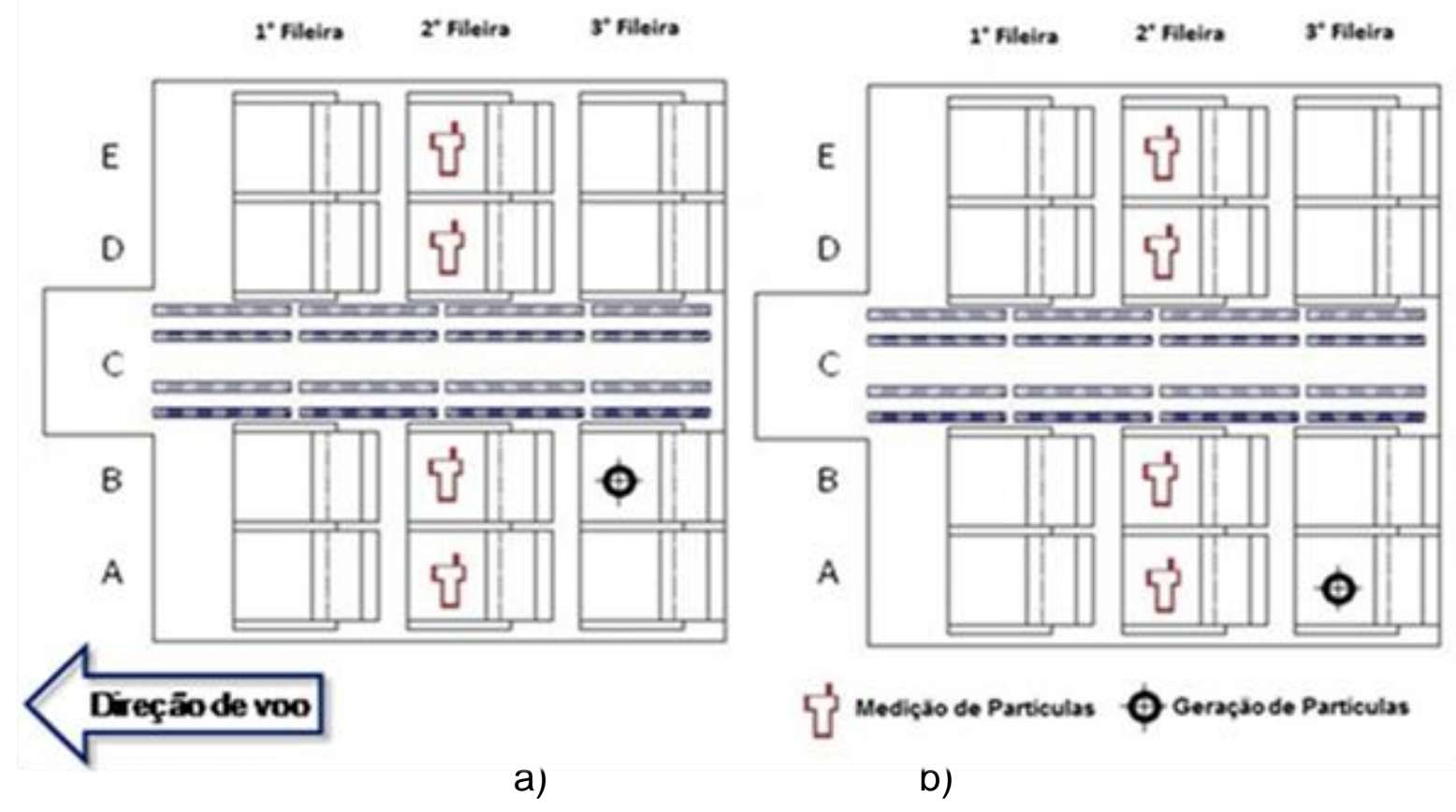

Figura 4.26 - Pontos de injeção e de medição das partículas no mock-up: (a) injeção de partículas pela poltrona 3A; (b) injeção de partículas pela poltrona 3B

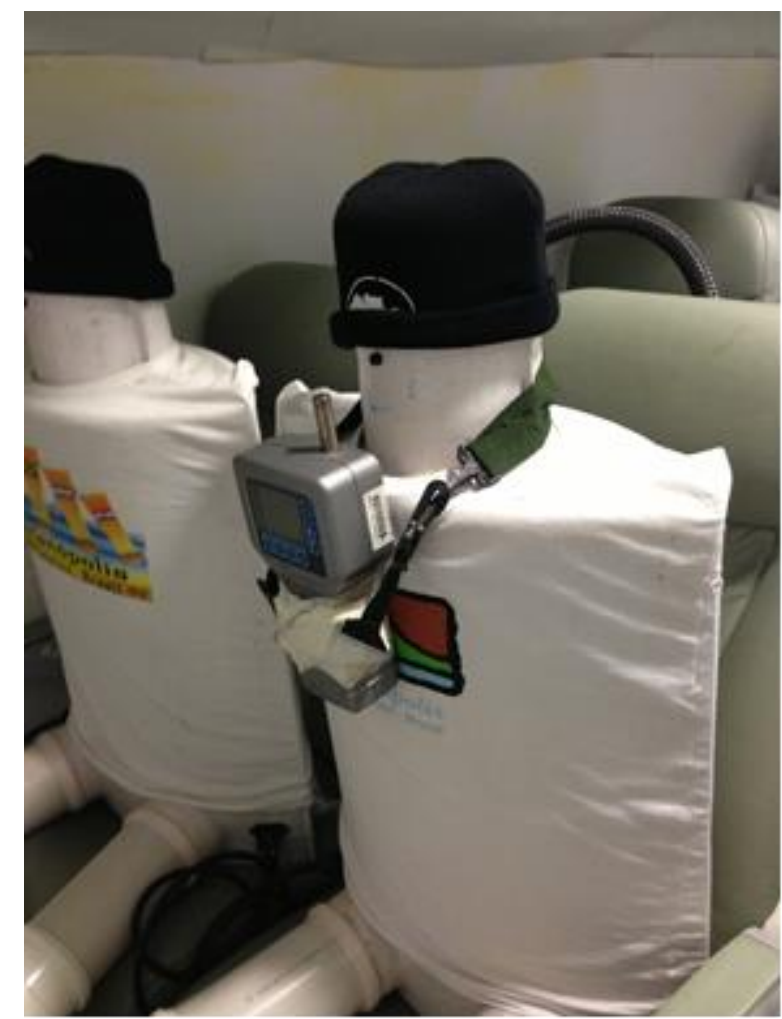

Figura 4.27 - Posição dos contadores de partículas 


\subsubsection{Intervalo entre as medições e tempo de medição das partículas}

O intervalo entre medições é função do tamanho das partículas analisadas. Quanto menor o tamanho das partículas, maior o tempo para a sua deposição após a ressuspensão causada pela movimentação no interior da cabine na troca da posição do contador de partículas.

Fabichak Jr. (2013) verificou a necessidade de 10 minutos para que ocorra a estabilização de partículas maiores que $3 \mu \mathrm{m}$, que também é a situação de estudo no presente trabalho. O tempo de medição também foi de 10 minutos, que é o mesmo tempo adotado na medição da velocidade e da temperatura do ar e de partículas por Zhang et al. (2007).

Os contadores foram ajustados para coletar partículas em intervalos de 30 segundos entre cada coleta. Portanto, durante o período de cada ensaio, 0 contador registrou 20 medições por assento em cada uma das arquiteturas realizadas.

\subsubsection{Repetitividade dos ensaios}

Para aumentar a confiabilidade das medições e dos resultados, para cada uma das arquiteturas propostas, os ensaios foram repetidos em três dias diferentes.

\subsubsection{Sequência experimental}

A seguir é apresentada a sequência experimental para efetuar as medições, apresentada na forma de rotina:

- Inicialmente, são ajustadas as válvulas dos dutos de insuflamento e exaustão do ar para a arquitetura em estudo;

- Em seguida, é ligado o sistema de automação e controle e demais equipamentos e configurados todos os parâmetros para o ensaio;

- Depois, são ligados os manequins aquecidos para iniciar o processo de estabilização;

- Feito isso, são ligados os ventiladores instalados nos dutos de exaustão do mock-up; 
- Em seguida, são realizadas medições da diferença de pressão nos manômetros diferenciais e realizados cálculos de vazão de ar, para o ajuste das vazões utilizando os dampers instalados em cada linha de exaustão;

- Depois, é iniciado o registro de dados do sistema de automação e controle e no Data Logger para determinar o período de estabilização das condições ambientais na cabine;

- Nesse momento, o gerador de partículas é ligado para que sua resistência seja aquecida, configurando-o para a geração do diâmetro e da concentração de partículas desejados;

- Feito isso, as sondas omnidirecionais são posicionadas na posição a ser medida, simultaneamente com o contador de partículas, colocados próximos à zona de respiração (a 1,10 m do piso);

- Após a estabilização das condições ambientais na cabine, são efetuadas as medições para cada uma das posições do plano de medição do mock-up;

- Finalizadas as medições, são efetuados os registros e armazenamento dos dados;

- Finalmente, verifica-se novamente a diferença de pressão nos manômetros para assegurar que não houve variação durante os ensaios e;

- Após as etapas anteriores, os equipamentos são desligados e o processo de medição é concluído.

\subsection{Resumo do procedimento nos ensaios}

Os ensaios realizados consistiram em reproduzir no mock-up as condições ambientais de cabines de aeronaves em situações normais de vôo. Embora a norma ASHRAE 161 (ASHRAE, 2007) permita que os limites de temperatura de cabine variem de $18^{\circ} \mathrm{C}$ a $24^{\circ} \mathrm{C}$, optou-se por trabalhar com valores de temperatura de cabine intermediários ou mais próximos do limite inferior da faixa recomendada. Essa escolha é justificada sob os seguintes pontos de vista: 
- Conforme mencionado no item 3.4, os filtros HEPA tem maior eficácia quando trabalham em temperaturas ligeiramente mais baixas à zona de conforto térmico. Em aeronaves convencionais o ar recirculado pode ser um fator indicativo de má qualidade do ar interno quando os filtros passam a não reter de forma adequada as partículas coletadas do ambiente interior. Deste modo, é importante simular esta condição durante os ensaios;

- Obriga a insuflar o ar em uma temperatura bem abaixo da faixa de conforto térmico. No caso do mock-up utilizado, a carga térmica gerada pelos manequins aquecidos requereu que a temperatura do ar de insuflamento fosse de $18^{\circ} \mathrm{C}$. Deste modo, a temperatura de cabine no interior do mock-up manteve-se na faixa entre $21^{\circ} \mathrm{C}$ e $23^{\circ} \mathrm{C}$ durante todos os ensaios, reproduzindo uma condição frequentemente encontrada em situações normais de voo. Esta situação de leve sensação de frio, também justifica a utilização do sistema personalizado proposto, como medida paliativa a propiciar condições de conforto térmico ao ocupante do assento avaliado;

- Em trabalhos anteriores, foi visto que as partículas expiratórias tendem a se dispersar por maiores distâncias quando, dentre os muitos fatores, a temperatura de insuflamento do ar é mais baixa. Logo, entende-se que esta condição, não somente é a mais comum como também é a mais critica para os ocupantes.

O procedimento de ensaio foi realizado, inicialmente, somente com o sistema MV em funcionamento, sendo esta a condição padrão. Nesta condição, ilustrada na Figura 4.28, foi feito todo o mapeamento térmico do mock-up, sendo medidas a temperatura e a velocidade do ar em toda a $2^{\underline{a}}$ fileira de assentos e também no corredor, nas cotas de altura de $0,10 \mathrm{~m}, 0,60 \mathrm{~m}$ e 1,10 m. Adicionalmente, nas três posições do corredor foi realizada medição também na altura de 1,60 m, equivalente à zona de respiração de um passageiro em pé.

Após esta etapa, o gerador de partículas foi ajustado para insuflar no ambiente as partículas expiratórias no tamanho e na concentração mencionadas no item 4.2.5. As partículas expiratórias foram insufladas, primeiramente no assento da terceira fileira (posição 3B) próximo ao corredor. A contagem das partículas expiratórias foi feita na zona de respiração dos manequins posicionados na fileira imediatamente à frente do ponto de injeção, em todos os assentos (posições $2 \mathrm{~A}$ a $2 \mathrm{E}$ ). O procedimento 
foi repetido, desta vez considerando-se a injeção das partículas feita pelo assento da terceira fileira junto da fuselagem lateral do mock-up (posição 3A) e a contagem das partículas expiratórias foi feita do mesmo modo, isto é, na zona de respiração dos manequins posicionados na fileira imediatamente à frente do ponto de injeção, em todos os assentos (posições 2A a 2E).

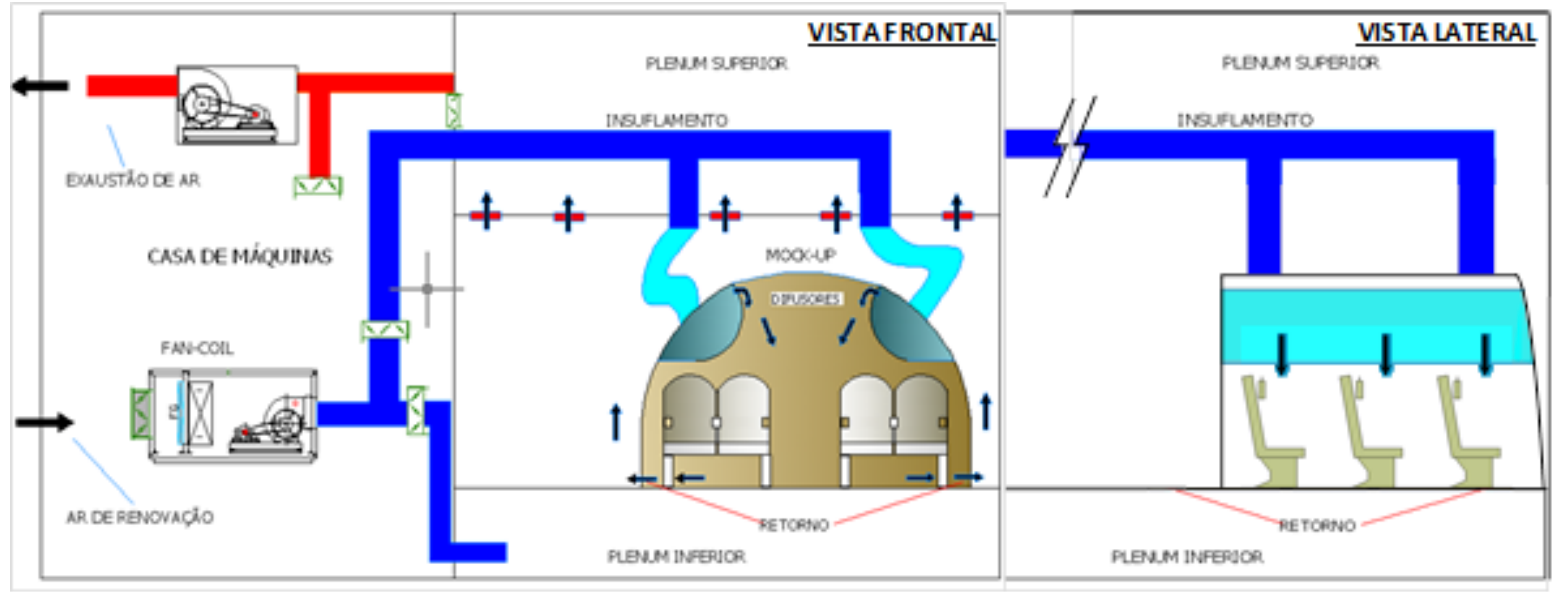

Figura 4.28 - Arquitetura I (referência): Sistema de ventilação por mistura (MV)

Depois de realizados os ensaios com o sistema global, foram feitos os ensaios utilizando o sistema de ventilação personalizada de poltrona proposto, ilustrado na Figura 4.29. O sistema de ventilação personalizada foi avaliado sob duas condições de inclinação. A primeira condição foi feita com o difusor totalmente apoiado no encosto do banco, ou seja, sem inclinação. E a segunda condição foi feita com o difusor totalmente inclinado para cima, na direção na zona de respiração dos ocupantes.

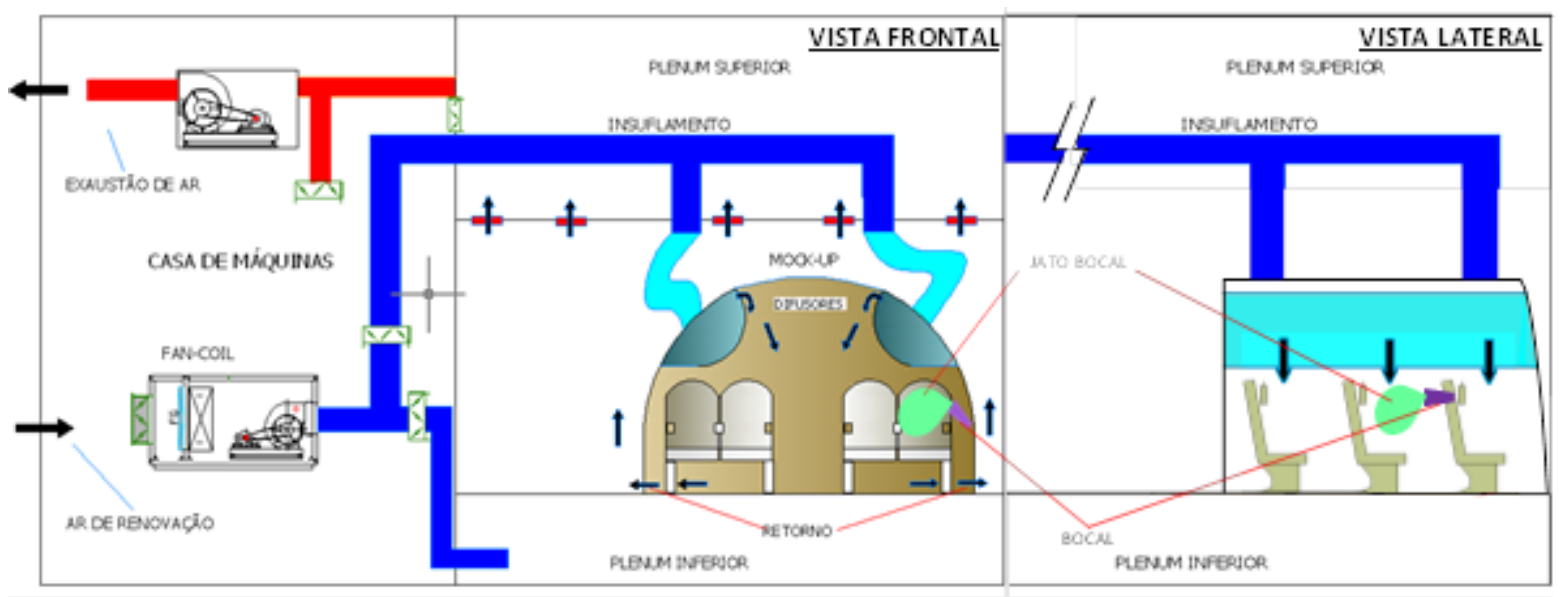

Figura 4.29 - Arquitetura II: Sistema de ventilação por mistura acrescentado de sistema de ventilação personalizada por bocal instalado na poltrona (MV+PV) 
Visando criar uma condição de conforto térmico ao ocupante, a temperatura de insuflamento do ar do sistema personalizado adotada foi de $24^{\circ} \mathrm{C}$. A vazão de ar fornecida pelo sistema personalizado foi calculada de acordo com o critério de Draught Rate (Fanger et al., 1988), considerando o percentual de pessoas insatisfeitas sendo $\leq 20 \%$ (ASHRAE 55, 2013). Deste modo, obteve-se um valor de vazão do sistema PV em torno de $3,0 \mathrm{l} / \mathrm{s}^{3}$. Após ajustada a vazão de ar, todo o procedimento do mapeamento de temperatura e velocidade no mock-up e da contagem das partículas é análogo ao ensaio na condição padrão. Na Tabela 4.1 mostra-se as condições de todos os ensaios experimentais realizados no presente trabalho.

Tabela 4.1. Matriz dos ensaios experimentais

\begin{tabular}{|c|c|c|}
\hline $\begin{array}{l}\text { Geração das } \\
\text { partículas }\end{array}$ & $\begin{array}{l}\text { Condição do ensaio } \\
\text { (temperaturas de } \\
\text { insuflamento do ar) }\end{array}$ & Observações \\
\hline \multirow{5}{*}{ Assento Corredor } & $\operatorname{MV}\left(18^{\circ} \mathrm{C}\right)^{4}$ & Condição Padrão - toda a cabine \\
\hline & \multirow{2}{*}{$\begin{array}{c}\mathrm{MV}\left(18^{\circ} \mathrm{C}\right)+\mathrm{PV}\left(24^{\circ} \mathrm{C}\right) \\
\text { \{poltrona esquerda\} }\end{array}$} & $\begin{array}{l}\text { Difusor tipo “U” invertido } \\
\text { (sem inclinação) }\end{array}$ \\
\hline & & $\begin{array}{c}\text { Difusor tipo "U" invertido } \\
\text { (com inclinação) }\end{array}$ \\
\hline & \multirow{2}{*}{$\begin{array}{c}\mathrm{MV}\left(18^{\circ} \mathrm{C}\right)+\mathrm{PV}\left(24^{\circ} \mathrm{C}\right) \\
\quad\{\text { poltrona direita\} }\end{array}$} & $\begin{array}{l}\text { Difusor tipo "U" invertido } \\
\text { (sem inclinação) }\end{array}$ \\
\hline & & $\begin{array}{l}\text { Difusor tipo "U" invertido } \\
\text { (com inclinação) }\end{array}$ \\
\hline \multirow{5}{*}{ Assento Fuselagem } & $\mathrm{MV}\left(18^{\circ} \mathrm{C}\right)$ & Condição Padrão - toda a cabine \\
\hline & \multirow{2}{*}{$\begin{array}{c}\mathrm{MV}\left(18^{\circ} \mathrm{C}\right)+\mathrm{PV}\left(24^{\circ} \mathrm{C}\right) \\
\text { \{poltrona esquerda\} }\end{array}$} & $\begin{array}{l}\text { Difusor tipo “U” invertido } \\
\text { (sem inclinação) }\end{array}$ \\
\hline & & $\begin{array}{l}\text { Difusor tipo “U” invertido } \\
\text { (com inclinação) }\end{array}$ \\
\hline & \multirow{2}{*}{$\begin{array}{l}\mathrm{MV}\left(18^{\circ} \mathrm{C}\right)+\mathrm{PV}\left(24^{\circ} \mathrm{C}\right) \\
\quad\{\text { poltrona direita\} }\end{array}$} & $\begin{array}{c}\text { Difusor tipo "U" invertido } \\
\text { (sem inclinação) }\end{array}$ \\
\hline & & $\begin{array}{l}\text { Difusor tipo "U” invertido } \\
\text { (com inclinação) }\end{array}$ \\
\hline
\end{tabular}

${ }^{3}$ O memorial de cálculo encontra-se disponível no Apêndice A.

${ }^{4}$ A utilização da proporção da vazão de ar para o sistema de ventilação por mistura é de $40 \%$ na parte superior dos bins e de 60\% na parte lateral inferior destes, usual no setor aeronáutico (Fabichak Jr., 2013). 


\section{Resultados Experimentais}

Conforme mostrado no item 4.2.4, foram posicionados termopares em pontos específicos do mock-up, com o objetivo de monitorar a temperatura em diferentes pontos da cabine. Durante os ensaios, os dados de cada um dos termopares eram gravados pelo Data-Logger a cada 10 segundos. Conforme pode ser visto no gráfico da Figura 5.1, a estabilização das condições de temperatura do mock-up era atingida, em média, em 80 minutos.

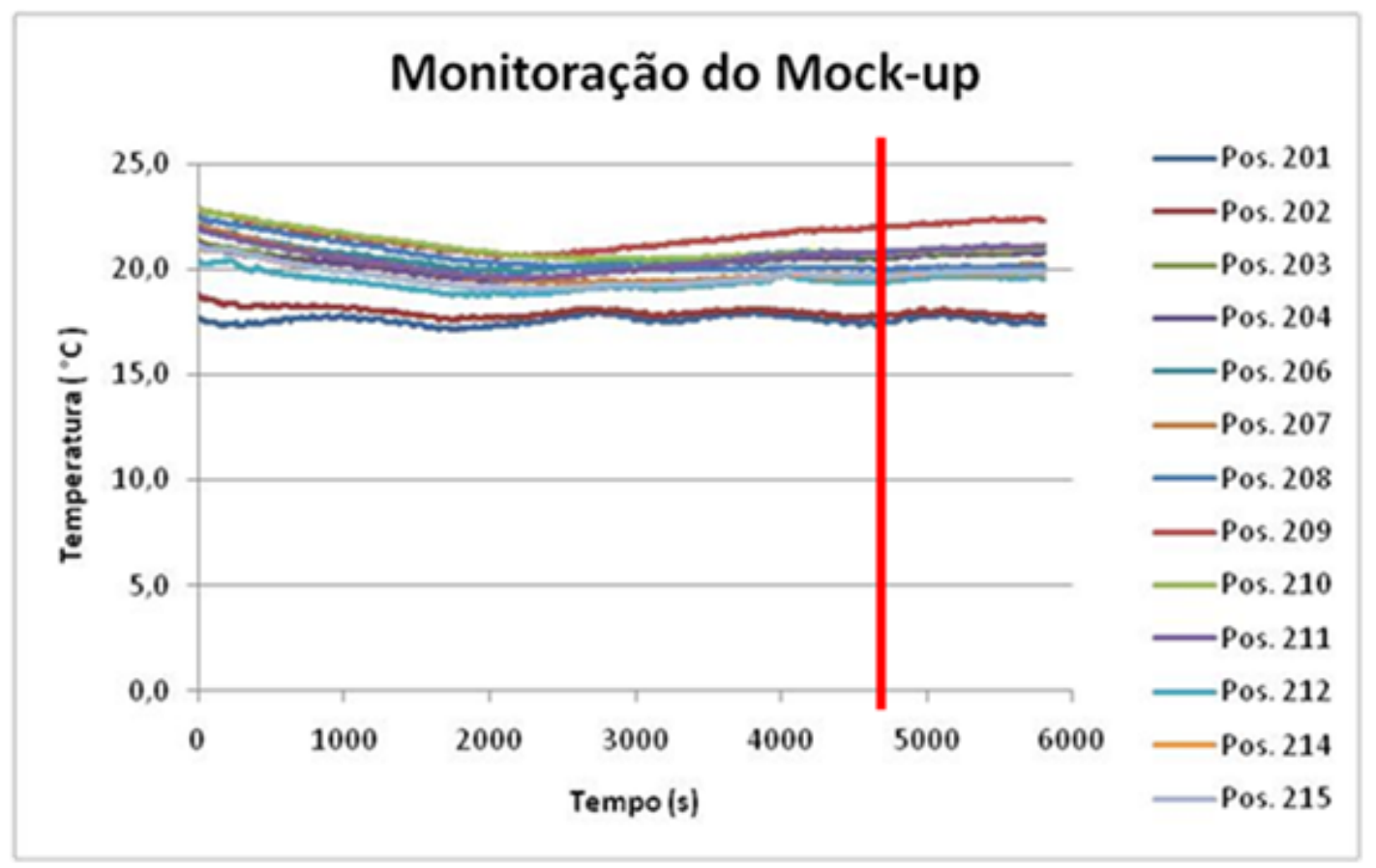

Figura 5.1 - Estabilização da temperatura do mock-up ao longo do tempo

Com o objetivo de identificar a influência do sistema personalizado proposto, os gráficos que seguem na Figura 5.2 e na Figura 5.3 mostram os perfis de velocidade e temperatura do ar na segunda fileira do mock-up, considerando insuflamento das partículas pelo corredor e pela lateral da fuselagem, respectivamente. Convém observar que os perfis de velocidade são diferentes para cada arquitetura avaliada e, função disso, resulta em diferentes padrões de distribuição de partículas na cabine, conforme mostra-se nos gráficos da Figura 5.4 e da Figura 5.5. Os dados para a obtenção destes gráficos são mostrados no Apêndice B, na Tabela B.1 e na Tabela B.2, referindo-se ao insuflamento pelo corredor e pela lateral da fuselagem, respectivamente. 

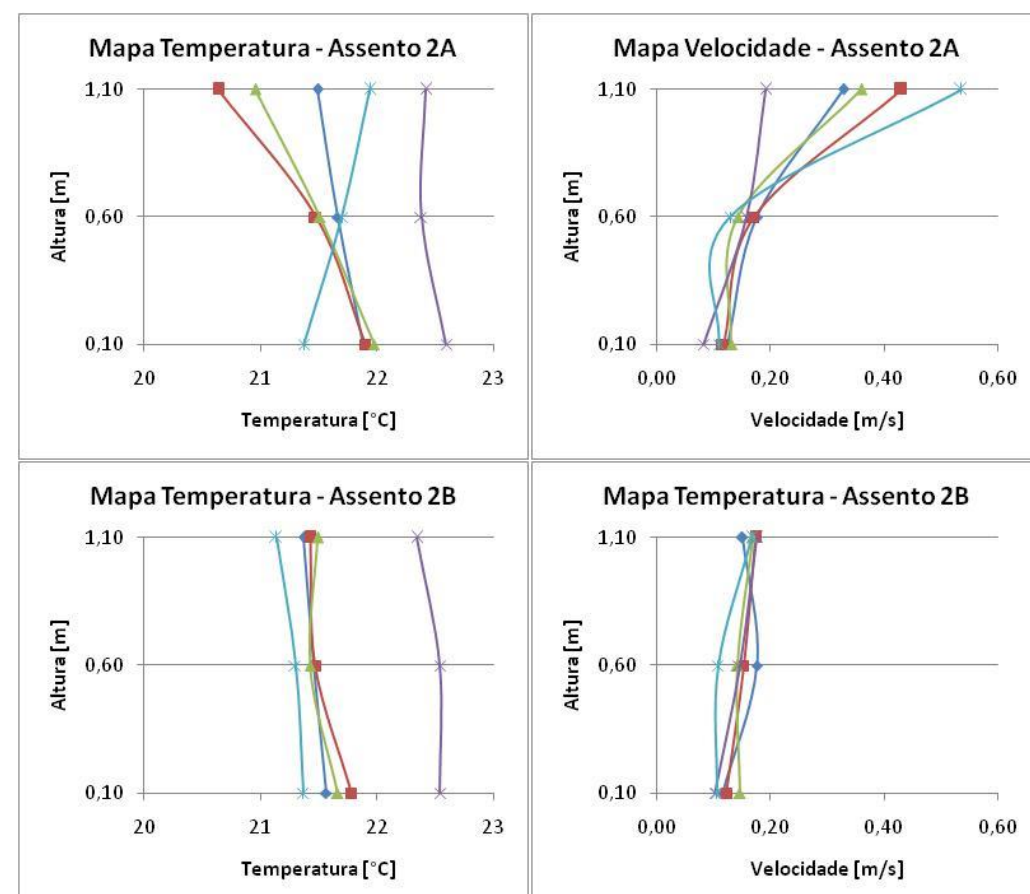

\section{Mapa Temperatura - Assento 2B}
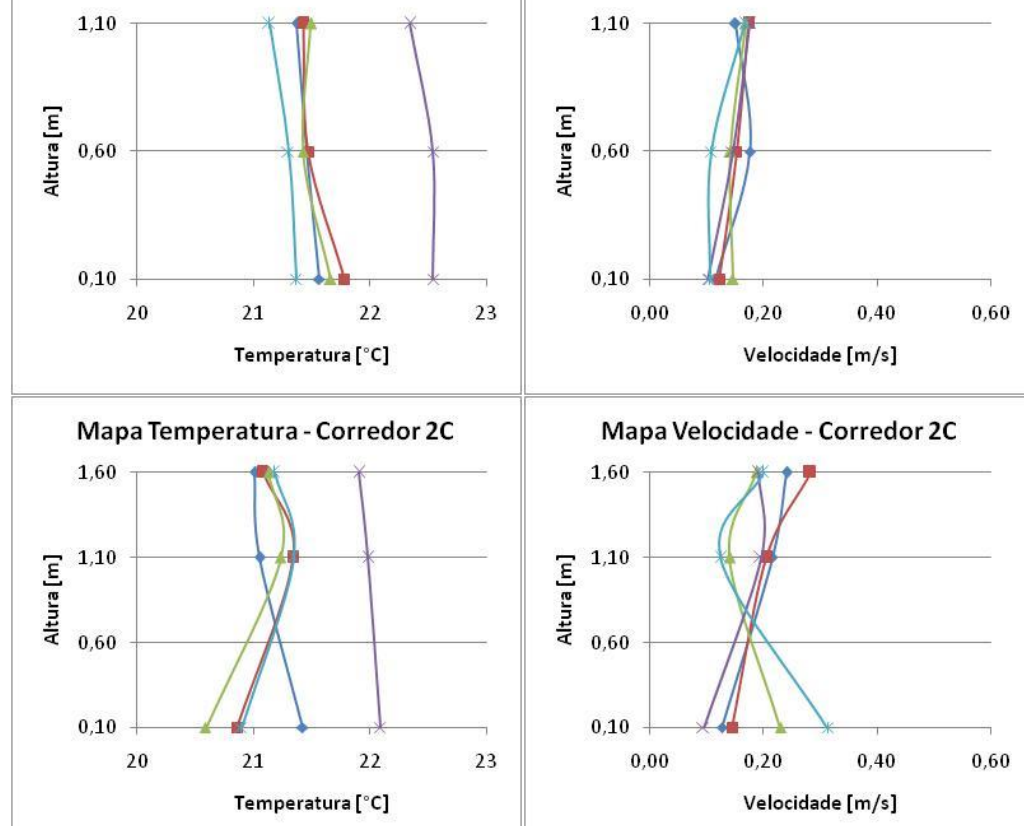

Mapa Velocidade - Corredor $2 \mathrm{C}$

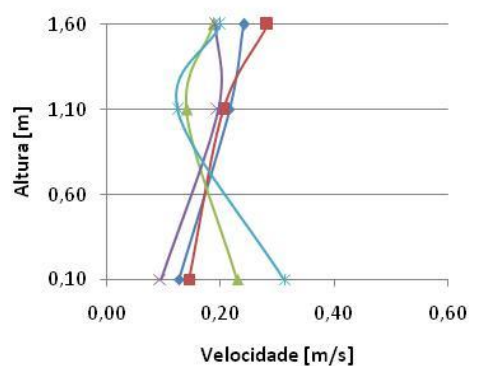

Mapa Temperatura - Assento 2D

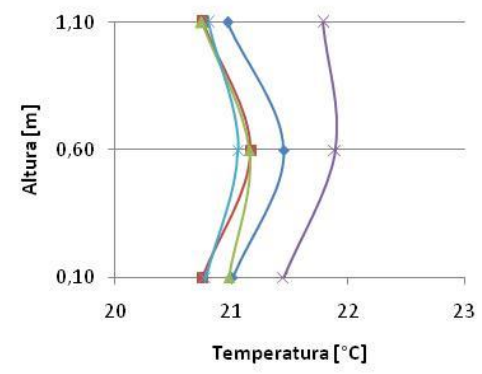

Mapa Velocidade - Assento 2D

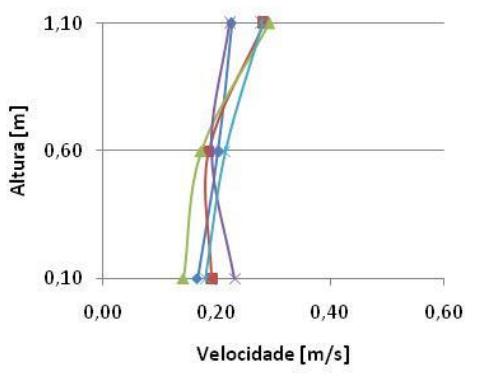

Mapa Temperatura - Assento 2E
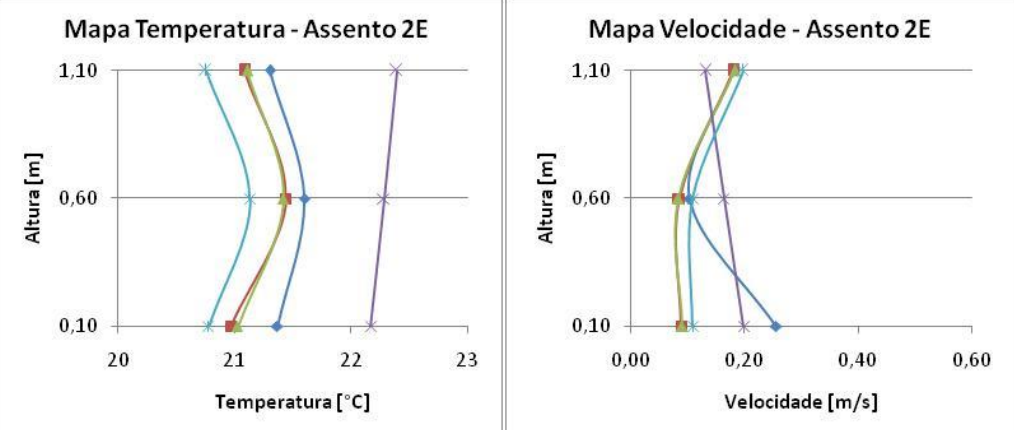

$\multimap$ Sistema MV $\rightarrow$ - Sistema PVesq s/ incl. $\longrightarrow$ Sistema PVesq c/ incl. $\multimap$ Sistema PVdir s/ incl. $\multimap$ Sistema PVdir c/ incl.

Figura 5.2 - Perfis de temperatura e de velocidade do ar no interior do mock-up, considerando injeção de partículas pelo corredor (posição 3B) 

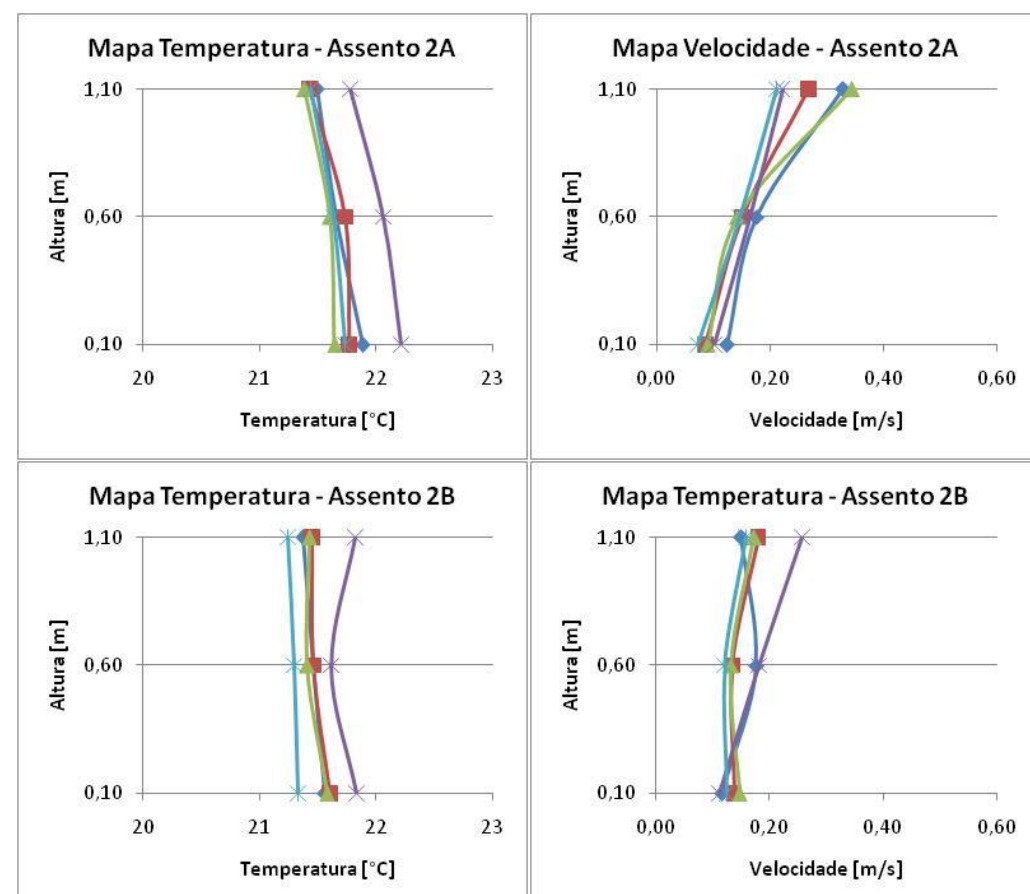

\section{Mapa Temperatura - Assento 2B}
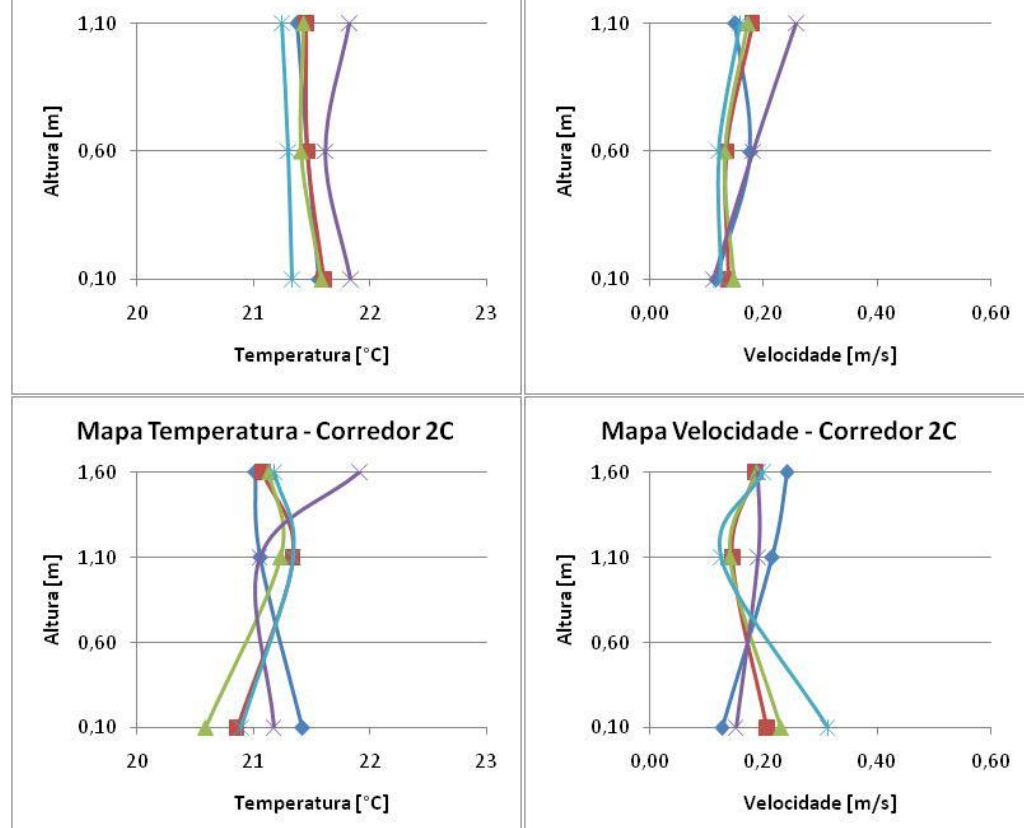

Mapa Velocidade - Corredor $2 \mathrm{C}$

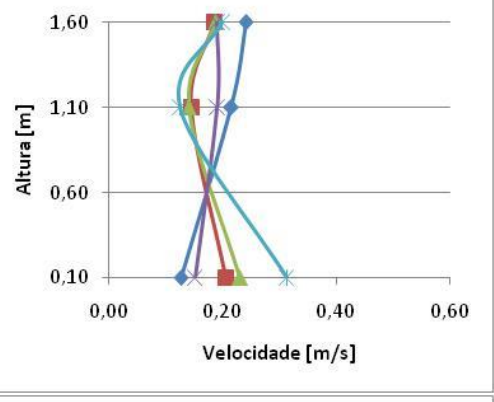

Mapa Temperatura - Assento 2D

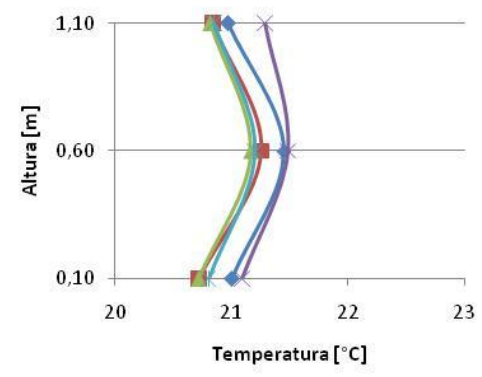

Mapa Velocidade - Assento 2D

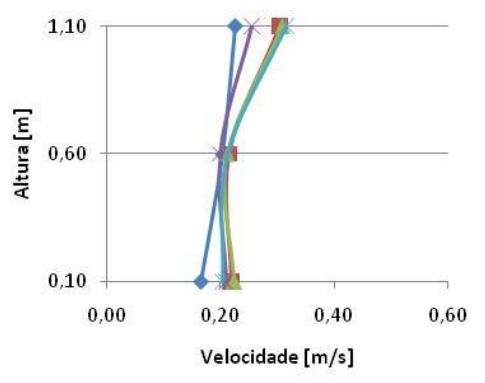

Mapa Temperatura - Assento 2E
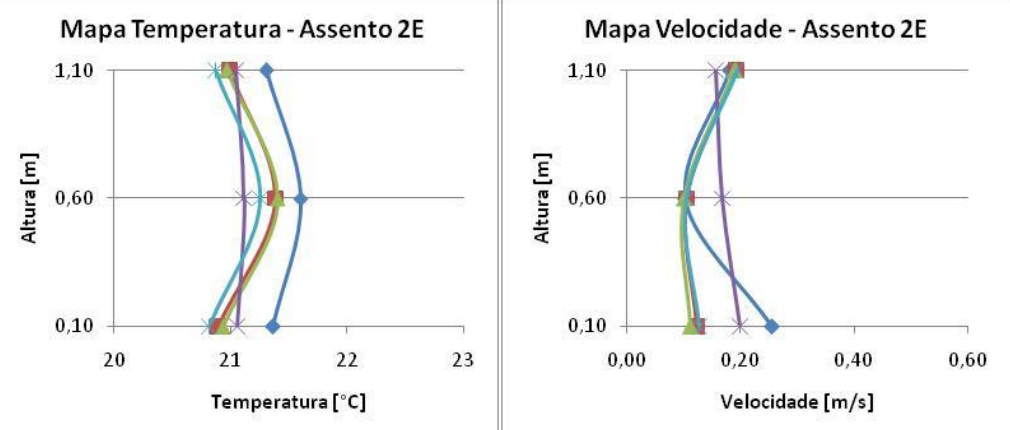

$\multimap$ Sistema MV $\rightarrow$ - Sistema PVesq s/ incl. $\longrightarrow$ Sistema PVesq c/ incl. $\multimap$ Sistema PVdir s/ incl. $\multimap$ Sistema PVdir c/ incl.

Figura 5.3 - Perfis de temperatura e de velocidade do ar no interior do mock-up, considerando injeção de partículas pela lateral (posição 3A) 


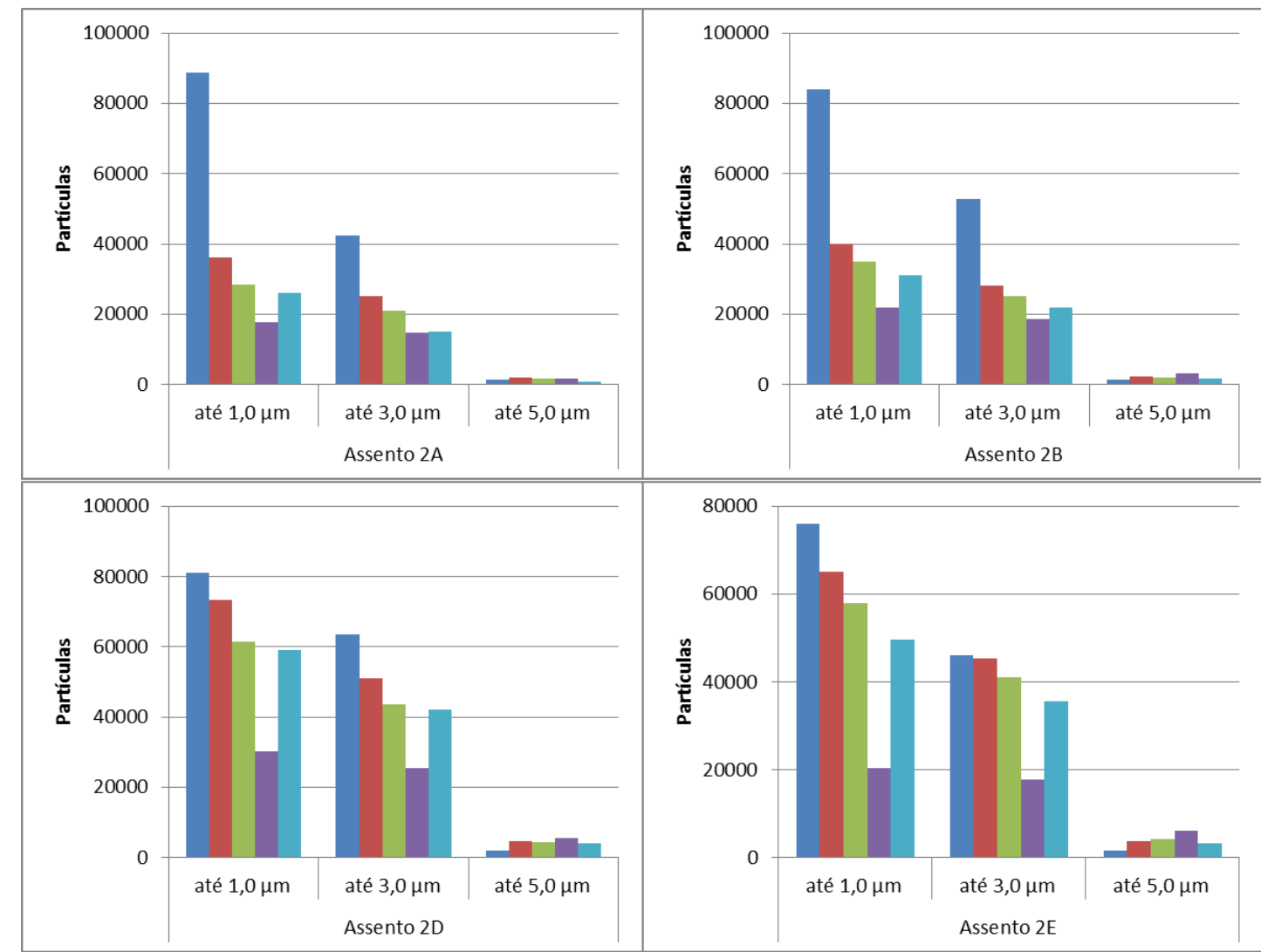

$\multimap$ Sistema MV $\rightarrow$ - Sistema PVesq s/ incl. $\longrightarrow$ Sistema PVesq c/ incl. $\longrightarrow$ Sistema PVdir s/incl. $\longrightarrow$ Sistema PVdir $\mathrm{c} /$ incl.

Figura 5.4 - Distribuição de partículas pela cabine - injeção de partículas pelo corredor

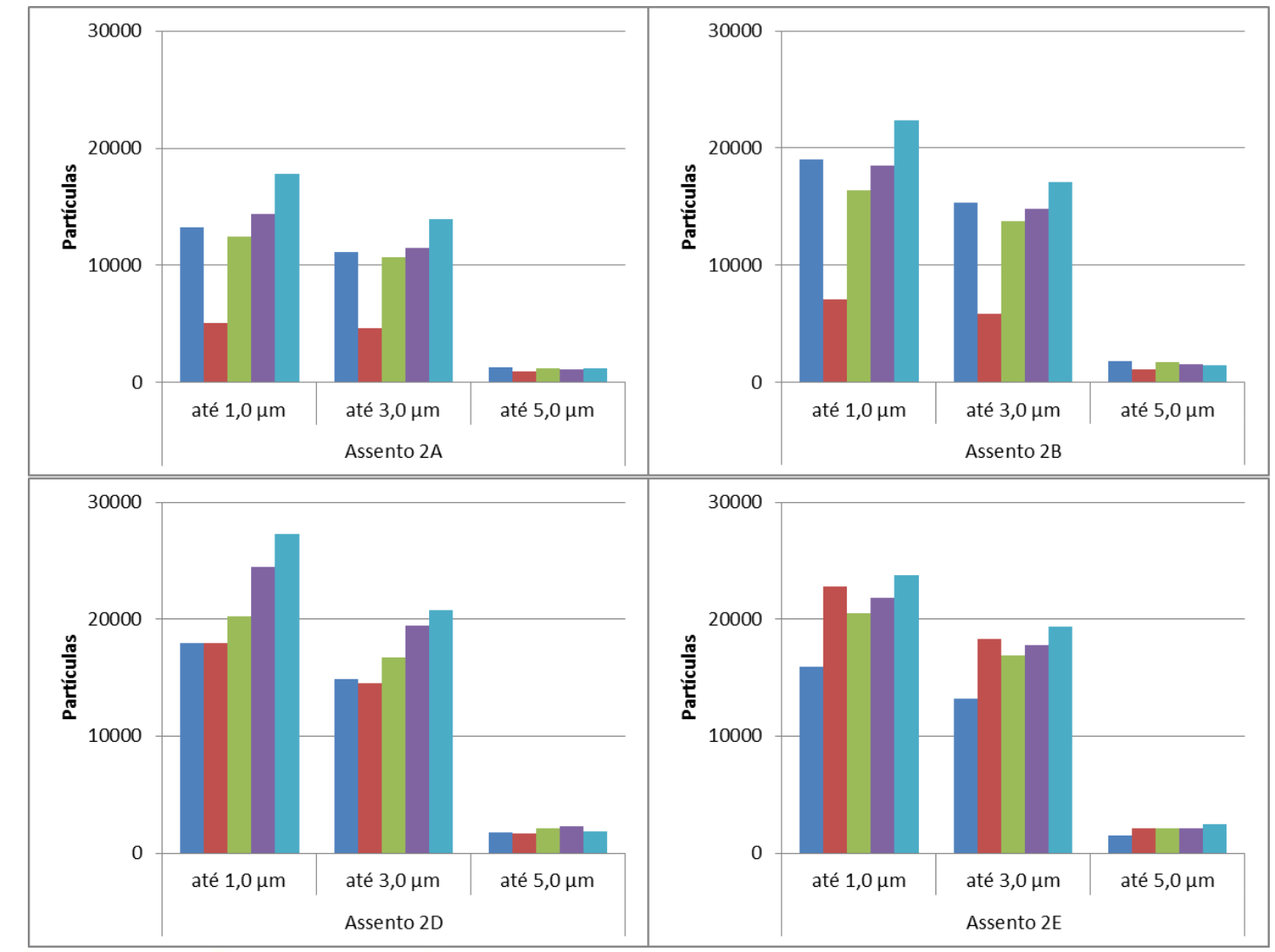

$\multimap$ Sistema MV $\longrightarrow$-Sistema PVesq s/ incl. $\longrightarrow$ Sistema PVesq c/ incl. $\multimap$ Sistema PVdir s/incl. $\multimap$ Sistema PVdir c/ incl.

Figura 5.5 - Distribuição de partículas pela cabine - injeção de partículas pela lateral 
Das Tabelas 5.1 até 5.5 , é comparado o potencial de contaminação dos ocupantes quanto ao ponto de origem da fonte contaminante, isto é, lateral ou corredor, considerando-se o diâmetro de partículas expiratórias na faixa de 3 a $5 \mu \mathrm{m}$.

O cálculo do termo percentual de risco foi feito considerando a quantidade de partículas em cada assento, considerando a injeção das partículas pelo corredor como sendo a condição de referencia, por ter os maiores índices de dispersão nesta condição. Portanto o potencial de risco tomando-se, por exemplo, a poltrona $2 \mathrm{~A}$ avaliada somente com o sistema MV para partículas de $3 \mu \mathrm{m}$ é de:

$$
\% \text { Risco }=\left(\frac{P_{\text {CORREDOR }}-P_{\text {LATERAL }}}{P_{\text {LATERAL }}}\right) \cdot 100=\left(\frac{42280-11138}{11138}\right) \cdot 100=279,6 \%
$$

Para este exemplo, significa que quando a geração de partículas acontece pelo corredor (assento 3B), o ocupante do assento 2A tem quase três vezes mais possibilidade (risco) de inalar as partículas expiratórias em comparação quando a geração das partículas acontece pela lateral (assento 3A).

Nas Tabelas 5.6 e 5.7, é mostrada a eficácia na remoção de partículas expiratórias das arquiteturas avaliadas, tomando-se como base o sistema de climatização operando sem o controle personalizado de ventilação, com base na injeção de partículas pelo corredor e pela lateral, respectivamente.

Tabela 5.1. Potencial de contaminação - sistema MV

\begin{tabular}{|c|c|c|c|c|}
\hline \multirow[b]{2}{*}{$S$} & \multicolumn{4}{|c|}{ Risco de Contaminação para partículas de $3 \mu \mathrm{m}$} \\
\hline & Pos. Inj. & Corredor & Lateral & Risco \\
\hline $\mathbf{I}$ & Assento $2 \mathrm{~A}$ & 42280 & 11138 & $279,61 \%$ \\
\hline $\mathbf{S}$ & Assento 2B & 52730 & 15335 & $243,84 \%$ \\
\hline $\mathbf{T}$ & Assento 2D & 63420 & 14923 & $324,99 \%$ \\
\hline $\mathbf{E}$ & Assento $2 \mathrm{E}$ & 46062 & 13259 & $247,39 \%$ \\
\hline M & \multicolumn{4}{|c|}{ Risco de Contaminação para partículas de $5 \mu \mathrm{m}$} \\
\hline A & Inj. & Corredor & Lateral & Risco \\
\hline \multirow{4}{*}{$\begin{array}{l}M \\
V\end{array}$} & Assento $2 \mathrm{~A}$ & 1300 & 1285 & $1,19 \%$ \\
\hline & Assento $2 \mathrm{~B}$ & 1801 & 1531 & $17,63 \%$ \\
\hline & Assento 2D & 1855 & 1792 & $3,50 \%$ \\
\hline & Assento 2E & 1563 & 1484 & $5,35 \%$ \\
\hline
\end{tabular}


Tabela 5.2. Potencial de contaminação - sistema PVesq sem inclinação

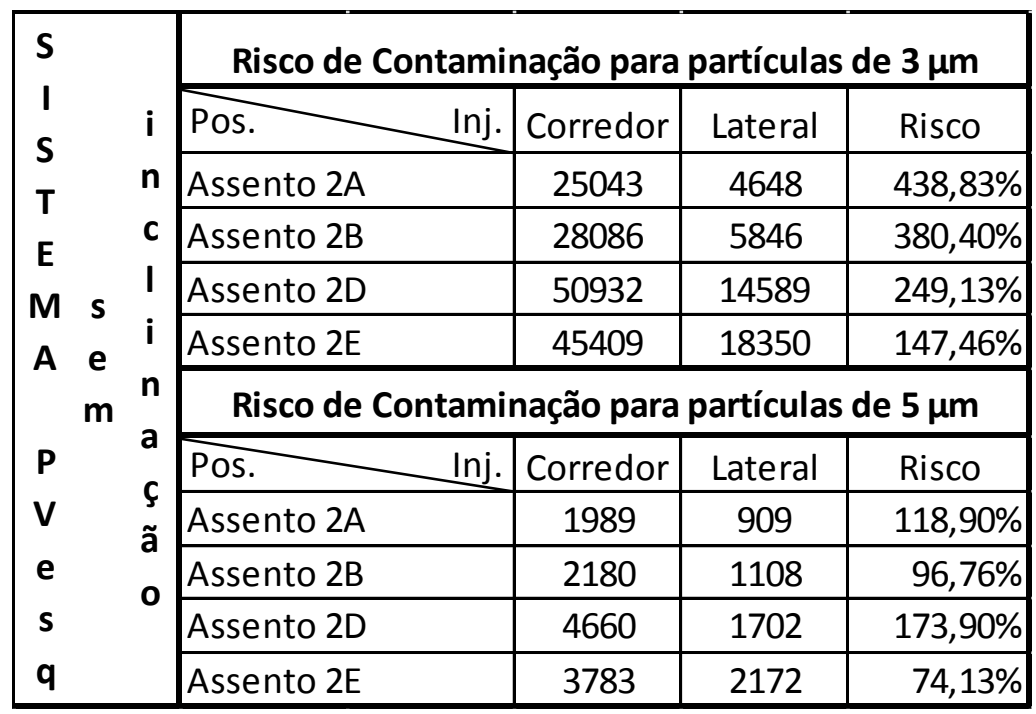

Tabela 5.3. Potencial de contaminação - sistema PVesq com inclinação

\begin{tabular}{|c|c|c|c|c|}
\hline \multirow{2}{*}{$\begin{array}{l}S \\
1 \\
S\end{array}$} & \multicolumn{4}{|c|}{ Risco de Contaminação para partículas de $\mathbf{3} \mu \mathrm{m}$} \\
\hline & Pos. Inj. & Corredor & Lateral & Risco \\
\hline \multirow{3}{*}{$\begin{array}{l}\mathrm{D} \\
\mathrm{T} \\
\mathrm{E}\end{array}$} & Assento $2 \mathrm{~A}$ & 20975 & 10705 & $95,93 \%$ \\
\hline & Assento $2 \mathrm{~B}$ & 25180 & 13783 & $82,70 \%$ \\
\hline & Assento 2D & 43663 & 16757 & $160,57 \%$ \\
\hline \multirow{2}{*}{$\begin{array}{cc}M & c \\
A & 0\end{array}$} & Assento $2 \mathrm{E}$ & 41116 & 16950 & $142,57 \%$ \\
\hline & Risco de Contami & nação para & partícula & $5 \mu \mathrm{m}$ \\
\hline \multirow{5}{*}{$\begin{array}{l}P \\
\text { V } \\
\text { e } \\
\text { s } \\
q\end{array}$} & Pos. Inj. & Corredor & Lateral & Risco \\
\hline & Assento $2 \mathrm{~A}$ & 1624 & 1256 & $29,24 \%$ \\
\hline & Assento 2B & 1983 & 1715 & $15,64 \%$ \\
\hline & Assento 2D & 4489 & 2156 & $108,23 \%$ \\
\hline & Assento 2E & 4212 & 2162 & $94,80 \%$ \\
\hline
\end{tabular}

Tabela 5.4. Potencial de contaminação - sistema PVdir sem inclinação

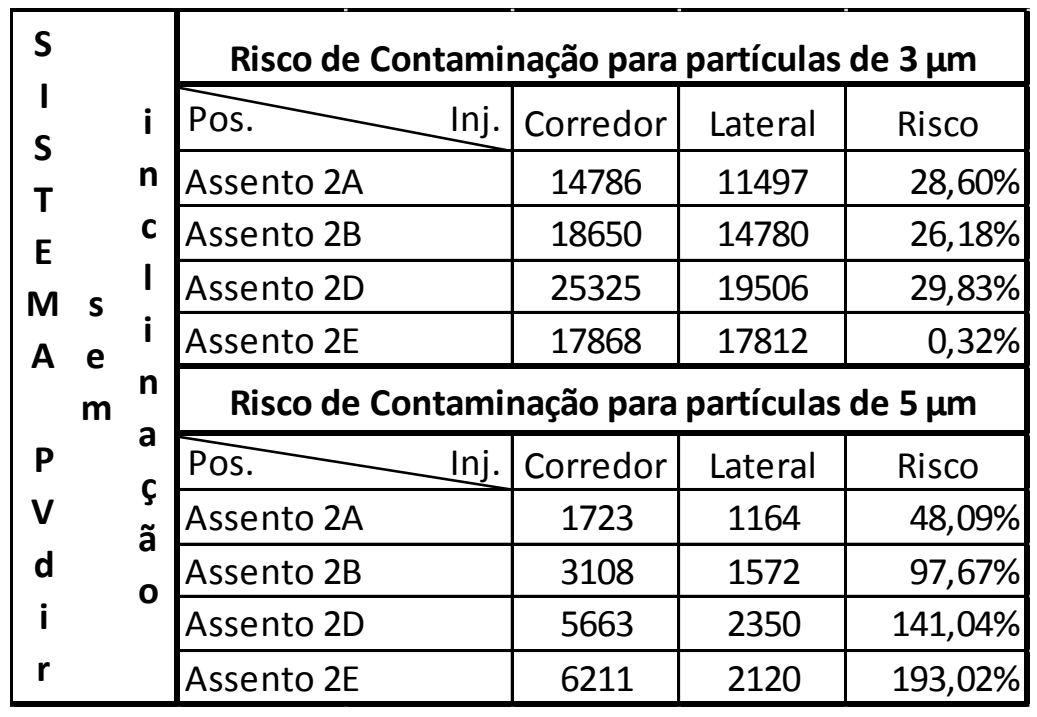


Tabela 5.5. Potencial de contaminação - sistema PVdir com inclinação

\begin{tabular}{|c|c|c|c|c|}
\hline $\mathbf{S}$ & Risco de Contami & nação para & partícula & e $3 \mu \mathrm{m}$ \\
\hline s & Pos. $\quad$ Inj. & Corredor & Lateral & Risco \\
\hline T & Assento $2 \mathrm{~A}$ & 15094 & 13904 & $8,56 \%$ \\
\hline$F$ & Assento 2B & 21988 & 17086 & $28,69 \%$ \\
\hline$M c$ & Assento 2D & 42048 & 20769 & $102,46 \%$ \\
\hline A 0 & Assento $2 \mathrm{E}$ & 35537 & 19366 & $83,50 \%$ \\
\hline m & Risco de Contami & nação para & partícula & e $5 \mu \mathrm{m}$ \\
\hline $\mathbf{P}$ & Pos. Inj. & Corredor & Lateral & Risco \\
\hline v & Assento $2 \mathrm{~A}$ & 903 & 1220 & $-26,00 \%$ \\
\hline d & Assento 2B & 1728 & 1431 & $20,80 \%$ \\
\hline $\mathbf{i}$ & Assento 2D & 3929 & 1918 & $104,86 \%$ \\
\hline $\mathbf{r}$ & Assento $2 \mathrm{E}$ & 3218 & 2511 & $28,18 \%$ \\
\hline
\end{tabular}

Tabela 5.6. Remoção das partículas expiratórias entre 3 e $5 \mu \mathrm{m}$ insufladas via corredor ORIGEM DA FONTE CONTAMINANTE: INSUFLAMENTO DE PARTICULAS PELO CORREDOR

\begin{tabular}{|c|c|c|c|}
\hline \multicolumn{2}{|c|}{ Dispersão de Particulas na poltrona $2 \mathrm{~A}$} & \multicolumn{2}{|c|}{ Dispersão de Particulas na poltrona 2B } \\
\hline Tam. Particula & entre $3,0 \mu \mathrm{m}$ e $5,0 \mu \mathrm{m}$ & Tam. Particula & entre $3,0 \mu \mathrm{m}$ e 5,0 \\
\hline Sistema MV [Referencia] & $0,0 \%$ & Sistema MV [Referencia] & $0,0 \%$ \\
\hline Sistema MV + PVesq (s/ inclinação) & $-40,8 \%$ & Sistema MV + PVesq (s/ inclinação) & $-46,7 \%$ \\
\hline Sistema MV + PVesq (c/ inclinação) & $-50,4 \%$ & Sistema MV + PVesq (c/ inclinação) & $-52,2 \%$ \\
\hline Sistema MV + PVdir (s/ inclinação) & $-65,0 \%$ & Sistema MV + PVdir (s/ inclinação) & $-64,6 \%$ \\
\hline Sistema MV + PVdir (c/ inclinação) & $-64,3 \%$ & Sistema MV + PVdir (c/ inclinação) & $-58,3 \%$ \\
\hline \multicolumn{2}{|c|}{ Dispersão de Particulas na poltrona 2D } & \multicolumn{2}{|c|}{ Dispersão de Particulas na poltrona 2E } \\
\hline Tam. Particula & entre $3,0 \mu \mathrm{m}$ e $5,0 \mu \mathrm{m}$ & Tam. Particula & entre $3,0 \mu \mathrm{m}$ e 5,0 \\
\hline Sistema MV [Referencia] & $0,0 \%$ & Sistema MV [Referencia] & $0,0 \%$ \\
\hline Sistema MV + PVesq (s/ inclinação) & $-19,7 \%$ & Sistema MV + PVesq (s/ inclinação) & $-1,4 \%$ \\
\hline Sistema MV + PVesq (c/ inclinação) & $-31,2 \%$ & Sistema MV + PVesq (c/ inclinação) & $-10,7 \%$ \\
\hline Sistema MV + PVdir (s/ inclinação) & $-60,1 \%$ & Sistema MV + PVdir (s/ inclinação) & $-61,2 \%$ \\
\hline Sistema MV + PVdir (c/ inclinação) & $-33,7 \%$ & Sistema MV + PVdir (c/ inclinação) & $-22,9 \%$ \\
\hline
\end{tabular}

Tabela 5.7. Remoção das partículas expiratórias entre 3 e $5 \mu \mathrm{m}$ insufladas via lateral

\begin{tabular}{|c|c|c|c|}
\hline \multirow{2}{*}{\multicolumn{2}{|c|}{\begin{tabular}{|c|} 
ORIGEM DA FONTE CONTAMINANTE: INSU \\
Dispersão de Particulas na poltrona 2A
\end{tabular}}} & \multicolumn{2}{|c|}{ LAMENTO DE PARTICULAS PELA LATERAL } \\
\hline & & Dispersão de Particulas na po & Itrona 2B \\
\hline Tam. Particula & entre $3,0 \mu \mathrm{m}$ e $5,0 \mu \mathrm{m}$ & Tam. Particula & entre $3,0 \mu \mathrm{m}$ e $5,0 \mu \mathrm{m}$ \\
\hline Sistema MV [Referencia] & $0,0 \%$ & Sistema MV [Referencia] & $0,0 \%$ \\
\hline Sistema MV + PVesq (s/ inclinação) & $-58,3 \%$ & Sistema MV + PVesq (s/ inclinação) & $-61,9 \%$ \\
\hline Sistema MV + PVesq (c/ inclinação) & $-3,9 \%$ & Sistema MV + PVesq (c/ inclinação) & $-10,1 \%$ \\
\hline Sistema MV + PVdir (s/ inclinação) & $-3,2 \%$ & Sistema MV + PVdir (s/ inclinação) & $-3,6 \%$ \\
\hline Sistema MV + PVdir (c/ inclinação) & $-24,8 \%$ & Sistema MV + PVdir (c/ inclinação) & $-11,4 \%$ \\
\hline \multicolumn{2}{|c|}{ Dispersão de Particulas na poltrona 2D } & \multicolumn{2}{|c|}{ Dispersão de Particulas na poltrona $2 \mathrm{E}$} \\
\hline Tam. Particula & entre $3,0 \mu \mathrm{m}$ e $5,0 \mu \mathrm{m}$ & Tam. Particula & entre $3,0 \mu \mathrm{m}$ e $5,0 \mu \mathrm{n}$ \\
\hline Sistema MV [Referencia] & $0,0 \%$ & Sistema MV [Referencia] & $0,0 \%$ \\
\hline Sistema MV + PVesq (s/ inclinação) & $-2,2 \%$ & Sistema MV + PVesq (s/ inclinação) & $-38,4 \%$ \\
\hline Sistema MV + PVesq (c/ inclinação) & $-12,3 \%$ & Sistema MV + PVesq (c/ inclinação) & $-27,8 \%$ \\
\hline Sistema MV + PVdir (s/ inclinação) & $-30,7 \%$ & Sistema MV + PVdir (s/ inclinação) & $-34,3 \%$ \\
\hline Sistema MV + PVdir (c/ inclinação) & $-39,2 \%$ & Sistema MV + PVdir (c/ inclinação) & $-46,1 \%$ \\
\hline
\end{tabular}




\subsection{Análise dos resultados}

Analisando os gráficos da seção anterior, nota-se que a dispersão das partículas insufladas sempre alcançou maiores valores quando a injeção foi feita pelo corredor (posição 3B). Por esta razão, inicia-se a análise dos resultados considerando inicialmente o insuflamento das partículas pelo passageiro junto ao corredor.

Em função da característica de funcionamento do sistema MV, verificou-se que o perfil de velocidade na região do corredor (posição $2 \mathrm{C}$ ) foi o mais elevado dentre toda a região da segunda fileira. Com isso, as partículas injetadas foram conduzidas por maiores distâncias dentro da cabine.

Quando foi feita a avaliação com o sistema personalizado na poltrona esquerda (posição $2 \mathrm{~A}$ ), o perfil de velocidade foi relativamente maior em comparação com o sistema PV desligado. Este efeito era, de fato, esperado. Com isso, houve uma redução na quantidade de partículas expiratórias na zona de respiração do ocupante que estava na poltrona $2 \mathrm{~A}$ e, em menor intensidade na poltrona $2 \mathrm{~B}$, independentemente do difusor estar inclinado ou não. Porém, para os assentos do lado oposto (posições 2D e 2E), a quantidade de partículas contadas foi praticamente a mesma de quando o sistema PV estava desligado. Ou seja, na prática, o funcionamento do sistema $\mathrm{PV}$ na poltrona $2 \mathrm{~A}$ foi benéfico somente para aquele ocupante. Nos ensaios com o difusor 2A inclinado, a quantidade de partículas expiratórias neste assento foi da ordem de 10\% menor, comparado com os ensaios considerando o difusor 2A sem inclinar. Uma das razões para essa redução se deve ao fato da proximidade do assento junto aos dutos de retorno do ar, facilitando a remoção das partículas geradas.

Quando foi feita a avaliação com o sistema personalizado na poltrona direita (posição 2B), o perfil de velocidade influenciou também na posição 2A e 2C. Por esta razão, a dispersão de partículas foi severamente reduzida. Nesta condição, a dispersão das partículas foi cerca de $65 \%$ menor em comparação com o sistema MV, não somente na poltrona que estava em funcionamento (posição 2B), mas também no assento ao lado (posição 2A). No entanto, convém observar que as partículas expiratórias que foram retidas nestes assentos foram dispersas para o outro lado da cabine (posições 2D e 2E). Outra observação a ser feita é que a dispersão de partículas atingiu níveis maiores quando o difusor da poltrona 2B foi inclinado. Uma das razões pode ser o efeito da turbulência do ar local, facilitando dispersar os 
contaminantes para as regiões adjacentes. Em termos de grandeza, o difusor inclinado na poltrona junto ao corredor dispersou em torno de 10\% mais contaminantes em comparação com o ensaio considerando o difusor 2B sem inclinar e cerca de $40 \%$ mais contaminantes para os assentos localizados do outro lado da cabine.

Em avaliação análoga, são realizadas as mesmas medições, porém com o insuflamento das partículas feito próximo da lateral da aeronave (posição 3A). Observa-se que a dispersão das partículas sempre foi menor quando comparada com o insuflamento foi feito junto à poltrona do corredor. Isso indica que as partículas quando insufladas próximas da lateral da aeronave tendem a ser coletadas pelo sistema de exaustão do ar interior devido ao fluxo de ar próximo da fuselagem estar em direção descendente. Independentemente da arquitetura de distribuição de ar avaliada, a quantidade de partículas mostrada no gráfico da Figura 5.4 (insuflamento das partículas pelo corredor) foi maior do que a respectiva quantidade de partículas mostrada no gráfico da Figura 5.5 (insuflamento do contaminante pelo assento lateral).

Para a avaliação somente com o sistema MV em funcionamento, a dispersão das partículas expiratórias no tamanho equivalente ao produzido pelas pessoas foi em média 3 vezes menor quando a contaminação ocorre próximo da lateral, em comparação com a fonte de contaminação próxima ao corredor, reiterando a ideia de que a proximidade com os dutos de retorno do ar facilita a reduzir a dispersão das partículas pela cabine.

Quando o sistema personalizado da poltrona esquerda (posição 2A) foi colocado em funcionamento, a redução das partículas expiratórias neste assento atingiu redução de até $60 \%$ em comparação ao sistema MV isolado, obtendo praticamente os mesmos índices de melhora na qualidade do ar encontrados quando a origem da contaminação foi junto ao corredor. Nesta configuração, obteve-se os melhores índices de qualidade do ar, pois o fato do insuflamento das partículas expiratórias ser próxima da lateral da cabine auxiliou na remoção destes contaminantes por meio da atuação do sistema personalizado. Além disso, o usuário do assento imediatamente ao lado (posição 2B) também se beneficiou deste recurso, pois a quantidade de partículas na zona de respiração deste ocupante foi cerca de três vezes menor em comparação quando o sistema personalizado estava desligado. Quanto à inclinação do difusor 2A, o número de partículas dispersas foi $10 \%$ menor em comparação aos 
ensaios com o difusor $2 \mathrm{~A}$ sem inclinar. Porém, para o ocupante do assento imediatamente ao lado (posição $2 \mathrm{~B}$ ) e também para os assentos do lado oposto (posições 2D e 2E), este efeito não se mostrou influente, ou seja, na prática, é como se o sistema PV local estivesse desligado, pois a quantidade de partículas medidas nestes assentos atingiu praticamente os mesmos valores da análise com o sistema $\mathrm{MV}$ isolado.

Quando o sistema personalizado da poltrona direita (posição 2B) foi colocado em funcionamento, notou-se que a concentração das partículas foi ligeiramente menor em comparação com os ensaios feitos sob a condição de origem da contaminação junto ao corredor. Nesta condição, o fato do difusor 2B estar ou não inclinado não fez muita diferença em relação à dispersão de partículas para outras regiões da cabine, pois o fato da fonte contaminante estar próxima da lateral facilitou a captação das partículas pelos dutos de retorno de ar do mock-up. Para este ensaio, a observação que pode ser feita é que o sistema personalizado quando funcionando junto ao corredor auxilia a minimizar a contaminação também para os assentos do outro lado da cabine (posições 2D e 2E), onde os níveis de contaminação foram cerca de $20 \%$ a $40 \%$ menores em comparação aos ensaios com insuflamento das partículas pela poltrona do corredor.

Baseado nos resultados dos gráficos da Figura 5.4 e da Figura 5.5, pode-se afirmar ainda que o sistema personalizado funcionando no assento próximo da fuselagem tem uma eficácia local de melhora na qualidade do ar no interior da cabine, ao passo que quando este mesmo sistema está funcionando no assento junto ao corredor, a melhora da qualidade do ar no interior da cabine é global, pois nesta condição verificaram-se reduções significativas da quantidade de partículas expiratórias dispersas no ambiente em todos os assentos da $2^{\underline{a}}$ fileira. 


\section{Conclusão}

O monitoramento das variáveis ambientais mostrou que o sistema de ventilação por mistura, MV, é, de fato, capaz de prover uma condição relativamente homogênea da temperatura do ar na cabine. Observou-se que, durante todos os ensaios, a temperatura ambiente ficou dentro dos intervalos previstos. Além disso, também foi observada que a estratificação da temperatura do ar foi inferior a $2^{\circ} \mathrm{C}$,

Os resultados das análises experimentais mostraram que a dispersão e a concentração de partículas expiratórias na cabine são fortemente influenciadas pelo ponto de origem da fonte contaminante.

Ao injetar as partículas expiratórias em um assento junto à fuselagem, em comparação com passageiro sentado em assento próximo ao corredor do mock-up, resultou em uma menor dispersão de partículas na zona de respiração na cabine. Resultado este também obtido por Wan, Chao e Fang (2005), Yan et al. (2009), Fabichak Jr. (2013), Li et al. (2014) e Mazumdar, Long e Chen (2014). Conseqüentemente, quando as partículas expiratórias são geradas por um passageiro sentado junto ao corredor, existe um potencial maior de que estas sejam inaladas por outros passageiros da cabine. Essa conclusão é válida para as três arquiteturas analisadas, conforme Tabela 4.1.

Fazendo-se uma associação com uma situação real de voo, a possibilidade de um ocupante inalar as partículas expiratórias expelidas por outro passageiro é maior se estiver viajando em um assento junto ao corredor.

Ao utilizar-se do recurso do sistema de ventilação personalizada proposto, observou-se uma maior eficácia na remoção das partículas expiratórias na zona de respiração quando funcionando junto ao corredor. Nesta posição, o sistema conseguiu reduzir a concentração de partículas inclusive para o ocupante sentado junto à fuselagem, aumentando o campo de atuação do sistema de ventilação personalizada, também verificado por Conceição (2012) na avaliação da influência da válvula gasper.

Por outro lado, deve-se ressaltar que direcionar o jato para a zona de respiração, trouxe mais malefícios que benefícios para os ocupantes, pois a dispersão de partículas foi maior comparada aos ensaios com o difusor sem estar inclinado. Isto 
pode ser atribuído ao fato de que como o retorno do ar é feito por baixo, existe uma tendência natural de que as partículas tendam a seguir um fluxo descendente. Por esta razão, insuflar o ar no sistema personalizado por um fluxo ascendente pode prejudicar na remoção dos contaminantes expiratórios dispersos no ambiente.

Finalmente, o sistema personalizado proposto foi capaz de remover até $65 \%$ mais partículas expiratórias na faixa de 3 a $5 \mu \mathrm{m}$ em relação ao sistema convencional de distribuição de ar por mistura, justificando sua implementação em aeronaves com a mesma condição de dois assentos por fileira e corredor central. Este valor de melhora na qualidade do ar é muito próximo ao obtido por Fabichak Jr. (2013), em sua dissertação de mestrado, ao testar diferentes arquiteturas de distribuição de ar como alternativa ao sistema de ventilação por mistura das aeronaves atuais.

\subsection{Sugestões para trabalhos futuros}

Como proposta para continuidade do presente trabalho, são propostos os seguintes estudos:

a. Fazer o mapeamento da dispersão de partículas em toda a cabine;

b. Avaliar a influência deste sistema de ventilação personalizada, juntamente com outros sistemas de ventilação, tais como o DV e o UFAD, na dispersão de partículas na cabine;

c. Investigar se o sistema de ventilação personalizada proposto influencia significativamente no conforto térmico e na qualidade do ar local, comparando entre si diferentes arquiteturas de distribuição de ar;

d. Avaliar a influência da variação da vazão do sistema de ventilação personalizada na dispersão e concentração de partículas expiratórias, no conforto térmico e na qualidade do ar;

e. Otimizar a geometria do difusor. Como propostas, poderiam ser objeto de estudo:

a. Melhorar a distribuição de entrada do ar no interior do difusor, propondo múltiplos pontos de entrada de ar;

b. Propor uma geometria de direcionamento do fluxo de ar através de aletas, tais como os difusores de ar dos painéis dos automóveis. 


\section{Referências Bibliográficas}

ACER. Airliner Cabin Environmental Research, 2010. Disponivel em: $<$ https://www.fire.tc.faa.gov/2010Conference/files/Cabin_Safety_V/HaneyOverfeltSens ors/HaneyOverfeltSensorsPres.pdf>. Acesso em: 18 jan. 2016.

ANDERSON, M. D. Effect of gaspers on airflow patterns and the transmission of airborne contaminants within an aircraft cabin environment. A. Thesis for Master of Science Degree. Department of Mechanical and Nuclear Engineering of Kansas State University, 2012.

ANSI/ASHRAE Standard 161. Air Quality Within Commercial Aircraft. American Society of Heating, Refrigerating and Air-Conditioning Engineers, Inc., 1791 Tullie Circle, NE,Atlanta, GA30329, 2007.

ASHRAE 55. Thermal environmental conditions for human occupancy. American Society of Heating, Refrigerating and Air Conditioning Engineers Inc., 1791 Tullie Circle, NE, Atlanta, GA30329, 2013.

ASHRAE Guideline. Air Quality Within Commercial Aircraft. American Society of Heating, Refrigerating and Air-Conditioning Engineers, Inc.,1791 Tullie Circle, NE, Atlanta, GA30329, 2008. 28p.

BALLOUET, J.C. What is known about cabin air?: a global survey. In: $67^{\text {th }}$ ANNUAL MEETING, ICAO SESSION, OF AEROSPACE MEDICAL ASSOCIATION (AsMA), May. 1996, Atlanta: Aerospace Medical Association, 1996.

BÉMER, D.; CALLÉ, S.; GODINOT, S.; RÉGNIER, R.; DESSAGNE, J.M. Measurement of the Emission Rate of an Aerosol Source-Comparison of Aerosol and Gas Transport Coefficients. Journal of Appl. Occup. Environ. Hyg., 2000. 15:904-910.

BENEKE, J. M. Small diameter particle dispersion in a commercial cabin aircraft. A. Thesis for Master of Science Degree. Department of Mechanical and Nuclear Engineering of Kansas State University, 2010.

BHANGAR, S.; NAZAROFF, W.W. Intake Fraction for contaminants in aircraft passenger cabins. Proceedings of Indoor Air 2008, 17-22 August 2008, Copenhagen, Denmark - Paper ID:614.

BOEING. Operations Manual of B737-300/-400/-500. The Boeing Company Seattle, Washington, 98124-2207, 2015.

BOSBACH, J.; HEIDER, A.; DEHNE, T.; MARKWART, M.; GORES, I.; BENDFELDT, $P$. Evaluation of cabin displacement ventilation under fight conditions. ICAS Brisbane, 2012.

BROOKER, C. Pilots disabled by poisoned air. Telegraph, UK, Disponível em: <http://www.telegraph.co.uk/news/main.jhtml?xml=/news/2007/06/24/nbook124a.xmls. Acesso em: out. 2013.

CHAO, C.Y.H.; WAN, M.P. A study of the dispersion of expiratory aerosols in unidirectional downward and ceiling-return type airflows using a multiphase approach. Journal of Indoor Air, 2006. 16:296-312. 
CHAO, C.Y.H.; WAN, M.P.; MORAWSKA, L.; JOHNSON, G.R.; RISTOVSKI, Z.D.; HARGREAVES, M.; MENGERSEN, K.; CORBETTE, S.; LI, Y.; XIE, X.; KATOSHEVSKI, D. Characterization of expiration air jets and droplet size distributions immediately at the mouth opening. Journal of Aerosol Science, 2009. 40:122-133.

CHEN, Q.; MCDEVITT, J.J.; GUPTA, J.K.; JONES, B.W.; MAZUMDAR, S.; POUSSOU, S.B. Infectious disease transmission in airliner cabins. Report No. RITE-ACER-CoE-2012-1. Auburn, USA: National Air Transportation Center of Excellence RITE/ACER, 2012.

CONCEIÇÃO, S.T.; PEREIRA, M.L.; TRIBESS, A. A review of methods applied to study airborne biocontaminants inside aircraft cabins. Hindawi Publishing Corporation, International Journal of Aerospace Engineering, artigo 824591, 2011. 15 p.

CONCEIÇÃO, S. T. Contaminação aérea em cabines climatizadas: Processo de avaliação e análise da influência de sistema de ventilação personalizada. Tese de Doutorado. Departamento de Engenharia Mecânica, Escola Politécnica da USP, São Paulo, 2012. 218p.

CONNOR, M. Transmission of diseases and long-haul flights. ICE International Aviation Conference, NHS Dumfires \& Galloway, UK Scotland, 2009.

DECHOW, M.; SOHN, J.; STEINHANSES, J. Concentrations of cabin air of airbus arcraft, chemosphere, 1997. 35:21-31.

DLR. DLR and Airbus flight-test new aircraft ventilation system, 2011. Disponível em: <http://www.dlr.de/dlr/en/desktopdefault.aspx/tabid-10256/366_read-1664>. Acesso em: 23 mar. 2015.

DUMYAHN, T.S.; SPENGLER, J.D.; BURGE, H.A.; MUILENBURG, M. Comparison of the Environments of Transportation Vehicles: Results of Two Surveys. Pp. 13-25 In: Air Quality and Comfort in Airliner Cabins, N.L. Nagda, ed., ASTM International, West Conshohocken, PA, 2000.

DUGUID, J. P. The Size and the Duration of Air-Carriage of Respiratory Droplets and Droplet-Nuclei. J. Hyg., 1946. 44:471-479.

FAA. AMT Airframe Handbook Volume 2 -FAA-H-8083-31. Chapter 16: Cabin Environmental Control Systems. Federal Aviation Administration, 2012. Disponível em:<https://www.faa.gov/regulations_policies/handbooks_manuals/aircraft/amt_airfra me_handbook/media/ama_Ch16.pdf>. Acesso em: 21 Ago. 2015.

FABIAN, P.; MCDEVITT, J.J.; DEHAAN, W.H.; FUNG, R.O.P.; COWLING, B.J.; CHAN, K.H.; LEUNG, G.M.; MILTON, D.K. Influenza virus in human exhaled breath: an observational study. PLoS ONE, 3(7), e2691, 2008.

FABICHAK Jr., D. Arquiteturas de distribuição de ar em cabines de aeronaves: Análise experimental da dispersão de partículas expiratórias. Dissertação de Mestrado. Departamento de Engenharia Mecânica, Escola Politécnica da USP, São Paulo, Brasil, 2013. 126p.

FAIRCHILD, C.I.; STAMPFER, J.K. Particle concentration in exhaled breath., Journal of Am. Ind. Hyg. Assoc., 1987. 48(11):948-949.

FANGER, P. O.; MELIKOV, A. K.; HAMNZAWA, H.; RING, J. Air turbulence and sensation of draught. Energy and Buildings, 1988. 12:21-39. 
FISER, J.; MIROSLAV, J. Impact of air distribution system on quality of ventilation in small aircraft cabin. Building and Environment Technická 2896/2, 616 69 Brno, Czech Republic, 2013.

FOX, R. W.; Mc DONALD, A. T.; PRITCHARD, P. J. Introdução à Mecânica dos Fluidos. LTC, 6ª Ed., Rio de Janeiro, 2006.

GAO, N.P.; NIU, J.L. Personalized ventilation for commercial aircraft cabins. $45^{\text {th }}$ AIAA Aerospace Sciences Meeting and Exhibit. 8-11 January 2007, Reno, Nevada, 2007a. AIAA 2007-514.

GAO, N.P.; NIU, J.L. Investigation indoor air quality and thermal comfort using numerical thermal manikin. Indoor and Built Environment 2007;16, 2007b. 1:7-17.

GRUN, G.; HELLWIG, R. T.; TRIMMEL, M.; HOLM, A. H. Interrelations of comfort parameters in a simulated aircraft cabin. Proccedings of Indoor air 2008. Copenhagen, Dinamarca, 2008.

GÜNTHER, G. J.; BOSBACH, J.; PENNECOT, C.; WAGNER, T.; LERCHE, I.; GORES. Experimental and numerical simulations of idealized aircraft cabin flows. Aerospace Science and Technology, 2006. 10: 563-573.

GUPTA, J.K.; LIN, C.H.; CHEN, Q. Flow dynamics and characterization of a cough. Indoor Air 2009. 19:517-525.

GUPTA, J.K.; LIN, C.H.; CHEN, Q. Transport of expiratory droplets in an aircraft cabin. Indoor Air 2011. 21:3-11.

HEACE. Health Effects in Aircraft Cabin Environment. Disponível em: <http://www.heace.org/index.html >. Acesso em: 27 set. 2012.

HINDS, W. C. Aerosol Technology. New York, John Wiley \& Sons, Inc., 1999.

HOCKING, M. B. Indoor air quality: recommendations relevant to aircraft passengers cabins. American Industrial Hygiene Association Journal, 1998. 59:446454.

HOCKING, M. B. Passengers aircraft cabin air quality: trends, effects, societal costs, proposals. Environmental Science \& Pollution Research International, 2000. (7): Part 3: 173.

HUNT, E. H.; SPACE, D. R. The Airplane Cabin Environment - Issues Pertaining to Flight Attendant Comfort. The Boeing Company, International In-flight Service Management Organization Conference, Montreal, Canada, 1994.

ICE. Ideal Cabin Environment, 2010. Disponível em: <http://www.asdstan.org/lCE.html>. Acesso em: set. 2012.

ISO 7726. Thermal Environments - Instruments and Methods for Measuring Physical Quantities. International Organization for Standardization, Geneva, 1998.

ISO 7730. Ergonomics of the Thermal Environment - Analytical Determination and Interpretation of Thermal Comfort using Calculation of the PMV and PPD Indices and Local Thermal Criteria. International Organization for Standardization, Geneva, 2005.

JONES, R.; NICAS, M. Experimental Determination of Supermicrometer Particle Fate Subsequent to a Point Release within a Room under Natural and Forced Mixing. Aerosol Science and Technology, 2009. 43:9, 921-938. 
KACZMARCZYK, J.; MELIKOV, A. K.; FANGER, P. O. Human response to personalized ventilation and mixing ventilation. Journal of Indoor Air, 2004. 14(8): 17-29.

KACZMARCZYK, J.; MELIKOV, A. K.; BOLASHIKOV, Z.; NIKOLAIEV, L.; FANGER, $P$. O. Human response to five designs of personalized ventilation. HVAC\&R Research, 2006. 12(2): 367-384.

KLEPEIS, N. E.; NAZAROFF, W. W. Characterizing size-specific ETS particle emissions. Proceedings of Indoor Air 2002. 162-167.

KHOSROW, E. Numerical simulation of a turbulent airflow, tracer gas diffusion and particle dispersion in a mock-up cabin aircraft. A. Thesis for Doctor of Philosophy Degree. Department of Mechanical and Nuclear Engineering of Kansas State University, 2012.

KULKARNI, P.; BARON, P. A.; WILLEKE, K. Aerosol Measurement: Principles, Techniques and Applications. New York, John Wiley \& Sons, Inc., 2011.

LATIMER, B.; TANG, P. ISO 21501-4: Calibration of Air Particle Counters from a Metrology Perspective. HACH white paper, 2012.

LEITE, B. C. C.; TRIBESS, A. Analysis of thermal comfort in an office environment with underfloor air supply in a tropical climate. HVAC\&R Research, 2006. 12(2): 215-229.

LI, Y.; LEUNG, G. M.; TANG, J. W.; YANG, X.; CHAO, C. Y. H.; LI, J. Z.; LU, J. W.; NIELSEN, P. V.; NIU, J.; QIAN, H.; SLEIGH, A. C.; SU, J.; SUNDELL, J.; WONG, T. W.; YUEN, P. L. Role of ventilation in airborne transmission of infectious agents in the built environment - a multidisciplinary systematic review. Indoor Air 2007, 17: 2-18.

LI, R.; SEKHAR, S. C.; MELIKOV, A. K. Thermal comfort and IAQ assessment of under-floor air distribution system integrated with personalized ventilation in hot and humid climate. Building and Environment, 2010. 45: 1906-1913.

LI, F.; LIU, J.; PEI, J.; LIN, C.-H.; CHEN, Q. Experimental study of gaseous and particulate contaminants distribution in an aircraft cabin. Atmospheric Environment, 2014. 85:223-233.

LI, B.; LI, J.; HUANG, Y.; YIN, H.; LIN, C.-H.; WEI, D.; SHEN, X.; LIU, J.; CHEN, Q. Experimental studies of thermal environment and contaminant transport in a commercial aircraft cabin with gaspers on. Accepted by Indoor Air, 2016.

LIU, W.; CHEN, Q. Current studies on air distribution in commercial airliner cabins. Accepted by Theoretical \& Applied Mechanics Letters, 2013.

MANGILI, A.; GENDREAU, M. A. Transmission of infectious diseases during commercial air travel. Lancet, 2005. 365: 989-996.

MASTERTON, R. G.; GREEN, A. D. Dissemination of human pathogens by airline travel. Soc. Appl. Bacteriol. Symp Ser., 1991. 20:31S-38S.

MAZUMDAR, S.; CHEN, Q. Response of contaminant detection sensors and sensor systems in a commercial aircraft cabin. Proceedings: Building Simulation, 2007. 
MAZUMDAR, S.; CHEN, Q. Influence of cabin conditions on placement and response of contaminant detection sensors in a commercial aircraft. Journal of Environmental Monitoring, 2008. 10: 71-81.

MAZUMDAR, S.; LONG, Z.; CHEN, Q. A coupled CFD and analytical model to simulate airborne contaminant transmission in cabins. Indoor and Built Environment, 2014. 23: 946-954.

MELIKOV, A. K. Personalized ventilation. Journal of Indoor Air, 2004. 14, suppl. 7:157-167.

MELIKOV, A. K. Indoor Environment: Health, Comfort and Performance. State of Art. CTU in Prague, October $20^{\text {th }}$ 2010. International Centre for Indoor Environment and Energy, 2010.

MENDELL, M. J.; FISK, W. J.; PETERSEN, M.; DONG, M. X.; HINES, C. J.; FAULKNER, D.; DEDDENS, J. A.; RUDER, A. M.; SULLIVAN, D.; BOENIGER, M.F. Enhanced particle filtration in a non-problem office environment: summary findings from a double-blind crossover intervention study. Pp. 974- 975 in Indoor Air 99, Proceedings of the 8th International Conference on Indoor Air Quality and Climate, Edinburgh, Scotland, 8-13 Aug. 1999, Vol. 4, G. Raw, C. Aizlewood and P. Warren, eds. London: Construction Research Communications.

MET ONE HHPC-6. Handheld Airborne Particle Counter Data Sheet, Hach Ultra Analytics, Estados Unidos da América, 2010.

MORAWSKA, L. Droplet fate in indoor environments, or can we prevent the spread of infection?. Proceedings of Indoor Air 2005, Beijing, China, 2005.

MOURA, D. Condições do escoamento e de conforto térmico em cabine de aeronave. Dissertação de Mestrado. Departamento de Engenharia Mecânica da Escola Politécnica da USP, São Paulo, Brasil, 2009. 74p.

MÜLLER, D.; SCHMIDT, M.; MÜLLER, B. Application of a displacement ventilation system for air distribution in aircraft cabins. AST 2011, Hamburg, Germany, March $31^{\text {st }}-$ April $1^{\text {st }}, 2011$.

NAGDA, N. L.; FORTMANN, R. C.; KOONTZ, M. D.; BAKER, S. R.; GINEVAN, M. E.; Measurement of cabin air quality aboard commercial airliners. Atmospheric Environment, 1992, Vol. 26A No. 12: pp. 2203-2210.

NAGDA, N. L.; RECTOR, H. E.; ZHIDONG, L.; SPACE, D. R. Aircraft cabin air quality: a critical review of past monitoring studies. Air Quality and Comfort in Airliner Cabins, ASTMSTP 1393, N L Nagda Ed. ASTM, West Conshohocken, PS, 2000.

NAS. National Academy of Science. Committee on Air Quality in Passengers Cabins of Commercial Aircraft, Board on Environmental Studies and Toxicology; National Research Council: The airliner cabin environment and the health of passengers and crew. Copyright 2002 by National Academy Press 2101 Constitution Ave., NW Box 285 Washington, DC 20055 800-624-6242 202-334-3313; 345.p, 2002.

NBR 16401. Instalações de ar-condicionado - Sistemas centrais e unitários: Parte 1 - Projetos das instalações, Parte 2 - Parâmetros de conforto térmico, Parte 3 - Qualidade do ar interior. NBR 16401:2008 (antiga NBR 6401:1980). ABNT - ASSOCIAÇÃO BRASILEIRA DE NORMAS TÉCNICAS, Rio de Janeiro, Brasil, 2008. 
NICAS, M.; NAZAROFF, W. W.; HUBBARD, A. Toward Understanding the Risk of Secondary Airborne Infection: Emission of Respirable Pathogens. Journal Occup. Environ. Hyg., 2005. 2:143-154.

NIELSEN, P. V.; BARTHOLOMAEUSSEN, N. M.; JAKUBOWSKA, E.; JIANG, H.; JONSSON, O. T.; KRAWIECKA, K.; MIERZEJEWSKI, A.; THOMAS, S. J.; TRAMPCZYNSKA, K.; POLAK, M.; SOENNICHSEN, M. Chair with integrated personalized ventilation for minimizing cross infection. Procedings of Roomvent 2007.

NIELSEN, P. V.; BARSZCZ, E.; CZARNOTA, T.; DYMALSKI, D. P.; JASIENSKI, M. A.; NOWOTKA, A.; MOZER, A.; WIANKOWSKA, S. M.; JENSEN, R. L. The influence of draught on a seat with integrated personalized ventilation. Proceedings of Indoor Air 2008, 17-22 August 2008, Copenhagen, Denmark - Paper ID:247.

NRC. National Research Council. The Airliner Cabin Environment: Air Quality and Safety. National Academy Press, Washington, DC, 1986.

NRC. National Research Council. The airliner cabin environment and the health of passengers and crew. National Academy Press, Washington, DC, 2002.

OLSEN, S. J.; CHANG, H. L.; CHEUNG, T. Y. Transmission of the severe acute respiratory syndrome on aircraft. New England Journal of Medicine, 2003. 349: 2416-2422.

OSMAN, S.; LA DUC, M. T.; DEKAS, A.; NEWCOMBE, D.; VENKATESWARAN, K. Microbial burden and diversity of commercial airline cabin air during short and long durations of travel. International Society for Microbial Ecology. The ISME Journal, 2008. 2: 482-497.

PADILLA, A. M. Experimental Analysis of Particulate Movement in a large eddy simulation chamber. A. Thesis for Master of Science Degree. Department of Mechanical and Nuclear Engineering of Kansas State University, 2008.

PANG, L.; XU, J.; FANG, L.; GONG, M.; ZHANG, H.; ZHANG, Y. Evaluation of an improved air distribution system for aircraft cabin. Building and Environment, 2013. 59: 145e52.

PAPINENI, R. S.; ROSENTHAL, F. S. The Size Distribution of Droplets in the Exhaled Breath of Healthy Human Subjects. J. Aerosol Med., 1997. 10: 105-161.

PEREIRA, M. L.; GRAUDENZ, G.; TRIBESS, A.; MORAWSKA, L. Determination of particle concentration in the breathing zone for four different types of office ventilation systems. Building and Environment, 2009. 44: 904-911.

PIERCE, W. M.; JANCZEWSKI, J. N.; ROETHLISBERGER, B.; JANCZEWSKI, M. G. Air Quality on Commerical Aircraft. ASHRAE Journal, 1999. 41(9):26-34.

POUSSOU, S. B.; MAZUMDAR, S.; PLESNIAK, M. W.; SOJKA, P. W.; CHEN, Q. Flow and contaminant transport in an airliner cabin induced by a moving body: Model experiments and CFD predictions. Journal of Atmospheric Environment, 2010. 44: 2830-2839.

PRESTON, F. S.; ERNSTING, J.; KING, P. Commercial aviation and health: general aspects. Aviation Medicine. Cambridge: Buttterworth-Heinemann LTD., Second Edition reprinted, 1995. 493-496. 
SILVA, E. S., 2013. Arquiteturas de distribuição de ar em cabines de aeronaves: Análise experimental do desconforto térmico local. Dissertação de Mestrado, Departamento de Eng. Mecânica, Escola Politécnica da USP, São Paulo, Brasil, 2013. $131 p$.

STANCATO, F. Análise do ambiente térmico de cabine de aeronave. Tese de Doutorado, Departamento de Eng. Mecânica, Escola Politécnica da USP, São Paulo, Brasil, 2009. 154p.

STEFFENS, J. Desempenho de filtros fibrosos operando na remoção de partículas nanométricas de aerossóis. Tese de Doutorado, Departamento de Eng. Química, Centro de Ciências Exatas e Tecnologia, Universidade Federal de São Carlos, São Paulo, Brasil, 2007.

STROM-TEJSEN, P. S.; WYON, D. P.; ZUKOWSJA, D.; JAMA, A.; FANG, L. Occupant evaluation of 7-hours exposures in a simulated aircraft cabin. Part 2: thermal effects. Proceedings Indoor Air 2005. Beijing, China, 2005.

SZE TO, G. N.; WAN, M. P.; CHAO, C. Y. H.; FANG, L.; MELIKOV, A. Experimental Study of Dispersion and Deposition of Expiratory Aerosols in Aircraft Cabins and Impact on Infectious Disease Transmission. Aerosol Science and Technology, 2009. 43:5, 466-485.

TANG, J. W.; LI, Y.; EAMES, I.; CHAN, P. K. S.; RIDGWAY, G. L. Factors involved in the aerosol transmission of infection and control of ventilation in healthcare premises. Journal of Hospital Infection, 2006. 64: 100-114.

THATCHER, T.; LAI, A. C. K.; JACKSON, R. M.; SEXTRO, R. G.; NAZAROFF, W. W. Effects of room furnishings and air speed on particle deposition rates indoors. Atmospheric Environment, 2002. 36: 1811-1819.

THIBEAULT, C. Cabin Air Quality, Aviation Space and Environmental Medicine. January 1997, Vol 68, No. 1, pp 80-82.

TOPAS. Descrição técnica do aerossol DEHS (Di-Etil-Hexil-Sebacato), 2012. Disponível em: <www.topas-gmbh.de>. Acesso em: jul. 2015.

TSI. Particle Generator Model 3079 - Manufacturer manual. Disponível em: $<w w w . a t i t e s t . c o m />$. Acesso em: jul. 2015. TSI. Model 3475 Condensation Monodisperse Aerosol Generator Instruction Manual, Revision E, out. 2004, TSI, 2010.

UVA, A. S. Exposição a ozono em cabinas de avião. Saúde Ocupacional, Escola Nacional de Saúde Pública, Universidade Nova de Lisboa, 2000, Vol 18, No. 2, p. 3554.

UVA, A. S. Qualidade do ar interior em aeronaves de aviação comercial. Observatório Português de Sistemas de Saúde, Escola Nacional de Saúde Pública, Universidade Nova de Lisboa, 2002.

VDI Guideline 3491. Particulate matter measurement; characteristics of suspended particulate matter in gases: terms and definitions. Technical Division Environmental Measurement Technologies, The Association of German Engineers, 2005.

VOLAVÝ, J.; FISER, J.; NÖSKE, I. Prediction of air temperature in the aircraft cabin under different operational conditions. EPJ Web of Conferences 45 01096, 2013. 
WAGNER, B. G.; COBURN; BLOWER. Calculating the potential for within-flight transmission of influenza A (H1N1). BMC Medicine, 7:81 doi:10.1186/1741-7015-781, 2009.

WALKINSHAW, D. S. Passengers aircraft indoor air quality challenges and solutions. Part II - Presentation to the ASHRAE Ottawa Valley Chapter Meeting, May $20^{\text {th }}, 2008$.

WALKINSHAW, D. S. Germs flying and the Truth. ASHRAE Journal, Vol. 52, 2010.

WALKINSHAW, D. S. Venturi Filtration added to gaspers, diffusers, VAV boxes and air curtains. Published in ASHRAE IAQ Conference 2010, C162-10, 2011.

WAN, M. P.; CHAO, C. Y. H.; FANG, L. Transmission characteristics of passenger-exhaled droplets in a simulated air-cabin environment. Proceedings of Indoor Air 2005.

WAN, M. P.; CHAO, C. Y. H.; NG, Y. D.; SZE TO, G. N.; YU, W. C. Dispersion of Expiratory Aerosols in a General Hospital Ward with Ceiling Mixing Type Mechanical Ventilation System. Journal of Aerosol Sci. Technol., 2007. 41: 244-258.

WAN, M. P.; SZE TO, G. N.; CHAO, C. Y. H.; FANG, L.; MELIKOV, A. Modeling the Fate of Expiratory Aerosols and the Associated Infection Risk in an Aircraft Cabin Environment'. Aerosol Science and Technology, 2009. 43:4, 322-343.

WANG, A. J.; ZHANG, Y. H.; TOPMILLER, J. L.; BENNETT, J. S.; DUNN, K. H. Tracer Study of Airborne Disease Transmission in an Aircraft Cabin Mock-Up. ASHRAE Transactions 2006; 112: Part 2, 2006.

WANG, M.; LIN, C. H.; CHEN, Q. Simulation of particle deposiiton in an airplane cabin mockup. SIMUL 2011: The Third Conference on Advances in Systems Simulation, 2011. ISBN: 978-1-61208-169-4 , 38-43.

XIE, X.; LI, Y.; CHWANG, A. T. Y.; HO, P. L.; SETO, W. H. How far droplets can move in indoor environments - revisiting the Wells evaporation-falling curve. Indoor Air 2007, 17:211-225.

YAN, W.; ZHANG, Y.; SUN, Y. ;LI, D. Experimental and CFD study of unsteady airborne pollutant transport within an aircraft cabin mock-up. Building and Environment, 2009. 44: 34-43.

YANAGIHARA, J.; GASPAROTTI, A. Projeto EMBRAER-FAPESP: Conforto expandido e design de cabines - desenvolvimento e análise integrada de critérios de conforto e metodologia de design. São Paulo, 2006. 27-29p.

YANG, C.; YANG, X.; XU, Y.; SREBRIC, J. Contaminant dispersion in personal displacement ventilation. Proceedings of Building Simulation, 2007.

YIN S.; ZHANG T. A new under-aisle displacement air distribution system for wide-body aircraft cabins. Building Simulation 2009. Eleventh International IBPSA Conference - Glasgow, Scotland. July 27-30, 2009.

YOO, S.H.; CHAE, S. K.; LIU, B. Y. H. Influence of Particle Refractive Index on the Lower Detection Limit of Light Scattering Aerosol Counters. Aerosol Science and Technology, 1996. 25:1, 1-10.

YU, I. T. S.; LI, Y.; WONG, T. W.; TAM, W.; CHAN, A. T.; LEE, J. H. W.; LEUNG, D. Y. $\mathrm{C}$.; $\mathrm{HO}, \mathrm{T}$. Evidence of airborne transmission of the severe acute respiratory syndrome virus. The New England Journal of Medicine, 2004. 350(17): 1731-1739. 
ZEIDLER, O.; DANILAK, M.; MÜLLER, D.; GORES, I.; BENDFELD, P. Experimental study of different air distribution systems for aircraft cabins. Proceedings of Indoor Air 2008, 17-22 August 2008, Copenhagen, Denmark - Paper ID:925.

ZHANG, T.; CHEN, Q. Novel air distribution systems for commercial aircraft cabins. Building and Environment, 2007. 42:1675-1684.

ZHANG, Z.; CHEN, X.; MAZUNDAR, S.; ZHANG, T.; CHEN, Q. Experimental and numerical investigation of airflow and contaminant transport in an airliner cabin mock-up. Proceedings of the $10^{\text {th }}$ International Conference on Air Distribution in Rooms, Building and Environment, Roomvent 2007. Helsinki.

ZHANG T.; YIN S.; WANG S.; An under-aisle air distribution system facilitating humidification of commercial aircraft cabins. Building and Environment, 2010. 45(4): 907-915.

ZHANG T.; LI, P. H.; WANG, S.,G. A personal air distribution system with air terminals embedded in chair armrests on commercial airplanes. Building and Environment, 2012. 41: 89-99.

ZHANG Z.; CHEN X.; MAZUNDAR, S.; ZHANG, T.; CHEN, Q. Experimental and numerical investigation of airflow and contaminant transport in an airliner cabin mock-up. Building and Environment, 2009. 44(1): 85-94.

ZUKOWSKI, M. A new formula for determining a minimum recommended value of inlet air velocity from UFAD system to prevent occupants from draught risk. Building and Environment, 2007. 42: 171-179. 


\section{ANEXO A}

O seguinte memorial de cálculo para o manômetro diferencial foi proposto por Fabichak Jr. (2013) em sua dissertação, baseado nas dimensões do equipamento disponível no laboratório.

\section{Memorial de cálculo do manômetro diferencial}

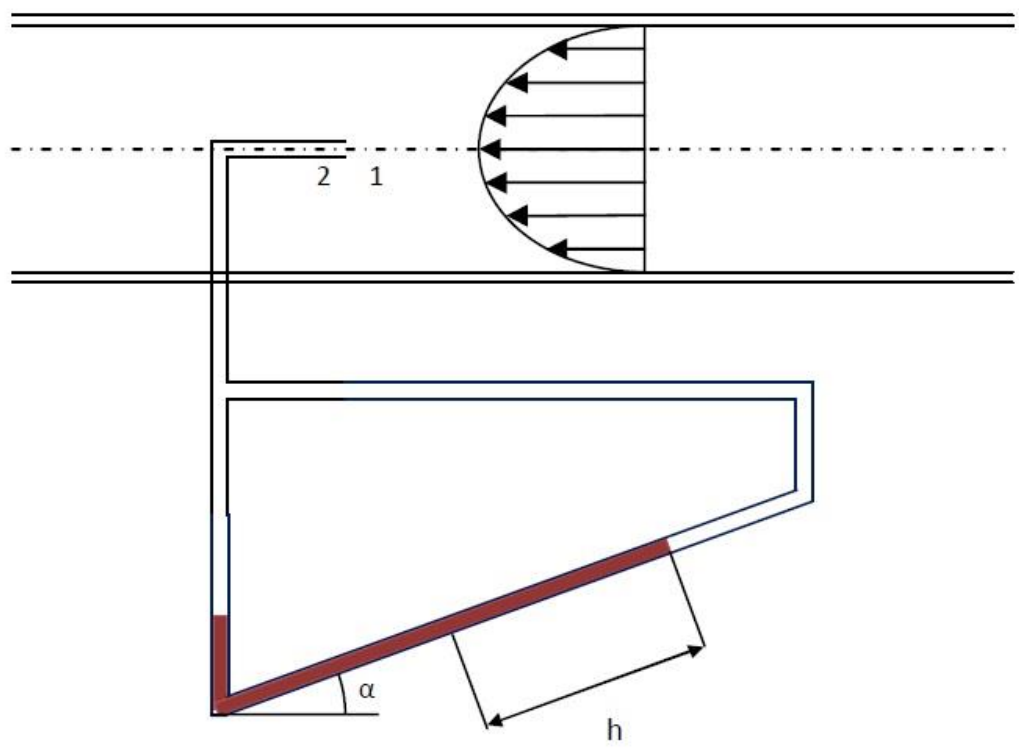

Utilizando a equação de conservação de energia

$H_{1}=H_{2}$

$\frac{v_{1}^{\frac{1}{2}}}{2 g}+\frac{P_{1}}{y}+z_{1}=\frac{v_{2}^{2}}{2 g}+\frac{P_{2}}{y}+z_{2}$

Adotando-se o ponto 1 muito próximo do ponto 2 tem-se:

$v_{1}=\sqrt[2]{2 g\left(\frac{P_{2}-P_{1}}{\gamma_{a r}}\right)}$

Pois,

$z_{1}=z_{2}=0$

$v_{2}=0$ (ponto de estagnação)

Aplicando-se a equação manométrica entre os pontos 1 e 2 tem-se:

$P_{2}+\gamma_{a r} \cdot h-\gamma_{f} \cdot h=P_{1}$

Portanto, tem-se:

$\frac{P_{2}-P_{1}}{\gamma_{a r}}=h\left(\frac{\gamma_{f}}{\gamma_{a r}}-1\right)$

Substituindo (2) em (1) tem-se:

$v_{1}=\sqrt[2]{2 g\left[h\left(\frac{\gamma_{f}}{\gamma_{a r}}-1\right)\right]}$

Em que:

$v_{1}=v_{\text {max }}$

Se o escoamento for turbulento, $\operatorname{Re}>2400$ 
$v_{\text {méd }}=\frac{49}{60} v_{\text {máx }}$

Se o escoamento for laminar, $\operatorname{Re}<2400$

$v_{\text {méd }}=0,5 \cdot v_{\text {máx }}$

A vazão média é dada por:

$Q_{\text {méd }}=A \cdot v_{\text {méd }}$

Em que:

$A=\frac{\pi \cdot d^{2}}{4}$

Dados para o cálculo do manômetro

glocal $=9,7856 \frac{\mathrm{m}}{\mathrm{s}}$

$\rho_{\text {ar @20 }}{ }^{\circ \mathrm{C}}=1,204 \frac{\mathrm{kg}}{\mathrm{m}^{2}}$

$\rho_{\text {fluido }}=0,8260 @ 20{ }^{\circ} \mathrm{C}$

$\rho_{H_{2}}$ @ @ 20 " $=998,2071 \frac{\mathrm{kg}}{\mathrm{m}^{\mathrm{a}}}$

$\mu_{\text {ar }}=1,74 \times 10^{-5} \mathrm{~Pa} \cdot \mathrm{s}$

$d_{\text {duto }}=100 \mathrm{~mm}$

Substituindo os valores, tem-se:

$v_{1}=115,685 \sqrt[2]{h}$

( $h$ é dado em metros)

$\mathrm{ou}$

$v_{1}=3,658 \sqrt[2]{h}$

( $h$ é dado em milímetros) 


\section{APÊNDICE A}

O critério de correntes de ar (Draught Rate) é um dos métodos de avaliação do desconforto térmico local. Esse resfriamento localizado é mais sensível às partes expostas do corpo, tais como pés, tornozelos, ombro, pescoço e face.

Conforme recomendação das normas ASHRAE-55 (2013) e NBR-16401 (2008), o percentual de pessoas insatisfeitas devido a correntes de ar $\left(P P D_{D R}\right)$ deve ser menor igual a $20 \%$.

Aplicando a equação da conservação de massa entre a entrada e a saída:

$$
Q m_{1}=Q m_{2}
$$

Sendo a vazão média dada por:

$$
Q_{\text {méd }}=A \cdot v_{\text {méd }}
$$

Onde:

$$
A=\frac{\pi \cdot d^{2}}{4}
$$

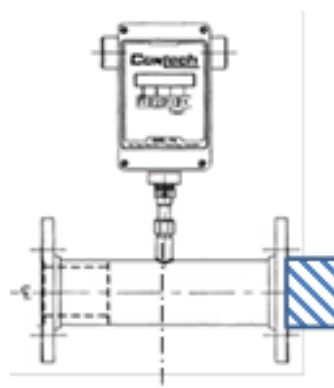

(1)

(2)

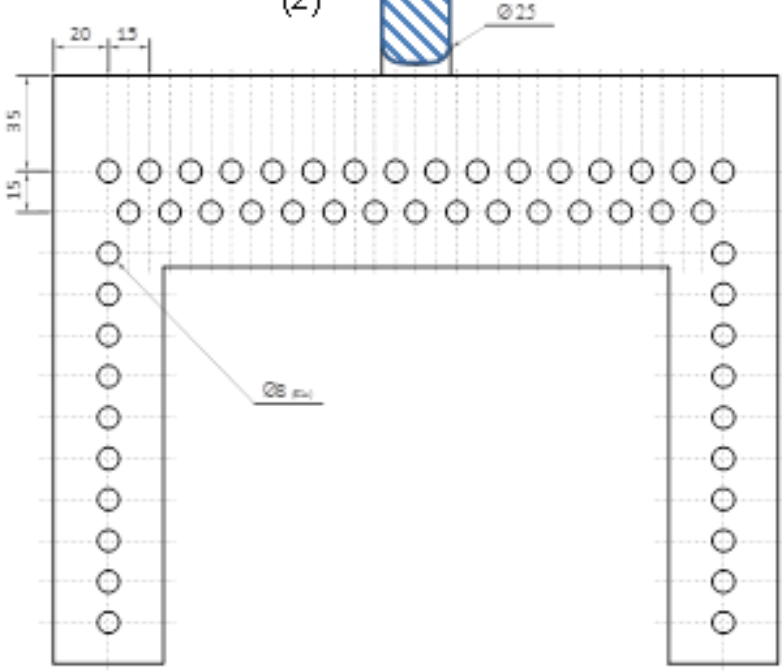


Sendo:

$d_{1}=35,7 \mathrm{~mm}$ (Diâmetro do bocal onde está localizado o elemento sensor)

$d_{2}=25,0 \mathrm{~mm}$ (Diâmetro do bocal do difusor)

A velocidade no bocal de saída do difusor foi medida com anemômetro de fio quente. Os valores de velocidade foram medidos em intervalos de $5 \mathrm{~s}$, durante 10 minutos. Com isso, obteve-se uma velocidade média no bocal de saída:

$v_{2}=7,45 \pm 0,26 \mathrm{~m} / \mathrm{s}$

Substituindo-se os valores em (1), temos que:

$v_{1} A_{1}=v_{2} A_{2}$

$v_{1}=3,65 \pm 0,26 \mathrm{~m} / \mathrm{s}$

Logo:

$Q_{1}=3,65 \cdot\left(\frac{\pi \cdot\left(35,7 \times 10^{-3}\right)^{2}}{4}\right) \cdot 3600$

$Q_{1}=13,17 m^{3} / h$

Porém, vale ressaltar que o medidor de vazão empregado nos fornece o resultado da vazão em Normal Metro Cúbico por hora $\left(\mathrm{Nm}^{3} / \mathrm{h}\right)$. O valor de $Q_{1}$ acima está em escala absoluta. Portanto, é necessário realizar uma conversão, de acordo com os dados ensaiados para o sistema personalizado.

$Q_{1 \text { (NORM })}=Q_{1} \cdot\left(\frac{273,15}{273,15+T_{1}}\right) \cdot\left(\frac{P_{1}-(R h \cdot P v)}{1,033}\right)$

Onde:

$\mathrm{T}_{1}=$ Temperatura do ar do sistema personalizado (igual a $24^{\circ} \mathrm{C}$ )

$P_{1}=$ Pressão atmosférica local (igual a $0,95 \mathrm{kgf} / \mathrm{cm}^{2}$ )

$\mathrm{Rh}=$ Umidade relativa do ar (em torno de 50\%)

$\mathrm{PV}=$ Pressão parcial do vapor de água (para a temperatura de insuflamento do ar de $24^{\circ} \mathrm{C}$, este valor vale $0,03016 \mathrm{kgf} / \mathrm{cm}^{2}$ (FOX; McDonald; Pritchard, 2006)

Deste modo:

$Q_{1(\text { NORM })}=10,93 \mathrm{Nm}^{3} / \mathrm{h}$ ou $Q_{1(\text { NORM })}=3,04 \ell / \mathrm{s}$ 
Fazendo-se a verificação se a vazão de insuflamento proposta para o sistema personalizado tende a causar desconforto por correntes de ar, recorremos aos dados experimentais.

Os valores médios para a temperatura e velocidade do ar e de intensidade de turbulência foram em média:

$$
\begin{aligned}
& \overline{T_{A R}}=24^{\circ} \mathrm{C} \\
& \overline{v_{A R}}=0,25 \mathrm{~m} / \mathrm{s} \\
& T_{U}=30 \%
\end{aligned}
$$

Finalmente, substitui-se os valores na equação 2.1 , mostrada no inicio do Capítulo 2. Assim sendo, o percentual de pessoas insatisfeitas devido a correntes de ar vale:

$$
P P D_{D R}=20,6 \%
$$

Portanto, a vazão de insuflamento de ar proposto para o funcionamento do sistema personalizado, mesmo muito próximo do valor máximo recomendado, não tende a causar desconforto térmico por correntes de ar. 


\section{APÊNDICE B}

Nesta seção, é detalhado o cálculo das incertezas nas medições da quantidade de partículas expiratórias, conforme citado no item 4.2.6.

A incerteza global das medições é atribuída como sendo a raiz quadrada da soma quadrática das incertezas locais, que representam as variáveis de erro associadas.

Deste modo, pode ser calculada a incerteza global como a combinação da distribuição de Poisson, da curva de distribuição de Gauss e do erro de coincidência do próprio equipamento de medição.

$$
\begin{aligned}
& \Delta N= \pm \sqrt{(\sqrt{N})^{2}+(\underbrace{\left.\sqrt{\frac{\sum\left(N_{i}-\bar{N}\right)^{2}}{n(n-1)}}\right)^{2}}+(\underbrace{(\sqrt{+5 \% N})^{2}}} \\
& \text { Poisson Gauss Coincidência }
\end{aligned}
$$

Tomando-se como exemplo a incerteza da medição de partículas de 3,0 $\mu \mathrm{m}$ para a arquitetura $\mathrm{MV}$ no assento $2 \mathrm{~B}$, considerando-se insuflamento de partículas pelo corredor. De acordo com os dados experimentais, as incertezas de acordo com cada um dos critérios acima listados valem, para este caso:

$$
\begin{aligned}
& \Delta N= \pm \sqrt{(230)^{2}+(734)^{2}+(2637)^{2}} \\
& \Delta N= \pm 2747
\end{aligned}
$$

Comparado com a quantidade de partículas deste caso ( $\mathrm{N}=52730)$, percebe-se que a incerteza combinada desta medição $\left(\frac{\Delta N}{N}\right)$ vale $5,2 \%$.

Os dados que seguem nas tabelas B.1 e B.2 são utilizados para a elaboração dos gráficos da Figura 5.4 e da Figura 5.5, para os casos do insuflamento das partículas pelo corredor e pela lateral da fuselagem, respectivamente. 
Tabela B.1. Dados referentes ao insuflamento das partículas pelo corredor

\begin{tabular}{|c|c|c|c|c|c|c|c|c|c|c|c|c|}
\hline \multicolumn{13}{|c|}{ SISTEMA MV - INSUFLAMENTO CORREDOR } \\
\hline & \multicolumn{6}{|c|}{ Assento 2A } & \multicolumn{6}{|c|}{ Assento 2B } \\
\hline & \multicolumn{6}{|c|}{ Concentração de Partículas } & \multicolumn{6}{|c|}{ Concentração de Partículas } \\
\hline & até $0,3 \mu \mathrm{m}$ & até $0,5 \mu \mathrm{m}$ & até $0,7 \mu \mathrm{m}$ & até $1,0 \mu \mathrm{m}$ & até $3,0 \mu \mathrm{m}$ & até 5,0 um & até $0,3 \mu \mathrm{m}$ & até $0,5 \mu \mathrm{m}$ & Taté $0,7 \mu \mathrm{m}$ & atée $1,0 \mu \mathrm{m}$ & |até $3,0 \mu \mathrm{m}$ & até $5,0 \mu \mathrm{m}$ \\
\hline Média & 108307 & 91881 & 90889 & 88653 & 42280 & 1300 & 112970 & 93104 & 85702 & 83948 & 52730 & 1531 \\
\hline DV-pad & 2806 & 5604 & 8541 & 5485 & 2501 & 431 & 3936 & 8694 & 6031 & 5832 & 2938 & 245 \\
\hline & \multicolumn{6}{|c|}{ Assento 2D } & \multicolumn{6}{|c|}{ Assento 2E } \\
\hline & \multicolumn{6}{|c|}{ Concentração de Partículas } & \multicolumn{6}{|c|}{ Concentração de Partículas } \\
\hline & até $0,3 \mu \mathrm{m}$ & até $0,5 \mu \mathrm{m}$ & até $0,7 \mu \mathrm{m}$ & até $1,0 \mu \mathrm{m}$ & até $3,0 \mu \mathrm{m}$ & até $5,0 \mu \mathrm{m}$ & até $0,3 \mu \mathrm{m}$ & até $0,5 \mu \mathrm{m}$ & 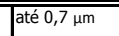 & | até $1,0 \mu \mathrm{m}$ & | até $3,0 \mu \mathrm{m}$ & 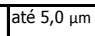 \\
\hline Média & 90808 & 84462 & 83457 & 81068 & 63420 & 1855 & 83451 & 77619 & 73003 & 76023 & 46062 & 1484 \\
\hline DV-pad & 4925 & 6691 & 7576 & 3568 & 1880 & 329 & 3828 & 6066 & 5948 & 5756 & 2859 & 394 \\
\hline \multicolumn{13}{|c|}{ SISTEMA MV+PVesq (sem inclinação) - INSUFLAMENTO CORREDOR } \\
\hline & \multicolumn{6}{|c|}{ Assento 2A } & \multicolumn{6}{|c|}{ Assento 2B } \\
\hline & \multicolumn{6}{|c|}{ Concentração de Partículas } & \multicolumn{6}{|c|}{ Concentração de Partículas } \\
\hline & até $0,3 \mu \mathrm{m}$ & até $0,5 \mu \mathrm{m}$ & até $0,7 \mu \mathrm{m}$ & até $1,0 \mu \mathrm{m}$ & até $3,0 \mu \mathrm{m}$ & até $5,0 \mu \mathrm{m}$ & até $0,3 \mu \mathrm{m}$ & até $0,5 \mu \mathrm{m}$ & |até $0,7 \mu \mathrm{m}$ & | até $1,0 \mu \mathrm{m}$ & | até $3,0 \mu \mathrm{m}$ & 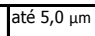 \\
\hline Média & 53215 & 41894 & 38113 & 36245 & 25043 & 1989 & 47894 & 41636 & 40753 & 40094 & 28086 & 2180 \\
\hline DV-pad & 4646 & 2093 & 1817 & 2150 & 1665 & 175 & 7294 & 6840 & 6734 & 6626 & 4382 & 404 \\
\hline & \multicolumn{6}{|c|}{ Assento 2D } & & & Asse & nto $2 \mathrm{E}$ & & \\
\hline & & & nncentraçã & o de Partí & ulas & & & & oncentraçãc & o de Partí & culas & \\
\hline & até $0,3 \mu \mathrm{m}$ & até $0,5 \mu \mathrm{m}$ & até $0,7 \mu \mathrm{m}$ & até $1,0 \mu \mathrm{m}$ & até $3,0 \mu \mathrm{m}$ & até $5,0 \mu \mathrm{m}$ & até $0,3 \mu \mathrm{m}$ & até $0,5 \mu \mathrm{m}$ & até $0,7 \mu \mathrm{m}$ & até $1,0 \mu \mathrm{m}$ & |até $3,0 \mu \mathrm{m}$ & |até $5,0 \mu \mathrm{m}$ \\
\hline Média & 82931 & 74889 & 74223 & 73215 & 50932 & 4660 & 72933 & 66378 & 65850 & 65022 & 45409 & 3783 \\
\hline DV-pad & 7348 & 6395 & 6360 & 6268 & 4257 & 569 & 5613 & 5026 & 4989 & 4896 & 3210 & 363 \\
\hline & & SISTE & MA MV & PVesq & co & $y^{\prime}$ & - INSUI & LA & JTO COR & REDOR & & \\
\hline & & & Asse & nto $2 A$ & & & & & Asser & nto 2B & & \\
\hline & & & ncentraçã & o de Partíc & ulas & & & & oncentraçãc & o de Partí & culas & \\
\hline & até $0,3 \mu \mathrm{m}$ & até $0,5 \mu \mathrm{m}$ & até $0,7 \mu \mathrm{m}$ & até $1,0 \mu \mathrm{m}$ & até $3,0 \mu \mathrm{m}$ & até $5,0 \mu \mathrm{m}$ & até $0,3 \mu \mathrm{m}$ & até $0,5 \mu \mathrm{m}$ & Taté $0,7 \mu \mathrm{m}$ & até $1,0 \mathrm{~mm}$ & até $3,0 \mu \mathrm{m}$ & 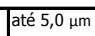 \\
\hline Média & 33206 & 28892 & 28617 & 28338 & 20975 & 1624 & 39617 & 35527 & 35260 & 34905 & 25180 & 1983 \\
\hline DV-pad & 3091 & 3409 & 3406 & 3366 & 2276 & 152 & 2996 & 2913 & 2896 & 2848 & 1947 & 192 \\
\hline & & & Asse & nto $2 \mathrm{D}$ & & & & & Asse & nto $2 \mathrm{E}$ & & \\
\hline & & & ncentraçã & o de Partíc & ulas & & & & oncentraçãc & o de Partí & culas & \\
\hline & até $0,3 \mu \mathrm{m}$ & até $0,5 \mu \mathrm{m}$ & até $0,7 \mu \mathrm{m}$ & até $1,0 \mu \mathrm{m}$ & até $3,0 \mu \mathrm{m}$ & até $5,0 \mu \mathrm{m}$ & até $0,3 \mu \mathrm{m}$ & até $0,5 \mu \mathrm{m}$ & | até $0,7 \mu \mathrm{m}$ & |até $1,0 \mathrm{\mu m}$ & até $3,0 \mu \mathrm{m}$ & |até $5,0 \mu \mathrm{m}$ \\
\hline Média & 70459 & 62830 & 62292 & 61477 & 43663 & 4489 & 65914 & 59075 & 58565 & 57815 & 41116 & 4212 \\
\hline DV-pad & 6027 & 5361 & 5324 & 5237 & 3561 & 466 & 3139 & 2937 & 2923 & 2897 & 2036 & 283 \\
\hline & & SISTE & MA MV & +PVdir ( & sem inc & linação & INSUF & LAMEN & TO COR & REDOR & & \\
\hline & & & Asse & nto $2 A$ & & & & & Asser & nto 2B & & \\
\hline & & & ncentraçã & o de Partíc & ulas & & & & oncentraçãa & o de Partí & ulas & \\
\hline & até $0,3 \mu \mathrm{m}$ & até $0,5 \mu \mathrm{m}$ & até $0,7 \mu \mathrm{m}$ & até $1,0 \mu \mathrm{m}$ & até $3,0 \mu \mathrm{m}$ & até $5,0 \mu \mathrm{m}$ & até $0,3 \mu \mathrm{m}$ & até $0,5 \mu \mathrm{m}$ & até $0,7 \mu \mathrm{m}$ & até $1,0 \mu \mathrm{m}$ & até $3,0 \mu \mathrm{m}$ & Jaté $5,0 \mu \mathrm{m}$ \\
\hline Média & 24447 & 18062 & 17800 & 17660 & 14786 & 1723 & 28222 & 22312 & 22056 & 21875 & 18650 & 3108 \\
\hline DV-pad & 1625 & 2329 & 2334 & 2315 & 1797 & 300 & 1090 & 1209 & 1212 & 1197 & 870 & 211 \\
\hline & & & Asse & nto 2D & & & & & Asse & nto $2 \mathrm{E}$ & & \\
\hline & & & ncentraçã & o de Partíc & ulas & & & & oncentracãa & o de Partí & culas & \\
\hline & até $0,3 \mu \mathrm{m}$ & até $0,5 \mu \mathrm{m}$ & até $0,7 \mu \mathrm{m}$ & até $1,0 \mu \mathrm{m}$ & até $3,0 \mu \mathrm{m}$ & até 5,0 um & até $0,3 \mu \mathrm{m}$ & até $0,5 \mu \mathrm{m}$ & |até $0,7 \mu \mathrm{m}$ & atée $1,0 \mathrm{\mu m}$ & até 3,0 um & |até 5,0 um \\
\hline Média & 38425 & 30885 & 30547 & 30256 & 25325 & 5663 & 28035 & 20674 & 20423 & 20257 & 17868 & 6211 \\
\hline DV-pad & 6090 & 6007 & 5988 & 5921 & 4434 & 894 & 7424 & 7989 & 7951 & 7850 & 5672 & 744 \\
\hline & & SISTE & MA MV & +PVdir ( & om inc & nação & INSUF & LAMEN & |TO COR & REDOR & & \\
\hline & & & Asse & nto $2 A$ & & & & & Asser & nto 2B & & \\
\hline & & & ncentraçã & o de Partíc & ulas & & & & oncentracãa & o de Partí & culas & \\
\hline & até $0,3 \mu \mathrm{m}$ & até $0,5 \mu \mathrm{m}$ & até $0,7 \mu \mathrm{m}$ & até $1,0 \mu \mathrm{m}$ & até $3,0 \mu \mathrm{m}$ & até 5,0 um & até $0,3 \mu \mathrm{m}$ & até $0,5 \mu \mathrm{m}$ & | até $0,7 \mu \mathrm{m}$ & até $1,0 \mu \mathrm{m}$ & até $3,0 \mu \mathrm{m}$ & Jaté $5,0 \mu \mathrm{m}$ \\
\hline Média & 31366 & 27154 & 26682 & 26039 & 15094 & 903 & 35429 & 31797 & 31525 & 31198 & 21988 & 1728 \\
\hline DV-pad & 5240 & 5409 & 5181 & 4623 & 746 & 166 & 2321 & 2316 & 2310 & 2286 & 1712 & 168 \\
\hline & & & Asse & nto 2D & & & & & Asse & nto $2 \mathrm{E}$ & & \\
\hline & & & ncentraçã & o de Partíc & ulas & & & & oncentraçã & o de Partí & culas & \\
\hline & até $0,3 \mu \mathrm{m}$ & até $0,5 \mu \mathrm{m}$ & até $0,7 \mu \mathrm{m}$ & até $1,0 \mu \mathrm{m}$ & até $3,0 \mu \mathrm{m}$ & até 5,0 um & até $0,3 \mu \mathrm{m}$ & até $0,5 \mu \mathrm{m}$ & |até $0,7 \mu \mathrm{m}$ & até $1,0 \mu \mathrm{m}$ & até 3,0 um & |até 5,0 um \\
\hline Média & 66996 & 60353 & 59885 & 59129 & 42048 & 3929 & 55590 & 50480 & 50113 & 49524 & 35537 & 3218 \\
\hline DV-pad & 7802 & 6982 & 6916 & 6807 & 4419 & 745 & 6964 & 6249 & 6203 & 6117 & 4455 & 437 \\
\hline
\end{tabular}


Tabela 5.2. Dados referentes ao insuflamento das partículas pela lateral

\begin{tabular}{|c|c|c|c|c|c|c|c|c|c|c|c|c|}
\hline \multicolumn{13}{|c|}{ SISTEMA MV - INSUFLAMENTO LATERAL } \\
\hline & \multicolumn{6}{|c|}{ Assento 2A } & \multicolumn{6}{|c|}{ Assento 2B } \\
\hline & \multicolumn{6}{|c|}{ Concentração de Partículas } & \multicolumn{6}{|c|}{ Concentração de Partículas } \\
\hline & até $0,3 \mu \mathrm{m}$ & até $0,5 \mu \mathrm{m}$ & até $0,7 \mu \mathrm{m}$ & até $1,0 \mu \mathrm{m}$ & até $3,0 \mu \mathrm{m}$ & até $5,0 \mu \mathrm{m}$ & até $0,3 \mu \mathrm{m}$ & até $0,5 \mu \mathrm{m}$ & até $0,7 \mu \mathrm{m}$ & até $1,0 \mu \mathrm{m}$ & até $3,0 \mu \mathrm{m}$ & até $5,0 \mu \mathrm{m}$ \\
\hline Média & 31800 & 14429 & 13510 & 13255 & 11138 & 1285 & 30089 & 19811 & 19219 & 18985 & 15335 & 1801 \\
\hline DV-pad & 564 & 2711 & 2820 & 2827 & 2121 & 286 & 1716 & 2281 & 2323 & 2323 & 1877 & 213 \\
\hline & \multicolumn{6}{|c|}{ Assento 2D } & \multicolumn{6}{|c|}{ Assento 2E } \\
\hline & \multicolumn{6}{|c|}{ Concentração de Partículas } & \multicolumn{6}{|c|}{ Concentração de Partículas } \\
\hline & até $0,3 \mu \mathrm{m}$ & até $0,5 \mu \mathrm{m}$ & até $0,7 \mu \mathrm{m}$ & até $1,0 \mu \mathrm{m}$ & 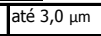 & até $5,0 \mu \mathrm{m}$ & até $0,3 \mu \mathrm{m}$ & atée $0,5 \mu \mathrm{m}$ & até $0,7 \mu \mathrm{m}$ & até $1,0 \mu \mathrm{m}$ & Taté $3,0 \mu \mathrm{m}$ & atée $5,0 \mu \mathrm{m}$ \\
\hline Média & 28788 & 18724 & 18205 & 18016 & 14923 & 1792 & 27350 & 16669 & 16133 & 15943 & 13259 & 1563 \\
\hline DV-pad & 1132 & 1656 & 1674 & 1663 & 1232 & 213 & 895 & 1117 & 1149 & 1148 & 938 & 161 \\
\hline \multicolumn{13}{|c|}{ SISTEMA MV+PVesq (sem inclinação) - INSUFLAMENTO LATERAL } \\
\hline & \multicolumn{6}{|c|}{ Assento 2A } & \multicolumn{6}{|c|}{ Assento 2B } \\
\hline & \multicolumn{6}{|c|}{ Concentração de Partículas } & \multicolumn{6}{|c|}{ Concentração de Partículas } \\
\hline & até $0,3 \mu \mathrm{m}$ & até $0,5 \mu \mathrm{m}$ & até $0,7 \mu \mathrm{m}$ & até $1,0 \mu \mathrm{m}$ & até $3,0 \mu \mathrm{m}$ & até $5,0 \mu \mathrm{m}$ & até $0,3 \mu \mathrm{m}$ & até $0,5 \mu \mathrm{m}$ & até $0,7 \mu \mathrm{m}$ & até $1,0 \mu \mathrm{m}$ & até $3,0 \mu \mathrm{m}$ & até $5,0 \mu \mathrm{m}$ \\
\hline Média & 14526 & 5576 & 5196 & 5100 & 4648 & 909 & 15252 & 7437 & 7144 & 7062 & 5846 & 1108 \\
\hline DV-pad & 1094 & 904 & 891 & 895 & 801 & 161 & 2987 & 3949 & 3980 & 3974 & 3393 & 601 \\
\hline & \multicolumn{6}{|c|}{ Assento 2D } & & & Asse & nto $2 \mathrm{E}$ & & \\
\hline & & & ncentraçã & o de Partíc & ulas & & & & ncentraçã & o de Partíc & culas & \\
\hline & até $0,3 \mu \mathrm{m}$ & até $0,5 \mu \mathrm{m}$ & até $0,7 \mu \mathrm{m}$ & até $1,0 \mu \mathrm{m}$ & até $3,0 \mu \mathrm{m}$ & até $5,0 \mu \mathrm{m}$ & até $0,3 \mu \mathrm{m}$ & atée $0,5 \mu \mathrm{m}$ & até $0,7 \mu \mathrm{m}$ & até $1,0 \mu \mathrm{m}$ & até $3,0 \mu \mathrm{m}$ & até $5,0 \mu \mathrm{m}$ \\
\hline Média & 22006 & 19682 & 18546 & 18014 & 14589 & 1702 & 25092 & 23518 & 23080 & 22797 & 18350 & 2172 \\
\hline DV-pad & 1058 & 1507 & 1771 & 1894 & 1527 & 202 & 1023 & 4192 & 4242 & 4205 & 3135 & 424 \\
\hline & & SIST & EMA MI & $\mathrm{V+PVesq}$ & (com i & nclinaçấ & o) - INS & UFLAME & NTO LA & TERAL & & \\
\hline & & & Asse & nto $2 A$ & & & & & Asse & nto 2B & & \\
\hline & & & ncentraçã & o de Partíc & ulas & & & & ncentraçã & o de Partí & ullas & \\
\hline & até $0,3 \mu \mathrm{m}$ & até $0,5 \mu \mathrm{m}$ & até $0,7 \mu \mathrm{m}$ & até $1,0 \mu \mathrm{m}$ & até $3,0 \mu \mathrm{m}$ & até $5,0 \mu \mathrm{m}$ & até $0,3 \mu \mathrm{m}$ & até $0,5 \mathrm{~mm}$ & |até $0,7 \mu \mathrm{m}$ & até $1,0 \mu \mathrm{m}$ & 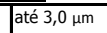 & até $5,0 \mu \mathrm{m}$ \\
\hline Média & 18674 & 12715 & 12499 & 12412 & 10705 & 1256 & 21259 & 16690 & 16477 & 16364 & 13783 & 1715 \\
\hline DV-pad & 1730 & 1933 & 1937 & 1926 & 1523 & 227 & 772 & 1043 & 1052 & 1049 & 794 & 153 \\
\hline & & & Asse & nto 2D & & & & & Asse & nto $2 E$ & & \\
\hline & & & ncentraçã & o de Partíc & ulas & & & & ncentraçã & o de Partí & unlas & \\
\hline & até $0,3 \mu \mathrm{m}$ & até $0,5 \mu \mathrm{m}$ & até $0,7 \mu \mathrm{m}$ & até $1,0 \mu \mathrm{m}$ & até $3,0 \mu \mathrm{m}$ & até $5,0 \mu \mathrm{m}$ & até $0,3 \mu \mathrm{m}$ & até $0,5 \mathrm{~mm}$ & até $0,7 \mu \mathrm{m}$ & até $1,0 \mu \mathrm{m}$ & até $3,0 \mu \mathrm{m}$ & até $5,0 \mu \mathrm{m}$ \\
\hline Média & 24807 & 20609 & 20427 & 20280 & 16757 & 2156 & 25331 & 20836 & 20651 & 20501 & 16950 & 2162 \\
\hline DV-pad & 1988 & 2188 & 2193 & 2167 & 1675 & 261 & 2273 & 2561 & 2562 & 2533 & 1886 & 309 \\
\hline & & SIS & A & V+PVdi & SEIII & 111 & ) - INS & LAIVIE & D LA & ERAL & & \\
\hline & & & Asse & nto $2 \mathrm{~A}$ & & & & & Asse & nto $2 B$ & & \\
\hline & & & ncentraçã & o de Partíc & ulas & & & & ncentraçã & o de Partí & unlas & \\
\hline & até $0,3 \mu \mathrm{m}$ & até $0,5 \mu \mathrm{m}$ & laté $0,7 \mu \mathrm{m}$ & | até $1,0 \mu \mathrm{m}$ & até $3,0 \mu \mathrm{m}$ & até $5,0 \mu \mathrm{m}$ & até $0,3 \mu \mathrm{m}$ & até $0,5 \mu \mathrm{m}$ & até $0,7 \mu \mathrm{m}$ & até $1,0 \mu \mathrm{m}$ & | até $3,0 \mu \mathrm{m}$ & até $5,0 \mu \mathrm{m}$ \\
\hline Média & 23476 & 15329 & 14751 & 14412 & 11497 & 1164 & 24445 & 18910 & 18642 & 18474 & 14780 & 1572 \\
\hline DV-pad & 1861 & 1687 & 1813 & 1932 & 1841 & 239 & 1071 & 2339 & 2360 & 2329 & 1299 & 192 \\
\hline & & & Asse & nto 2D & & & & & Asse & nto $2 \mathrm{E}$ & & \\
\hline & & & ncentraçã & o de Partíc & ulas & & & & ncentraçã & o de Partí & unlas & \\
\hline & até $0,3 \mu \mathrm{m}$ & até $0,5 \mu \mathrm{m}$ & até $0,7 \mu \mathrm{m}$ & até $1,0 \mu \mathrm{m}$ & 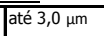 & até $5,0 \mu \mathrm{m}$ & até $0,3 \mu \mathrm{m}$ & até $0,5 \mathrm{~mm}$ & até $0,7 \mu \mathrm{m}$ & até $1,0 \mu \mathrm{m}$ & Taté $3,0 \mu \mathrm{m}$ & Taté $5,0 \mu \mathrm{m}$ \\
\hline Média & 30061 & 24991 & 24731 & 24509 & 19506 & 2350 & 27768 & 22252 & 21992 & 21810 & 17812 & 2120 \\
\hline DV-pad & 3957 & 4731 & 4741 & 4688 & 3093 & 383 & 2335 & 2680 & 2686 & 2660 & 1979 & 299 \\
\hline & & SI & MA & V+PVdir & $C 01111$ & IIIC & $1-1100$ & TLAIVIL & NTO LAT & TERAL & & \\
\hline & & & Asse & nto $2 A$ & & & & & Asse & nto 2B & & \\
\hline & & & ncentraçã & o de Partíc & alas & & & & incentraçã & o de Partí & culas & \\
\hline & até $0,3 \mu \mathrm{m}$ & até $0,5 \mu \mathrm{m}$ & até $0,7 \mu \mathrm{m}$ & até $1,0 \mu \mathrm{m}$ & até 3,0 um & até $5,0 \mu \mathrm{m}$ & até $0,3 \mu \mathrm{m}$ & até $0,5 \mathrm{~mm}$ & |até $0,7 \mu \mathrm{m}$ & até $1,0 \mu \mathrm{m}$ & Taté $3,0 \mu \mathrm{m}$ & até $5,0 \mu \mathrm{m}$ \\
\hline Média & 23418 & 18154 & 17917 & 17774 & 13904 & 1220 & 26775 & 22762 & 22567 & 22375 & 17086 & 1431 \\
\hline DV-pad & 1403 & 1969 & 1963 & 1935 & 1321 & 173 & 2741 & 3049 & 3047 & 3004 & 2057 & 196 \\
\hline & & & Asse & nto 2D & & & & & Asse & nto $2 \mathrm{E}$ & & \\
\hline & & & nncentraçã & o de Partíc & ulas & & & & ncentraçã & o de Partí & culas & \\
\hline & até $0,3 \mu \mathrm{m}$ & até $0,5 \mu \mathrm{m}$ & até $0,7 \mu \mathrm{m}$ & até $1,0 \mu \mathrm{m}$ & até $3,0 \mu \mathrm{m}$ & até $5,0 \mu \mathrm{m}$ & até $0,3 \mu \mathrm{m}$ & até $0,5 \mu \mathrm{m}$ & até $0,7 \mu \mathrm{m}$ & até $1,0 \mu \mathrm{m}$ & até $3,0 \mu \mathrm{m}$ & até $5,0 \mu \mathrm{m}$ \\
\hline Média & 32022 & 27799 & 27534 & 27267 & 20769 & 1918 & 28137 & 24152 & 23949 & 23759 & 19366 & 2511 \\
\hline DV-pad & 5824 & 6034 & 6013 & 5911 & 3913 & 291 & 3200 & 3251 & 3236 & 3191 & 2344 & 319 \\
\hline
\end{tabular}


Nas Tabelas B.3 até B.12, são extraídos os dados referentes às incertezas na contagem das partículas para cada uma das arquiteturas avaliadas, considerando-se os critérios das incertezas descritos no item 4.2.6.

Tabela B.3. Incertezas na contagem das partículas insufladas pelo corredor - Sistema MV

\begin{tabular}{|c|c|c|c|c|c|c|c|c|c|c|c|c|}
\hline \multicolumn{13}{|c|}{ SISTEMA MV - INSUFLAMENTO CORREDOR } \\
\hline & \multicolumn{6}{|c|}{ Assento 2A } & \multicolumn{6}{|c|}{ Assento 2B } \\
\hline & \multicolumn{6}{|c|}{ Concentração de Partículas } & \multicolumn{6}{|c|}{ Concentração de Partículas } \\
\hline & até $0,3 \mu \mathrm{m}$ & até $0,5 \mu \mathrm{m}$ & até $0,7 \mu \mathrm{m}$ & até $1,0 \mu \mathrm{m}$ & até $3,0 \mu \mathrm{m}$ & até $5,0 \mu \mathrm{m}$ & até $0,3 \mu \mathrm{m}$ & até $0,5 \mu \mathrm{m}$ & até $0,7 \mu \mathrm{m}$ & até $1,0 \mu \mathrm{m}$ & até $3,0 \mu \mathrm{m}$ & até $5,0 \mu \mathrm{m}$ \\
\hline Média & 108307 & 91881 & 90889 & 88653 & 42280 & 1300 & 112970 & 93104 & 85702 & 83948 & 52730 & 1531 \\
\hline DV-pad & 2806 & 5604 & 8541 & 5485 & 2501 & 431 & 3936 & 8694 & 6031 & 5832 & 2938 & 245 \\
\hline Gauss & 701 & 1401 & 2135 & 1371 & 625 & 108 & 984 & 2174 & 1508 & 1458 & 734 & 61 \\
\hline Coincidência & 5415 & 4594 & 4544 & 4433 & 2114 & 65 & 5649 & 4655 & 4285 & 4197 & 2637 & 77 \\
\hline Poisson & 329 & 303 & 301 & 298 & 206 & 36 & 336 & 305 & 293 & 290 & 230 & 39 \\
\hline \multirow[t]{4}{*}{ Incerteza } & 5470 & 4812 & 5030 & 4649 & 2214 & 131 & 5743 & 5147 & 4552 & 4453 & 2747 & 106 \\
\hline & \multicolumn{6}{|c|}{ Assento 2D } & \multicolumn{6}{|c|}{ Assento 2E } \\
\hline & \multicolumn{6}{|c|}{ Concentração de Partículas } & \multicolumn{6}{|c|}{ Concentração de Partículas } \\
\hline & até $0,3 \mu \mathrm{m}$ & até $0,5 \mu \mathrm{m}$ & até $0,7 \mu \mathrm{m}$ & até $1,0 \mu \mathrm{m}$ & até $3,0 \mu \mathrm{m}$ & até $5,0 \mu \mathrm{m}$ & até $0,3 \mu \mathrm{m}$ & até $0,5 \mu \mathrm{m}$ & até $0,7 \mu \mathrm{m}$ & até $1,0 \mu \mathrm{m}$ & até $3,0 \mu \mathrm{m}$ & até $5,0 \mu \mathrm{m}$ \\
\hline Média & 90808 & 84462 & 83457 & 81068 & 63420 & 1855 & 83451 & 77619 & 73003 & 76023 & 46062 & 1484 \\
\hline DV-pad & 4925 & 6691 & 7576 & 3568 & 1880 & 329 & 3828 & 6066 & 5948 & 5756 & 2859 & 394 \\
\hline Gauss & 1231 & 1673 & 1894 & 892 & 470 & 82 & 957 & 1517 & 1487 & 1439 & 715 & 99 \\
\hline Coincidência & 4540 & 4223 & 4173 & 4053 & 3171 & 93 & 4173 & 3881 & 3650 & 3801 & 2303 & 74 \\
\hline Poisson & 301 & 291 & 289 & 285 & 252 & 43 & 289 & 279 & 270 & 276 & 215 & 39 \\
\hline Incerteza & 4714 & 4552 & 4592 & 4160 & 3216 & 131 & 4291 & 4176 & 3951 & 4074 & 2421 & 129 \\
\hline
\end{tabular}

Tabela B.4. Incertezas na contagem das partículas insufladas pelo corredor - Sistema PVesq (sem inclinação)

\begin{tabular}{|c|c|c|c|c|c|c|c|c|c|c|c|c|}
\hline \multicolumn{13}{|c|}{ SISTEMA MV+PVesq (sem inclinação) - INSUFLAMENTO CORREDOR } \\
\hline & \multicolumn{6}{|c|}{ Assento 2A } & \multicolumn{6}{|c|}{ Assento 2B } \\
\hline & \multicolumn{6}{|c|}{ Concentração de Partículas } & \multicolumn{6}{|c|}{ Concentração de Partículas } \\
\hline & até $0,3 \mu \mathrm{m}$ & até $0,5 \mu \mathrm{m}$ & 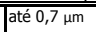 & $\overline{\text { até } 1,0 \mu \mathrm{m}}$ & Jaté $3,0 \mu \mathrm{m}$ & até 5,0 $\mu \mathrm{m}$ & até $0,3 \mu \mathrm{m}$ & até $0,5 \mu \mathrm{m}$ & Jaté $0,7 \mu \mathrm{m}$ & $\overline{\text { até } 1,0 \mu \mathrm{m}}$ & Jaté $3,0 \mu \mathrm{m}$ & até $5,0 \mu \mathrm{m}$ \\
\hline Média & 53215 & 41894 & 38113 & 36245 & 25043 & 1989 & 47894 & 41636 & 40753 & 40094 & 28086 & 2180 \\
\hline DV-pad & 4646 & 2093 & 1817 & 2150 & 1665 & 175 & 7294 & 6840 & 6734 & 6626 & 4382 & 404 \\
\hline Gauss & 1199 & 525 & 424 & 515 & 403 & 40 & 1539 & 1542 & 1540 & 1523 & 1011 & 84 \\
\hline Coincidência & 2661 & 2095 & 1906 & 1812 & 1252 & 99 & 2395 & 2082 & 2038 & 2005 & 1404 & 109 \\
\hline Poisson & 231 & 205 & 195 & 190 & 158 & 45 & 219 & 204 & 202 & 200 & 168 & 47 \\
\hline \multirow[t]{4}{*}{ Incerteza } & 2927 & 2169 & 1962 & 1894 & 1325 & 116 & 2855 & 2599 & 2562 & 2525 & 1738 & 146 \\
\hline & \multicolumn{6}{|c|}{ Assento 2D } & \multicolumn{6}{|c|}{ Assento 2E } \\
\hline & \multicolumn{6}{|c|}{ Concentração de Partículas } & \multicolumn{6}{|c|}{ Concentração de Partículas } \\
\hline & até $0,3 \mu \mathrm{m}$ & até $0,5 \mu \mathrm{m}$ & até $0,7 \mu \mathrm{m}$ & até $1,0 \mu \mathrm{m}$ & até $3,0 \mu \mathrm{m}$ & até $5,0 \mu \mathrm{m}$ & até $0,3 \mu \mathrm{m}$ & até $0,5 \mu \mathrm{m}$ & até $0,7 \mu \mathrm{m}$ & até $1,0 \mu \mathrm{m}$ & até $3,0 \mu \mathrm{m}$ & até $5,0 \mu \mathrm{m}$ \\
\hline Média & 82931 & 74889 & 74223 & 73215 & 50932 & 4660 & 72933 & 66378 & 65850 & 65022 & 45409 & 3783 \\
\hline DV-pad & 7348 & 6395 & 6360 & 6268 & 4257 & 569 & 5613 & 5026 & 4989 & 4896 & 3210 & 363 \\
\hline Gauss & 1803 & 1547 & 1540 & 1516 & 1023 & 138 & 1503 & 1346 & 1334 & 1309 & 858 & 91 \\
\hline Coincidência & 4147 & 3744 & 3711 & 3661 & 2547 & 233 & 3647 & 3319 & 3292 & 3251 & 2270 & 189 \\
\hline Poisson & 288 & 274 & 272 & 271 & 226 & 68 & 270 & 258 & 257 & 255 & 213 & 62 \\
\hline Incerteza & 4531 & 4061 & 4027 & 3972 & 2754 & 279 & 3953 & 3591 & 3562 & 3514 & 2437 & 219 \\
\hline
\end{tabular}

Tabela B.5. Incertezas na contagem das partículas insufladas pelo corredor - Sistema PVesq (com inclinação)

\begin{tabular}{|c|c|c|c|c|c|c|c|c|c|c|c|c|}
\hline \multicolumn{13}{|c|}{ SISTEMA MV+PVesq (com inclinação) - INSUFLAMENTO CORREDOR } \\
\hline & \multicolumn{6}{|c|}{ Assento 2A } & \multicolumn{6}{|c|}{ Assento 2B } \\
\hline & \multicolumn{6}{|c|}{ Concentração de Partículas } & \multicolumn{6}{|c|}{ Concentração de Partículas } \\
\hline & até $0,3 \mu \mathrm{m}$ & até $0,5 \mu \mathrm{m}$ & até $0,7 \mu \mathrm{m}$ & até $1,0 \mu \mathrm{m}$ & até $3,0 \mu \mathrm{m}$ & até $5,0 \mu \mathrm{m}$ & até $0,3 \mu \mathrm{m}$ & até $0,5 \mu \mathrm{m}$ & até $0,7 \mu \mathrm{m}$ & até $1,0 \mu \mathrm{m}$ & até $3,0 \mu \mathrm{m}$ & até $5,0 \mu \mathrm{m}$ \\
\hline Média & 33206 & 28892 & 28617 & 28338 & 20975 & 1624 & 39617 & 35527 & 35260 & 34905 & 25180 & 1983 \\
\hline DV-pad & 3091 & 3409 & 3406 & 3366 & 2276 & 152 & 2996 & 2913 & 2896 & 2848 & 1947 & 192 \\
\hline Gauss & 730 & 801 & 798 & 788 & 527 & 38 & 806 & 785 & 781 & 769 & 526 & 50 \\
\hline Coincidência & 1660 & 1445 & 1431 & 1417 & 1049 & 81 & 1981 & 1776 & 1763 & 1745 & 1259 & 99 \\
\hline Poisson & 182 & 170 & 169 & 168 & 145 & 40 & 199 & 188 & 188 & 187 & 159 & 45 \\
\hline \multirow[t]{4}{*}{ Incerteza } & 1823 & 1661 & 1647 & 1630 & 1183 & 98 & 2148 & 1951 & 1937 & 1916 & 1374 & 120 \\
\hline & \multicolumn{6}{|c|}{ Assento 2D } & \multicolumn{6}{|c|}{ Assento 2E } \\
\hline & \multicolumn{6}{|c|}{ Concentração de Partículas } & \multicolumn{6}{|c|}{ Concentração de Partículas } \\
\hline & até $0,3 \mu \mathrm{m}$ & até $0,5 \mu \mathrm{m}$ & até $0,7 \mu \mathrm{m}$ & até $1,0 \mu \mathrm{m}$ & até $3,0 \mu \mathrm{m}$ & até $5,0 \mu \mathrm{m}$ & até $0,3 \mu \mathrm{m}$ & até $0,5 \mu \mathrm{m}$ & até $0,7 \mu \mathrm{m}$ & até $1,0 \mu \mathrm{m}$ & até $3,0 \mu \mathrm{m}$ & até $5,0 \mu \mathrm{m}$ \\
\hline Média & 70459 & 62830 & 62292 & 61477 & 43663 & 4489 & 65914 & 59075 & 58565 & 57815 & 41116 & 4212 \\
\hline DV-pad & 6027 & 5361 & 5324 & 5237 & 3561 & 466 & 3139 & 2937 & 2923 & 2897 & 2036 & 283 \\
\hline Gauss & 1544 & 1387 & 1381 & 1359 & 929 & 114 & 871 & 808 & 804 & 796 & 544 & 70 \\
\hline Coincidência & 3523 & 3142 & 3115 & 3074 & 2183 & 224 & 3296 & 2954 & 2928 & 2891 & 2056 & 211 \\
\hline Poisson & 265 & 251 & 250 & 248 & 209 & 67 & 257 & 243 & 242 & 240 & 203 & 65 \\
\hline Incerteza & 3856 & 3443 & 3416 & 3370 & 2382 & 261 & 3419 & 3072 & 3046 & 3008 & 2136 & 231 \\
\hline
\end{tabular}


Tabela B.6. Incertezas na contagem das partículas insufladas pelo corredor - Sistema PVdir (sem inclinação)

\begin{tabular}{|c|c|c|c|c|c|c|c|c|c|c|c|c|}
\hline \multicolumn{13}{|c|}{ SISTEMA MV+PVdir (sem inclinação) - INSUFLAMENTO CORREDOR } \\
\hline & \multicolumn{6}{|c|}{ Assento 2A } & \multicolumn{6}{|c|}{ Assento 2B } \\
\hline & \multicolumn{6}{|c|}{ Concentração de Partículas } & \multicolumn{6}{|c|}{ Concentração de Partículas } \\
\hline & até $0,3 \mu \mathrm{m}$ & até $0,5 \mu \mathrm{m}$ & até $0,7 \mu \mathrm{m}$ & até $1,0 \mu \mathrm{m}$ & até $3,0 \mu \mathrm{m}$ & até $5,0 \mu \mathrm{m}$ & até $0,3 \mu \mathrm{m}$ & até $0,5 \mu \mathrm{m}$ & até $0,7 \mu \mathrm{m}$ & até $1,0 \mu \mathrm{m}$ & até $3,0 \mu \mathrm{m}$ & até $5,0 \mu \mathrm{m}$ \\
\hline Média & 24447 & 18062 & 17800 & 17660 & 14786 & 1723 & 28222 & 22312 & 22056 & 21875 & 18650 & 3108 \\
\hline DV-pad & 1625 & 2329 & 2334 & 2315 & 1797 & 300 & 1090 & 1209 & 1212 & 1197 & 870 & 211 \\
\hline Gauss & 406 & 607 & 608 & 603 & 458 & 74 & 264 & 292 & 293 & 289 & 217 & 54 \\
\hline Coincidência & 1222 & 903 & 890 & 883 & 739 & 86 & 1411 & 1116 & 1103 & 1094 & 932 & 155 \\
\hline Poisson & 156 & 134 & 133 & 133 & 122 & 42 & 168 & 149 & 149 & 148 & 137 & 56 \\
\hline \multirow[t]{4}{*}{ Incerteza } & 1297 & 1096 & 1086 & 1077 & 878 & 121 & 1445 & 1163 & 1151 & 1141 & 967 & 174 \\
\hline & \multicolumn{6}{|c|}{ Assento 2D } & \multicolumn{6}{|c|}{ Assento 2E } \\
\hline & \multicolumn{6}{|c|}{ Concentração de Partículas } & \multicolumn{6}{|c|}{ Concentração de Partículas } \\
\hline & até $0,3 \mu \mathrm{m}$ & até $0,5 \mu \mathrm{m}$ & até $0,7 \mu \mathrm{m}$ & até $1,0 \mu \mathrm{m}$ & até $3,0 \mu \mathrm{m}$ & até $5,0 \mu \mathrm{m}$ & até $0,3 \mu \mathrm{m}$ & até $0,5 \mu \mathrm{m}$ & até $0,7 \mu \mathrm{m}$ & até $1,0 \mu \mathrm{m}$ & até $3,0 \mu \mathrm{m}$ & até $5,0 \mu \mathrm{m}$ \\
\hline Média & 38425 & 30885 & 30547 & 30256 & 25325 & 5663 & 28035 & 20674 & 20423 & 20257 & 17868 & 6211 \\
\hline DV-pad & 6090 & 6007 & 5988 & 5921 & 4434 & 894 & 7424 & 7989 & 7951 & 7850 & 5672 & 744 \\
\hline Gauss & 2157 & 2138 & 2128 & 2103 & 1549 & 234 & 1943 & 2107 & 2096 & 2070 & 1492 & 203 \\
\hline Coincidência & 1921 & 1544 & 1527 & 1513 & 1266 & 283 & 1402 & 1034 & 1021 & 1013 & 893 & 311 \\
\hline Poisson & 196 & 176 & 175 & 174 & 159 & 75 & 167 & 144 & 143 & 142 & 134 & 79 \\
\hline Incerteza & 2895 & 2643 & 2625 & 2596 & 2007 & 375 & 2402 & 2351 & 2336 & 2309 & 1745 & 380 \\
\hline
\end{tabular}

Tabela B.7. Incertezas na contagem das partículas insufladas pelo corredor - Sistema PVdir (sem inclinação)

\begin{tabular}{|c|c|c|c|c|c|c|c|c|c|c|c|c|}
\hline \multicolumn{13}{|c|}{ SISTEMA MV+PVdir (com inclinação) - INSUFLAMENTO CORREDOR } \\
\hline & \multicolumn{6}{|c|}{ Assento 2A } & \multicolumn{6}{|c|}{ Assento 2B } \\
\hline & \multicolumn{6}{|c|}{ Concentração de Partículas } & \multicolumn{6}{|c|}{ Concentração de Partículas } \\
\hline & até $0,3 \mu \mathrm{m}$ & até $0,5 \mu \mathrm{m}$ & até $0,7 \mu \mathrm{m}$ & até $1,0 \mu \mathrm{m}$ & até $3,0 \mu \mathrm{m}$ & até $5,0 \mu \mathrm{m}$ & até $0,3 \mu \mathrm{m}$ & até $0,5 \mu \mathrm{m}$ & até $0,7 \mu \mathrm{m}$ & até $1,0 \mu \mathrm{m}$ & até $3,0 \mu \mathrm{m}$ & até $5,0 \mu \mathrm{m}$ \\
\hline Média & 31366 & 27154 & 26682 & 26039 & 15094 & 903 & 35429 & 31797 & 31525 & 31198 & 21988 & 1728 \\
\hline DV-pad & 5240 & 5409 & 5181 & 4623 & 746 & 166 & 2321 & 2316 & 2310 & 2286 & 1712 & 168 \\
\hline Gauss & 1181 & 1208 & 1155 & 1023 & 171 & 41 & 641 & 627 & 625 & 617 & 442 & 43 \\
\hline Coincidência & 1568 & 1358 & 1334 & 1302 & 755 & 45 & 1771 & 1590 & 1576 & 1560 & 1099 & 86 \\
\hline Poisson & 177 & 165 & 163 & 161 & 123 & 30 & 188 & 178 & 178 & 177 & 148 & 42 \\
\hline \multirow[t]{4}{*}{ Incerteza } & 1971 & 1825 & 1772 & 1664 & 783 & 68 & 1893 & 1718 & 1705 & 1687 & 1194 & 105 \\
\hline & \multicolumn{6}{|c|}{ Assento 2D } & \multicolumn{6}{|c|}{ Assento 2E } \\
\hline & \multicolumn{6}{|c|}{ Concentração de Partículas } & \multicolumn{6}{|c|}{ Concentração de Partículas } \\
\hline & até $0,3 \mu \mathrm{m}$ & até $0,5 \mu \mathrm{m}$ & até $0,7 \mu \mathrm{m}$ & até $1,0 \mu \mathrm{m}$ & até $3,0 \mu \mathrm{m}$ & até $5,0 \mu \mathrm{m}$ & até $0,3 \mu \mathrm{m}$ & até $0,5 \mu \mathrm{m}$ & até $0,7 \mu \mathrm{m}$ & até $1,0 \mu \mathrm{m}$ & 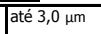 & até $5,0 \mu \mathrm{m}$ \\
\hline Média & 66996 & 60353 & 59885 & 59129 & 42048 & 3929 & 55590 & 50480 & 50113 & 49524 & 35537 & 3218 \\
\hline DV-pad & 7802 & 6982 & 6916 & 6807 & 4419 & 745 & 6964 & 6249 & 6203 & 6117 & 4455 & 437 \\
\hline Gauss & 3086 & 2781 & 2751 & 2705 & 1674 & 182 & 1734 & 1569 & 1558 & 1542 & 1157 & 112 \\
\hline Coincidência & 3350 & 3018 & 2994 & 2956 & 2102 & 196 & 2780 & 2524 & 2506 & 2476 & 1777 & 161 \\
\hline Poisson & 259 & 246 & 245 & 243 & 205 & 63 & 236 & 225 & 224 & 223 & 189 & 57 \\
\hline Incerteza & 4562 & 4111 & 4074 & 4015 & 2696 & 275 & 3285 & 2980 & 2959 & 2926 & 2129 & 204 \\
\hline
\end{tabular}

Tabela B.8. Incertezas na contagem das partículas insufladas pela lateral - Sistema MV

\begin{tabular}{|c|c|c|c|c|c|c|c|c|c|c|c|c|}
\hline \multicolumn{13}{|c|}{ SISTEMA MV - INSUFLAMENTO LATERAL } \\
\hline & \multicolumn{6}{|c|}{ Assento 2A } & \multicolumn{6}{|c|}{ Assento 2B } \\
\hline & \multicolumn{6}{|c|}{ Concentração de Partículas } & \multicolumn{6}{|c|}{ Concentração de Partículas } \\
\hline & até $0,3 \mu \mathrm{m}$ & até $0,5 \mu \mathrm{m}$ & até $0,7 \mu \mathrm{m}$ & até $1,0 \mu \mathrm{m}$ & até $3,0 \mu \mathrm{m}$ & até $5,0 \mu \mathrm{m}$ & até $0,3 \mu \mathrm{m}$ & até $0,5 \mu \mathrm{m}$ & até $0,7 \mu \mathrm{m}$ & até $1,0 \mu \mathrm{m}$ & até $3,0 \mu \mathrm{m}$ & até $5,0 \mu \mathrm{m}$ \\
\hline Média & 31800 & 14429 & 13510 & 13255 & 11138 & 1285 & 30089 & 19811 & 19219 & 18985 & 15335 & 1801 \\
\hline DV-pad & 564 & 2711 & 2820 & 2827 & 2121 & 286 & 1716 & 2281 & 2323 & 2323 & 1877 & 213 \\
\hline Gauss & 83 & 355 & 373 & 374 & 293 & 43 & 261 & 405 & 414 & 414 & 330 & 40 \\
\hline Coincidência & 1590 & 721 & 676 & 663 & 557 & 64 & 1504 & 991 & 961 & 949 & 767 & 90 \\
\hline Poisson & 178 & 120 & 116 & 115 & 106 & 36 & 173 & 141 & 139 & 138 & 124 & 42 \\
\hline \multirow[t]{4}{*}{ Incerteza } & 1602 & 813 & 780 & 770 & 638 & 85 & 1537 & 1079 & 1055 & 1045 & 844 & 107 \\
\hline & \multicolumn{6}{|c|}{ Assento 2D } & \multicolumn{6}{|c|}{ Assento 2E } \\
\hline & \multicolumn{6}{|c|}{ Concentração de Partículas } & \multicolumn{6}{|c|}{ Concentração de Partículas } \\
\hline & até $0,3 \mu \mathrm{m}$ & até $0,5 \mu \mathrm{m}$ & até $0,7 \mu \mathrm{m}$ & até $1,0 \mu \mathrm{m}$ & até $3,0 \mu \mathrm{m}$ & até $5,0 \mu \mathrm{m}$ & até $0,3 \mu \mathrm{m}$ & até $0,5 \mu \mathrm{m}$ & até $0,7 \mu \mathrm{m}$ & até $1,0 \mu \mathrm{m}$ & até $3,0 \mu \mathrm{m}$ & até $5,0 \mu \mathrm{m}$ \\
\hline Média & 28788 & 18724 & 18205 & 18016 & 14923 & 1792 & 27350 & 16669 & 16133 & 15943 & 13259 & 1563 \\
\hline DV-pad & 1132 & 1656 & 1674 & 1663 & 1232 & 213 & 895 & 1117 & 1149 & 1148 & 938 & 161 \\
\hline Gauss & 197 & 305 & 308 & 306 & 223 & 39 & 144 & 194 & 200 & 200 & 167 & 31 \\
\hline Coincidência & 1439 & 936 & 910 & 901 & 746 & 90 & 1367 & 833 & 807 & 797 & 663 & 78 \\
\hline Poisson & 170 & 137 & 135 & 134 & 122 & 42 & 165 & 129 & 127 & 126 & 115 & 40 \\
\hline Incerteza & 1463 & 994 & 970 & 961 & 788 & 106 & 1385 & 865 & 841 & 832 & 693 & 93 \\
\hline
\end{tabular}


Tabela B.9. Incertezas na contagem das partículas insufladas pela lateral - Sistema PVesq (sem inclinação)

\begin{tabular}{|c|c|c|c|c|c|c|c|c|c|c|c|c|}
\hline \multicolumn{13}{|c|}{ SISTEMA MV+PVesq (sem inclinação) - INSUFLAMENTO LATERAL } \\
\hline & \multicolumn{6}{|c|}{ Assento 2A } & \multicolumn{6}{|c|}{ Assento 2B } \\
\hline & \multicolumn{6}{|c|}{ Concentração de Partículas } & \multicolumn{6}{|c|}{ Concentração de Partículas } \\
\hline & até $0,3 \mu \mathrm{m}$ & até $0,5 \mu \mathrm{m}$ & até $0,7 \mu \mathrm{m}$ & até $1,0 \mu \mathrm{m}$ & até $3,0 \mu \mathrm{m}$ & até $5,0 \mu \mathrm{m}$ & até $0,3 \mu \mathrm{m}$ & até $0,5 \mu \mathrm{m}$ & até $0,7 \mu \mathrm{m}$ & até $1,0 \mu \mathrm{m}$ & até $3,0 \mu \mathrm{m}$ & até $5,0 \mu \mathrm{m}$ \\
\hline Média & 14526 & 5576 & 5196 & 5100 & 4648 & 909 & 15252 & 7437 & 7144 & 7062 & 5846 & 1108 \\
\hline DV-pad & 1094 & 904 & 891 & 895 & 801 & 161 & 2987 & 3949 & 3980 & 3974 & 3393 & 601 \\
\hline Gauss & 284 & 232 & 229 & 231 & 212 & 39 & 835 & 1088 & 1096 & 1095 & 912 & 152 \\
\hline Coincidência & 726 & 279 & 260 & 255 & 232 & 45 & 763 & 372 & 357 & 353 & 292 & 55 \\
\hline Poisson & 121 & 75 & 72 & 71 & 68 & 30 & 123 & 86 & 85 & 84 & 76 & 33 \\
\hline \multirow[t]{4}{*}{ Incerteza } & 789 & 370 & 354 & 352 & 322 & 67 & 1137 & 1153 & 1156 & 1154 & 961 & 165 \\
\hline & \multicolumn{6}{|c|}{ Assento 2D } & \multicolumn{6}{|c|}{ Assento 2E } \\
\hline & \multicolumn{6}{|c|}{ Concentração de Partículas } & \multicolumn{6}{|c|}{ Concentração de Partículas } \\
\hline & até $0,3 \mu \mathrm{m}$ & até $0,5 \mu \mathrm{m}$ & até $0,7 \mu \mathrm{m}$ & até $1,0 \mu \mathrm{m}$ & até $3,0 \mu \mathrm{m}$ & até $5,0 \mu \mathrm{m}$ & até $0,3 \mu \mathrm{m}$ & até $0,5 \mu \mathrm{m}$ & até $0,7 \mu \mathrm{m}$ & até $1,0 \mu \mathrm{m}$ & até $3,0 \mu \mathrm{m}$ & até $5,0 \mu \mathrm{m}$ \\
\hline Média & 22006 & 19682 & 18546 & 18014 & 14589 & 1702 & 25092 & 23518 & 23080 & 22797 & 18350 & 2172 \\
\hline DV-pad & 1058 & 1507 & 1771 & 1894 & 1527 & 202 & 1023 & 4192 & 4242 & 4205 & 3135 & 424 \\
\hline Gauss & 332 & 415 & 484 & 510 & 408 & 53 & 884 & 1041 & 1052 & 1041 & 768 & 103 \\
\hline Coincidência & 1100 & 984 & 927 & 901 & 729 & 85 & 1255 & 1176 & 1154 & 1140 & 917 & 109 \\
\hline Poisson & 148 & 140 & 136 & 134 & 121 & 41 & 158 & 153 & 152 & 151 & 135 & 47 \\
\hline Incerteza & 1159 & 1077 & 1055 & 1044 & 844 & 108 & 1543 & 1578 & 1569 & 1551 & 1204 & 157 \\
\hline
\end{tabular}

Tabela B.10. Incertezas na contagem das partículas insufladas pela lateral - Sistema PVesq (com inclinação)

\begin{tabular}{|c|c|c|c|c|c|c|c|c|c|c|c|c|}
\hline \multicolumn{13}{|c|}{ SISTEMA MV+PVesq (com inclinação) - INSUFLAMENTO LATERAL } \\
\hline & \multicolumn{6}{|c|}{ Assento 2A } & \multicolumn{6}{|c|}{ Assento 2B } \\
\hline & \multicolumn{6}{|c|}{ Concentração de Partículas } & \multicolumn{6}{|c|}{ Concentração de Partículas } \\
\hline & até $0,3 \mu \mathrm{m}$ & até $0,5 \mu \mathrm{m}$ & até $0,7 \mu \mathrm{m}$ & até $1,0 \mu \mathrm{m}$ & até $3,0 \mu \mathrm{m}$ & até $5,0 \mu \mathrm{m}$ & até $0,3 \mu \mathrm{m}$ & até $0,5 \mu \mathrm{m}$ & até $0,7 \mu \mathrm{m}$ & até $1,0 \mu \mathrm{m}$ & até $3,0 \mu \mathrm{m}$ & até $5,0 \mu \mathrm{m}$ \\
\hline Média & 18674 & 12715 & 12499 & 12412 & 10705 & 1256 & 21259 & 16690 & 16477 & 16364 & 13783 & 1715 \\
\hline DV-pad & 1730 & 1933 & 1937 & 1926 & 1523 & 227 & 772 & 1043 & 1052 & 1049 & 794 & 153 \\
\hline Gauss & 399 & 477 & 480 & 477 & 387 & 54 & 169 & 241 & 244 & 243 & 177 & 40 \\
\hline Coincidência & 934 & 636 & 625 & 621 & 535 & 63 & 1063 & 835 & 824 & 818 & 689 & 86 \\
\hline Poisson & 137 & 113 & 112 & 111 & 103 & 35 & 146 & 129 & 128 & 128 & 117 & 41 \\
\hline \multirow[t]{4}{*}{ Incerteza } & 1024 & 803 & 796 & 791 & 669 & 90 & 1086 & 878 & 869 & 863 & 721 & 103 \\
\hline & \multicolumn{6}{|c|}{ Assento 2D } & \multicolumn{6}{|c|}{ Assento 2E } \\
\hline & \multicolumn{6}{|c|}{ Concentração de Partículas } & \multicolumn{6}{|c|}{ Concentração de Partículas } \\
\hline & até $0,3 \mu \mathrm{m}$ & até $0,5 \mu \mathrm{m}$ & até $0,7 \mu \mathrm{m}$ & até $1,0 \mu \mathrm{m}$ & até $3,0 \mu \mathrm{m}$ & até $5,0 \mu \mathrm{m}$ & até $0,3 \mu \mathrm{m}$ & até $0,5 \mu \mathrm{m}$ & até $0,7 \mu \mathrm{m}$ & até $1,0 \mu \mathrm{m}$ & até $3,0 \mu \mathrm{m}$ & até $5,0 \mu \mathrm{m}$ \\
\hline Média & 24807 & 20609 & 20427 & 20280 & 16757 & 2156 & 25331 & 20836 & 20651 & 20501 & 16950 & 2162 \\
\hline DV-pad & 1988 & 2188 & 2193 & 2167 & 1675 & 261 & 2273 & 2561 & 2562 & 2533 & 1886 & 309 \\
\hline Gauss & 502 & 546 & 546 & 540 & 409 & 68 & 608 & 689 & 689 & 681 & 509 & 84 \\
\hline Coincidência & 1240 & 1030 & 1021 & 1014 & 838 & 108 & 1267 & 1042 & 1033 & 1025 & 847 & 108 \\
\hline Poisson & 158 & 144 & 143 & 142 & 129 & 46 & 159 & 144 & 144 & 143 & 130 & 46 \\
\hline Incerteza & 1347 & 1175 & 1167 & 1157 & 941 & 135 & 1414 & 1258 & 1249 & 1239 & 997 & 144 \\
\hline
\end{tabular}

Tabela B.11. Incertezas na contagem das partículas insufladas pela lateral - Sistema PVdir (sem inclinação)

\begin{tabular}{|c|c|c|c|c|c|c|c|c|c|c|c|c|}
\hline \multicolumn{13}{|c|}{ SISTEMA MV+PVdir (sem inclinação) - INSUFLAMENTO LATERAL } \\
\hline & \multicolumn{6}{|c|}{ Assento 2A } & \multicolumn{6}{|c|}{ Assento 2B } \\
\hline & \multicolumn{6}{|c|}{ Concentração de Partículas } & \multicolumn{6}{|c|}{ Concentração de Partículas } \\
\hline & até $0,3 \mu \mathrm{m}$ & até $0,5 \mu \mathrm{m}$ & até $0,7 \mu \mathrm{m}$ & |até $1,0 \mu \mathrm{m}$ & até $3,0 \mu \mathrm{m}$ & até $5,0 \mu \mathrm{m}$ & até $0,3 \mu \mathrm{m}$ & até $0,5 \mu \mathrm{m}$ & até $0,7 \mu \mathrm{m}$ & até $1,0 \mu \mathrm{m}$ & até $3,0 \mu \mathrm{m}$ & até $5,0 \mu \mathrm{m}$ \\
\hline Média & 23476 & 15329 & 14751 & 14412 & 11497 & 1164 & 24445 & 18910 & 18642 & 18474 & 14780 & 1572 \\
\hline DV-pad & 1861 & 1687 & 1813 & 1932 & 1841 & 239 & 1071 & 2339 & 2360 & 2329 & 1299 & 192 \\
\hline Gauss & 337 & 301 & 323 & 343 & 323 & 40 & 187 & 459 & 463 & 456 & 231 & 37 \\
\hline Coincidência & 1174 & 766 & 738 & 721 & 575 & 58 & 1222 & 945 & 932 & 924 & 739 & 79 \\
\hline Poisson & 153 & 124 & 121 & 120 & 107 & 34 & 156 & 138 & 137 & 136 & 122 & 40 \\
\hline \multirow[t]{4}{*}{ Incerteza } & 1231 & 833 & 814 & 807 & 668 & 79 & 1246 & 1060 & 1050 & 1039 & 784 & 96 \\
\hline & \multicolumn{6}{|c|}{ Assento 2D } & \multicolumn{6}{|c|}{ Assento 2E } \\
\hline & \multicolumn{6}{|c|}{ Concentração de Partículas } & \multicolumn{6}{|c|}{ Concentração de Partículas } \\
\hline & até $0,3 \mu \mathrm{m}$ & até $0,5 \mu \mathrm{m}$ & até $0,7 \mu \mathrm{m}$ & | até $1,0 \mu \mathrm{m}$ & até $3,0 \mu \mathrm{m}$ & até $5,0 \mu \mathrm{m}$ & até $0,3 \mu \mathrm{m}$ & até $0,5 \mu \mathrm{m}$ & até $0,7 \mu \mathrm{m}$ & até $1,0 \mu \mathrm{m}$ & até $3,0 \mu \mathrm{m}$ & até $5,0 \mu \mathrm{m}$ \\
\hline Média & 30061 & 24991 & 24731 & 24509 & 19506 & 2350 & 27768 & 22252 & 21992 & 21810 & 17812 & 2120 \\
\hline DV-pad & 3957 & 4731 & 4741 & 4688 & 3093 & 383 & 2335 & 2680 & 2686 & 2660 & 1979 & 299 \\
\hline Gauss & 745 & 899 & 902 & 891 & 577 & 63 & 400 & 478 & 480 & 475 & 354 & 52 \\
\hline Coincidência & 1503 & 1250 & 1237 & 1225 & 975 & 117 & 1388 & 1113 & 1100 & 1091 & 891 & 106 \\
\hline Poisson & 173 & 158 & 157 & 157 & 140 & 48 & 167 & 149 & 148 & 148 & 133 & 46 \\
\hline Incerteza & 1687 & 1548 & 1539 & 1523 & 1142 & 142 & 1454 & 1220 & 1209 & 1199 & 968 & 127 \\
\hline
\end{tabular}


Tabela B.12. Incertezas na contagem das partículas insufladas pela lateral - Sistema PVdir (com inclinação)

\begin{tabular}{|c|c|c|c|c|c|c|c|c|c|c|c|c|}
\hline \multicolumn{13}{|c|}{ SISTEMA MV+PVdir (com inclinação) - INSUFLAMENTO LATERAL } \\
\hline & \multicolumn{6}{|c|}{ Assento 2A } & \multicolumn{6}{|c|}{ Assento 2B } \\
\hline & \multicolumn{6}{|c|}{ Concentração de Partículas } & \multicolumn{6}{|c|}{ Concentração de Partículas } \\
\hline & até $0,3 \mu \mathrm{m}$ & até $0,5 \mu \mathrm{m}$ & até $0,7 \mu \mathrm{m}$ & até $1,0 \mu \mathrm{m}$ & até $3,0 \mu \mathrm{m}$ & até $5,0 \mu \mathrm{m}$ & até $0,3 \mu \mathrm{m}$ & até $0,5 \mu \mathrm{m}$ & até $0,7 \mu \mathrm{m}$ & até $1,0 \mu \mathrm{m}$ & até $3,0 \mu \mathrm{m}$ & até $5,0 \mu \mathrm{m}$ \\
\hline Média & 23418 & 18154 & 17917 & 17774 & 13904 & 1220 & 26775 & 22762 & 22567 & 22375 & 17086 & 1431 \\
\hline DV-pad & 1403 & 1969 & 1963 & 1935 & 1321 & 173 & 2741 & 3049 & 3047 & 3004 & 2057 & 196 \\
\hline Gauss & 362 & 514 & 514 & 507 & 359 & 46 & 672 & 739 & 738 & 730 & 507 & 52 \\
\hline Coincidência & 1171 & 908 & 896 & 889 & 695 & 61 & 1339 & 1138 & 1128 & 1119 & 854 & 72 \\
\hline Poisson & 153 & 135 & 134 & 133 & 118 & 35 & 164 & 151 & 150 & 150 & 131 & 38 \\
\hline \multirow[t]{4}{*}{ Incerteza } & 1235 & 1052 & 1041 & 1032 & 791 & 84 & 1507 & 1365 & 1357 & 1344 & 1002 & 96 \\
\hline & \multicolumn{6}{|c|}{ Assento 2D } & \multicolumn{6}{|c|}{ Assento 2E } \\
\hline & \multicolumn{6}{|c|}{ Concentração de Partículas } & \multicolumn{6}{|c|}{ Concentração de Partículas } \\
\hline & até $0,3 \mu \mathrm{m}$ & até $0,5 \mu \mathrm{m}$ & até $0,7 \mu \mathrm{m}$ & Jaté $1,0 \mu \mathrm{m}$ & até $3,0 \mu \mathrm{m}$ & até 5,0 $\mu \mathrm{m}$ & até $0,3 \mu \mathrm{m}$ & até $0,5 \mu \mathrm{m}$ & até $0,7 \mu \mathrm{m}$ & até $1,0 \mu \mathrm{m}$ & até $3,0 \mu \mathrm{m}$ & até $5,0 \mu \mathrm{m}$ \\
\hline Média & 32022 & 27799 & 27534 & 27267 & 20769 & 1918 & 28137 & 24152 & 23949 & 23759 & 19366 & 2511 \\
\hline DV-pad & 5824 & 6034 & 6013 & 5911 & 3913 & 291 & 3200 & 3251 & 3236 & 3191 & 2344 & 319 \\
\hline Gauss & 1491 & 1540 & 1534 & 1508 & 1013 & 78 & 835 & 847 & 843 & 830 & 608 & 76 \\
\hline Coincidência & 1601 & 1390 & 1377 & 1363 & 1038 & 96 & 1407 & 1208 & 1197 & 1188 & 968 & 126 \\
\hline Poisson & 179 & 167 & 166 & 165 & 144 & 44 & 168 & 155 & 155 & 154 & 139 & 50 \\
\hline Incerteza & 2195 & 2081 & 2068 & 2040 & 1458 & 131 & 1644 & 1483 & 1473 & 1457 & 1152 & 155 \\
\hline
\end{tabular}

